\title{
The Relationship Between Copyright and Contract Law
}

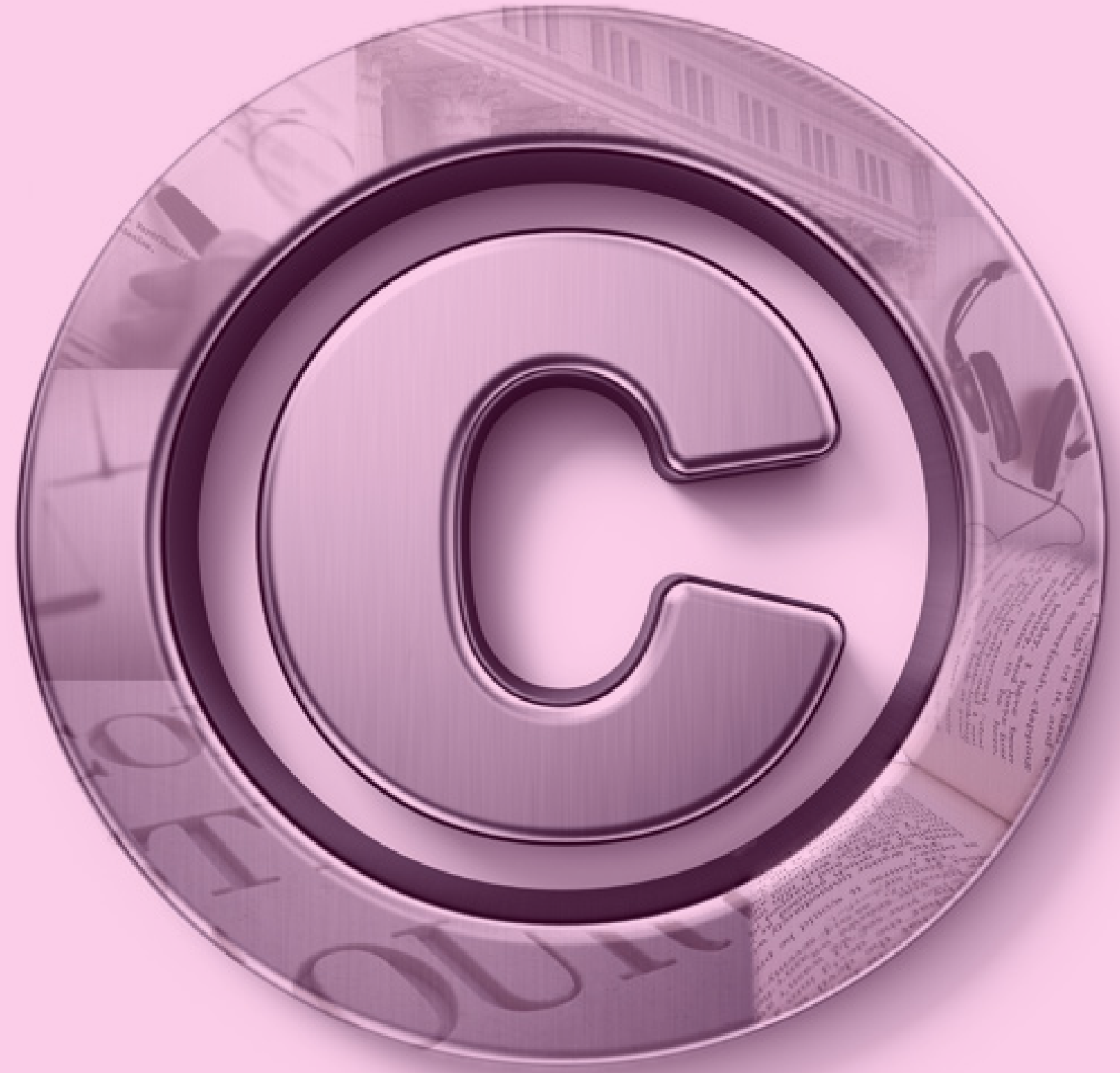

Research commissioned by SABIP

Providing Government with strategic, independent and evidence-based advice on intellectual property policy 


\section{Research commissioned by the Strategic Advisory Board for Intellectual Property Policy, and carried out by}

\section{Martin Kretschmer}

Professor of Information Jurisprudence, Director, Centre for Intellectual Property Policy \& Management (www.cippm.org.uk), Bournemouth University, mkretsch@bournemouth.ac.uk

\section{Estelle Derclaye}

Associate Professor \& Reader in Intellectual Property Law, School of Law, University of Nottingham, estelle.derclaye@nottingham.ac.uk

\section{Marcella Favale}

Postdoctoral researcher, University of Nottingham, marcella.favale@gmail.com

\section{Richard Watt}

Associate Professor, Department of Economics, Canterbury University (NZ), richard@serci.org 


\section{CONTENTS}

SUMMARY CHAPTER

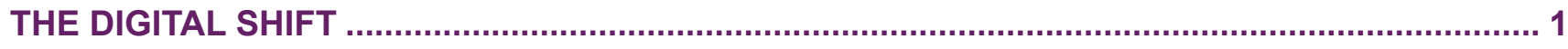

STRUCTURE AND METHODOLOGY OF THE REPORT ......................................................... 2

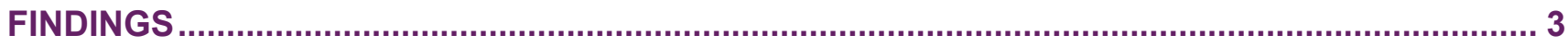

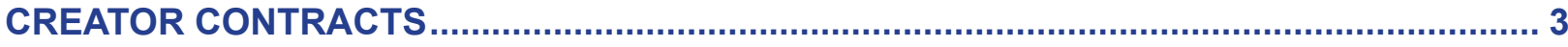

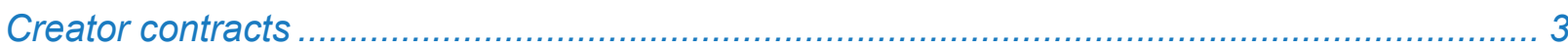

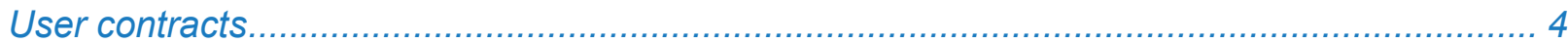

EVIDENCE ON CURRENT RANGE OF REGULATORY TOOLS ........................................ 5

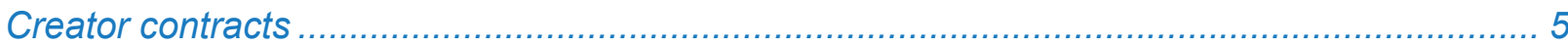

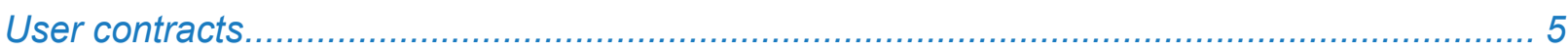

RESEARCH GAP I: EFFECTS OF KEY REGULATORY TOOLS ...................................... 5

1. Creator contracts: Effects of rules on first ownership .............................................. 5

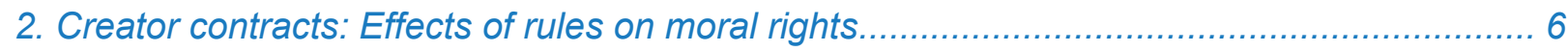

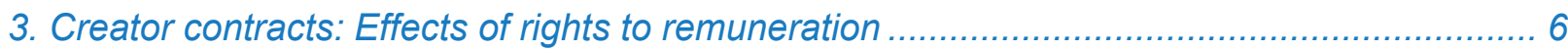

4. Creator and user contracts: Effects of reversionary term ....................................... 8

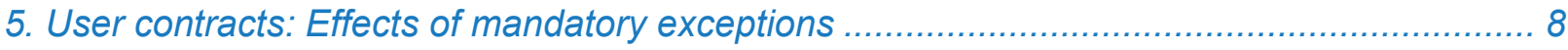

RESEARCH GAP II: NORMATIVE AIMS OF CONTRACTUAL REGULATION ....................... 9

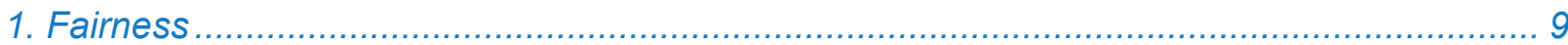

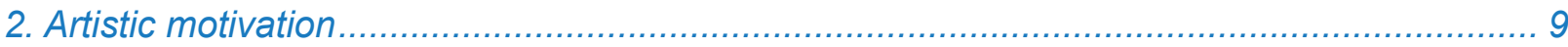

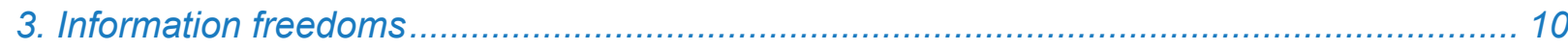

RESEARCH GAP III: SOLUTIONS FROM OUTSIDE COPYRIGHT AND CONTRACT LAW . 10

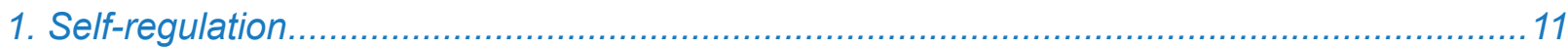

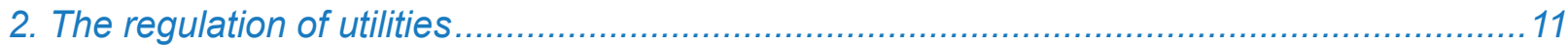

RESEARCH GAP IV: CONTRACTING FOR DIGITAL SERVICES ................................... 12 


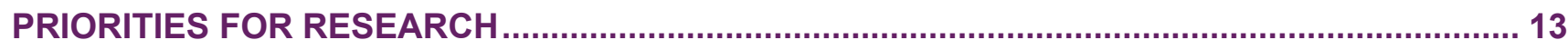

1. USER CONTRACTS (RATIONALE OF EXCEPTIONS) .................................................... 13

2. USER CONTRACTS (LICENSING PRACTICES) ............................................................. 14

3. CREATOR CONTRACTS (TERM REVERSAL) ……….................................................... 14

4. CREATOR CONTRACTS (MORAL RIGHTS) …………................................................. 14

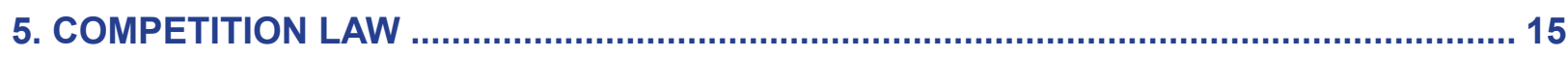

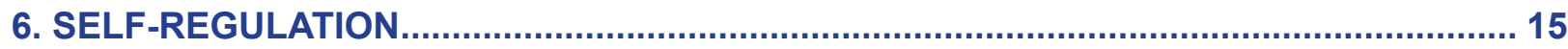

7. COPYRIGHT BUSINESS MODELS ……................................................................. 15

PAPER 1 - ECONOMIC THEORY OF COPYRIGHT CONTRACTS..................................... 16-40

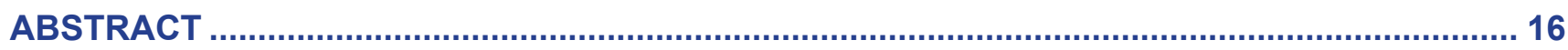

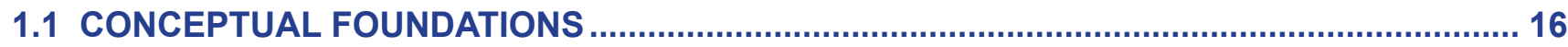

1.1.1 Copyright and the contractable space …….............................................................. 17

1.1.2 Copyright law and the parties to contracts for copyright goods ................................... 19

1.1.3 Standard contract theory, and special characteristics of copyright contracts ................ 19

1.2 INDIVIDUAL CONTRACTING .............................................................................................. 23

1.2.1 The structure of royalty contracts - royalty vs. buy-out ................................................ 24

1.2.2 Copyright royalty contracts and risk sharing ............................................................ 24

1.2.3 Contracts and infringement (piracy) ........................................................................ 27

1.2.4 The effect of copyright law on royalty contracts......................................................... 28

1.3 ASPECTS RELATED TO THE 'FAIRNESS' OF COPYRIGHT CONTRACTS............................ 34

1.4 COLLECTIVE ADMINISTRATION OF COPYRIGHT CONTRACTS ....................................... 35

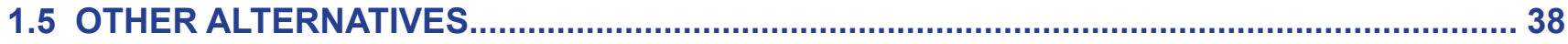

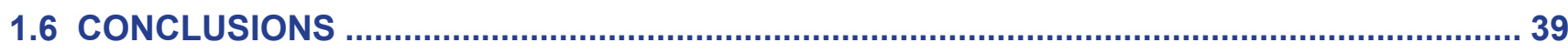


2.1 CREATORS, AND THE PURPOSE OF COPYRIGHT LAW ............................................... 41

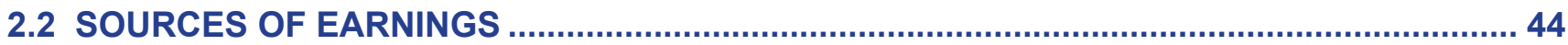

(a) Statutory right: Individually negotiated income ............................................................... 45

(b) Statutory right: Collectively negotiated income ............................................................ 45

(c) Income from artistic activity: Non-statutory subject matter ............................................ 45

(d) Income from non-artistic sources ............................................................................ 45

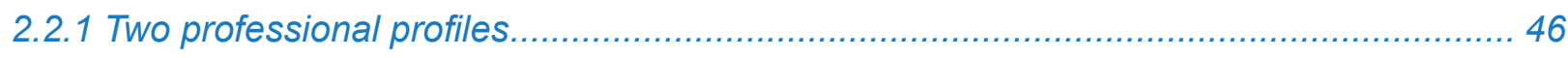

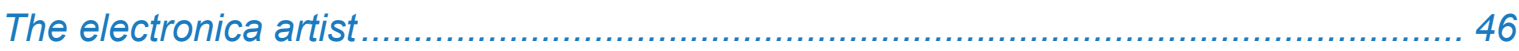

The children's book illustrator ...................................................................................... 46

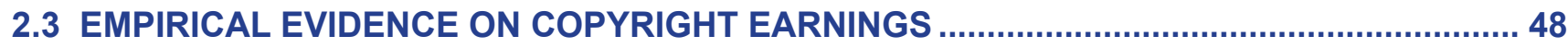

2.3.1 The distribution of earnings in the cultural professions................................................ 48

2.3.2 Earnings from principal artistic activity .................................................................. 58

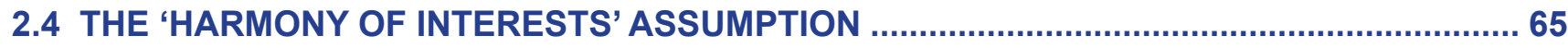

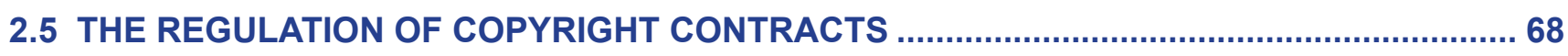

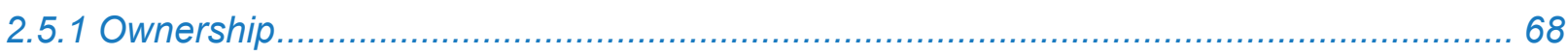

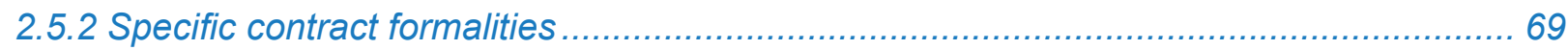

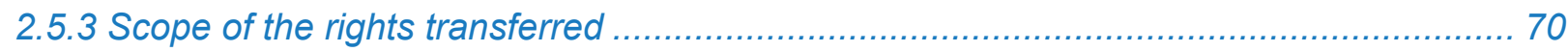

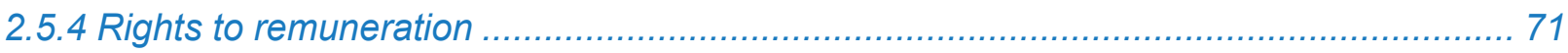

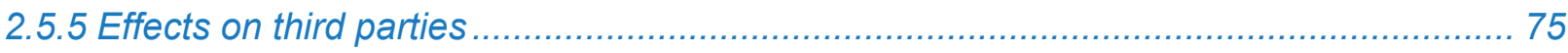

2.5. 6 Provisions relating to the revision and termination of contracts...................................... 76

2.5.7 General contract doctrine / Unfair contracts ................................................................ 77

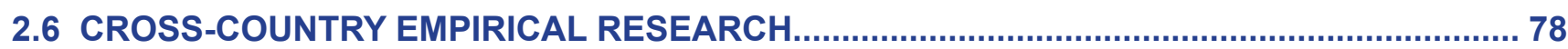

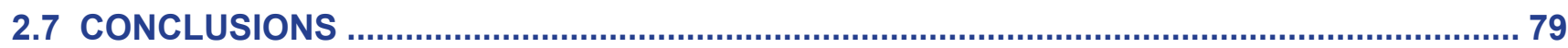




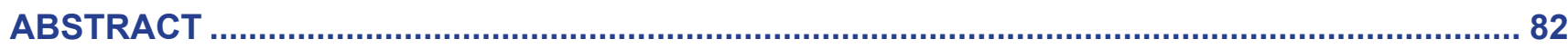

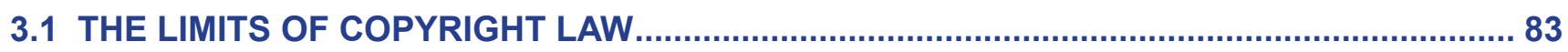

3.1.1 The effects of copyright limits on contracting out ......................................................... 83

3.1.2 Comparative review of copyright limits in various countries ...................................... 87

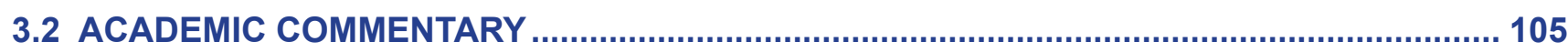

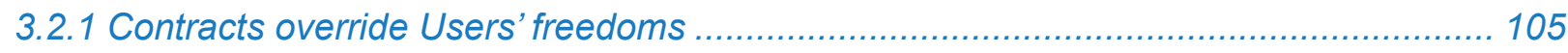

3.2.2 Contracts are more efficient than Copyright ........................................................... 108

3.2.3 Copyright and Contracts are independent ..................................................................110

3.3 COPYRIGHT WORKS AND THEIR COMMERCIALISATION ............................................. 111

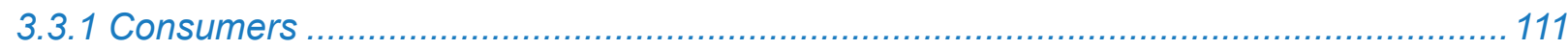

3.3.2 Libraries and educational institutions.....................................................................118

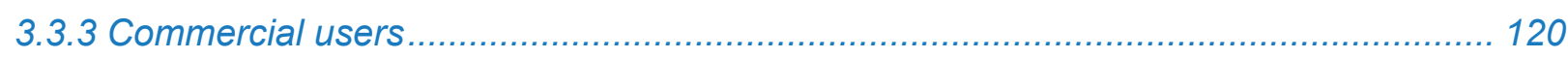

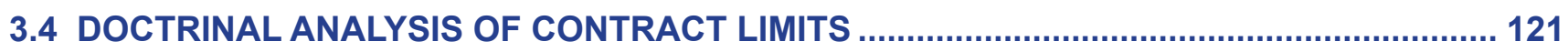

3.4.1 Unconscionability and Good Faith ......................................................................... 122

3.4.2 Limits to Contracts set by Copyright Law: The Doctrine of Preemption ........................ 124

3.4.3 The Doctrines of Misuse and Abuse of Rights....................................................... 128

3.4.4 Other Limits to Contracts: Public Policy................................................................ 130

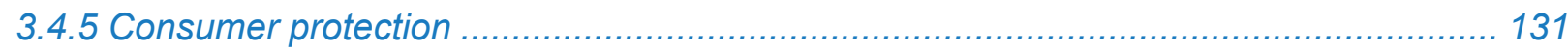

3.4.6 Constitutional limits to Contracts .......................................................................... 133

3.5 DIGITAL RIGHTS MANAGEMENT (DRM), AND THE ENFORCEMENT OF CONTRACTS .. 135

3.5.1 The Dangers of Digital Lock-up ............................................................................. 135

3.5.2 Remedies for Users against 'unfair' DRM ................................................................ 138

3.6 EMPIRICAL AND COMPARATIVE STUDIES OF USER CONTRACTS AND DRM................... 141

3.6.1 Proportion of copyright material diffused electronically ............................................. 141

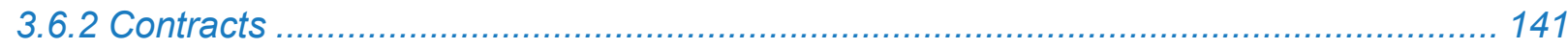

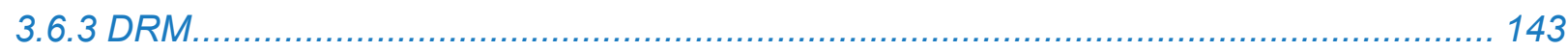

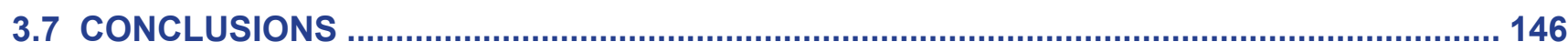




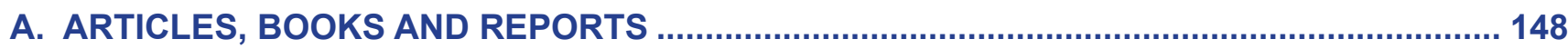

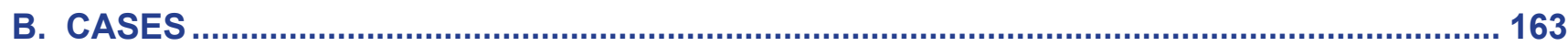

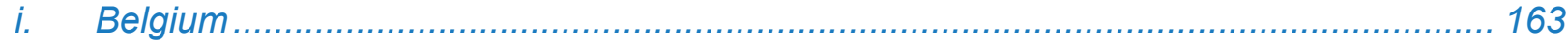

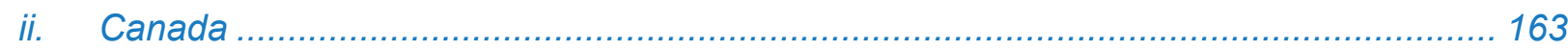

iii. European Commission Decisions ............................................................................ 164

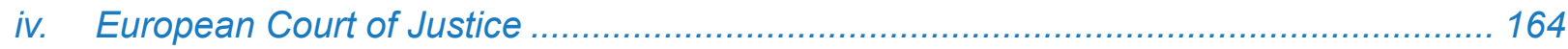

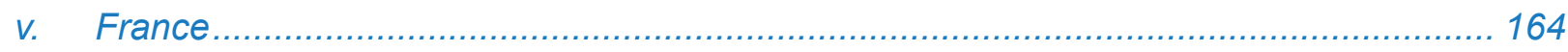

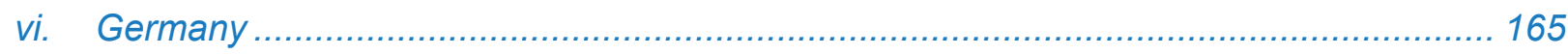

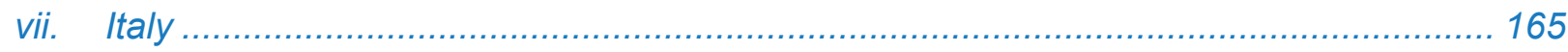

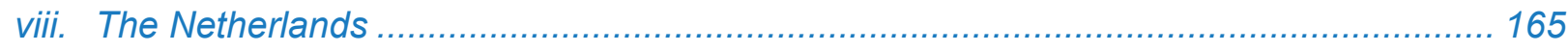

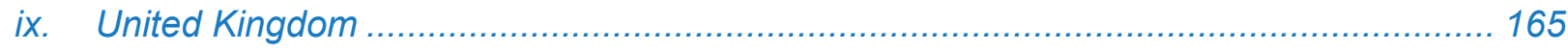

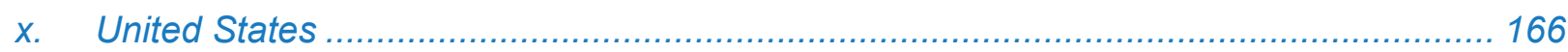

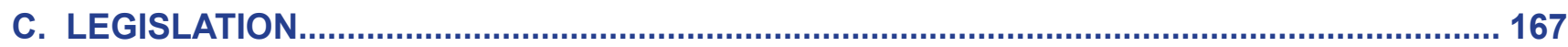

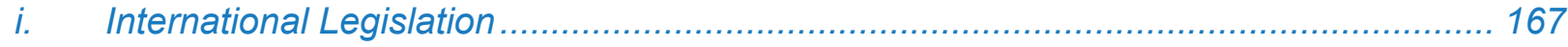

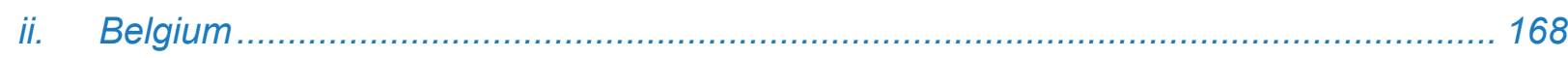

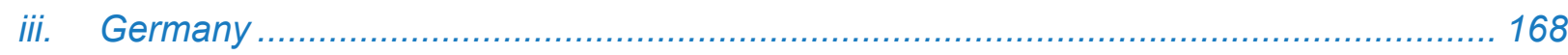

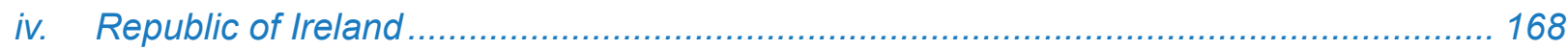

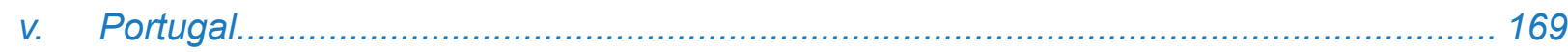

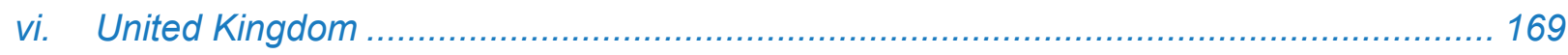

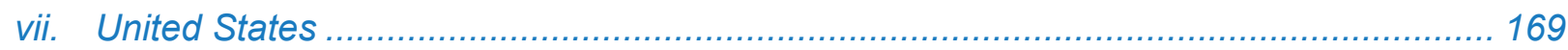

D. EUROPEAN DIRECTIVES (CHRONOLOGICAL) ................................................................. 170

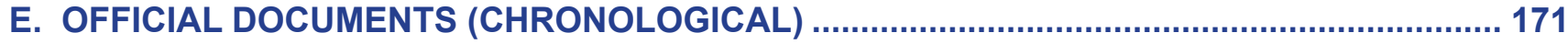





\section{SUMMARY CHAPTER}

\section{THE DIGITAL SHIFT}

Contracts lie at the heart of the regulatory system governing the creation and dissemination of cultural products in two main respects:

(i) The exclusive rights provided by copyright law may turn into financial reward, and thus incentives to creators, through a contract with a third party to exploit protected material.

(ii) From a user perspective purchases of protected material may take the form of a licensing contract, governing behaviour after the initial transaction.

The renewed interest in the relationship of copyright and contract law can be traced quite precisely to the mid-1990s. There was a major technological shift, with the rapid adoption of the WorldWideWeb as a consumer medium (Netscape's Navigator browser was released in 1994). In parallel, the media and entertainment sector experienced a wave of consolidation, with multinational enterprises keen to hedge their bets in the rapid growth of Internet services (in 2000, AOL merged with Time Warner to create the world's largest media company).

In the new 'private ordering of cyberspace', contracts played a major part. ${ }^{1}$ Not only was there a sudden question mark over who owned the rights to new digital uses of existing works, but changing contractual practices made clear that new forms of exploitation, and (if permitted by the governing law) unforeseen uses would soon be covered in all publishing and production agreements. Creators deride these new practices as 'rights grabbing'; publishers and producers characterise them as 'due diligence'.
The digital environment also changed the contractual relationship between buyers and sellers. Traditionally, the producers and distributors of copyright materials were not much concerned about the consumers' after-sale behaviour. General principles relating to trading standards and the sale of goods applied. Once a physical carrier was bought in good order, the relationship to the right owner was severed - at least in the private sphere. A consumer could read, play, modify, or even copy a work. The purchased book or record could also be sold on under the doctrines of 'first sale' (US), or 'exhaustion of rights' (EU).

In the digital world, the relationship between buyer and seller may persist after the initial transaction, prescribing conditions of use that have no source in copyright law. The chain of transactions governed by copyright contracts can be represented graphically as follows:

\section{The location of copyright contracts}

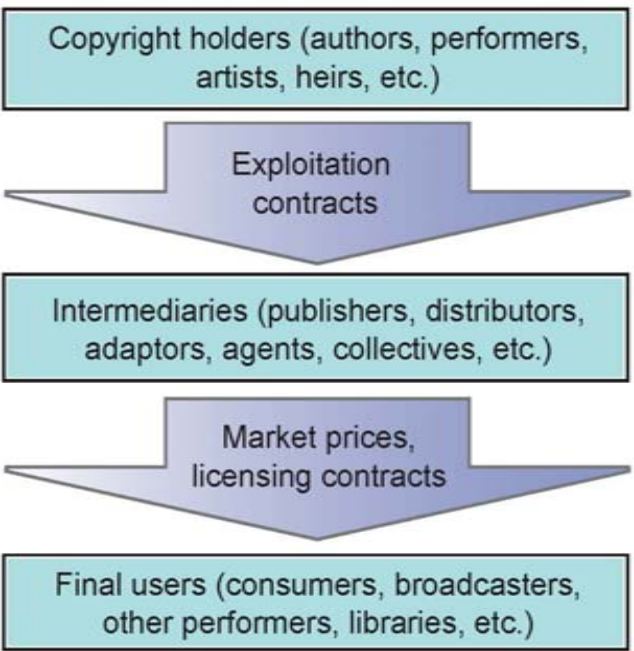


A review of the relationship between copyright and contract law has to address both supply- and demand-side issues.

On the supply side, policy concerns include whether copyright law delivers the often stated aim of securing the financial independence of creators. ${ }^{2}$ Particularly acute are the complaints by both creators and producers that they fail to benefit from the exponential increase in the availability of copyright materials on the Internet. ${ }^{3}$

On the demand side, the issue of copyright exceptions and their policy justification has become central to a number of reviews and consultations dealing with digital content. Are exceptions based on user needs or market failure? Do exceptions require financial compensation? Can exceptions be contracted out by licence agreements? ${ }^{4}$

\section{STRUCTURE AND METHODOLOGY OF THE REPORT}

The review of the relationship between copyright and contract law was conducted by a consortium of four academics. Estelle Derclaye and Marcella Favale (University of Nottingham) are doctrinal lawyers with a particular expertise in comparative law. Martin Kretschmer directs the Centre for
Intellectual Property Policy \& Management (www.cippm.org.uk) at Bournemouth University, the only UK research centre specializing in empirical research on intellectual property. Richard Watt (Canterbury University, NZ) is the Secretary of the Society for Economic Research on Copyright Issues (SERCI), and one of the leading copyright economists. The consortium covers legal and economic perspectives on copyright and contracts, as well as native language capability in UK, Australian, Belgian, German, French and US law.

\section{Supply and demand side issues related to} copyright contracts were initially allocated in the following way. Richard Watt covered economic theory of contracts, value chains and transaction costs. Martin Kretschmer reviewed the literature on creator and intermediaries contracts, and labour markets. Estelle Derclaye and Marcella Favale reviewed user contracts, with particular regard to the implications of digital rights management systems, and jurisdictions that had legislated on the contractual status of copyright exceptions. The researchers took a comparative international approach, reviewing the evidence for the UK and several other countries. Rather than selecting a set number of jurisdictions, the consortium drew on different countries for different parts of the review. The aim was (i) to identify a comprehensive range of regulatory options, (ii) to survey the empirical evidence on their effects, and (iii) where none was available, to extrapolate predicted effects from theory.

For one example of many such statements, see Recital 11 of the Directive on the harmonisation of certain aspects of copyright and related rights in the information society: Information Society Directive (2001/29/EC): 'A rigorous, effective system for the protection of copyright and related rights is one of the main ways of ensuring that European cultural creativity and production receive the necessary resources and of safeguarding the independence and dignity of artistic creators and performers.'

In a survey of 25,000 British and German literary and audio-visual writers conducted in 2006 , only $14.7 \%$ of UK authors and $9.2 \%$ of German authors claim to have received specific payments for Internet uses of their works. For audio-visual authors the figures are even lower (UK: 11.1\%, Germany: 6.9\%). See Kretschmer and Hardwick, 2007, p. 32.

\begin{abstract}
In the UK, the debate is taking place in the context of the Gowers Review of Intellectual Property (London: HM Treasury 2006). Gowers encouraged a greater flexibility of the copyright system with recommendations on copyright exceptions relating to private copying, archiving, educational and research use, parody and pastiche, and orphan works. For the state of play, see Taking Forward the Gowers Review of Intellectual Property: Second stage consultation on copyright exceptions (UK Intellectual Property Office, December 2009). In Europe, the European Commission consulted recently on a Green Paper Copyright in the Knowledge Economy (Brussels, COM(2008) 466/3) and on a Reflection Document Creative Content in a European Digital Single Market: Challenges for the Future (Brussels, DG INFSO and DG MARKT, 22 October 2009).
\end{abstract}


Having mapped out the areas to be covered, the authors drafted each paper independently, using their own disciplinary approach. Findings were then analysed and consolidated. The report was coordinated, and the synopsis drafted by Martin Kretschmer who is both a legal scholar and a social scientist. The Bournemouth Symposium on 'Copyright, Contracts and Creativity' on 25 September 2009 (co-organised by Professor Ruth Towse), as well as an internal SABIP workshop on 19 October 2009 provided a forum for assessing the evidence on creator and user contracts, and for discussion of possible research avenues. The authors would like to acknowledge the insightful critical commentary received on these occasions. All authors contributed to the assessment of appropriate methodologies for the research questions identified throughout the report.

\section{FINDINGS}

Under the standard economic conception of property rights, it is copyright law that allows contracts to be written: copyright law defines the characteristics of the work and the property rights in the work - the contract space.

A core methodological problem is how to conceptually distinguish the role of statutory copyright in contractual arrangements. Consider two simple examples:

- The literary author:

A typical contract may assign the copyright in a work to a publisher, against an advance and a royalty on copies sold.

- The professional footballer:

A typical contract may bind a footballer exclusively to a club against a signing-on fee and salary payments that depend on appearances and success.
The former is a copyright contract, the latter a contract not based on a right defined by statute. Yet their commercial features resemble each other. Thus if a journalist supplies a commissioned text to an online magazine, to what extent is that service dependent on the right subsisting in the text? Similarly, if a user decides to subscribe to the online magazine, to what extent is the contract permitting access dependent on statutory concepts?

Under various economic models, we would expect copyright law to affect contracts, depending on time preferences (patience); risk, and risk aversion; outside and inside options; and the extent of asymmetric information between the parties - but there is no evidence that this is empirically the case.

A major research gap is therefore how a change in copyright law will affect the bargaining outcome between parties contracting over material protected by copyright law.

\section{EVIDENCE ON CURRENT OUTCOME OF CONTRACT BARGAINING}

\section{Creator contracts}

Cultural markets are winner-take-all markets. They are very risky for both creators and investors. The earnings data available from labour market statistics, tax and insurance audits, and surveys indicate that the top $10 \%$ of creators receive a disproportionally large share of total income in the creative professions (for literary authors about $60-70 \%$ of total income; for composers/songwriters about $80 \%$ of total income). ${ }^{5}$ For most other creators, 'portfolio lives' are typical: about two thirds of professional creators have earnings from a second job.

Overall, the income of creators is well below the national median income. income (Annual Survey of Hours and Earnings (ASHE), UK Office for National Statistics). 
There are some variations by sector, but broadly the picture is consistent across the developed world.

Unsurprisingly, the bargaining outcome over rights is tilted towards bestsellers. Creators with a track record of success are able to negotiate contracts that preserve their interests. For most others, in particular new entrants to the entertainment industries, assignment of rights is common. Mechanisms of collective bargaining (for example through unions, professional associations and collecting societies) appear to have a greater effect than statutory (ownership) rights because the latter, typically, will be varied and/or transacted by contract.

\section{User contracts}

In the digital environment licensing contracts, rather than outright sales, are predominant. The market for electronic services is growing rapidly, and users' access to copyright content is increasingly governed by contract. There is robust evidence that licence agreements for software, digital consumer services and educational content routinely conflict with statutory copyright exceptions (for example regarding back-up copies and archiving). Similarly, consumer protection legislation is often ignored or hard to enforce (for example, many online licence agreements are not easily understood, and contain excessive exclusions of liability).
This bargaining outcome is tilted towards right owners, because fragmented end-users (such as consumers) typically are not in a position to contest the terms of licences offered. Even where users should be in position to negotiate, for example in the education, archive and library sectors, there is evidence that statutory limitations and exceptions under copyright law are becoming irrelevant. The reasons are not well understood but competition issues may play a part (with large bundles of rights controlled by few companies).

Digital Rights Management systems (DRM) do not necessarily conflict with copyright exceptions (see Paper 3.6). We know that no complaints have been made to the Secretary of State under section 296ZE of the UK Copyright, Design and Patent Act 1988 ('Remedy where effective technological measures prevent permitted acts'). ${ }^{6}$

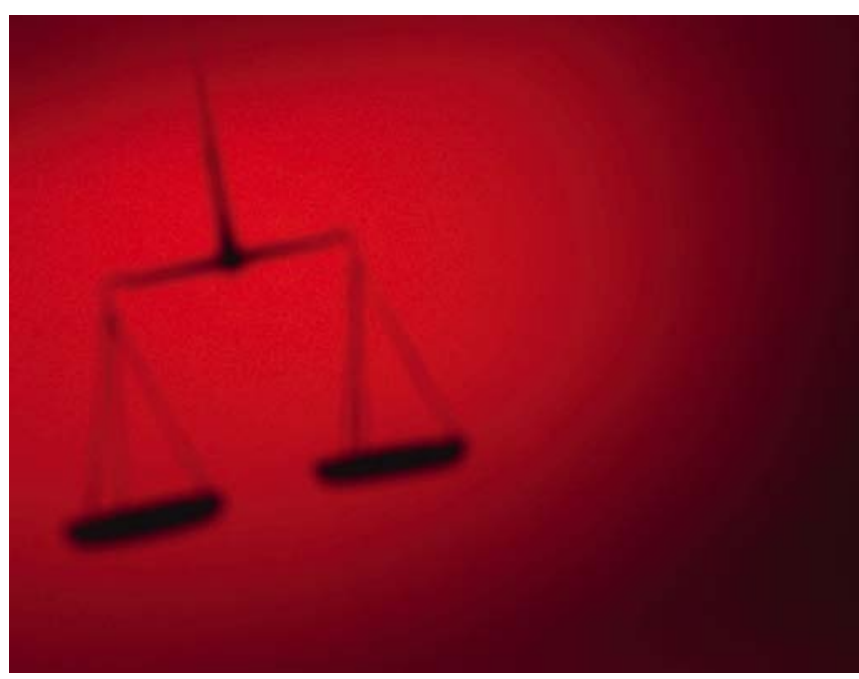
legitimate user needs are not met due to DRM technology. It should be noted that the section is very narrowly drafted (it does not apply to computer programs nor to online services offered on agreed contractual terms). Thus, users may choose to circumvent copy protection technology rather than formally complain. This would indicate regulatory failure. Non-use of Section 296ZE was confirmed by the Copyright and IP Enforcement Directorate of the UK Intellectual Property Office for this Report (e-mail Janette McNeill, Head of Copyright Framework, 30 September 2009). 


\section{EVIDENCE ON CURRENT RANGE OF REGULATORY TOOLS}

\section{Creator contracts}

The comparative international review of the regulation of copyright contracts uncovered a range of regulatory tools that attempt to balance the bargaining powers of the parties. These provisions relate to Ownership; Requirements of Form; Scope of Rights Transferred; Rights to Remuneration; Effects on Third Parties; Revision and Termination; and Unfair Contracts. Very little empirical evidence is available about the effectiveness of these provisions, but this report contains a number of methodological suggestions how regulatory tools could be assessed (if policy was to desire to adjust the bargaining outcome between creators and investors). Options identified by the literature include intervening in situations of non-exploitation; strengthening rights that cannot be transferred (such as the right to be credited as the author); and privileging instruments of collective bargaining. It should be noted that regulating contracts creates potential inefficiencies.

\section{User contracts}

An analysis of legislation, case law, and the literature of the targeted countries reveals a substantial body of literature and case law on the interplay between copyright and user contracts. The freedom to vary copyright limitations and execeptions by contract is typically decided on a case-by-case basis by courts, with no principled classification of copyright limitations and exceptions by rationale (such as fundamental rights, public policy or market failure). Among EU member states, the United Kingdom and Belgium provided the richest doctrinal contribution to the present study.
There are no empirical studies about the effects of introducing imperative exceptions (nonoverridable by contract), or about the differences between countries having imperative exceptions and countries where freedom of contract prevails.

\section{RESEARCH GAP I: EFFECTS OF KEY REGULATORY TOOLS}

There is a considerable need for systematic studies into the empirical effects of key regulatory tools under discussion. However, these cannot be researched directly without comparing to some other 'counter-factual' situation - hence the interest on the part of researchers in 'with' and 'without', and 'before and after' situations. ${ }^{7}$ Such studies have methodological challenges, as laws are never the only parameter of change, and possible differences may be explained by other causes (such as the economic cycle, changes in taste, etc.).

Feasible studies focussing on differences between countries, or studies capturing changes in the market before and after the introduction of new legislation include the following.

\section{Creator contracts: Effects of rules on first ownership}

In the UK, film directors have been treated as authors only since 1 July 1994. This implemented the 1993 EU Duration Directive, harmonising the copyright term. ${ }^{8}$ Previously, films were treated as entrepreneurial works (1956 Copyright Act, and CDPA 1988 before it was amended). First owner was the person who undertook the arrangements necessary for making the film (i.e. typically the producer).

\footnotetext{
7 See summary of discussions at the Bournemouth Symposium on Copyright, Contracts and Creativity (25/9/09 - available at www.cippm.org.uk).
} film are the producer and the principal director. The Term Harmonisation Directive was codified as 2006/116/EC. 
The question of why this change should have made any difference at all merits consideration, as the new right remains assignable. Yet it seems that a participation in revenues from certain secondary uses (that is, uses that have not been included in the primary exploitation contract with a producer or broadcaster) was negotiated as a result of that change. Economic theory predicts that primary producers would pay directors a lower fee to allow for further earnings arising from secondary usage. There are also costs to the system needed to administer these new rights, possibly reducing the 'pie' available for distribution. ${ }^{9}$ These are generic questions about the effects of new rights that would greatly benefit from empirical research.

\section{Creator contracts: Effects of rules on moral rights}

The Rome revisions (1928, Art. 6bis) to the 1886 Berne Convention provided for the right to claim first authorship of a work (so-called 'paternity right') and the right to object to any distortion, mutilation or other modification which would be prejudicial to the honour or reputation of the author (so-called 'integrity right'). These provisions are also known as droit moral from their roots in $19^{\text {th }}$ century French case law (Ginsburg 1990). Moral rights are distinct from copyright as an economic (property) right in that they cannot be transferred or waived (at least in most civil law countries).

The UK gave formal recognition to moral rights only with CDPA 1988 ss. 77-85: right to be identified as author or director (paternity right) (ss. 77-79); right to object to derogatory treatment (integrity right) (ss. 80-83). In the UK, the right to be identified as author or director has to be asserted (s. 78), and both rights can be waived by way of agreement in writing (s. 87). (Contractual waivers of moral rights are inserted as a matter of routine in contracts for audio-visual works.) Did the introduction of these rights have any effects?

In retaining a persisting link to their works, moral rights may improve the author's bargaining power. Alternatively, they could be seen as introducing inefficiencies similar to other limits on contractual freedom. An empirical study of attribution practices in certain media sectors is certainly feasible, using samples of publications over time. ${ }^{10}$ Kretschmer and Hardwick (2007, p.31) show that disputes over moral rights are more frequent in Germany (where these rights cannot be waived), but the data is not conclusive on any effects on authors' earnings compared to the UK. It should be possible to apply models about the economic effects of attribution developed in the economics of trade marks to the copyright environment. ${ }^{11}$

\section{Creator contracts: Effects of rights to remuneration}

As discussed in Paper 2, claims to remuneration can be introduced via collective licensing schemes. In European countries, this regulatory strategy has taken hold since the 1965 German Urheberrecht law that introduced a statutory claim to remuneration for unauthorised private copying, compensated via a levy on copying media and equipment.

Collecting societies may be mandated by statute as the only mechanism for exercising certain rights (as is the case for rental and cable retransmission rights under European Directives 92/100/EEC (codified as Directive 2001/84/EC) and $93 / 83 E E C$ and the resale right or droit de suite (Directive 2001/84/EC).

9 Towse and Taylor (1998) analyse this for performers' rights.

10 This proposal stems from discussions with Professor Lionel Bently.

11 Since incomplete information (or informational asymmetry between buyers and sellers) about product quality is a form of market failure, any improvement in the provision of information could potentially enhance efficiency (Landes and Posner 2003). 
The German copyright contract law (Urhebervertragsrecht) of 2002 introduced a new general entitlement to equitable remuneration (§32 - angemessene Vergütung) from any copyright contract (with the express purpose of rebalancing the bargain between creators and intermediaries). $\$ 36$ provided that collectively negotiated tariffs are deemed to be equitable. The German legislation is the most far-reaching recent attempt at regulating author contracts directly, and would benefit from research from a comparative perspective. Questions may include: Did the introduction of these changes have any effects on the remuneration of authors? As discussed in Paper 2, only one tariff has been collectively agreed in Germany between 2003 and 2009. Why is this? There are important issues surrounding the role of the institutional framework of collective bargaining that might be applicable to the UK.

It would be possible to study, both theoretically and empirically, the kinds of situation in which outright sale appears to hold more promise as an efficient mechanism for contracting access to copyright material than rental type contracts. As argued in Paper 1, if the empirical analysis does point to the prominence of rental arrangements, whereas the theoretical analysis suggests outright sale (at least in some cases, as appears to be the case studied by Liebowitz 1987), then it would be very interesting to attempt to address the reasons

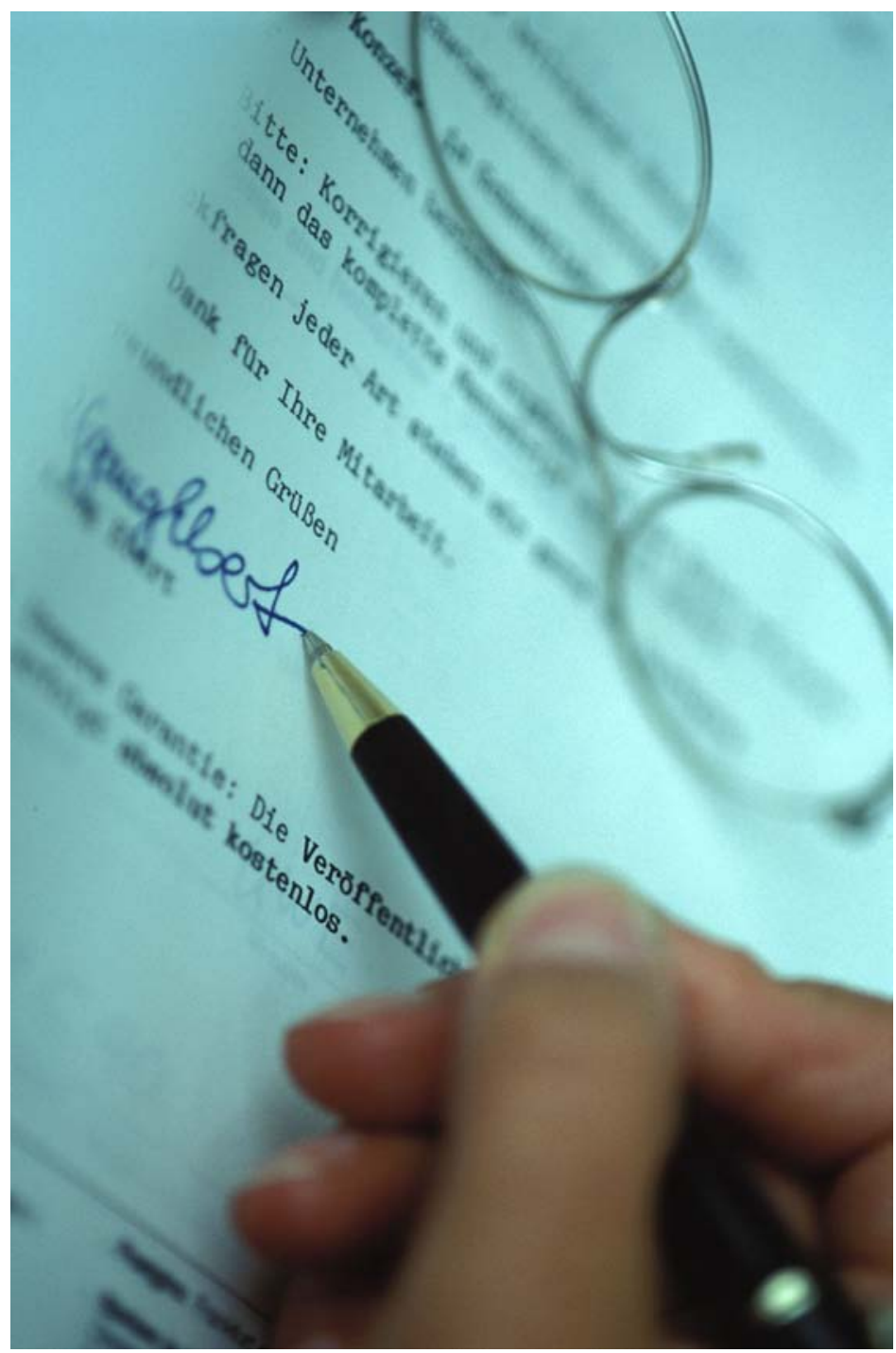
for such a divergence.

Amending Directive 2006/116/EC of the European Parliament and of the Council on the term of protection of copyright and certain related rights (proposal presented by the Commission, $\operatorname{COM}(2008) 464 / 3$ ), Article 10a (Transitional measures relating to the transposition of directive), subsection (6): If, after the moment at which, by virtue of Article 3 (1) and (2) in their version before amendment by Directive [// insert: Nr. of this amending directive]/EC, the performer and the phonogram producer would be no longer protected in regard of, respectively, the fixation of the performance and the phonogram, the phonogram producer ceases to offer copies of the phonogram for sale in sufficient quantity or to make it available to the public, by wire or wireless means, in such a way that members of the public may access them from a place and at a time individually chosen by them, the performer may terminate the contract on transfer or assignment. Where a phonogram contains the fixation of the performances of a plurality of performers, they may terminate their contracts on transfer or assignment only jointly. If the contract on transfer or assignment is terminated pursuant to sentences 1 or 2 , the rights of the phonogram producer in the phonogram shall expire.

The renewed interest in bringing non-exploited works to market is also reflected in a failed amendment to the Digital Economy bill tabled by Conservative Peer Lord Lucas that proposed an 'artists' right to re-market' if a work is not available in all common current electronic formats in all geographical regions within two years after first publication, or five years after its creation, it had not been published. Digital Economy Bill, Amendments debated in the House of Lords (6 January 2010): http://www.publications. parliament.uk/pa/ld200910/ldbills/001/amend/ml001-ire.htm. 


\section{Creator and user contracts: Effects of reversionary term}

Theoretically, reversing assigned rights to the author after a fixed period would be an effective way of improving the earnings of authors from works which are still in demand after reversion. Term reversion should also have access benefits to users in opening up archives of back-catalogues. ${ }^{12}$ Something similar to term reversion has re-surfaced as a regulatory tool in the proposed European Directive, extending the copyright term for sound recordings. ${ }^{13}$

Unfortunately, there appears to be no live example of a functioning reversionary term regime. Under the first statutory law, the Statute of Anne of 1710, copyright fell back to the author after a term of 14 years, and the author could then assign it again for one further term. Until the 1976 Copyright Act, the United States still followed this structure, with an initial copyright term of 28 years that could be renewed once. ${ }^{14}$ In the Italian model (providing for the possibility of termination of exploitation contracts after two years - see Paper 2) publishers appear to find contractual means around possible reversion.

It would be desirable to conduct both doctrinal studies on the implications of term reversion in the current framework of international and European law, and historical studies on the empirical effects of past regimes.

\section{User contracts: Effects of mandatory exceptions}

As discussed in Paper 3, apart from a few notable exceptions, ${ }^{15}$ hardly any literature or case law discusses the impact that imperative copyright exceptions had on contracting licences in those countries that stipulate mandatory exceptions. Moreover, the difference between countries implementing imperative exceptions and countries where freedom of contract prevails has not been the object of a comparative empirical study. Following the model of the British Library study (discussed in Paper 3, section 3.6), a representative sample of licences offered to educational institutions and libraries could be compared for jurisdictions with and without mandatory exceptions. For digital services aimed at consumers, sweeping techniques would be appropriate to locate licences and analyse their potential conflict with statutory copyright permissions and consumer protection legislation.

In addition, the needs of Libraries and educational institutions in terms of copyright permissions as well as their ability to negotiate clauses should be explored. A qualitative, interview based methodology would be appropriate here.

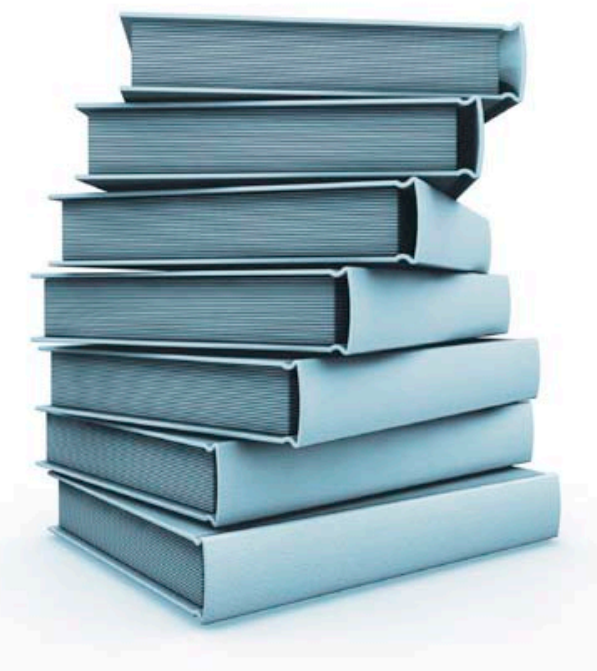

For Belgium, Dubuisson (2001) and Dusollier (2007). 


\section{RESEARCH GAP II: NORMATIVE AIMS OF CONTRACTUAL REGULATION}

Research should be undertaken to analyse the aims of regulatory tools. Surprisingly, the brief for this review has been silent on this issue. Yet, there are obvious conflicts between the aims of competition law, the aims of copyright law to provide an incentive by excluding competition, the aims of droit d'auteur inspired legislation to secure a livelihood for creators and protect their personality, and general principles of efficient contracting that may or may not conflict with other notions of fairness. The regulation of contracts may also have to take note of fundamental rights and freedoms (such as constitutional principles and human rights).

\section{Fairness}

Economists regard copyright law in terms of its 'efficiency' effects in providing an incentive to increase creative output rather than in terms of equity (see Paper 1, section 1.3). There may not be an inherent clash between these views but economics has a much less developed view of fairness than of efficiency. On the specific notion of fairness that is often invoked in policy discussion about creator and user contracts, there are a number of questions that need to be explored, relating to economic, legal and moral notions of fairness. ${ }^{16}$
- How should 'fairness' be defined for the context of copyright contracts?

- Are existing contracts really 'unfair'?

- Do alternative contracts, within the current copyright law, exist that would be perceived as being 'fairer'? If they do exist, do those contracts sacrifice efficiency?

- To what extent does any perceived 'unfairness' depend upon copyright law?

- Can copyright law be altered in order that the balance of bargaining positions be changed and the resulting contracts are 'fair'?

\section{Artistic motivation}

Another set of questions relate to widespread assumptions about creators' interests and motivations that are frequently used in the policy discourse. Empirical work seems to suggest that an incentive structure built on exclusive rights fails to motivate creators, particularly early in their careers (see Paper 2, section 2.4.1).

It would appear to be important to have more robust evidence on creators' interests that can only be gathered by primary research. Professional organisations that speak on behalf of creators have an important role here, but typically they are also subject to complex interdependencies with exploiters of copyright works. Research would have to be truly independent. organisations of journalists, illustrators, photographers, film directors, composers, songwriters and performers/featured artists considered the following contractual trends to be unfair (see report of the Symposium, available at http://www.cippm. org.uk/symposia/symposium-2009.html ): In the UK, creators are routinely required to waive their moral rights in contracts. Creators are routinely required to sign contracts that assign all their rights to the publisher or producer (meaning the enterprise or organisation that publishes and distributes their work), and cover every potential use in a blanket manner. Contracts for digital use are just bolted on to standard 'analogue' contracts and do not make provision for additional payment. If creators do not comply, others are found who will comply, especially young creators who need to break in. 


\section{Information freedoms}

As discussed in Paper 3, regulating the relationship between copyright and contract law with respect to limitations and exceptions may depend on different groups of justifications. For market failure remedies (such as, under one reading, exceptions for private copying), contracts may legitimately trump statutory permissions. For fundamental rights (such as those implied by exceptions for criticism or parody), these must trump. In addition, some exceptions may have several underlying objectives or justifications which are sometimes contradictory (e.g. is the private copying exception based on a market failure or on the right to privacy or both?). The most contentious exceptions are those based on 'policy', but it is not clear what policy. There is more comparative and analytical work needed on the justificatory basis of exceptions, as well as on their economic impact. The Gowers Review of Intellectual Property (2006) recommended the introduction of more flexibility into the copyright system but did not analyse the rationale for exceptions beyond vague references to reasonableness and transaction costs: 'UK copyright law provides a number of 'exceptions' to the broad rights granted to the owner of a copyright work to enable 'reasonable' use to be made of the work freely and without permission.' (p. 40) '[O]ne of the purposes of exceptions to copyright is to reduce burdensome transaction costs associated with having to negotiate licences.' (p. 47) ${ }^{17}$

The exclusion of digital copyright works from a number of user privileges, as in Article 6(4) of the InfoSoc Directive (2001/29/EC), is underpinned by their status as services rather than goods. Both their status and their exclusion from copyright exceptions could be usefully addressed by theoretical research.

\section{RESEARCH GAP III: SOLUTIONS FROM OUTSIDE COPYRIGHT AND CONTRACT LAW}

The only UK body charged with reviewing copyright contracts is the Copyright Tribunal. It has a very narrow mandate, covering dispute resolution of certain collective licensing schemes. ${ }^{18}$

It has been estimated that the costs of a referral and full adjudication proceedings amounts to at least $£ 250,000$. $^{19}$

\begin{abstract}
Gowers' flexibility recommendations were: Recommendation 8: Introduce a limited private copying exception by 2008 for format shifting for works published after the date that the law comes into effect. There should be no accompanying levies for consumers. Recommendation 9: Allow private copying for research to cover all forms of content. This relates to the copying, not the distribution, of media. Recommendation 10a: Amend s.42 of the CDPA by 2008 to permit libraries to copy the master copy of all classes of work in permanent collection for archival purposes and to allow further copies to be made from the archived copy to mitigate against subsequent wear and tear. Recommendation 10b: Enable libraries to format shift archival copies by 2008 to ensure records do not become obsolete. Recommendation 11: Propose that Directive 2001/29/EC be amended to allow for an exception for creative, transformative or derivative works, within the parameters of the Berne Three Step Test. Recommendation 12: Create an exception to copyright for the purpose of caricature, parody or pastiche by 2008. Recommendation 13: Propose a provision for orphan works to the European Commission, amending Directive 2001/29/EC. Recommendation 14a: The Patent Office should issue clear guidance on the parameters of a 'reasonable search' for orphan works, in consultation with rights holders, collecting societies, rights owners and archives, when an orphan works exception comes into being. Recommendation 14b: The Patent Office should establish a voluntary register of copyright; either on its own, or through partnerships with database holders, by 2008. For the current status of these recommendations, see Taking Forward the Gowers Review of Intellectual Property: Second Stage Consultation on Copyright Exceptions (UK Intellectual Property Office, December 2009, http://www.ipo.gov.uk/consult-2009-gowers2.htm).
\end{abstract}

The Tribunal's jurisdiction is defined in Sections 149, 205B and Schedule 6 of the Copyright, Designs and Patents Act 1988 (as amended). Some matters may be referred to the Tribunal by the Secretary of State even though collecting societies are not involved. For example, it can settle disputes between publishers of television programme listings and broadcasters over royalties payable.

Responses to UKIPO consultation on Reform of Copyright Tribunal Rules, 9 April 2009; UKIPO workshop (notes on file with M. Kretschmer). 
There are models for reviewing tariffs, contractual terms and industry practices in other areas of public policy. These should be assessed systematically for their suitability to the copyright environment.

\section{Self-regulation}

Against overreaching licence agreements the examined literature proposed self-regulatory solutions, to be enacted through model licences and codes of conduct. ${ }^{20} \mathrm{~A}$ study on the feasibility of such solutions would be interesting for policy makers. The relationship of self-regulation, collective bargaining and competition law may warrant further research. Concerns have been voiced that standard agreements may be in violation of competition law, specifically the prohibition against anti-competitive agreements and concerted practices (Art. 81, EC = Art. 101, Treaty on the Functioning of the EU). ${ }^{21}$

\section{The regulation of utilities}

A further line of possible research concerns the applicability of models from the regulation of utilities. The Utilities Contracts Regulations $2006^{22}$ define services as utilities under the following categories: water, electricity, gas, heat, exploration and exploitation of oil and gas, coal and other solid fuels and transport. Airport and postal services are subject to related regulatory constraints, as is the communications sector, regulated in the UK by OFCOM under the Communications Act 2003 (covering TV and radio, fixed line telecoms, mobiles, and airwaves).

Regulation in all these areas involves issues of market access, price control, and contractual supervision. Research may analyse the available instruments as applicable to the regulation of information markets and copyright contracts. ${ }^{23}$

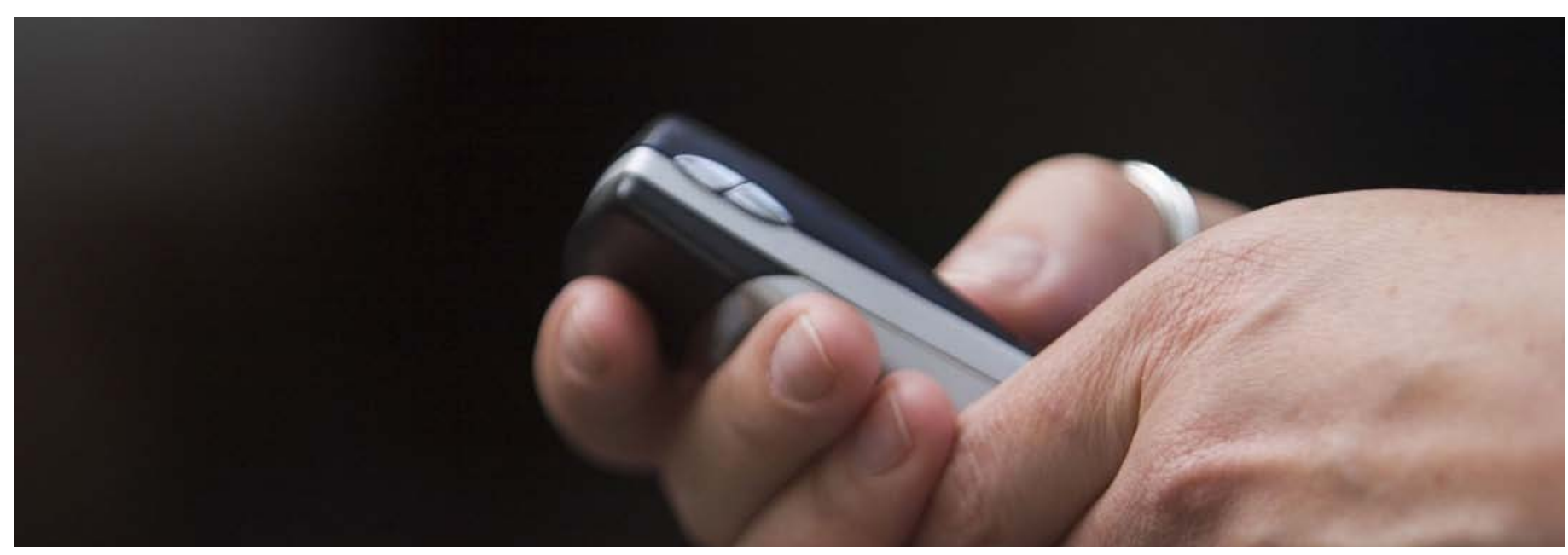

See discussion in Chapter 4 of the EC Green Paper on Copyright in the Knowledge Economy 2008, the Australian CLRC Study 2002, Garnett 2006, Hugenholtz 2008.

In Albany International and Brentjens the ECJ ruled that agreements on compulsory pension schemes fall outside the scope of Article 81: Case C-67/96, Albany International BV v. Stichting Bedrijfspensioenfonds Textielindustrie [1999] ECR I-5751, [2000] 4 CMLR 446; Cases C-115 to 117/97, Brentjens v. SBVHB, [1999] ECRI-6025, [2000] 4 CMLR 566. AG Jacobs opinion in Albany laid down four conditions for disapplying Art. 81. The collective bargaining agreement (i) was made as part of normal collective bargaining, (ii) was made in good faith, rather than to conceal anti-competitive restrictions, (iii) dealt with core aspects of collective bargaining, such as wages or other conditions of work, and (iv) did not affect third parties.

The Digital Britain report (June 2009) explicitly likens the digital information infrastructure to a utility, and proposes regulatory measures to curb copyright infringements in broadband networks. However, the debate has so far omitted to analyse the economic rationales for non-judicial intervention. 


\section{RESEARCH GAP IV: CONTRACTING FOR DIGITAL SERVICES}

While many of the above research gaps could be addressed separately, and may offer long term evidential benefits, it appears that many of the most pressing issues surrounding the regulation of copyright contracts stem from the creation of new digital services. They typically require complex contracting on the creator, producer and user sides, and often involve some form of collective licensing. There has been a proliferation of new arrangements, often without precedent. Private ordering appears well ahead of policy here. Examples include offering equity stakes in new services that are potentially infringing to major right holders (YouTube, Spotify). This avoids potential liability, but reports suggest that very little money from such services flows back to the smaller producers and creators. ${ }^{24}$ Other sensitive licensing issues surround digitisation initiatives (such as the Google books project), information aggregators, the treatment of user generated content on social networking sites, and the obligations of Internet Service Providers.

Following a flurry of initiatives by the European Commission, ${ }^{25}$ there is also a process of reorganisation of collecting societies under way, through the private ordering device of joint ventures. Examples include Armonia (2007), a one-stop-shop licensing platform for online and mobile use of the repertoires of the collecting societies of Spain (SGAE), France (SACEM) and Italy (SIAE), and CELAS (2007) a joint venture between the German collecting society GEMA and the UK's MCPS-PRS for the European-wide administration of the repertoire of EMI Music Publishing for online and mobile use.
Again the implications for creators, smaller intermediaries and users have not been systematically explored.

There are several methodological approaches that could be pursued here. Theoretical economic research could consider the degree to which contracts can substitute for copyright protection at all points along the value chain. ${ }^{26}$ Developing digital services could be researched using social science perspectives on private ordering, from a strategic management perspective on business models, or from a consumer perspective (acceptability of levels of payment and various levels of copy restrictions). Some of this work is underway.

In the context of this report we see an immediate need to create an inventory of these new contractual arrangements. There have been some limited reviews of collecting societies (mostly in the EU) from a legal perspective. These studies compile the rights managed collectively in each country, whether they are administered voluntarily or on a statutory basis, and what regulatory supervision (if any) is in place.

There have been no studies that take primarily an approach by economic activity. The key questions here would be: (i) What kind of activity can copyright users (e.g. broadcasters, online aggregators, consumers) in each country undertake under collective licences? (ii) How are these activities priced? (iii) How are the licence fees distributed between the various right holders (intermediaries and creators)?

Examples are given in the response by Consumer Focus (the UK statutory body campaigning for Consumers) to the European Commission consultation on Creative Content Online (http://www.consumerfocus.org.uk/assets/1/files/2009/06/ Consumer-Focus-response-to-Creative-Content-reflection-consultation-final2.pdf - January 2010). Document Study on a Community Initiative on the Cross-Border Collective Management of Copyright, 7 July 2005; Commission Recommendation On the Collective Cross-border Management of Copyright and Related Rights for Legitimate Online Music Services, adopted 12 October 2005. 
To give a few examples: blanket licences (musical works) for commercial radio stations are typically set at a percentage (often 2-3\%) of revenue. Blanket licences (musical works) for CDs are set as a percentage of the wholesale price (6$9 \%$ of the published price to the dealer). Blanket licences/levies for private copying may be set as a percentage of the retail price $(5 \%)$ of copying equipment/media. Blanket licences for course readers at universities may be priced as a fixed fee per student. ${ }^{27}$

A methodological obstacle to a comprehensive inventory is the commercial sensitivity of some of the contractual arrangements beyond the tariffs advertised by collecting societies. However, a SABIP endorsed review, backed up by content analysis of secondary reporting in industry publications, should be able to provide a sound evidential basis.

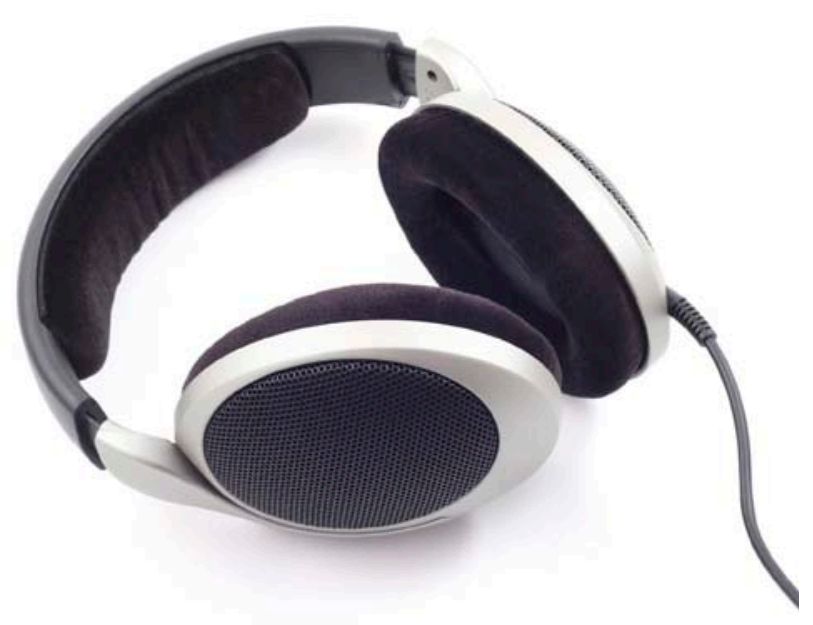

\section{PRIORITIES FOR RESEARCH}

\section{USER CONTRACTS (RATIONALE OF EXCEPTIONS)}

Some countries have enacted imperative exceptions; however, the legislature has not given reasons for making the exceptions imperative. The fact that three countries reviewed (Portugal, Ireland and Belgium) made all their exceptions imperative without distinction indicates a lack of thought as to the normative aims of contractual regulation, i.e. what interests copyright should take into account (most commentators would say that, for instance, fundamental rights and freedoms should be taken into account). Also no country has made other limits imperative (such as the idea/expression dichotomy, the originality requirement, the term, the economic rights, the exhaustion principle), despite these being as crucial if not more so than the exceptions to the economic rights. In this respect, more comparative and analytical work is needed on the justificatory basis of copyright limits, as well as on their economic impact. A similar question is raised by Article 6(4) of the InfoSoc Directive which excludes some important exceptions from the mechanism without apparent reason (this exclusion of digital copyright works from a number of users' privileges seems underpinned by their status as services rather than goods despite the fact that they are copyright works in every respect). Board, there is an extensive jurisprudence on the setting of tariffs (when they have been challenged). To our knowledge there is no tradition of jurisprudence on the distribution of these fees (e.g. between various categories of rights, between authors and publishers, between major and minor earners, thresholds) although some countries set certain elements by law (for example in relation to the private copy levy). 


\section{USER CONTRACTS (LICENSING PRACTICES)}

The theoretically undesirable effects of overriding some or all copyright limits by contract or by technological protection measures (TPMs) need to be assessed by empirical studies. The effects of imperative limits could be investigated by focussing on differences between countries having imperative exceptions and countries where freedom of contract prevails. Preferably studies should be undertaken by specific sectors, such as software, database, music, and film, and should distinguish between commercial users, consumers, libraries and educational establishments. Studies might attempt to obtain and analyse the contents of a representative sample of contracts for each sector. If the contracts are similar despite the law being different, consumer behaviours should be analysed to see if they behave similarly or differently (i.e. whether they are aware of their rights or not).

Again this may differ per sector and per type of user. For instance, a representative sample of licences offered to educational institutions and libraries could be compared for jurisdictions with and without mandatory exceptions. The needs of libraries and educational institutions and their ability to negotiate clauses could be explored through a qualitative, interviewbased methodology. For consumer contracts, sweeping techniques (locating online licences) as well as survey research methods (for example, sampling shrinkwrap licences) would be suitable.

\section{CREATOR CONTRACTS (TERM REVERSAL)}

Reversing assigned rights to the author (after a fixed period, or because of nonexploitation) is likely to be an effective way of improving the earnings of the author. Term reversion should also have access benefits to users from opening up archives of back-catalogues. It would be feasible to conduct both doctrinal studies on the implications of term reversion in the current framework of international and European law, and studies on the empirical effects of historical regimes of rights reversal.

\section{CREATOR CONTRACTS} (MORAL RIGHTS)

Under the UK Copyright, Designs and Patents Act 1988, the so-called 'moral rights' include the right to be identified as author (paternity right), and the right to object to derogatory treatment (integrity right). Contractual waivers of moral rights are inserted frequently into copyright contracts. If these rights were made unwaivable by statute, such a persisting link between author and work might improve the author's bargaining power. Alternatively, such an intervention could be seen as introducing inefficiencies similar to other limits on contractual freedom. Feasible research projects include empirical studies of attribution practices in certain sectors, and of differences in the treatment of moral rights across jurisdictions, and their impact on authors' earnings.

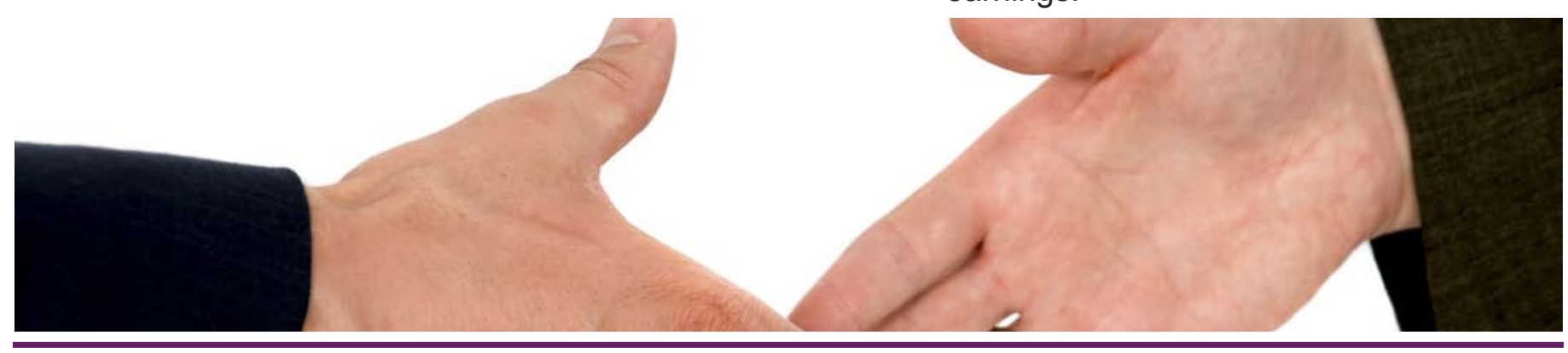

Providing Government with strategic, independent and evidence-based advice on intellectual property policy.

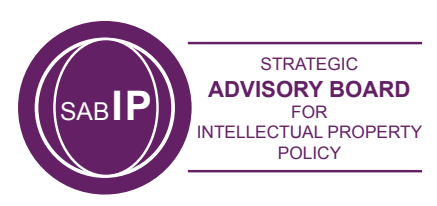




\section{COMPETITION LAW}

Linked to the above priorities is the question of whether contractual practices in certain sectors (to be discovered through the first batch of studies recommended as a first priority) are in fact breaching competition law (Arts. 81 and 82, EC = Arts. 101 and 102, TFEU). Rather than commissioning a study, SABIP could refer the matter to the European Commission and, in the UK, to the OFT.

\section{SELF-REGULATION}

Doctrinal as well as empirical research should be done to study the feasibility of model licences and codes of conduct to solve the problem of the overridability of copyright limits. In the context of creator contracts the status under competition law of standard form contracts and the effectiveness of collective negotiations through professional bodies should be examined.

\section{COPYRIGHT BUSINESS MODELS}

It would be desirable to pursue several of the research priorities identified above in an integrated manner, since digitisation appears to have a systemic effect on contracting. For example, contracts over copyright materials may now be formed simultaneously on the supply side and the demand side (user-generated content) or be negotiated as bundles (ISP/mobile services).
How is the role of intermediaries changing? Can predictions of disintermediation be substantiated? To what degree can contracts substitute for copyright protection at all points along the value chain? Are developments sector specific?

Are collecting licenses meeting the challenges of the digital era? What kind of activity can copyright users (e.g. broadcasters, online aggregators, consumers) in each country undertake under collective licences? How are these activities priced? How are the licence fees distributed between the various right holders (intermediaries and creators)?

Such a larger project is likely to be interdisciplinary, using multiple methods, and may subsume several of the research priorities identified above.

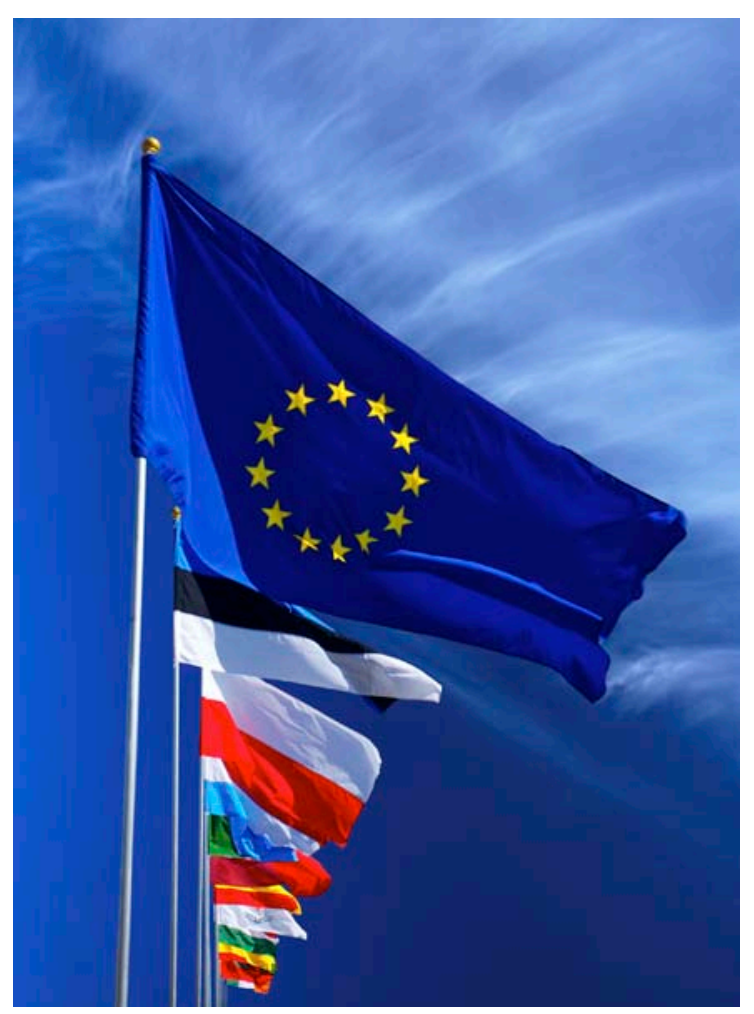


PAPER 1 - ECONOMIC THEORY OF COPYRIGHT CONTRACTS, Richard Watt

\section{ABSTRACT}

The economic theory of copyright is now well advanced, and has covered many issues related to the grant of copyright and the supply and consumption of copyright goods. However, a very important aspect of the value chain has been largely ignored - the fact that between creation and consumption many contracts are likely to be involved, and copyright will, logically, have effects upon the way those contracts are written and interpreted. It is interesting that economists themselves have not put the issue of contracts into the forefront of the economics of copyright, since the study of contracts and the incentives that they create is certainly of prime interest to economists generally.

This paper reviews the scant economics literature that does deal with the relationships between the legal institution of copyright and the contracts that are then written along the value chain. It is to be emphasised that this paper only deals with the economic theory literature, and does not consider the legal literature. The principal objective is to identify clearly the research gaps that exist, and to put somewhat into perspective the question of how these gaps might be prioritised in terms of importance or urgency.

\subsection{CONCEPTUAL FOUNDATIONS}

The economics of copyright often approaches the topic using an incentives argument - copyright is granted to authors in order that they can be appropriately remunerated for their work, and so they thereby have the appropriate incentive to provide that work. Under this approach, the central problem for determining the correct legal copyright parameters is the balancing at the margin of the incentive provided to authors and the access to works that is available for users.

However, and regardless of the parameters involved, the granting of copyright alone provides no guarantee of remuneration of any type or amount, and so copyright alone cannot provide any sort of incentive for authors. There are two other crucial elements that are also required in order that copyright does not become a 'straw-man'. These elements are enforcement of copyright, and contracts between rights holders and eventual users. Only contracts can provide remuneration and thus incentives, while copyright itself together with its effective enforcement are what pave the way for contracts to be written. That is, without copyright and enforcement, contracts would be impossible. Thus, in short, copyright itself is not an incentive mechanism, but (assuming that it is enforced) it does allow an incentive mechanism to operate, namely contracts.

It is also true that, under an enforced copyright system in the digital environment, it is only via contracts that users actually gain access to copyright material. Naturally, some of these access contracts might be very simple - you pay me $\$ 20$, and I allow you to take a CD-ROM with my content saved to it in such a way that you can access it, but payment of the price and acceptance of the disk imply that you are contracted not to repackage and resell the content in any way. Of course there are other, minor, ways in which one can gain some access to copyrighted content outside of a contract. For example, any fair-use that is provided for within the copyright law structure does precisely this. However, the principal means of access is via contracts, either explicit or implicit. ${ }^{28}$ sold, the contract's reach ended. The legal status of shrink-wrap, click-wrap and browse-wrap licences is not settled in many jurisdictions. Similarly, whether fair-use type exceptions survive contractual restrictions remains a point of contention. These issues are discussed in detail from a comparative legal perspective in Paper 3.

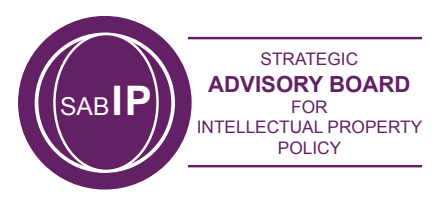




\section{PAPER 1 - ECONOMIC THEORY OF COPYRIGHT CONTRACTS}

If we then accept that the incentives provided to authors, and access provided to users, stem not so much from the grant of copyright itself, but rather from the ability that an enforced copyright law gives for bringing the parties together via contracting then we are justified in looking closely at the way in which contracts for access to copyright works are structured. And, I might add, the analysis of contracts is a very common theme within applied microeconomic theory. For that reason, in the present document, I propose to look at both the general economic theory of contracts, and the specific literature on contracts for copyright works, in order to see what sort of overlap actually exists, and thus to attempt to identify logical gaps in the specific literature that might be considered to be subject of future research.

\subsubsection{Copyright and the contractable space}

In general, copyright law can be seen to simply provide for a restricted space in which contracts can be written. If there were no copyright law, or alternatively, if there were no enforcement of the law, then the effective space for contracting becomes empty. Without copyright law an author would not be able to contract to provide access to his content to a publisher in exchange for royalties, since the publisher could envisage no revenue stream from which royalties could be paid. Of course this depends crucially upon the only incentive to the author being financial. If the author does have other incentives, for example, if they areonly motivated by gaining access to readership, then a contract might still be possible under which the author pays the publisher for producing and distributing the work. Precisely this type of contract is at the forefront of the so-called 'open access' movement in academic publishing, and it has recently been strongly proposed as a socially desirable situation by Steven Shavell that copyright in academic work might be best abolished (see Shavell 2009). In any case, in a scenario of pure financial motivation and yet no effective copyright law, contracting between authors and users becomes virtually impossible, and the incentive effects for authorship are diluted down to nothing. Any authorship that continues in such an environment cannot be due, in any important manner, to an expectation of financial reward. ${ }^{29}$

On the other hand, a maximal copyright law (enforced), with perhaps absolutely no fairuse provision and no expiry date, provides an unrestricted space for contracting, and thus a maximal expectation of reward since no access at all will be granted unless the right holder permits it (which he or she might only be persuaded to do in exchange for a financial payment). Intermediary options, in which copyright does restrict ownership in some way (certainly over time and most likely also over specific uses), lead to a restricted, but not empty, contract set.

Contracts that are written within a restricted set might differ from those in an unrestricted set, although this is certainly not a general result. Changes in copyright law and its enforcement will only have effects upon the contracts that are written when those contracts lie on the boundaries of the contractable set that copyright offers. Clearly this will be the case for when the initial set is very small, but it might not be the case when the initial set is very large. Thus a central topic in the economics of copyright contracts might be to look within the contracts to see where, and how, the current copyright law parameters are reflected. If they are not reflected in the contract, then we might understand that the contract in question does not lie on the boundary of the contractable space, and thus extensions in copyright law (which would simply expand the contractable space) would have no effect on the contract, and thus on the incentive and access effects. Similarly, if the current copyright provisions are present, explicitly or implicitly, in the contracts that are written, then changes in the copyright law will affect the contracts that are written, and thus will have both incentive and access effects.

concluded in a non-copyright environment (such as Friedrich Schiller's Horen contract of 1794 discussed in Paper 2) provide a telling counter example. This gap between orthodox economic theory and empirical evidence has profound policy implications.

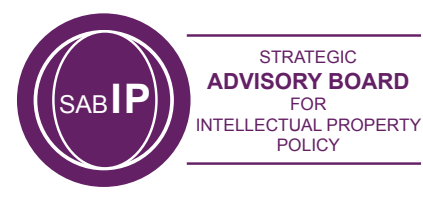


In order to illustrate, let's take a simple example. Suppose Mr. A, an author, has written a wonderful book that he would like to get published and marketed. So he negotiates with publisher $P$ for that purpose. $A$ and $P$ agree on a publishing contract, which stipulates that $A$ will supply the work to $P$ for the purpose of printing and sale, and that $P$ will pay a specific royalty to $A$ for each book that is sold. Upon signing of the contract, A duly supplies the work to P. However, at the end of the day, two things emerge; (1) even though there have been sales of the book, $P$ has not paid any royalties to $A$, and (2) it has been detected that a second publisher, $Q$, has also produced and sold copies of the same book. $Q$ has no contractual relationship with either $\mathrm{A}$ or $\mathrm{P}$. What can $\mathrm{A}$ do?

I would argue that $A$ can sue $P$ for breach of contract, and $A$ can sue $Q$ for breach of copyright law. In principle, A cannot sue $P$ for breach of copyright law, since the contract between them gives $\mathrm{P}$ the right to produce and market the book. The important aspect of this example might be the remedies that $A$ can expect from both $P$ and $Q$. Clearly, if $P$ is sued for breach of contract, then we must look to the contract itself for the remedy, which is likely to be that $P$ must pay $A$ the contracted royalty. On the other hand, the remedy that will be available from $Q$ will depend on copyright law. As long as $Q$ is indeed found liable for infringement, at the very least $Q$ will be ordered to stop producing and selling the book, and perhaps some sort of damages will also be awarded from $Q$ to $A$. The point is that the extent of the damages available under copyright law might well have contributed to the choice of the contracted royalty between $A$ and $P$. If the damages under copyright infringement were much lower than what would be contracted to as royalty payments, then publishers would have an incentive to infringe rather than to contract.
Thus, the copyright law 'standards' and parameters might be seen to affect the contractual conditions that are agreed to. Weak copyright standards might lead to unfavourable contracts for authors, while strong copyright standards might lead to favourable contracts for authors. ${ }^{30}$

In that sense, if the contracted royalty is heavily dependent upon the copyright standard, then we might expect that the royalty would change if the copyright standard changes. This is what is meant by a contract being on the boundary of the contractable set defined by the copyright law. In these cases, alterations in the law will have incentive effects via the contracts between authors and publishers. On the other hand, it might well be that the damages from copyright infringement are extremely high, and are impossible to approach in a voluntary access contract. Then the royalty in the contract will not be affected by any further increase in infringement damages. In this case, the contract is not on the boundary of the contractable set, and alterations in the law will have no effect upon the contracts that are written, and thus upon the incentives that are given.

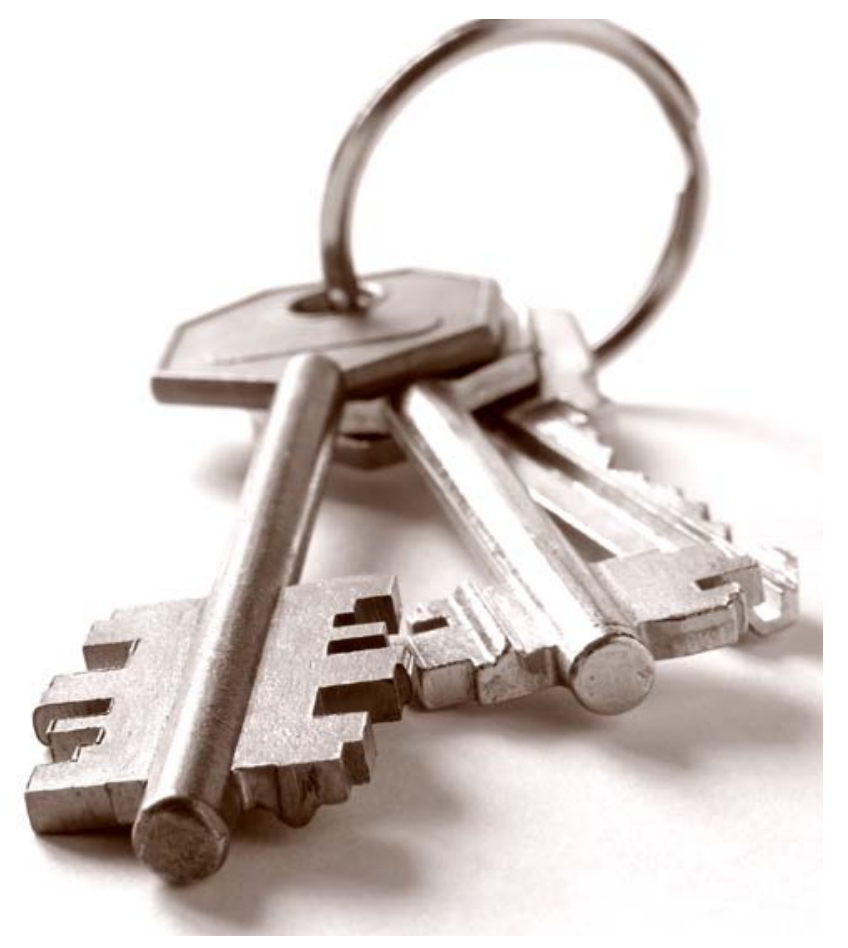
infringement case, the court may look to the contract between $\mathrm{A}$ and $\mathrm{P}$ for guidance as to what might constitute a reasonable royalty. Thus, not only might copyright law affect the contract, but also vice-versa.

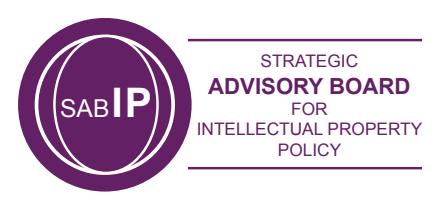




\subsubsection{Copyright law and the parties to contracts for copyright goods}

The relationship between copyright law and contracts can only really be fully understood in terms of parties that are not actually signatories to the contract. This has been clearly argued by Kretschmer (2006). There is no real need for any kind of copyright law for an author to contract with a publisher for the disclosure from the former to the latter of the relevant intellectual property. This can be done entirely within the domain of a private contract. However, what the publisher is willing to pay under that contract is, at least in part, determined by what potential competitors will or will not be able to do in the subsequent market in which the work will be made available to consumers. Since the competitors are not part of the contract, but they do influence the value of the contract, it is here that copyright law has its primary influence on contracts. ${ }^{31}$

Conventional wisdom holds that a strong copyright protection increases the value of the contract for the publisher, and thus (assuming that bargaining powers are not extreme) some of that additional value can be captured by the author through the contract with the publisher. In this way the level of protection offered by copyright law would influence the terms and conditions agreed to in the contract. This conventional wisdom has been challenged on many fronts, and may not hold at all. However, the important point to note is that not only might it be the case that copyright law directly influences what is and what is not contractable, but it also influences the terms contracted to via its indirect effects in governing the activities of agents who contribute to the value of the contract but who are not directly parties to it.
No existing literature has been found on this topic, and thus we propose it as an interesting gap in the literature, waiting to be filled. Research would consider the degree to which contracts can substitute for copyright protection at all points along the value chain. In principle, it would appear that where there are very high transaction costs from monitoring activities, an important impediment for contracting, a far greater reliance will be placed upon copyright protection rather than individual contracting. Similarly, when third parties (i.e. parties that are not signatories to a contract) are able to alter the value of that contract, then copyright law would become more important.

\subsubsection{Standard contract theory and special characteristics of copyright contracts}

In standard economic theory, the theory of contracts is intimately related to the concept of incentives. That is, a contract is a means under which a given party can be persuaded to carry out some task in such a way that is beneficial to a second party. In order for the persuasion to work, the contracted party must be given the correct incentives to do what the contractor would like, and this is typically done by linking outcomes with monetary payments. Contract theory in economics is typically spelled out within the context of the socalled 'principal-agent' model, in which the principal attempts to contract an agent to carry out some task. Of course, the task will generate revenue, and the contract is the mechanism that dictates how that revenue is shared between the two parties. The standard theory of contracts only really becomes interesting in situations of uncertainty and asymmetrical information, that is, scenarios in which the contractor (i.e. the principal) cannot fully observe all that he or she would like to regarding the behaviour or identity of the contracted party the 'publisher', considering them as one - perhaps the 'supply side' of the market for copyright goods. This is done as a simplification, and is justified by there being few differences in objectives between these two parties - that is, the incentives of authors and publishers are said to be largely aligned. This so-called 'harmony of interests' assumption is both conceptually and empirically problematic (for discussion, see Paper 2). In this case, of course, copyright has a direct influence on the contracts signed between this side of the market and the other (the demand side). Contracts written exclusively between parties on the supply side are dealt with in this survey below (royalty contract theory). 
(the agent). In such cases the issue of incentives comes to the fore, although economic theory has proposed very simple and intuitive solutions to the different types of problem that may occur, always based on contracts that link the agent's payments to the observed outcomes of the task to be carried out. ${ }^{32}$

Good discussions of the types of contracts that are commonly used along the value chain for copyright products can be found in Baumol and Heim (1967) for the case of writers, and in Connolly and Krueger (2006) for the case of music. Also the widely referenced text of Caves (2000) will be of use here, although it is concerned with a much wider set of contracts - those corresponding to the creative industries generally. However, none of those studies looks formally into the theoretical relationship between the level and nature of legal copyright protection and the contracts that are used along the value chain.

The particular case of contracts for the production and dissemination of copyright products is, in principle, no different from any of the more general situations that are commonly discussed in economic theory. Indeed, all that is required is to check that the assumptions made in the standard theory are relevant to the particular case of copyright, and if not, then to establish the correct set of assumptions under which the contract problem should be analysed. In this subsection we shall consider the most widely cited text on the topic of the kinds of contracts and the types of problems that are prevalent, in the particular case of the creation-production-consumption chain for the creative industry (a subset of which corresponds to copyright goods), namely Caves (2000).

In this book, Caves concentrates on the special features of cultural markets, and considers whether and to what extent the contracts typically seen in these markets conform or not to the accepted economic theory of incentive contracting. Most of the book is dedicated to looking at specific details of aspects of the arts, for which copyright may or may not be such an important feature, and so in that sense, copyright is more of a background theme to the book.

Caves' book is so comprehensive of the contractual means under which the value created in cultural industries is distributed among the participants of the creation-distribution-consumption chain that it becomes difficult to list each relevant aspect of the book under a series of corresponding topical areas. Thus, it is perhaps best to mention this important book separately, and trust that the interested reader will consult it for further details.

The claimed principal focus of Caves is to apply the standard principal-agent theory of applied microeconomics to the case of contracts along the value chain for creative goods. Nevertheless, the book does not provide any modelling on contract theory at all (almost certainly in the interests of a more general readership), but rather Caves limits his analysis to looking at specific features of the contracts that are typical in the real-world at specific points along the value chain for a wide range of creative processes, and noting their relevance to the economic theory of contracts.

Indeed the most interesting part of the Caves book (especially where relevance to the current survey is concerned) is the introductory chapter, which is the most general of all of the chapters in the book, and that which is most clearly focused on the relationship between traditional contract theory and creative industries generally. In that introductory chapter, Caves sets out the general aspects of cultural industries that should be present in any analysis of contracting for goods and services within those industries. He also looks at the general economic theory of contracts, and poses (perhaps somewhat implicitly) that the latter might require amendment in order to cater appropriately for the cultural sector. with asymmetric information. For example, the well known text by Hal Varian (Intermediate Microeconomics, 7th ed. 2007) would be a good place to start.

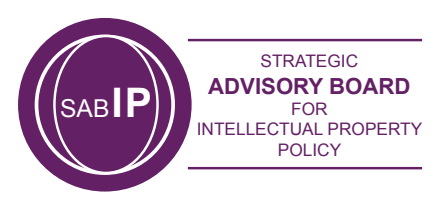


To the extent that transactions within cultural industries are reliant upon copyright this discussion by Caves, which sets out the salient aspects of contract, can be applied to contracts for the use of copyright (though Caves himself does not so).

To summarise, the principal features of cultural markets identified by Caves as being of importance for the theory of contracts are the following:

1. Demand uncertainty

2. The fact that creative workers care about their output

3. Some creative products require diverse skills

4. The existence of differentiated products

5. Vertically differentiated skill requirements

6. The importance of timing

7. The fact that cultural products are durable, leading to durable rent flows

8. The existence of essential inputs in the value chain.

It remains an open question for theory to look more closely at each of these aspects in turn, within the standard principal-agent contract theory set-up, to see how, or indeed if, they lead to a markedly different set of outcomes from those of the traditional theory. In fact the first of the aspects noted by Caves, namely demand uncertainty, is of course already a very common aspect of the standard theory of contracts, and so we can certainly consider that this has already been covered by the general theory. It is however less clear that points 3,4 , and 5 will require any major adjustments to the general theory, and they may instead simply imply a widened understanding of the inputs and outputs of agents. In short, instead of using a scalar interpretation of inputs and outputs, we might want to use a vectorial notation.
While certainly adding a level of complexity, doing this should not be impossible, and indeed one may well doubt whether it would add significant new insights as to the incentive effects of contracts. Likewise, Caves' points 7 and 8 are also unlikely to be of any great importance to standard contract theory. Durability of rent flows is often incorporated by simply taking variables in terms of present discounted values and, as far as essential inputs are concerned, the standard theory already has this aspect present in the sense that no principal gains any profit without an agent, and no agent gains any utility without the presence of a principal. Thus the essentiality of inputs in creative industries is unlikely to pose any challenge to contract theory, and it is also unlikely to lead to any significant alteration in the results of that theory.

However, the other points, namely point 2 (workers care about their output) and point 6 (the importance of timing) may well be more interesting. It is certainly true that in the standard theory of contracts workers are only concerned with the financial gains from their efforts, and not from any other aspect related to the output obtained. If trade-offs between monetary payments and other aspects of output (perhaps the level of sales itself) are able to be brought into the contract, it is to be expected that different outcomes will result. Finally, with respect to timing, when there are many acts within the sequence of actions required for an output to be gained, and when the ordering of these acts is important, then there is a clear incentive for strategic and collusive behaviour by the participants along the value chain. Again, these types of considerations are likely to impact upon the outcomes of traditional contract theory, in which generally there is a single act (that of the agent), and thus no scope at all for collusion and hold-up effects.

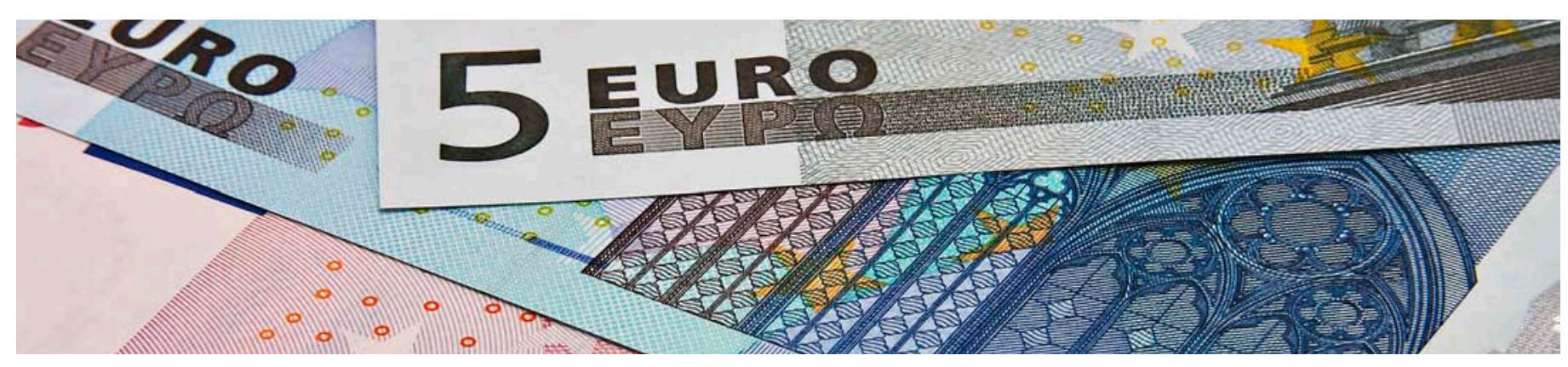

Providing Government with strategic, independent and evidence-based advice on intellectual property policy.

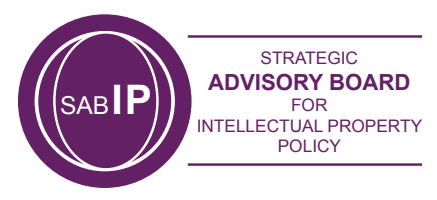


Thus, clearly we have another gap in the literature, namely the extension of the traditional principalagent framework to one that includes agents who care about more than just their monetary payments, and (independently of the previous suggestion) a greater complexity when considering possible strategic interactions among the players along the value chain. Both extensions to the basic model appear to be reasonably straightforward, and should not present any major modelling difficulties.

Notwithstanding Caves' invitation, implicit or otherwise, to economic theory for a consideration of some of the specific aspects of creative industries within contract theory, he himself refrains from providing any such analysis, retaining instead the standard (i.e. 'simple') theory of contracts. Indeed, in his own words (Caves, 2000, p. 11): 'Much of this book is about why contracts and deals are structured the way they are, and so simply contract theory plays a considerable role.' Thus, Caves limits his work to the use of the standard theory as an explicative device for specific aspects of contracts that are observed in the real world of the creative process value chain.

It is also true that Caves' book has relatively little to do with copyright, and specifically the relationship between copyright and contracts. Copyright is not mentioned until relatively late in the book (page 281 to be precise), and the first mention of copyright law is related to droit de suite for works of visual art, rather than copyrights for other forms of access, which are of greater interest to the current survey. However, the second to last chapter of the book, entitled 'Organising to Collect Rents: Music Copyrights' is certainly of relevance to the current survey.

This chapter offers a rather US-centric history of collective administration of the various royalty sources from music, but again does not discuss the way in which copyright law might affect the contractual relationships, or vice versa. However, interestingly, a testament to the highly controversial nature of the structure of royalty payments for music is apparent in the constant participation of the regulator in setting royalty fees.
For example, as Caves documents (for the case of USA at least), mechanical royalty fees have always been set by legal decree rather than contractual negotiation. It is also interesting to note that some contractual terms appear to be pure ly the result of historical antecedents rather than contractual negotiation. For example, the fact that (again, in the USA, as documented by Caves) the royalties for performance of music are split equally between authors and publishers appears to be purely the continuation of what was first decided, without recourse to further negotiation (that could be explained by contract theory).

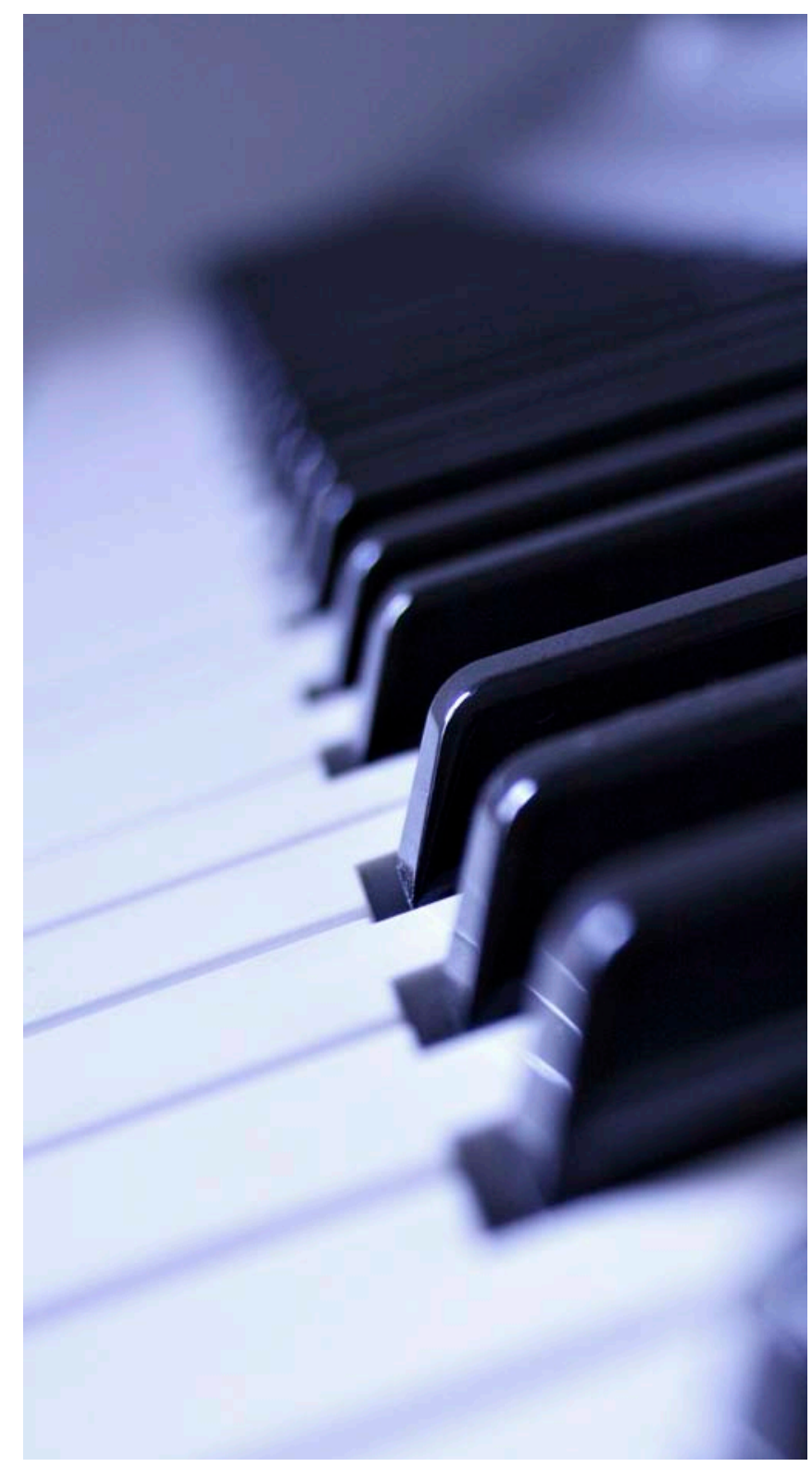




\subsection{INDIVIDUAL CONTRACTING}

As argued in the previous section, the divergence between the traditional economic theory focus of contracts and what is required for the particular case of copyright related transactions is not too great. In effect, most (if not all) of the assumptions that would be relevant to copyright are in fact present in the more general theory, and any assumptions that are not could feasibly be introduced (and indeed, they might be relevant for many particular cases, not only copyright), but at the not insignificant cost of complexity of analysis. In our opinion, the costs of re-working contract theory to accommodate such aspects as workers who care about their output, and timing issues, would outstrip the additional insights that would be gained by their inclusion.

In short, I find that the economic theory literature has paid very scant attention to the question of the relationship between copyright protection and contracts along the value chain for copyright goods. The question has only really been studied in passing, indirectly, or at best in an incomplete fashion. That said it is worthwhile pointing out that most of the earnings literature concludes that median authors actually earn rather little from copyright royalty contracts. ${ }^{33}$ For example, Connolly and Krueger (2006) find that on average, over the 35 top musical acts that toured during 2002 , less than $10 \%$ of income was generated by recordings (i.e. copyright royalty income), while some $73 \%$ was due to concert earnings. While copyright royalty income should clearly depend upon the legal copyright protection standard, it would be interesting to study exactly how other income streams do. For example, to what extent do concert earnings actually depend upon copyright? In Domon and Nakamura (2007) for example, empirical evidence from Vietnam is collected that shows that when the perceived level of copyright protection is low, artists rely heavily on concerts for income. Indeed, Domon and Nakamura show that, at least for the case of Vietnam, the lower the level of protection, the more recordings are heard (although most in illegal formats), and correspondingly the greater concert attendance is, and thus revenue. Thus there may exist a negative relationship between copyright strength and concert earnings, and if concert earnings are by far greater than earnings from sales of music (as is the case in Vietnam), then there will be a negative relationship between the strength of copyright protection and total earnings of artists.

Similarly we have a reasonable number of theoretical papers (see below for a discussion) that analyse the welfare effects of alterations in copyright, and these papers do (in some cases) include a consideration of the effects of copyright upon the price that is charged to consumers for access to the copyright good, which can clearly be seen as a rudimentary contract. However the contractual implications in these models are nothing more than a side-effect, and are not seen as being of principle importance. Indeed, the best of the models cannot actually sign the effect of an increase in the copyright standard upon the market price of an original, due to the incorporation of many other variables, related mainly to piracy. Finally, we have a literature that explains how copyright licensing contracts should be structured, but these models (at least the published ones) are not designed to consider the effect of an alteration in the copyright standard upon the contractual structure for a licensing agreement. Notwithstanding these comments, we shall now go on to review the literature that exists, above all since it does serve to highlight the large research gap concerning the relationship between contract structures and copyright protection. 


\subsubsection{The structure of royalty contracts - royalty vs. buy-out}

There is certainly one particular aspect of individual contracting for copyright goods that has been the subject of economic analysis - namely the structure of royalty contracts. Here, the questions that are often posed are the following:

i) How should a royalty contract be structured in terms of the use of royalty payments and fixed payments?

ii) Can it be optimal for the contract to stipulate only a fixed payment, that is, a buy-out?

iii) Is there any benefit in non-linear royalty contract structures?

iv) Should we expect that the same contractual terms would be optimal for all cases?

v) How can we understand and interpret upfront payments, along with royalties?

vi) How does a contract for access to an intellectual product relate risk and incentives?

In short, the answers to these six questions are, in order, i) outside of very special cases, both aspects should be present, ii) it is not generally optimal to exclude a royalty, iii) non-linear royalties would be more optimal than linear ones for all but one very special, and unrealistic, case, iv) we should expect different contractual terms to be optimal for different cases, v) up-front payments can be interpreted as insurance mechanisms, and vi) risk-sharing is just as important as financial remuneration as an incentive mechanism. In this section I shall discuss the two most important strands of literature - that regarding contracts and risk-sharing, and that regarding contracts and infringement (i.e. piracy).

\subsubsection{Copyright royalty contracts and risk sharing}

As a starting point, consider the paper by Liebowitz (1987). This is perhaps the first paper that explicitly recognises that the degree to which the risk embodied in intellectual products is retained by the creator depends entirely upon the terms of the contract under which access to the product is transferred. A royalty contract, where the royalty is calculated as a function of market revenue, shares the risk embodied in the revenue stream between the parties to the contract, whereas a fixed fee contract (where the user pays a fixed sum to the copyright holder, independent of revenue) transfers all risk away from the copyright holder. It is also true that, the greater the degree to which outright sale is avoided, for example, under a strict royalty agreement, the more the copyright holder retains post-contractual risk. The essence of the Liebowitz paper is to question the optimality of pure royalty contracts, especially when the first contracted user may affect the post-contract value of the intellectual property in question. The quandary is that, when the intellectual property is licensed and used, its value after that initial contract ends is often dependent upon what has happened during that contract. Under a pure royalty arrangement, the copyright holder alone would own the future income stream after the initial contract, but that income stream might well depend upon how the intellectual property is used during the initial contract. In a sense, under a pure royalty arrangement, access to the intellectual property is rented to the user for a determined length of time, and then after that period of time has expired, the copyright holder is once again the sole owner of any residual income stream. Most traditional economic theory would argue that, in cases such as this, the initial user should retain at least some of the post-contract income stream, in order that he or she has an incentive to maximise the value of the intellectual property intertemporarily. 


\section{PAPER 1 - ECONOMIC THEORY OF COPYRIGHT CONTRACTS}

As an extreme, the intellectual property might be sold outright to the first user, who would then retain the entire income stream after the first use. Liebowitz posits the possibility that outright sale, at least in some cases, might well be a better option for copyright holders.

As a possible research gap, it would be interesting to study, both theoretically and empirically, the kinds of situation in which outright sale, rather than rental type contracts, does appear to hold more promise as an efficient mechanism for contracting access to copyright material. If the empirical analysis does point to a prominence of rental arrangements, whereas the theoretical analysis suggests outright sale (as appears to be the case studied by Liebowitz), then it would be very interesting to attempt to address the reasons for such a divergence.

As soon as it is recognised that the market value of an intellectual product is risky, or subject to uncertainty, then it becomes important that any contract for access to an intellectual product shares this risk among the parties in an efficient manner. That is, not only should a contract provide an incentive for creators via a monetary remuneration from users, but it should also distribute the risks involved in an optimal manner among the copyright holder and the user. Economics sees both of these aspects as being equally important, and indeed economics is explicitly concerned with the way in which incentives and risk bearing are traded off via the contractual terms.
It is, perhaps, important to note clearly that any form of royalty arrangement in a contract for access to a copyright can only be understood as a manner in which risk is shared. That is, in absence of any risk or uncertainty as to the final market value of the work in question, we should never expect to see any royalty payments in contracts, only pure transfers of quantities of money. To see this clearly, assume that it is agreed by the author and the user of a work that it is worth either $\$ 100,000$ or $\$ 200,000$ in the market. Then the contract that they sign would have to stipulate how they should share the $\$ 100,000$ if that is what eventuates, or the $\$ 200,000$ if that turns out to be the case. The easiest way that this can be done is for the revenue to be shared according to some agreed rule, for example, the contract could stipulate that 20 percent of revenue is paid to the author and the remaining 80 percent is retained by the user. In this example, there is a royalty rate of 20 percent on revenue, and so the author would be paid $\$ 20,000$ if revenue is low and $\$ 40,000$ if revenue is high. This kind of contract shares the risk that is embodied in the uncertain revenue stream between the parties. On the other hand, imagine that there was no risk, and that it was known ex ante that revenue would be exactly $\$ 150,000$. Now there is absolutely no need to stipulate a royalty. Even if the parties still desired that the author were to retain 20 percent of revenue, this can be contracted to by simply stating that the user should pay the author $\$ 30,000$ for access to the work in question - that is, an upfront payment now suffices.

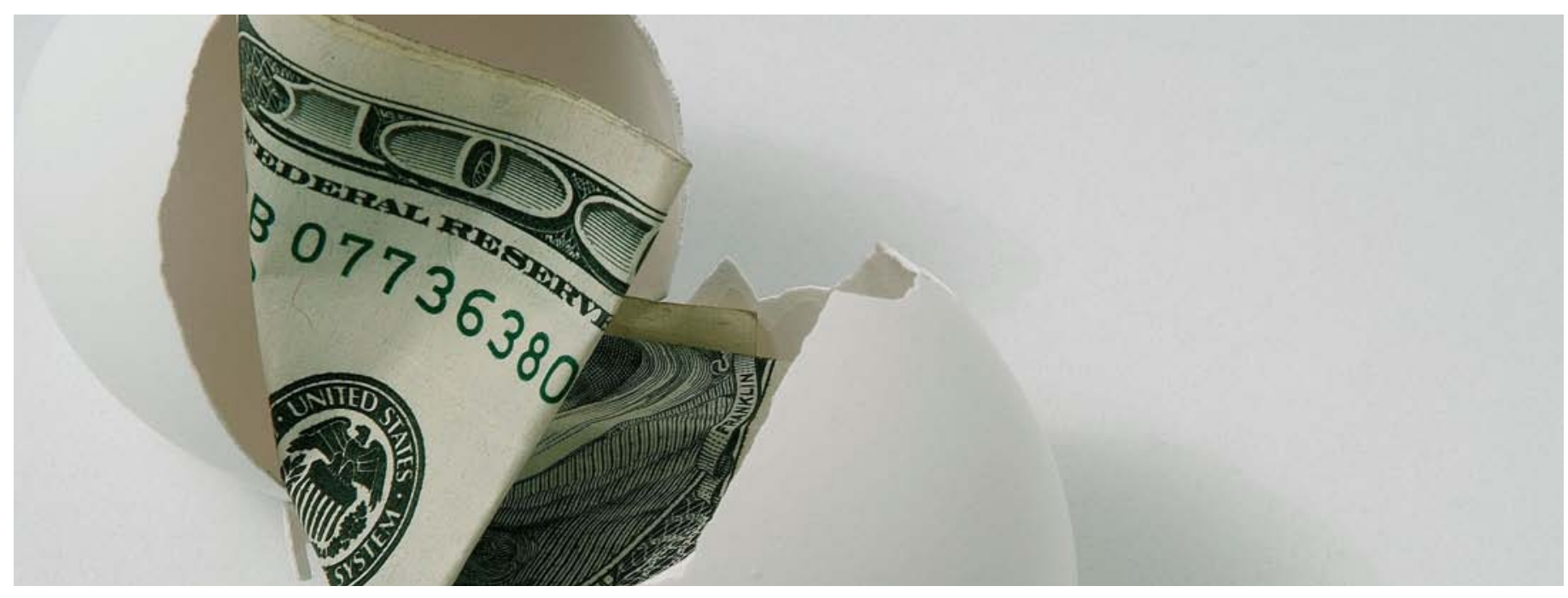

Providing Government with strategic, independent and evidence-based advice on intellectual property policy.

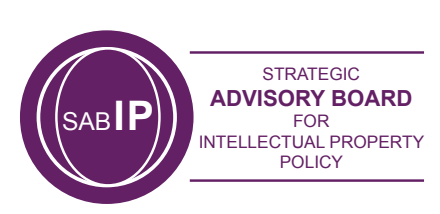


In Alonso and Watt (2003), which follows on from Watt (2000; pp. 90-104), the risk sharing aspect of royalty contracts for intellectual property is explicitly considered. Perhaps the most interesting result that arises in Alonso and Watt is the fact that, in all but one particular case ${ }^{34}$ the contract curve does not correspond to the diagonal of the Edgeworth box, which implies that any optimal contract will normally involve a royalty parameter that is a function of the revenue that is earned. This, of course, contrasts with the commonly seen royalty contract feature that the royalty parameter is independent of the amount of revenue earned - for instance, as in the example of the previous paragraph, it might be $20 \%$ of revenue, whatever that revenue might turn out to be, rather than $15 \%$ when revenue is high and $25 \%$ when revenue is low. Second, as long as both parties to the contract are risk-averse to some degree, a contract that transfers all risk to one party alone (e.g. a buy-out) will never be optimal. Thus, normally, we should expect that the contracts will involve a royalty, and that the royalty parameter will vary with the amount of revenue that the product ends up realising in the market. The fact that this does not actually tend to occur can perhaps be put down to such things as transactions costs (it is far less complex to have a single royalty parameter), or perhaps to the existence of asymmetrical information, which is assumed not to be present in Alonso and Watt.

One aspect of copyright contracts that is often observed can indeed be seen to be in harmony with economic theory. That is the existence of upfront payments to creators as remuneration for creating the intellectual property. Such payments are often stipulated as being forwarded royalty payments, in the sense that the up-front payment corresponds to a royalty advance, and the royalty payments only continue once the revenue from the market exploitation of the intellectual product has reached the level that would correspond to the royalty advanced. Alonso and Watt consider this aspect of copyright contracts, and they show that it corresponds exactly to a deductible insurance contract, where the user is insuring the creator. Since economic theory has proven that such a contract form is indeed optimal for risk-averse riskholders, up-front payments to creators are indeed an efficient inclusion in contracts between creators and users of intellectual property.

Aside from risk sharing, there is a second aspect that suggests royalty contracts rather than outright sale might be efficient. The argument is that, since new works by a given author might well affect the market value of existing works, it is efficient that authors retain a financial interest in their works, in order that they do have an incentive to continue to produce quality creations. This theory has been expounded by Towse (2001). It is also a common argument for the reason why visual artists should retain a resale royalty.

In spite of the theory of royalty contracts being relatively well covered in the literature there still exists an important research gap, which is precisely the relationship between the terms of efficient royalty contracts and the legal copyright protection standard. Economic theory has yet to attempt to analyse the way in which an optimal royalty contract would be altered should copyright law be somehow altered. If, for example, the risk that is encompassed in a copyright transaction is reduced by a strengthening of the copyright protection standard, then certainly we should expect to see alterations in the royalty structure, since the royalty structure is exactly what is used to share risk. However, such an analysis has yet to be attempted. common relative risk aversion. While constant relative risk aversion is believable, it is very hard to believe that copyright holders and users will be equally risk-averse.

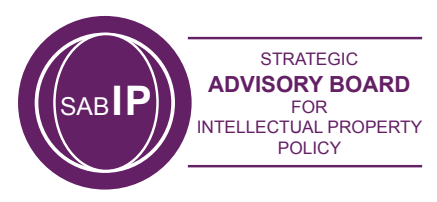




\section{PAPER 1 - ECONOMIC THEORY OF COPYRIGHT CONTRACTS}

\subsubsection{Contracts and infringement (piracy)}

Other important papers to have considered the different options for structuring a contract between a copyright holder and potential users of the intellectual property are Besen and Kirby (1989), and Varian (2000). However, rather than concentrating on risk-sharing, both of these papers are much more closely related to the relationship between the contractual structure used and the degree to which the intellectual property may have to compete in the market, perhaps with pirated versions. This aspect of contracts for access to copyright goods was also analysed by Watt (2000).

The relationship between a contract for access to a copyright good and piracy can be easily stated. In short, if a contract for access to a copyright product involves a per-unit royalty, then the marginal cost to the legal user has been artificially increased over and above the pure marginal reproduction cost. Take for example the case of pre-recorded music. There are pure costs involved in fixing a music track onto a physical format, say a CD rom, for sale to consumers. But if the copyright holder in the music must also be paid a royalty for each and every time a CD is produced, then the per-unit cost to the legal supplier of the CD is the sum of the production cost and the royalty. On the other hand, a pirate producer would avoid paying the royalty, and would only face the per-unit production cost. Thus, we can easily see that if a contract does involve a royalty payment, then it puts the legal producer at a marginal cost disadvantage with respect to pirate producers. In such a scenario, we might expect that the royalty contract acts as a device that fosters piracy, and hampers the revenue earning capability of the legal operation.

In Watt(2000), the marginal cost differential between the producer of originals and a pirate producer is at the forefront of the analysis. However, it is shown that in a traditional Cournot model of competition between the producer of originals and the pirate, it is not necessarily true that the existence of a royalty contract between the creator and the producer of originals will imply a level of piracy that is overly costly to the market earnings of originals. It also turns out that the optimal royalty parameter is very complex to calculate, and depends upon many other variables in the model. Nevertherless Woodfield (2006) shows that if the copyright holder can vary the royalty parameter over the two periods of Watt's model, then significant gains can be made.

In a small, but certainly interesting, literature, we have a series of similar models that analyse the effects of copyright upon welfare. These papers tend to concentrate upon the question of how copyright protection ends up affecting the profits of the firms that produce the protected good, consumer surplus, and social welfare generally. As a side-effect in these models it is common that the researchers include at least a consideration of the effects of legal protection (defined in a variety of ways) upon the market price of the legitimate product. In as much as the market price is a contract between the producer and consumers, here again we can find some work that explores the nature of the effect of copyright upon a contractual arrangement. However, it must be stressed that in none of the welfare type papers is this effect noted as being of primary interest to the papers. It is also true that it is customary in this literature to consider the author and the distributor as one, and so there is typically no room in the models for a consideration of the royalty arrangement between these two parties.

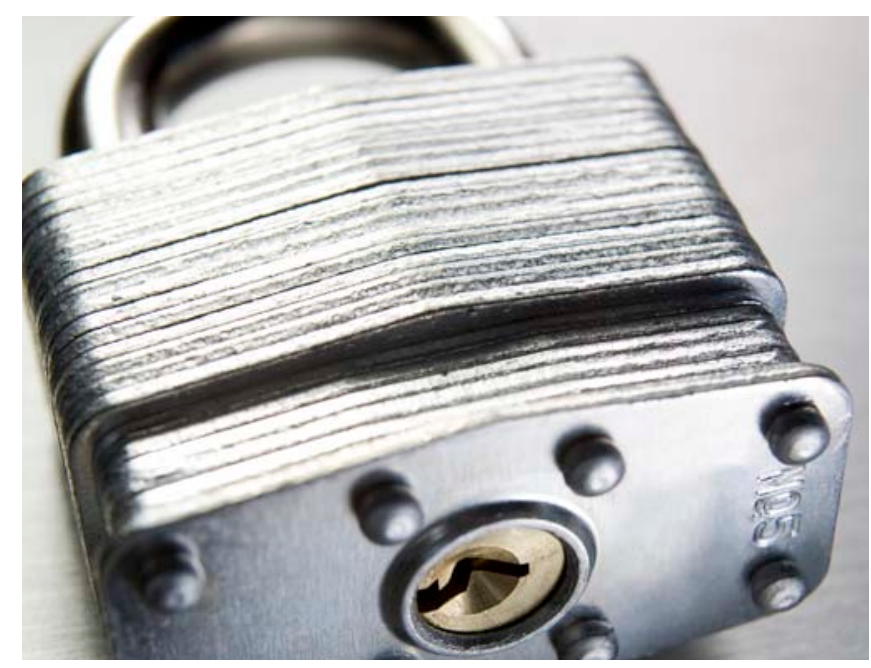

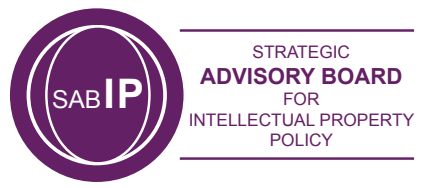


Good examples of such papers are Banerjee (2006) and Poddar (2006). While both of these two papers offer reduced form equations that state the market price of the legitimate product as a function of, among other things, variables that can be understood as representing copyright protection in some way, neither paper can conclude as to a specific sign for the relevant comparative static result. That is, the price at which the good would be marketed depends upon many things in the models, and so an increase in copyright protection will typically have an effect upon the market price of originals that depends upon the values of these other parameters. Thus, while certainly of interest to the relationship between market price and the copyright protection standard, these papers do little to resolve the question of the effect of copyright law upon the contractual terms at the point of sale to consumers.

So far, the literature concerning contracts for copyright has indicated a certain conflict between two opposing objectives. The inclusion of a royalty is a necessary ingredient for efficient risk sharing, but the royalty may well imply a lower shareable revenue due to the possibility that it provides a relative advantage to piracy operations. A full analysis of the trade-off between risk sharing and the amount of revenue to be shared as functions of the royalty parameter has yet to be attempted.

Of course, the relationship between royalty contracts and piracy has not, as far as I am aware, ever been studied empirically. Such a study would be of undoubted value, and this is a clear literature gap. An empirical study could be based simply upon looking at the prevalence of per-unit royalty agreements over different types of copyright good, where the differences would be taken in terms of the degree to which they are pirated. The theory would suggest, at first sight, that with those copyright goods for which there are no royalty payments there is less piracy. It would certainly be interesting to see what an empirical study would say.

\subsubsection{The effect of copyright law on royalty contracts}

In the above, we have looked at how copyright royalty contracts might be affected by two specific factors; (1) uncertainty of the market value of the work, and (2) the presence of a threat of piracy. Both of these factors are related in that one expects that they are affected by copyright law. Certainly it is generally accepted that the stronger the legal standard of protection offered the less worrying the threat of piracy is. Also, part of the demand uncertainty might be due precisely to piracy, and so again a stronger copyright standard might reduce that uncertainty. However, there are many other ways in which copyright law might affect the final configuration of the royalty contract. As far as I know, there is no concise theoretical paper that fully analyses the relationship between the legal standard and the terms of royalty contracts, but the paper by Muthoo (2006) makes many indirect inferences to what one might expect the relationship to be.

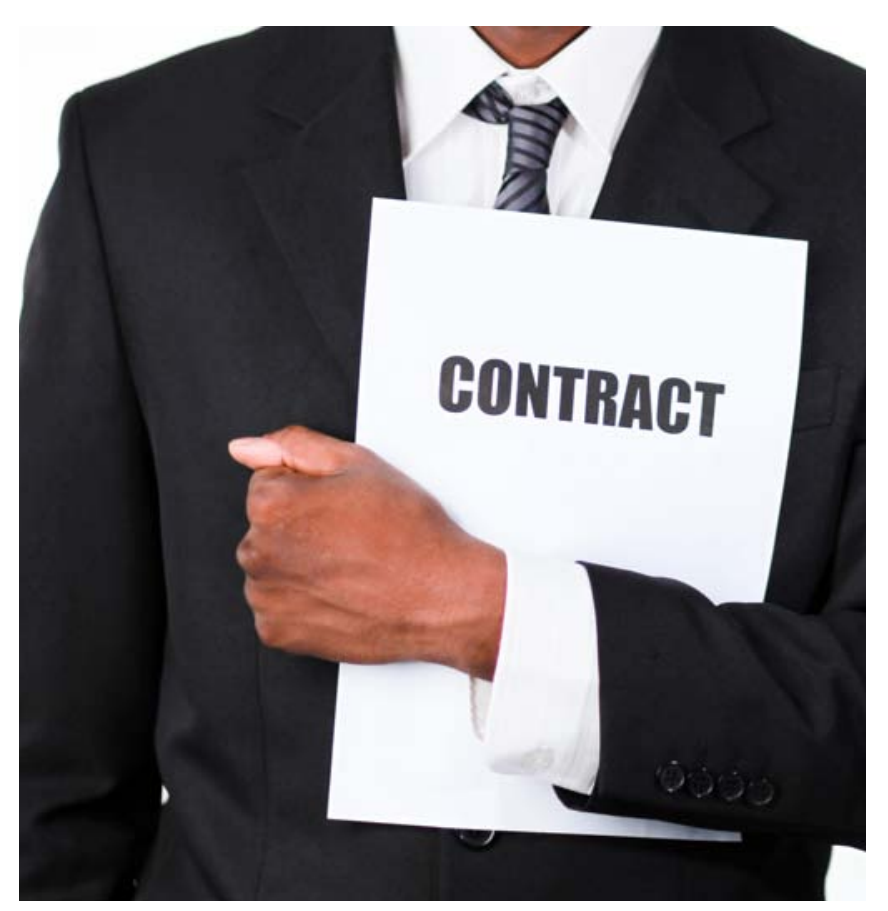


Muthoo correctly models copyright royalty contracts as the outcome of a voluntary bargaining process between two parties - the author and the publisher. Of course these two names are purely labels that might be altered to suit particular cases, and so we might rather prefer to use labels such as 'copyright holder' and 'copyright user'. In any case, Muthoo applies standard bargaining theory to the case of royalty contracts, and points out that the price at which the final bargain is struck will depend almost entirely upon the relative 'bargaining powers' of the parties. It is then interesting to see how the relative bargaining powers are affected by different aspects of the particular problem, and to then understand the effect of copyright law.

Muthoo's analysis is simplified to the extent that the contract is represented by a single number - a price - rather than a complex contractual structure perhaps involving up-front payments and royalty amounts that might depend upon intermediate outcomes. In reality, as has been argued above, this is really nothing more than an assumption of non-existence of risk or uncertainty as to the final market value of the work in question. Nevertheless, using a price as the surrogate for the contract even if some demand risk is present is certainly sufficient to garner the intuition as to how the copyright law standard might affect the final outcome.

Concretely, Muthoo identifies the following factors as the determinants of the final outcome:

\section{Reservation values}

2. Impatience

3. Risk of breakdown in negotiations

4. Existence and value of 'outside' and 'inside' options

5. Asymmetric information
Of these factors, copyright law can feasibly have an impact upon at least the first four, and can thereby have an influence upon the final contract that is arrived at. While Muthoo does not explicitly mention how copyright law might affect the factors that he discusses, we can rather easily consider that ourselves here.

The reservation values are the minimum price at which the copyright holder would be willing to trade, and the maximum price at which the user would be willing to trade. Clearly, in order for any mutually beneficial trade to occur, the maximum willingness-to-pay of the user must exceed the minimum willingness-to-accept of the copyright holder. We can expect that, if a contract is indeed signed, it will involve a price that is strictly between the two extremes. That said, the values of the two extremes will be of fundamental importance to the exact contracted price. For example, for many simple bargaining problems the agreed price is exactly half-way between the two extremes. Thus, if one (or both) of the extreme prices is altered, the contract will also be altered. Finally, since copyright law might well have a strong bearing upon the extreme prices, it influences the contract.

To illustrate, we can use Muthoo's numerical example. There, an author owns the copyright to some music, which he values at $\$ 100,000$, which represents the income that he can derive by privately distributing the music via the Internet. This $\$ 100,000$ is then the author's minimum willingness-to-accept in a contract with a publisher. The publisher values the music at $\$ 200,000$, which is the income that it would derive by recording the music on CDs and selling it to consumers. This $\$ 200,000$ is the publisher's maximum willingnessto-pay in a contract with the author. Now let us say that, given these two extreme prices, the two parties agree to contract at a price of $\$ 150,000$, where this is calculated as the number that lies exactly half-way between the two reservation prices, and that indeed such a deal would always be struck whatever the two reservation prices were. 
What happens, then, if copyright law is strengthened? Presumably both reservation prices would increase - the music will be more costly to pirate, both online and in CD-ROM format, and so both the author and the publisher would value the music more highly. As long as the final contract is still struck at half-way between the two reservation values the contract price must increase with the increase in the copyright standard. Note that the stronger copyright standard implies a greater contract price even if it is not true that both reservation prices increase: as long as at least one reservation price increases, and the other does not decrease, the contract price must increase with the copyright standard. ${ }^{35}$

However, if (for example) the reservation price of the publisher was actually decreased by the stronger copyright standard, then it would no longer be clear how the contract would be affected. For example perhaps it would be the case that, under the weaker copyright standard, the publisher was able not only to record and sell the music on CDROM format, but that it could also charge radio broadcasters for the right to broadcast the music. Then, let us say, a change in the copyright law conferred the right to charge radio for broadcasts only to the author, and not to the music publisher. This would likely increase the author's reservation price, and decrease that of the publisher. The point that is now half-way between might be greater than or less than (or even still equal to) the original $\$ 150,000$.

The second determining factor noted by Muthoo for the contract price is the relative impatience of the two parties. Again, copyright law might be a factor here, in as much as patience is (at least partially) determined by such things as levels of income from other sources. Muthoo notes that the final deal that is struck will, all other things equal, be more favourable to the relatively more patient party. If a party is more willing to wait, then it has a greater bargaining power when the deal is negotiated.
However, as is clearly implied by Muthoo, the relative degree of patience between the two parties will likely be heavily influenced by their abilities to earn money from sources other than what is being negotiated. For example, let us say the author only owns the copyright that is subject to negotiation, and he earns money in some other form of employment, perhaps as a music teacher. Assume that his ability to earn money as a music teacher is totally independent of the copyright law standard. On the other hand, the publisher will (presumably) already be working with other musicians, and the profitability of that ongoing business might well depend greatly on the copyright standard. In that case, a change in the copyright standard will affect the patience of the publisher, but not that of the author. If the copyright standard is increased, and if that increases the patience of the publisher relative to that of the author, then the final contract price can be expected to decrease.

Third, Muthoo establishes that the risk of breakdown in the negotiations is an important factor, along with the degrees of risk aversion of the two parties. Note that the risk of breakdown in negotiation is quite independent and different to demand uncertainty. A risk of breakdown occurs when, during the process of negotiation of the contract and of course before any deal is actually struck, events can occur that affect the value of the contract. Normally, it is thought that the possible events are detrimental to the value of the contract, but in principle there could also be events that actually increase the value of the contract. When these risks are known to exist, they are taken into account in the negotiations, and are duly reflected in the final contract.

35 It must be stressed that these are purely theoretical statements, based upon theoretical models of negotiation. Exactly how things would turn out empirically would also be of great interest.

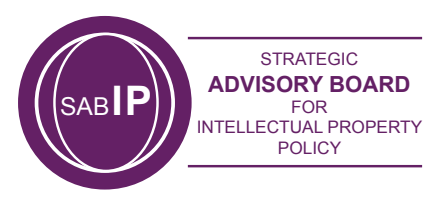




\section{PAPER 1 - ECONOMIC THEORY OF COPYRIGHT CONTRACTS}

Muthoo argues that, for a given risk of breakdown in negotiations, the more risk-averse a party is, the less his bargaining power, and thus the less favourable the royalty contract will be to him. For a given risk of breakdown, the more risk-averse party will be more eager to close a deal, and thus more willing to accept a less favourable price to him personally in exchange for getting the deal struck before any breakdown event occurs. It is unlikely that copyright law can affect the risk aversion of either party directly, ${ }^{36}$ but it will much more plausibly affect the actual probability of breakdown, or perhaps the payments to the two parties should a breakdown occur, and thereby the contract itself.

For example, imagine that competing works arrive according to some random process. Then, while negotiations regarding the contract for the current work are ongoing, there is some probability that a new work will arrive that can compete successfully with the current one. If this happens, it is likely to reduce the market value of the current work, thereby altering the parameters affecting the current contract. Perhaps copyright law is strengthened to the effect that the probability of close substitutes emerging is reduced. Then the risk of breakdown is reduced, and the contract that is signed should reflect that fact. So once again copyright law can be seen to directly affect the terms on which the deal is struck. If the alteration in copyright law does reduce the risk of breakdown then, relatively speaking, this should benefit the relatively more risk-averse of the two negotiating parties more. Thus, the relatively less risk-averse of the two should be able to obtain more favourable contractual terms.

The fourth important element that is mentioned by Muthoo is the existence of 'inside' and 'outside' options. Such options are reflections of what the negotiating parties can earn during the negotiation process (inside options) and as an alternative to striking a deal (outside options). The different options available play similar roles to impatience and reservation values. The greater a party's inside option, the less urgent it is for that party to arrive at a final contractual deal. In essence then, that party becomes more patient, and the effects upon the contractual terms would be the same as those already mentioned when impatience was discussed above.

Outside options are similar to, but not the same as, reservation values. An outside option only has an impact upon the contract if it is credible. To illustrate, go back to the original example suggested by Muthoo - the copyright holder values the work at $\$ 100,000$ and the publisher values it at $\$ 200,000$. Let us say that they would then contract to yield a payment of $\$ 150,000$ to the author. But then let us assume that the author has an outside option - an alternative exclusive licensing arrangement with some other publisher - that would pay the author $\$ x$. If $x<150,000$, then this outside option is not credible as a threat, since by exercising it the author would be worse off. Thus under this assumption the outside option is worthless and inconsequential to the contract. But what if $x>150,000$ ? Now the outside option is credible by exercising it the author would gain more than by closing the contract deal with the current publisher. In this case, the current publisher has no option other than to offer a deal that is equal to the outside option, and so we would expect that the final contract would stipulate a payment to the author of $\$ x$ (assuming, of course, that $x<200,000$ ).

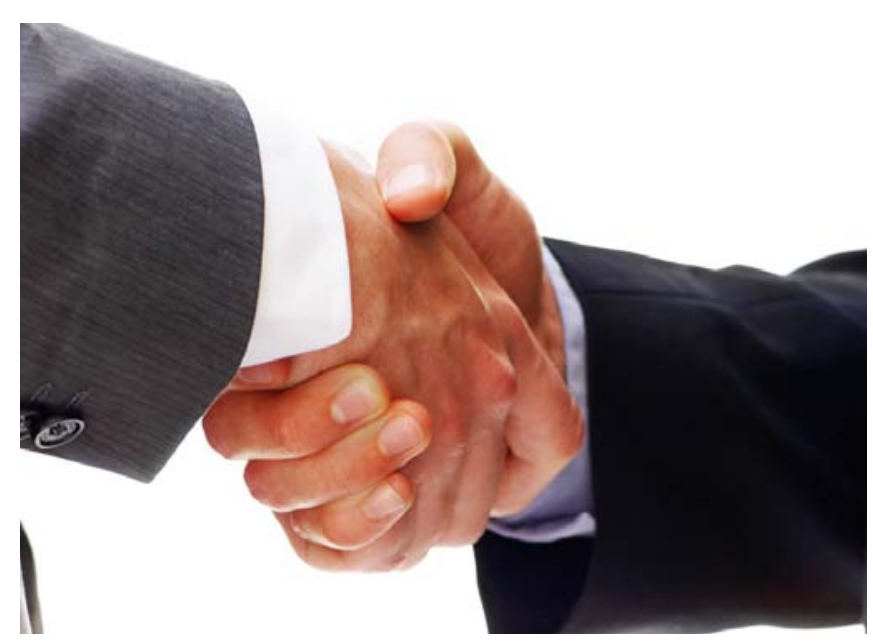

the copyright standard, then a change in the standard can affect the risk aversion of the parties when the current contract is being negotiated. This is a case of 'background risk', which is rather complex to deal with theoretically, and this will not be considered here.

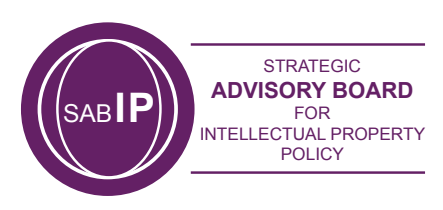


Again, copyright law might play a part in determining the values of outside options. As an example, take the case of music that is licensed to radio broadcasters. Imagine also that music is supplied to radio under a blanket license offered by a copyright collective. In many countries, copyright law stipulates that the same tariff rate should be charged to all radio stations, and that no station can be excluded so long as it pays the set tariff. But what would happen if this law were to change, and the music license could be charged to different stations at different prices, or could be offered to stations on an exclusive basis? Radio stations would be made to bid for music in a kind of auction game, and the licensing body's outside option for any exclusive contract with any one station is the value that the next station is willing to pay. This alteration in copyright law would certainly have important consequences for the contractual terms that are finally arrived at, and would even have major effects upon who the contracting parties are.

The final important aspect noted by Muthoo for contract negotiations is asymmetric information. However, it is hard to see how copyright law might influence the degree to which asymmetric information prevails. Perhaps the only way is when the law stipulates compulsory licensing since, as is noted by Muthoo, it may turn out that asymmetric information is so severe that voluntary contracts become impossible. If that is the case, then a law that stipulates compulsory licensing would certainly affect the contracts that are made, but it is very hard to work out exactly what would be the final terms of such contracts.

As we have seen in this section, economic theory (the theory of risk sharing, the theory of incentive contracts, and the general theory of bargaining) can all provide enlightening insights on how contracts for the access to copyright works should be structured. This has largely been done in reasonably simple theoretical environments, and has not really concentrated upon the effects of copyright law per se on the final terms and structures that would be involved in such contracts. Nevertheless, several interesting and intuitive conclusions can be reached by simply considering how copyright law affects some of the parameters of the negotiation process itself. I have here provided a summary synopsis of my own views on this enticing topic, but a full and detailed analysis has yet to be performed. I see this as being a clear gap in the literature, and one that in principle it should be possible to fill using standard economic theory techniques.

Some of the effects that have been alluded to with reference to the Muthoo paperwere in fact discussed by Michel (2006) in a paper that is perhaps the best effort available for attempting to determine the effects of the copyright standard upon contracts for access to copyright works. Nevertheless, we have to read between the lines again to get to the results. Michel provides a model in which a profit maximising music industry acts as intermediary between an author and final consumers of a copyright product (Michel specifically assumes the product is music). The consumers can copy the product, or purchase it, and here is where we can stretch Michel's model a bit to include a treatment of copyright law. The assumptions used are that consumers face transaction costs for copying, and that copies are of inferior quality to originals. Both of these factors can be taken to represent, in some way, the copyright standard - the stronger the protection level offered, the greater the transactions costs for copying, and the greater the quality differences between copies and originals. ${ }^{37}$

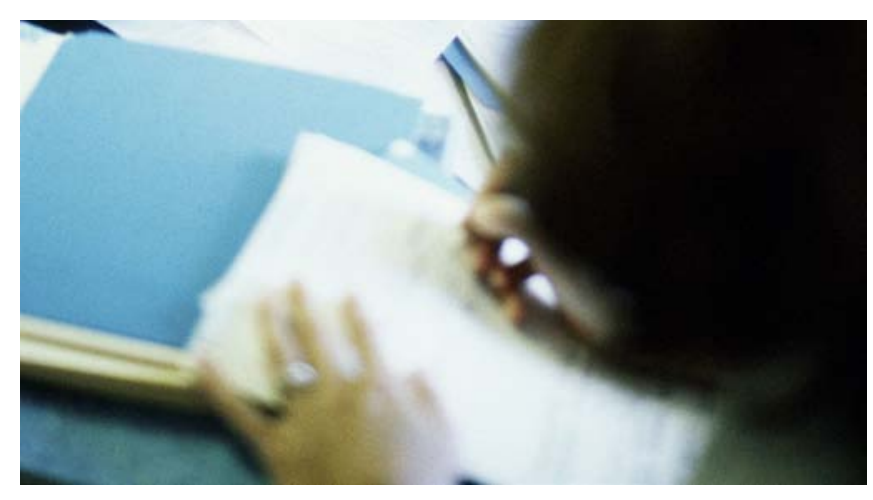
relevant to assume that the same copyright standard applies to each consumer in the same way. However, the insights from the Michel model are still very important for the case at hand.

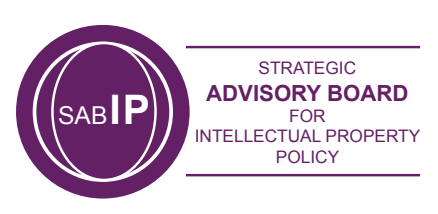




\section{PAPER 1 - ECONOMIC THEORY OF COPYRIGHT CONTRACTS}

tradition of models of copyright piracy by assuming that the contract that the music distributor has with consumers (only those who purchase rather than copy, of course) is captured by a price, p. On the other hand, the contract between the distributor and the author is captured entirely by a royalty parameter that stipulates how the market revenue is shared between them. These are simplified contracts, but still relevant enough to be of great interest to our current investigation.

The Michel model is solved using backward induction. Firstly, the optimal behaviour of the consumers is discovered, and this sets the demand curve that is faced by the music distributor as a function of the sales price. Then the optimal sales price can be determined as a function of the royalty parameter. Finally, the negotiation between the distributor and the author is modelled (using a Nash bargaining model) in order to determine the appropriate royalty contract parameter.

Of interest here are the comparative statics of the equilibrium with respect to what we are here interpreting as the copyright standard. It turns out that the results are quite clear-cut; an increase in the copyright standard leads to a higher market price of the work in question, and a higher royalty parameter. It is also possible to consider the effect on the two contracts while holding the copyright standard fixed. If the royalty rate increases, then the market price of the work also increases.

While the Michel model takes us quite a distance into the relevant framework for analysing the effects of copyright upon contracts, this is not the real objective of the paper, and we need to re-interpret some of the variables to ensure that the model does provide insights as to the effects that we are interested in here. The model is also somewhat simplified, and could be extended and improved, although it is not clear to what extent such extensions would yield different, or better, conclusions.
Finally it is also interesting to note that in the Michel model, the effects of the copyright standard can only be understood with respect to the relationship between the distributor and the consumers, and so copyright is not a direct input into the contract between the author and the distributor. This is exactly as we have already pointed out above - it might appear that what is important for the authorpublisher relationship is contract law, with copyright law having an indirect effect. On the other hand copyright law is fundamental to the contractual relationship between the publisher (distributor) and consumers. This is, of course, due entirely to the incomplete nature of the contracts that can be had between distributors and consumers, since there is a very high monitoring cost that makes a more complex contract unenforceable.

While the Michel model is, perhaps, the only attempt thus far at considering the relationship between copyright law and contractual terms, it still falls well short of being a complete analysis. Above all, the model concentrates entirely on the effects of copyright law on the contract between the distributor and consumers, and any effects on the royalty contract between the distributor and the author are purely indirect. That is, as we have hypothesised above, copyright law will certainly have important, and interesting, effects on the bargain that is struck between the author and the distributor, but the Michel model ignores all such effects.

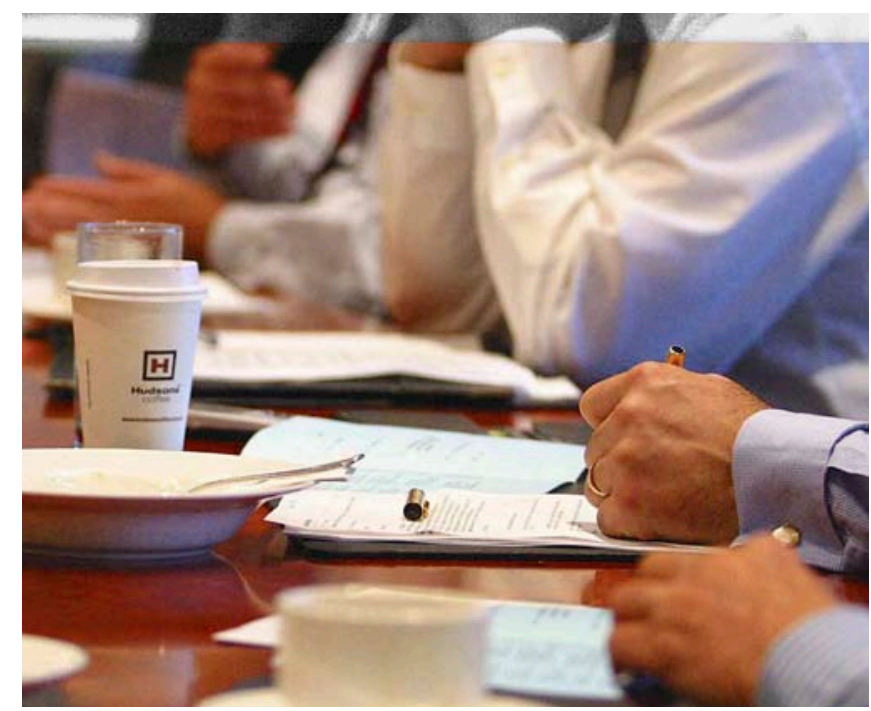

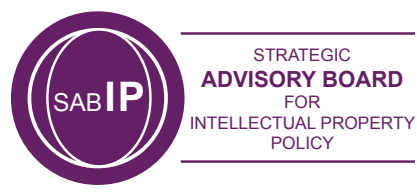




\subsection{ASPECTS RELATED TO THE 'FAIRNESS' OF COPYRIGHT CONTRACTS}

It has been argued that there exists a disparity of bargaining power between the parties to a copyright contract that leads to unfair terms and conditions being present in the contracts. The most frequent point of view is that the contracts between artists and the intermediary companies that make the works available publicly (e.g. producers, distributors, publishers, etc.) are 'unfair' to the artists and authors who actually create the works. This is an important aspect of contracting that the economics literature has yet to touch upon. Above all, if it is true that there is an element of unfairness in the contracts, one is left wondering how copyright law might be amended in order that the resulting contracts are fairer.

Again, in a certain sense it is strange that economists have neglected to study the fairness of copyright contracts. Although it is true that economics has traditionally been occupied with aspects of efficiency, there exists a well developed theory of fairness in economic theory (see Baumol 1987 for a survey of the field).
The economic theory of fairness has, in the past, been more concerned with the fairness of an allocation of goods over individuals rather than the contracts that determine those allocations. However, as long as what is really at issue in copyright contracts is not the fairness of the contracts, but rather the fairness of the resulting allocation of revenues (or perhaps of rights themselves), then the existing economic theory is surely of relevance. The questions that would appear to be of maximal interest are the following:

1. How should 'fairness' be defined for the context of copyright contracts?

2. Are existing contracts really 'unfair'?

3. Do alternative contracts, within the current copyright law, exist that would be perceived as being 'fairer'? If they do exist, do those contracts sacrifice efficiency?

4. To what extent does any perceived 'unfairness' depend upon copyright law?

5. Can copyright law be altered in order that the balance of bargaining positions is changed and the resulting contracts are 'fair'?

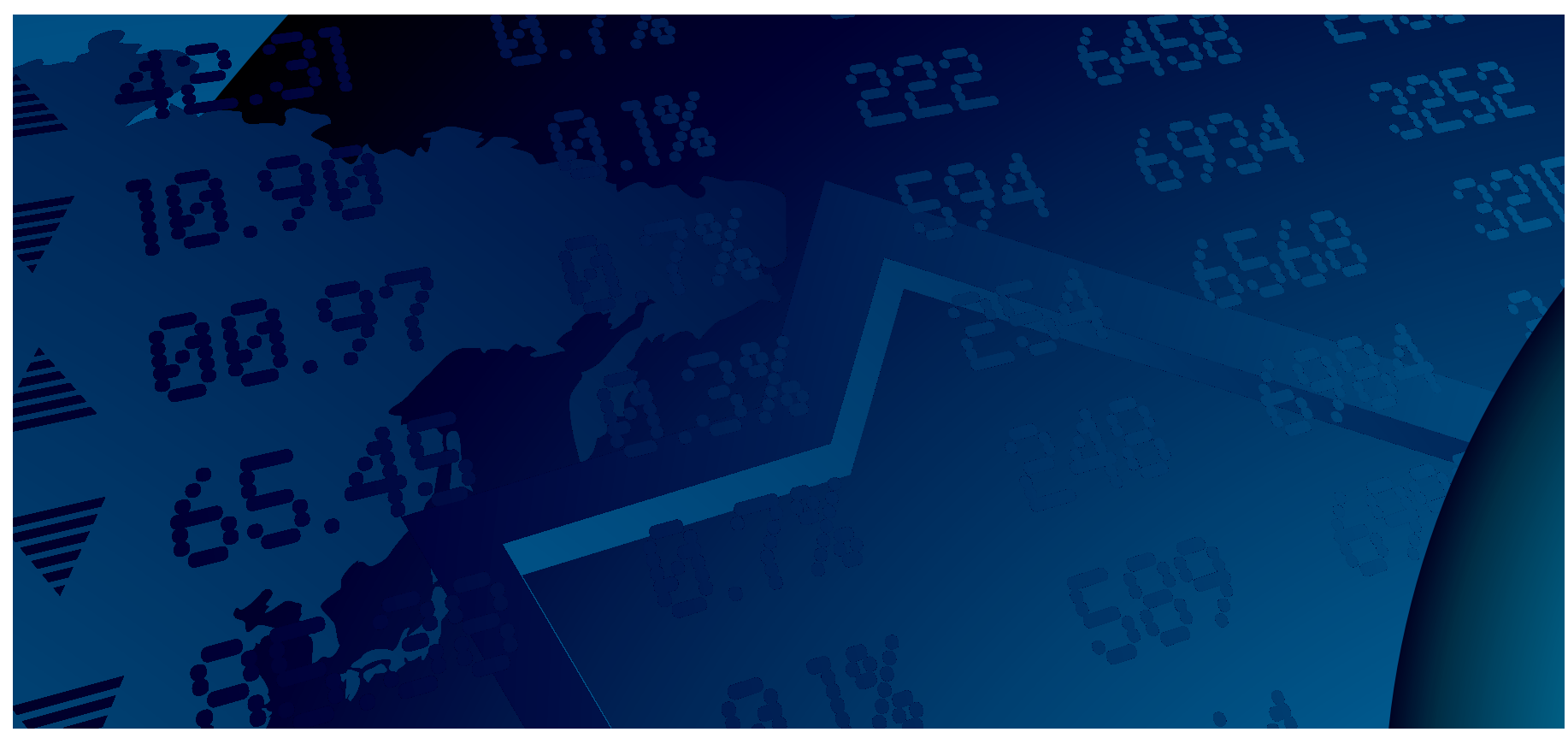

Providing Government with strategic, independent and evidence-based advice on intellectual property policy. 


\section{PAPER 1 - ECONOMIC THEORY OF COPYRIGHT CONTRACTS}

The study of fairness in the context of copyright contracts is bound to be fraught with difficulties, and it is likely to arrive at conclusions that might be seen as being provocative. The entire research agenda will rest squarely upon the definition of fairness that is adopted, and all conclusions reached will of course be subject to that definition. Of course it is therefore of fundamental importance to arrive at a definition of fairness that is itself considered to be fair by all parties. Not an easy task, but certainly one that is worthwhile working on.

\subsection{COLLECTIVE ADMINISTRATION OF COPYRIGHT CONTRACTS ${ }^{38}$}

In most jurisdictions the copyright law allows for copyright holders to join together into collectives for the purposes of exploitation of their rights. The origins of collective administration may appear to be a straightforward response to a problem of transaction costs. An evocative story recounts the visit of Ernest Bourget, a French composer of popular chansons and chansonettes comiques, to the Paris café Ambassadeurs in 1847 where, among other pieces, his music was being played without permission. He then refused to settle the bill for his drink of sugared water, at the time a fashionable beverage. In the resulting brawl, $M$. Bourget argued 'you consume my music, I consume your wares' - an argument he won before the Tribunal de Commerce de la Seine which upheld the revolutionary law of 1793 , recognising a right to public performance for the first time. ${ }^{39}$
Ernest Bourget understood that as an individual composer he should not devote his life to chasing unauthorised performances of his music. Vice versa, each venue performing popular music would incur considerable costs in tracking and negotiating with various holders of the relevant performing rights. The solution to the failures of individual contracting was collective administration, combining a comprehensive monitoring service of music usage with a facility to issue licenses, i.e. permissions to play against remuneration. Ernest Bourget, his colleagues Victor Parizot and Paul Henrion as well as the publisher Jules Colombier founded an Agence Centrale, the direct predecessor of the first modern collecting society Société des Auteurs et Compositeurs et Editeurs de Musique (SACEM). SACEM, established in 1851, became the European model, collecting at times even in Switzerland, Belgium and the UK.

Transaction cost economics recognises that there are costs of using markets, such as information costs, contract costs and governance costs. ${ }^{40}$ In the case of copyright, transaction costs may include (a) identifying and locating the owner, (b) negotiating a price (this includes information and time costs), and (c) monitoring and enforcement costs. The sparse economic literature on collecting societies tends to accept a transaction cost rationale for their existence. ${ }^{41}$

38 This section draws on Kretschmer 2002 and 2005a.

The French Acts of 1791 (regarding performances of theatre and musical drama) and 1793 (regarding the sale and dissemination of artistic works of any genre) replaced the old system of publishers' privileges with a system of authors' rights. can be more efficient than individual contracting (Williamson 1975; 1985). 
Under collective administration there is typically only one supplier of licences to the user of copyright works in one particular domain of rights (such as public performances). Reciprocal agreements with sister societies in other countries ensure that access to 'the world repertoire' can be granted through one licence. From the perspective of individual owners of copyright works there may be no alternative provider of a rights administration infrastructure. In consequence, market prices cannot form neither for licences to users nor for services to right holders. ${ }^{42}$

This monopolistic structure leaves copyright collecting societies in control of the terms of access and royalty distribution in their particular rights domain. In many areas of collective licensing administrative costs are high. The cost of collection may amount to a quarter of revenues - while for other complex services (such as health insurance) administrative deductions of $5 \%$ are seen as high. ${ }^{43}$ The tendency of collective administration to evolve into bureaucracies sheltered from competition has led to increasing state involvement in the supervision of collecting societies. As a general rule, collecting societies in all EU Member States cannot refuse to license their repertoire; they have to admit members subject to certain threshold rules; and they have to give some kind of public account of their finances. In the case of music performing rights and mechanical reproduction societies an intriguing feature of collective administration is the representation of both authors (composers and lyricists) and publishers - enforced by a governance structure under which changes to membership and distribution rules can only be implemented by mutual consent of both groups. Despite market pressures to the contrary, author members of German society GEMA receive $70 \%$ (compared to $30 \%$ for the publisher) of any performing right royalty distribution, and $60 \%$ of the mechanical rights. The British Performing Right Society (PRS) distributes 50:50 between publishers and creators, while the Mechanical Copyright Protection Society (MCPS) leaves the distribution shares to individual contracts between the parties. ${ }^{44}$ In addition, large right holders, whose works are easier to monitor and account for, in effect subsidise small members. These distribution decisions are treated as internal matters, and will not be publicised.

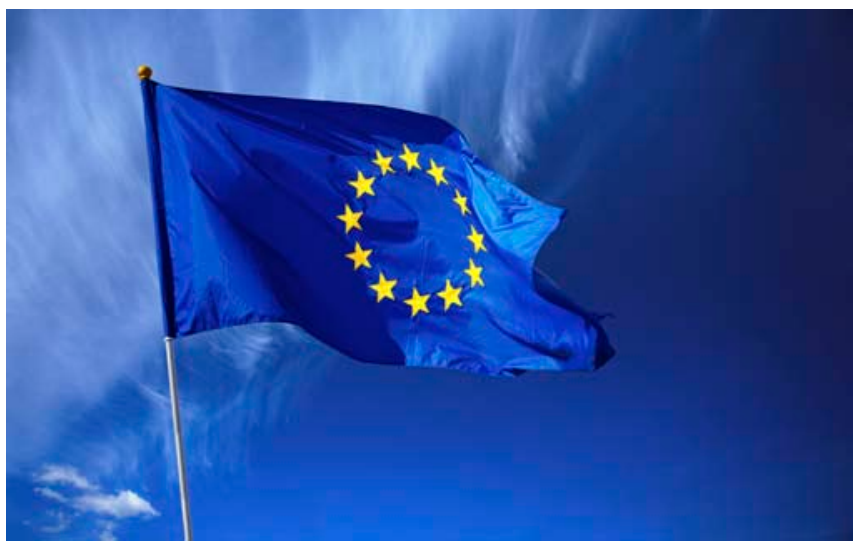

One strand of commentators has located the inefficiencies in collective administration in the nature of liability rules (Merges 1996). The argument derives from R.H. Coase's seminal paper 'The Problem of Social Cost' (1960). For a critique of natural monopoly analysis, see A. Katz (2005; 2006).

To give some examples: PRS performing right income is roughly equally split between income from broadcasting and from general performance (i.e. music at pubs, clubs, shops, aircraft, concerts). Unsurprisingly, the costs of collecting are much higher for the latter.

Naturally, it is hard to know what would be a market rate in the absence of a market (cf. Liebowitz 2006). Two observations indicate that the royalty fees available to music writers are above what would be negotiated in a competitive market between willing individual sellers and buyers: (i) they are very high compared to other markets, such as performers, or video game developers; (ii) authors are under pressure from publishers to accept (and have accepted) a lower percentage of the royalty distribution in countries without a tradition of collective author organisation (such as the new EU members which acceded in 2004 and 2007; see Kretschmer 2005b).

At GEMA, so-called 'evaluation committees' weigh the distribution of royalties to authors according to considerations of length of membership, past income, artistic personality and overall contribution of an œuvre. In the UK, the classical music subsidy in the royalty distribution formula was phased out following the Performing Rights Report of the Monopolies and Mergers Commission (1996). In 1999 a PRS foundation was established for the support of new music, regardless of genre. 
Many European collecting societies also weigh their distribution per copyright work according to a value judgment, including the amount of skill involved, and the cultural contribution of a genre or composer. ${ }^{45}$ Finally, under the guidelines of CISAC (Confédération Internationale des Sociétés d'Auteurs et Compositeurs), the international umbrella organisation of the author rights societies, up to $10 \%$ of collected licence fees may be channelled into socio-cultural funds. ${ }^{46}$

The analysis suggests that collective administration can also be viewed as a form of unionisation. Authors no longer enter the market as individuals (Peacock and Weir 1975, p. 41). This enables them to extract better terms than contracting individually with music publishers and music users (such as labels and broadcasters), and provide sociocultural support to creators.

There are several ways in which copyright law might affect the contractual business of copyright collectives, starting with the very fact that they are permitted to exist. As discussed, the justification for the existence of collectives is traditionally based upon the transaction costs savings that they are understood to provide. However, in exchange for being allowed to exist, and therefore for operating as monopolies, the activities of copyright collectives - including the prices that they charge for offering access to blanket licenses of their repertories - are normally subject to regulation. In as much as this regulation is understood to be part of copyright law, clearly we have an instance of copyright law affecting the contracts along the copyright value chain. If the regulations were not in force then we should expect that copyright collectives would operate differently, and so in that sense, we can understand that the contracts used by copyright collectives lie on the boundary of the contractable space, and would be affected by alterations in the laws regulating the collectives.
The types of contracts used by collectives and that are interesting from an economic theory perspective are those that govern the supply of repertoire by authors and the way in which authors are remunerated by the collective, and the contracts under which the collective makes its repertoire available to end-users.

A good deal of the regulatory environment facing copyright collectives in the US is discussed by Einhorn (2006). In general, it can be seen that what is provided is exactly what the law stipulates - when blanket licenses should be offered only on a non-exclusive basis they are, ${ }^{47}$ when a 'genuine choice' must be offered on a programme basis it is, and when there can be no discrimination between licensees there is not. Thus it would appear that the regulatory environment is truly restrictive in the sense that if these regulations were not in force, collectives would most likely attempt to contract with licensees in ways that would be different to what they do under the regulation. Of interest to the present survey is the question of exactly how the contracts used by copyright collectives would look under a different regulatory environment and who would be the winners and losers under a regulatory change. Unfortunately, there are no economic theory papers that have considered this issue. However, again it would seem that economic theory is in a good position to analyse such questions. 'culturally important works and contributions' (§7) and set up pension and social funds (§8). Anglo-American right holders often feel that their exported property subsidises foreign social and cultural policy (Harcourt 1996).

That is, individual licensing must also be allowed. However, individual licensing is almost never advantageous to the individuals themselves, and so is uncommon. 


\subsection{OTHER ALTERNATIVES}

One of the areas of the economics of copyright that has attracted most interest from economists is the study of the degree to which copyright is actually required. This literature assumes almost exclusively that the underlying objective of copyright is to provide incentives to authors to create new works (presumably by allowing contracts to be written), and that the provision of this incentive via a legal regulation like copyright law has certain negative effects socially. The literature does not typically consider that no incentive is required, but rather looks for alternative means under which the same, or similar, incentives can arise, but under which there are fewer harmful side-effects. Examples of the types of alternative mechanism that have been suggested are indirect appropriability (Liebowitz, 1985), network effects (Takeyama, 1994), DRM systems, bundling and versioning, taxes on blank supports and copy technologies, and public funding including prizes. A survey of this literature up to 2006 can be found in Liebowitz and Watt (2006). As a general conclusion from the literature, with the exception of the work by Michele Boldrin and David Levine (see Boldrin and Levine 2002, 2004 and 2005) who advocate for no need for any copyright protection at all, ${ }^{48}$ the literature suggests that some protection is in order, but that it should not be excessive.

Another good source of information on the alternative incentive mechanisms for copyright holders is Gallini and Scotchmer (2002). Although Gallini and Scotchmer are interested in intellectual property in general (i.e. both patent and copyright), their analysis is generally relevant to copyright. In their conclusions Gallini and Scotchmer find that legal protection is 'probably the best mechanism' when there is asymmetric information regarding the costs and benefits of the works in question. It would seem that this is likely true for the case of copyright. However, and perhaps more relevant to the present survey, Gallini and Scotchmer are cautious when it comes to the optimal design of any IP law, especially in as far as the ability of the parties to contract is concerned. In closing they note specifically the following: 'To understand whether the property system is strong, too weak, or not necessary at all requires us to understand the incentives for contracting, and its potential anticompetitive consequences.' Nevertheless, Gallini and Scotchmer do not offer any analysis of the copyright-contract relationship.

Given these two sources of survey information, here we concentrate upon the possible interconnections between alternative remuneration mechanisms and copyright law itself.

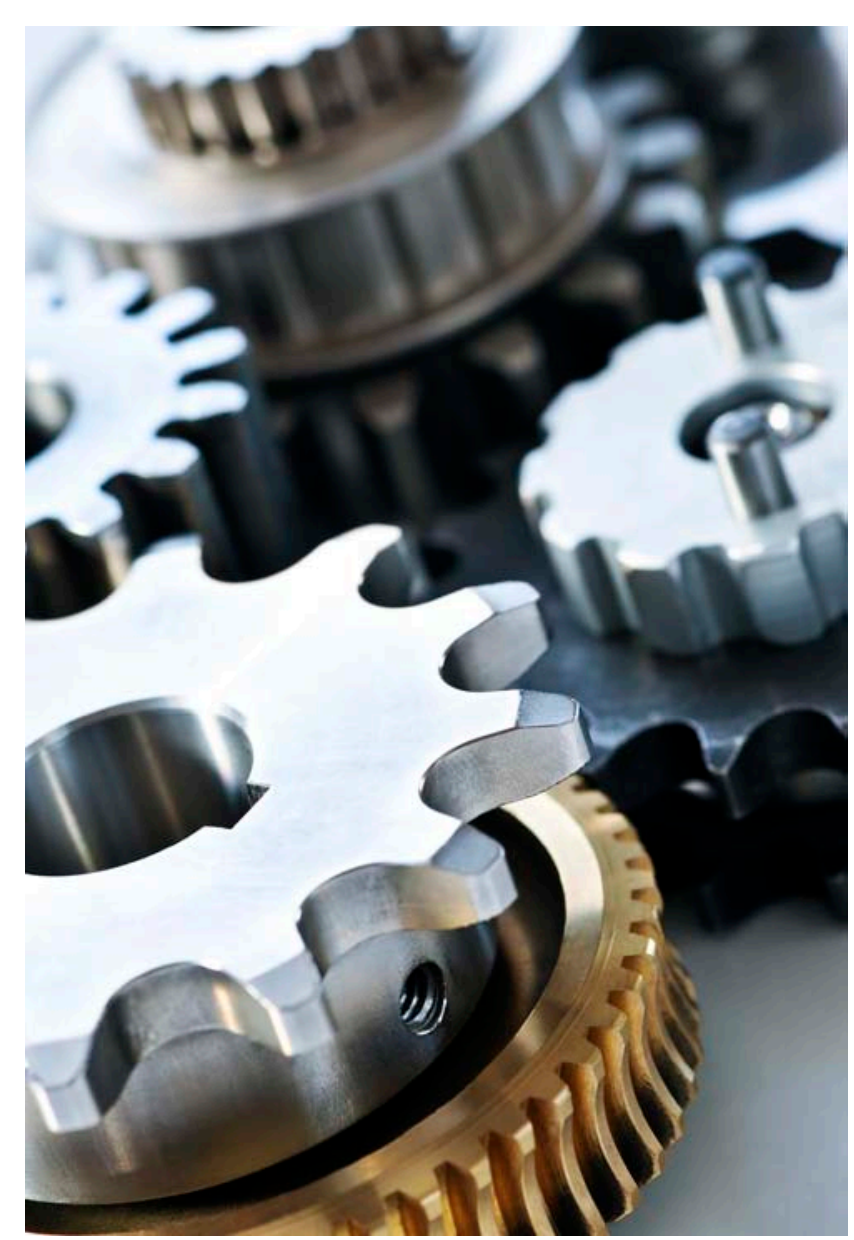
to earn money is guaranteed by their first-mover advantage. Most economists who have commented on the suggestion of Boldrin and Levine find that it is based on an economic reality that, while possibly still appropriate for patent goods, no longer exists for copyright goods.

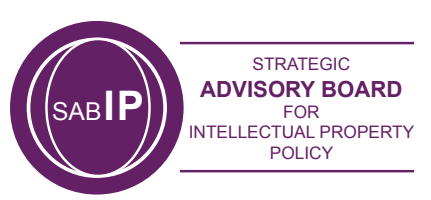




\section{PAPER 1 - ECONOMIC THEORY OF COPYRIGHT CONTRACTS}

First and foremost, it should be clearly pointed out that most alternative remuneration mechanisms require some form of protection to be in place. At the very least, a formal and legal recognition of a property right might be needed for the original author to be able to justify any type of mechanism that implies payment to him. Take for example the case of open-source software. It is widely recognised that this new intellectual property paradigm cannot exist without legal copyright (see, for example, Leveque and Meniere, 2007). Nevertheless, open source licensing is seen as an alternative to traditional proprietary mechanisms that rely more directly upon legal protection for ensuring royalty streams. Koski (2005) considers a set of Finnish software firms to see how the characteristics of the firm affect the type of licensing contracts that it might use - open source or proprietary. She finds that a firm's ownership structure has a major influence, with family owned firms opting largely for traditional licensing contracts, and diffusely held companies relying more heavily upon open source mechanisms.

With the possible exception of the general idea that the worse the copyright protection standard is the greater the reliance upon alternative mechanisms will be, I am not aware of any study that considers the marginal effect of alterations in the copyright standard upon the structure of alternative mechanisms.

\subsection{CONCLUSIONS}

It is fair to say that in general the economic theory profession has not considered in any detail the relationship between the legal institution of copyright and the types of contracts that are written along the value chain for copyright goods. The topic of contracts has been looked at mainly in terms of royalty contracts, and then only really between creators and intermediaries (e.g. publishers, distributors, etc.), whereby copyright itself is not explicitly brought into the picture. Perhaps the most important research gap, then, is to consider exactly how alterations in copyright protection (either some measure of enforcement, or perhaps some measure of scope, or of course the duration of copyright) would affect the terms that would be agreed to via royalty contracts. Of primary interest is the question of exactly how certain changes in copyright would end up affecting the welfare of the signatories to royalty contracts, thereby altering the balance of revenue flows and incentives.

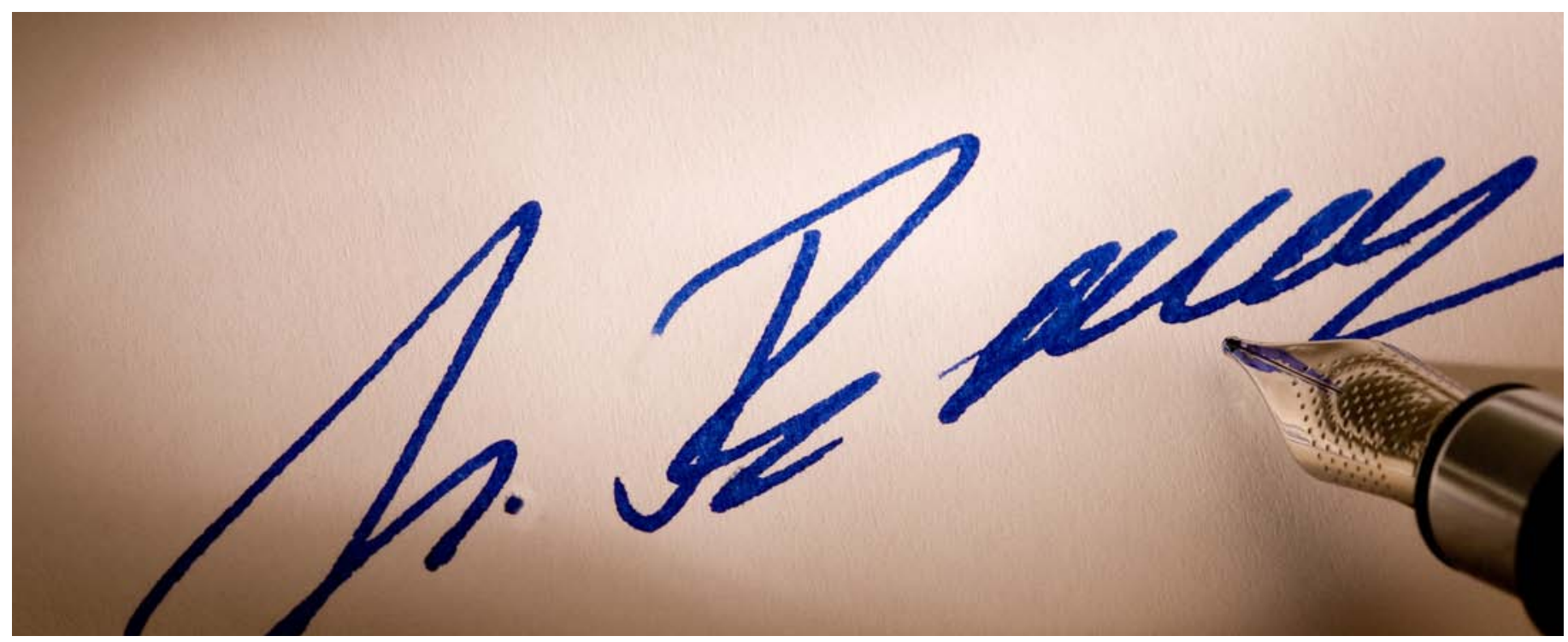

Providing Government with strategic, independent and evidence-based advice on intellectual property policy.

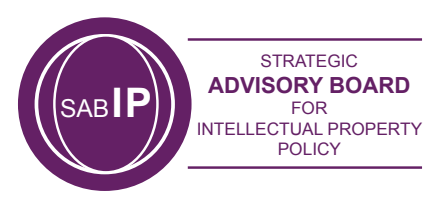


A second important research gap would involve the explicit consideration of the perceived 'fairness' of copyright contracts to the parties involved, and how (or indeed if) copyright law can be altered so as to ameliorate any perceived unfairness. Not so long ago such a study would not have been considered overly relevant for economics scholars, who are renowned for concentrating much more on issues of efficiency than issues of equity or fairness. However, there does exist an established general literature on the economics of fairness, which is based on solid economic theory ideals, and which could (in principle) be applied to the case of copyright contracts.

It is also interesting to consider whether copyright and contracts are always to be understood as complements, or whether they can also maintain a substitute relationship. That is, we are generally comfortable with the idea that a contract for a work of authorship might not be able to be written unless there is a copyright law that establishes the title of ownership, and what that owner may legally contract to. But it is also the case that contracts, being freely negotiated agreements, can also establish what can and cannot be done by the parties involved, including the remedies available for breach. Thus, in a well-defined sense, contracts can work as devices that substitute for copyright law, at least as far as the signatories to the contract are concerned. An important research gap, therefore, is to consider the nature of the substitutecomplement relationship between copyright and contracts, and above all, to determine what the nature of the relationship depends upon (with transaction costs being the most logical element). Once a clear idea has been achieved of the type of relationship that exists, at least for specific points along the value chain, then one can determine with much more authority the type of policy conclusion that is suggestive of how copyright law might be amended in order to provide the incentives for individuals to use contract terms as protection measures instead.
Finally, a fourth interesting aspect that provides a research gap is the relationship between what I have called the 'contractable space' and copyright law itself. If we understand that copyright law sets the boundaries of the contract space, then clearly the former affects the latter. But it is also likely that the types of contracts that are written may well affect copyright law, or at least the interpretation of copyright law. I therefore suggest as a fourth research proposal the issue of the study of the interrelationship between the contract space and the contracts that are written within it, and copyright law's parameters and interpretations.

Overall I think that a more careful, methodological, and above all a more formal application of the well-known principal-agent framework to the specific case of copyright constitutes the most logical first step forward for economists. Of course the principal-agent model is very well known to economic theory, and it relates directly to the issue of contracting. As parameters around the model one can easily bring in copyright law with a variety of free variables defining the legal protection parameters. This would then allow the researcher to study how alterations in the legal copyright standard affect the final equilibrium outcome.

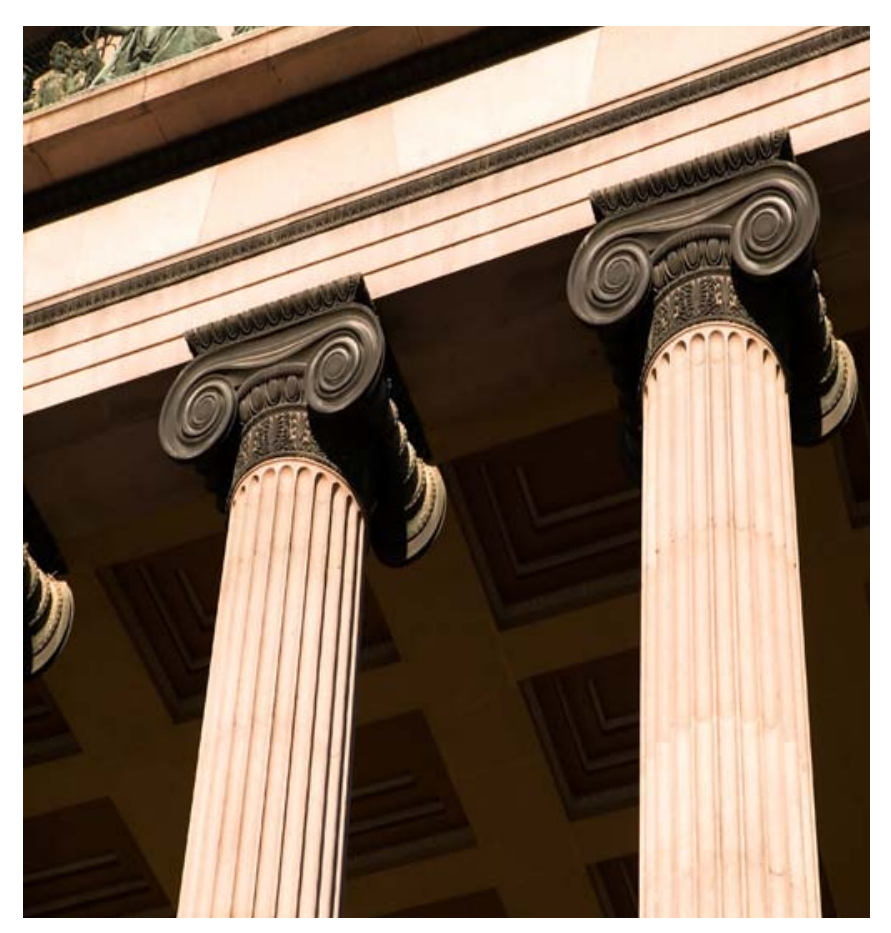

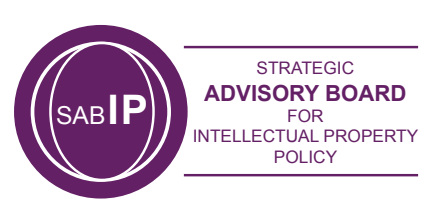


PAPER 2 - CREATOR CONTRACTS ('SUPPLY SIDE'), Martin Kretschmer

\section{ABSTRACT}

Cultural markets are winner-take-all markets.

They are very risky for both creators and investors. The earnings data available from labour market statistics, tax and insurance audits, and surveys indicate that the top $10 \%$ of creators receive a disproportionally large share of total income in the creative professions. The top $10 \%$ of literary authors earn about $60-70 \%$ of total income; the top $10 \%$ of composers/songwriters earn about about $80 \%$ of total income. This can be compared to earnings data for the total population of employees. Here the top $10 \%$ of earners earn about $20 \%$ of total income (Annual Survey of Hours and Earnings (ASHE), UK Office for National Statistics). For most creators, 'portfolio lives' are typical: about two thirds of professional creators have earnings from a second job. Overall, the income of creators is well below the national median income. There are some variations by sector, but broadly the picture is consistent across the developed world.

The bargaining outcome over rights is tilted towards bestsellers. Creators with a track record of success are able to negotiate contracts that preserve their interests. For most others, in particular new entrants to the entertainment industries, assignment of rights are common. Mechanisms of collective bargaining (for example through unions, professional associations and collecting societies) appear to have a greater effect than statutory (ownership) rights because the latter, typically, will be varied and/or transacted by contract.
The comparative international review of the regulation of copyright contracts uncovered a range of regulatory tools that attempt to balance the bargaining powers of the parties. These provisions relate to Ownership; Requirements of form; Scope of rights transferred; Rights to remuneration; Effects on third parties; Revision and termination; and Unfair contracts. Very little empirical evidence is available about the effectiveness of these provisions, but this paper contains a number of methodological suggestions how regulatory tools could be assessed (if policy was to desire to adjust the bargaining outcome between creators and investors). Options identified by the literature include intervening in situations of non-exploitation; strengthening rights that cannot be transferred (such as the right to be credited as the author); and privileging instruments of collective bargaining.

\subsection{CREATORS, AND THE PURPOSE OF COPYRIGHT LAW}

49 A term of 50 years post mortem auctoris was internationally formalised with the Berlin revision (1908) of the Berne convention (1886, last updated at Paris 1979). The US adopted a 'life plus' term only with the 1976 Copyright Act, and joined the Berne Convention in 1989. As Berne with the exception of Article 6bis (moral rights) has become incorporated into the WTO TRIPS Agreement (1994), an author-derived term of protection is now the prevailing law of the global free trade area. As of 23 July 2008, 153 countries are members of the World Trade organization.

50 Décret du 13-19 Janvier 1791 (regarding performances of theatre and musical drama): life plus 50 years; Décret du 19-24 Juillet 1793 (regarding the sale and dissemination of artistic works of any genre): life plus ten years.

$51 \quad 1837$ Prussian Copyright Act: life plus 30 years.

521842 Copyright Act: life plus seven years or 42 years from publications (whichever longer). Talfourd's 1837 bill (which failed to reach the statute book) had provided for a term of life plus 60 years. 
It is desirable that we should have a supply of good books: we cannot have such a supply unless men of letters are liberally remunerated; and the least objectionable way of remunerating them is by means of copyright. You cannot depend for literary instruction and amusement on the leisure of men occupied in the pursuits of active life. Such men occasionally produce compositions of great merit. But you must not look to such men for works which require deep meditation and long research. Works of that kind you can expect only from persons who make literature the business of their lives. ${ }^{53}$

Such arguments still underpin contemporary lobby efforts for extending the duration, scope and enforcement of copyright laws. In the European debate surrounding the implementation of the 1996 WIPO Internet Treaties, 400 recording artists signed a petition to the European Parliament entitled Take a stand for creativity. Take a stand for copyright: 'We make our living through our music. The music that we create touches the lives of millions of people all over the world. Our creativity and our success depend on strong copyright protection. We now need your help.' 54 The German publishers' campaign against the copyright exception for teaching and scientific research ( $\$ 52 a$ UrhG) argued: 'If copies of books are free, nobody will buy originals. If nobody buys originals, nobody will publish books or journals. The result: If nobody publishes, Germany's thinkers will soon have to look for a different employment'. ${ }^{55}$ The law suit filed by the US Authors Guild against the Google digital library project has been advanced under the slogan 'Not at the Writers' Expense': 'The alphabet ought to be free, most certainly, but the people who painstakingly arrange it into books deserve to be paid for their work. This, at the core, is what copyright is about. It's about a just return for work and the dignity that goes with it. ${ }^{56}$ Similar language can also be found in the Recitals to several European Directives. Information Society Directive (2001/29/EC) - Recital 10: 'If authors or performers are to continue their creative and artistic work, they have to receive appropriate reward for the use of their work, as must producers in order to finance their work...'; Recital 11: 'A rigorous, effective system for the protection of copyright and related rights is one of the main ways of ensuring that European cultural creativity and production receive the necessary resources and of safeguarding the independence and dignity of artistic creators and performers. ${ }^{57}$

According to the economic literature underpinning these arguments, authors' livelihoods depend on copyright law in the following way:

- Copyright structured as an exclusive property right gives authors something to sell to a third party for exploitation.

- $\quad$ Income is then derived from the contract assigning or licensing the copyright, typically to a publisher or producer. was created Baron in 1857, and is most commonly known as Lord Macaulay.

Petition 'Artists Unite for Strong Copyright', led by Jean Michel Jarre with the assistance of IFPI (19 January 1999), signed by among others Boyzone, the Corrs, Robbie Williams, Tom Jones, Eros Ramazotti, Mstisalav Rostropovich, Barbara Hendricks, Die Fantastischen Vier, Aqua and Roxette. work, they have to receive appropriate reward for the use of their work, as must producers in order to finance their work...'; Recital 11: 'A rigorous, effective system for the protection of copyright and related rights is one of the main ways of ensuring that European cultural creativity and production receive the necessary resources and of safeguarding the independence and dignity of artistic creators and performers.'

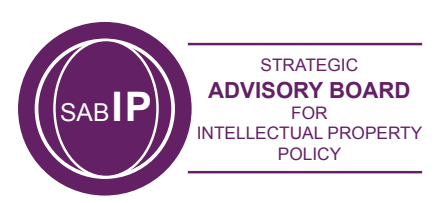


As Richard Watt summed it up in Paper 1: 'Copyright itself is not an incentive mechanism, but (assuming that it is enforced) it does allow an incentive mechanism to operate, namely contracts.'

\subsubsection{Pre-copyright and non-copyright contracts}

The effects of copyright law on copyright contracts are not easy to isolate. Consider two simple examples:

\section{The literary author}

A typical deal may transfer the copyright in a work to a publisher, against an advance and a royalty on copies sold.

\section{The professional footballer}

A typical deal may contract a footballer exclusively to a club against a signing-on fee, and salary payments that depend on appearances and success.

What looks like a copyright advance plus royalties is, in the case of the footballer, simply a contract. There is no Berne Convention for footballers. Would it have made a difference if footballers' performances were statutory subject matter? Vice versa, could not the literary author's copyright contract be conceptualised as a bilateral agreement? Without the existence of copyright, an author may still be commissioned for delivery of a novel, just as a footballer is paid to play football. Similarly, the author may contractually receive royalties, just as the footballer may receive a bonus for winning a title, or making an agreed number of appearances. ${ }^{58}$
The point can be illustrated with a sophisticated early publishing agreement. In 1794 Friedrich Schiller and publisher Johann Friedrich Cotta concluded a contract for the Horen journal (one of the most important periodicals of the German enlightenment). At that time, there was no statutory copyright law in the jurisdiction where the publishing house Cottaische Buchhandlung was established (the Southern German state of Württemberg), and unauthorised reprints in other German language jurisdictions were common. The Horen contract includes advances, royalties, options, and even a moral right type clause. ${ }^{59}$ Clause (5) reserves the right of the author to make modifications. Clause (8) provides that an essay submitted to the journal may not be reprinted elsewhere until the end of four years after the publication in Horen. Clause (9) secures an option to the publisher on all future writings of the editors, provided that they are not already contracted elsewhere. Clause (15) promises a royalty to the editors of one third of profits on sales beyond 2000 copies.

Although this agreement looks uncannily like a copyright contract, it is simply a bilateral agreement over the supply of a service (which we only now recognise as the exploitation of a copyright work).

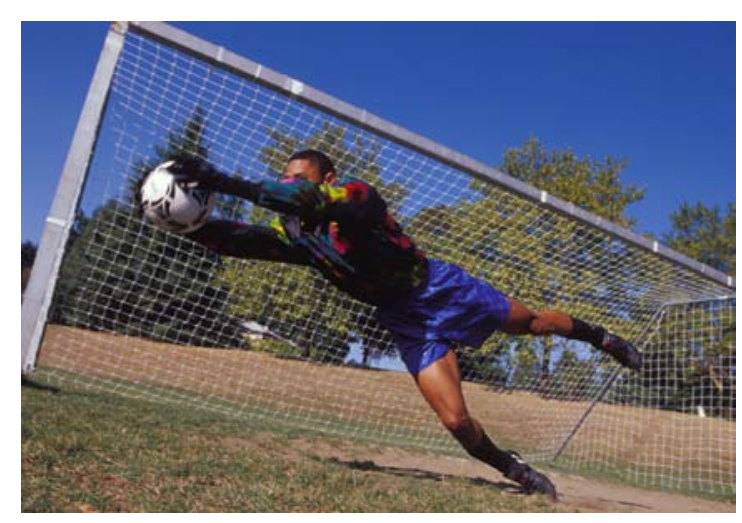
at all points along the value chain? (For discussion, see Paper 1, section 1.2.5). 
Another strand of literature suggests that an author may negotiate what a publisher can, or can't do but both, author and publisher have little contractual influence over the behaviour of competitors and consumers after publication. Here copyright law matters. To return to the football analogy, anybody may copy Ronaldo's step-over, but not the turn of phrase that is a substantial part of a copyright work. And presumably, the effects of subsequent copying are discounted in the price a publisher is prepared to pay for a work, depending on 'indirect appropriability'. ${ }^{60}$

If the relationship between creator (author) and investor (publisher/producer), such as duration, royalties, options etc, can be negotiated as a bilateral legal relationship sans droit d'auteur, it is only by conceptualising the further relationship of right holders to competitors and consumers that the regulatory function of copyright statutes becomes visible. In limiting competition, copyright statutes enable right owners to charge higher prices. Empirically, it remains an open question if this translates into higher earnings for the creator. ${ }^{61}$

\subsection{SOURCES OF EARNINGS}

If 'copyright law only lays down the rights of creators and performers, not their conditions of work' ${ }^{62}$, are there any methodologies for examining the effects of copyright contracts? One approach in the literature starts from the empirical phenomenon of artistic production, and considers the professional life of authors. As authors need to make a living in order to be productive, it should be possible to generate a taxonomy of possible sources of earnings (of which copyright contracts will be only one!) that can be empirically captured for each professional group. However there are very few studies that can be used as a starting point for this exercise. It is part of artistic folklore that many authors have lived at some stage of their career on the breadline, are holding down a second job, or are supported by members of their family. But is this true? If so, does it hold equally for all professions copyright law treats as authors in the sense of the Berne Convention: e.g. novelists, journalists, photographers, composers, screen-writers or architects? To what extent does it apply to professions that are populated by nonBerne artists, such as musical performers and actors (who are protected by related rights) ${ }^{63}$, or television format developers, sound engineers, set designers or gourmet chefs (who may have no statutory rights at all)? be able to charge higher prices because of unauthorised private copying: S.J. Liebowitz (1985), 'Copying and Indirect Appropriability', Journal of Political Economy 93(5): 945-957. For further discussion, see R. Watt (2005), 'Indirect Appropriability: 20 Years On', Symposium RERCI, 2(1), and Section 1.4 below.

61 The effects on authors' earnings of digital rights management systems (DRM) are even harder to gauge. Some proponents of DRM technologies claim that by tailoring prices to the customer's ability to pay, DRM protected markets become more efficient: 'The prescription, then, is to so structure rights that they enable differential pricing, except where transaction costs-the costs to copyright owners and users of locating and negotiating with each other-will defeat the practice, as they presently would with book resales.' - P. Goldstein (2003 [1994]), Copyright's Highway: From Gutenberg to the Celestial Jukebox, Stanford UP, p. 201. Even if this proposition held (for counter-arguments, see for example J. Litman (2001), Digital Copyright, NY: Prometheus), what would follow for the author's share of the surplus?

62 Ruth Towse, invitation to Bournemouth Symposium on Copyright, Contract and Creativity (25 September 2009): http://www. cippm.org.uk/symposia/symposium-2009.html.

The most important international treaties for related or neighbouring rights are the Rome Convention (1961) 'for the Protection of Performers, Producers of Phonograms and Broadcasting Organisations', the WTO TRIPS Agreement (1994), and the WIPO Performances and Phonograms Treaty (1996).

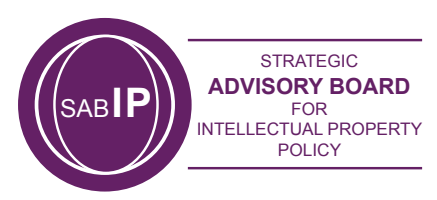


In an earlier paper ${ }^{64}$, I have suggested that the earnings' portfolio of cultural professionals can be analysed under the following four categories:

\section{(a) Statutory right: Individually negotiated income}

This type of income is likely to be based on publishing or production contracts, and poses conceptual problems in identifying the effects of the underlying statutory right.

\section{(b) Statutory right: Collectively negotiated income}

This type of income income is collected and distributed via collecting societies, typically for secondary use of protected subject matter that is difficult to monitor. These fees can often be directly linked to regulatory intervention, such as a statutory licence or a licence set in a copyright tribunal. ${ }^{65}$

\section{(c) Income from artistic activity: Non-statutory subject matter}

This type of income includes fees for live appearances (such as performances or readings), grants, teaching in the artist's field.

\section{(d) Income from non-artistic sources}

This category includes income from any nonartistic 'day time job', family support, capital income and benefits derived from the social security system.

Empirical data in these four categories are not easily available, unless collected through a specifically designed questionnaire instrument. However, there is a context of income, tax and insurance data available from government statistical sources that can be applied to the cultural professions. There is also useful information contained in surveys of creators. Finally, it is possible to make inferences on the likely balance of incomes from the published distributions of copyright collecting societies. ${ }^{66}$ Before the empirical evidence on artists' earnings is reviewed in detail, the conceptual approach is illustrated through the income profiles of two creators.

$64 \quad$ M. Kretschmer (2005), 'Artists' Earnings and Copyright: A review of British and German music industry data in the context of digital technologies', First Monday 10/1 (January): pp. 1-20. The approach has been used for the 2007 ALCS survey Authors' Earnings from Copyright and Non-Copyright Sources which provides an important source of data for this review.

65 Several European Directives have created rights that can only be exercised via collecting societies (rental 1992/100/EEC; cable retransmission 1993/83/EEC; droit de suite 2001/84/EC).

66 The UK collective licensing bodies include: Authors Licensing \& Collecting Society (ALCS) - secondary reproduction and audio-visual rights in the literary and dramatic copyright area; Broadcasting Dataservices - licenses programme listings; Christian Copyright Licensing International (CCLI) - licenses the reproduction of songs and hymns; Copyright Licensing Agency (CLA) - licenses reprographic copying of literary works; ComPact Collections - licenses cable retransmission rights for films; Design and Artists Copyright Society (DACS) - administers reproduction rights for visual artists; Educational Recording Agency Ltd (ERA) - licenses recording off-air by educational establishments; Filmbank and Motion Picture Licensing Corporation - licenses the showing of films in public; MCPS - mechanical reproduction rights of composers, lyricists, publishers;Newspaper Licensing Agency (NLA) - issues licences for copying of newspapers; Phonographic Performance Limited (PPL) - licenses certain uses of copyright sound recording; Publishers Licensing Society (PLS) - administers certain rights on behalf of publishers; PRS - performing rights of composers, lyricists, publishers; Video Performance Limited (VPL) - licenses certain uses of music video recordings. There are currently more than 150 collecting societies acting for right holders in the EU. Europe's largest society is Germany's GEMA (administering music performing and mechanical rights) with an annual turnover exceeding €800m (Annual Report 2008). 


\subsubsection{Two professional profiles}

\section{The electronica artist}

$X$ grew up in the techno/dance scene of the 1980 s, forming various bands. His music is entirely produced on a computer, and the traditional subject matter categories of copyright law are difficult to apply. However, contracts and income follows these categories: the composition as musical work ${ }^{67}$ (also known as 'publishing'); the sound recording ${ }^{68}$ (also known as 'master tape'); and the performance ${ }^{69}$.

Following a record deal with a major company, three of X's tracks made it into the UK Top Ten. The recording contract was structured as advance plus royalties, with ownership of the master tape resting with the record company. As is usual in the business, the advance was never recouped as the label can offset 'clearing samples', production and promotion costs. Thus no royalties have been paid, and a notional debt was retained against subsequent releases. 'You spend your pipeline before you get paid. The record companies don't want you to stop working.' X eventually changed the record company and now works on a 'per release' basis with an independent label.

The delivery of the master tape to the record company includes a payment for the performance of musicians who have been recorded (which may well be a MIDI file created by X). Subsequent broadcasts and rental of the recording entitle the performer to a small collectively negotiated royalty administered by collecting society PPL.
$X$ also has concluded a separate exclusive contract with a music publisher, which now covers 30 tracks (including his three chart hits). Publishing income on the one hand is automatically linked to the sales, rental and broadcasting of sound recordings of the musical work (i.e. the work of the record label); on the other hand it depends on the promotional activities of the publishing company itself which may attempt to place tracks for advertising or TV. The composer's share of revenue for 'air-time' is collectively negotiated, and according to the statutes of collecting society PRS, the publisher's share cannot exceed $50 \%$. This income stream therefore is less vulnerable to bargaining pressures.

Thirdly, X's band gives live concerts, and X personally is regularly invited to perform as DJ at major clubs, nationally and internationally. Due to $X$ 's fame, these gigs are well paid.

Looking at X's current income, there are three major elements: (i) advances paid by the record label; (ii) publishing royalties (of which the performing royalties for 'air-time' paid via PRS are the most important); and (iii) live performances as a DJ. (i) is based on a recording contract assigning statutory subject matter; (ii) is based on a publishing and collective administration contract licensing statutory subject matter; (iii) is not based on statutory subject matter.

\section{The children's book illustrator}

After graduating from art college, $Y$ worked as a graphic designer in the advertising industry. For a period, she was employed for a major agency that under her contract of employment owned her artwork $^{70}$.

\footnotetext{
67 In the UK, CDPA 1988, s. 1(1)(a) and s. 3

68 In the UK, CDPA 1988, s. 5A

69 In the UK, CDPA 1988, ss. 191, 192
}

70 An artistic work under CDPA 1988, s. 4(a) includes 'a graphic work'. Section 11(2) provides that '[w]here a literary, dramatic, musical or artistic work, or a film, is made by an employee in the course of his employment, his employer is the first owner of any copyright in the work subject to any agreement to the contrary'. See section 2.5 .1 below.

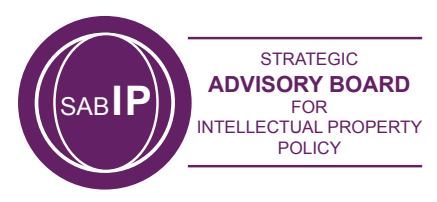


In mid-career, $Y$ decided to have a break in order to establish a family. The advertising agency continued to commission work from $Y$ on a project basis against one-off fees.

Through a number of chance encounters, $Y$ also began to illustrate children's texts, initially for free. Her partner continued to work full-time. Following a surprise best-selling success of one of her titles (for which she had received only a buy-out fee), $Y$ briefly became one of the best-paid illustrators, commanding royalties in excess of $10 \%$ of the retail price but has been unable to repeat her early success. Her best-selling book is still a public library favourite. She now visits schools, and gives creative seminars for which there is a steady demand.

Y's income profile has been very different during the three phases of her professional life. As an employed or commissioned graphic designer (i) her income was derived from the production of statutory subject matter, but her payment structure was that of an employee or freelancer. It is not clear whether the statutory protection of artistic works was relevant to the income received. During the second phase, artistic production was undertaken in an environment in which the main source of income was non-artistic (ii): the partner's job. During the third phase, income shifted to art-related, but non-statutory subject matter activity (iii): seminars and workshops, but there was also (iv) a small royalty stream from some of her earlier publication contracts and via the public lending right (which collects fees for the lending of books from public libraries). ${ }^{71}$
It is not claimed that either of these profiles is typical. In fact, studies on artists' labour markets stress that cultural workers constitute a very heterogeneous population. ${ }^{72}$ The historical example of pre-copyright contracts (section 2.1.2 above), and the earnings profiles constructed here merely demonstrate the methodological constraints that need to be overcome in order to identify the monetary contribution of copyright contracts to creative production.

The remainder of this paper is structured as follows: The next two sections review the available data on creators' earnings (2.3) and to what extent they can be assumed to reflect the current empirical outcome of contract bargaining (2.4), the final two sections provide an international comparative review of regulatory tools that may be used to adjust the bargaining outcome (2.5), and their potential effectiveness (2.6). as an intellectual property right, entirely separate from copyright. In the conceptual framework presented in this paper, PLR is closest to category (2) 'Statutory right: Collectively negotiated income'.

72 F. Benhamou (2003), 'Artists' Labour Markets', pp. 69-75 in R. Towse (ed.), A Handbook of Cultural Economics, Cheltenham: Edward Elgar.

The sections on Copyright Earnings draw on M. Kretschmer and P. Hardwick (2007), Authors' Earnings from Copyright and Non-copyright Sources, Bournemouth: CIPPM and ALCS. Exchange rates are calculated at the average exchange rate for the year in question. 


\subsection{EMPIRICAL EVIDENCE ON COPYRIGHT EARNINGS ${ }^{73}$}

The available data on authors' and artists' earnings come from three different sources: (a) government statistics (census, labour market surveys, tax); (b) questionnaire surveys of specific professional groups; and (c) collecting society payments. For the purposes of assessing the possible contribution of copyright law to authors' and artists' earnings, two aspects are of particular interest. (i) The level and distribution of earnings for cultural workers, compared to other professions; (ii) Earnings from the principal artistic activity compared to other sources of earnings.

\subsubsection{The distribution of earnings in the cultural professions}

A simple tool for making comparable the distribution of income for different groups of workers in a given population is the so-called Lorenz Curve. To construct a Lorenz curve, the cumulative percentage income in the vertical $y$-axis is plotted against the cumulative percentage of the population in the horizontal $x$-axis. The Lorenz curve is used to calculate the Gini Coefficient.

In what follows, the distribution of income is reported in terms of the mean ('average income'), and median ('income at mid-point of the sample'). In some sense, the median is the income of a 'typical' member of the population, as the mean may be distorted by some very high or low earners.

\section{Distribution of UK employee earnings}

As a baseline example, consider the distribution of earnings (gross) for all UK employees in 2005 derived from the Annual Survey of Hours and Earnings (ASHE). ASHE is run by the Office for National Statistics (ONS) and based on a 1\% sample of employees on the Inland Revenue PAYE register, weighted to be representative of the whole population. The Survey provides information about the levels, distribution and make-up of earnings and hours worked for employees in all industries and occupations. ${ }^{74}$ In re-formatting the earnings data into a Lorenzcurve it is easy to see that the bottom $40 \%$ of employees earn about $20 \%$ of total income; and that the top $10 \%$ equally earn about $20 \%$ of total income. This deviation from the diagonal equal distribution line produces a Gini Coefficient of $0.33 .{ }^{75}$

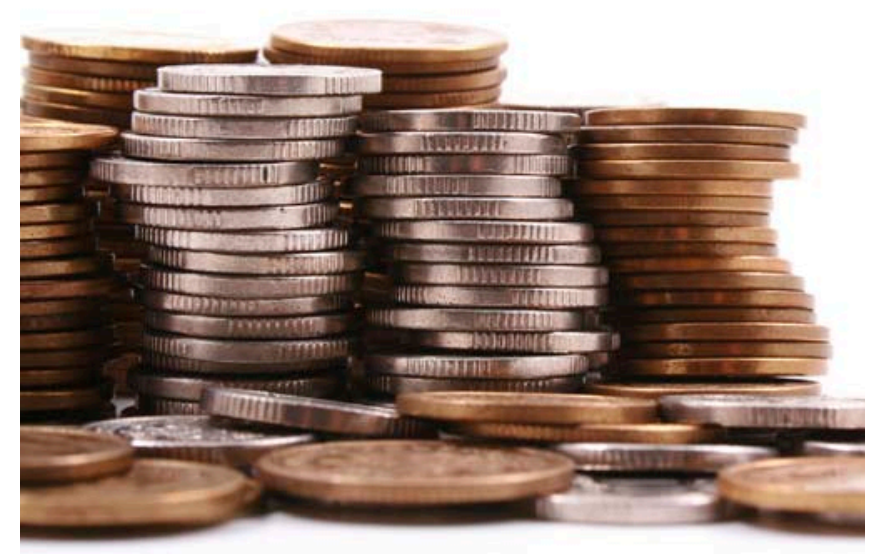

74 The job-types that are under-represented tend to be males, tend to be working in London and the Southeast and tend to be in Standard Occupational Classification (SOC) 2000 major groups 1 to 3 (1: Managers and Senior Officials; 2: Professional Occupations; 3: Associate Professional and Technical Occupations). Therefore these jobs receive larger weights (cf. Bird, 2004). ASHE data can be downloaded as Excel files from the website of the Office for National Statistics (http://www. statistics.gov.uk).

For comparison, consider the distribution of income for all households as given by the United Nations Human Development Programme Report (2004, pp. 50-53): Germany: 0,274 (2003); France: 0,327 (1995); UK: 0,360 (1999); Japan: 0,249 (1993); USA 0,408 (2000). Within the UK, equal earnings professions include 'skilled metal and electrical trades' (occupational class 52 ; Gini $=0.22$ ) and 'health and social welfare associate professionals' (occupational class 32 ; Gini $=0.25$ ). Higher inequality professions include 'corporate managers' (occupational class 11; Gini $=0.39$ ). 
Figure 2.1

UK: Annual earnings (gross) all employees (2005)

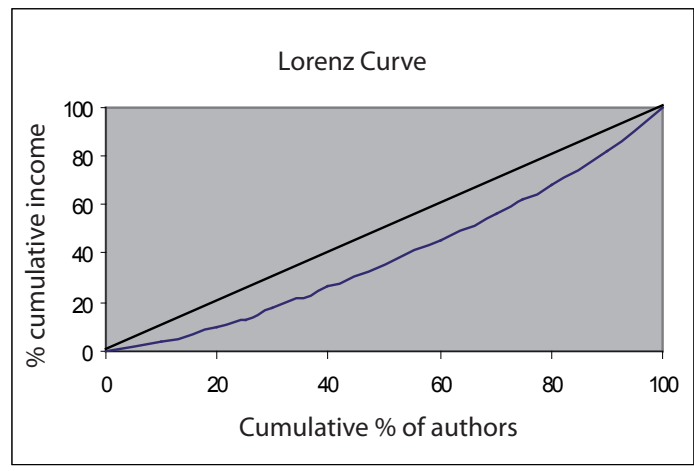

Mean ('average') earnings

$£ 23,400$

Median ('typical') earnings

$£ 19,190$

Gini Coefficient ('measure of inequality')
0.33
- Artists (class 3411, no member in sample)

- Authors, writers (class 3412, 14 members insample $)^{76}$

Source: Hours and Earnings (ASHE) Office for National Statistics

- Actors, entertainers (class 3413, no member in sample)

- Dancers and choreographers (class 3414, no member in sample)

- Musicians (class 3415, no member in sample) Arts officers, producers and directors (class 3416, 9 members in sample)

In any case, ASHE data does not capture self-employed earnings (which copyright earnings would be almost by definition).

The Annual Survey of Hours and Earnings (ASHE) separates out earnings data for occupational class 34: Culture, Media and Sport Occupations (sample size: 204), a sub-class of major class 3: Associate Professional and Technical Occupations (sample size: 2785). Mean $(£ 27,474)$ and median $(£ 22,919)$ earnings for this group (class 34) are both above average, while the Gini Coefficient (0.34) is in line with all employees. However, the data are not broken down to a sufficient level of detail, covering a diverse range of professions from designers (class 3422) and journalists (class 3431) to public relations (class 3433 ) and fitness instructors (class 3443). The sample for the core group of Artistic and Literary Occupations (class 341) is too small to draw reliable probabilistic inferences:

\section{Artists' insurance data Germany}

A fine-grained large-scale data set on artists' earnings is available as part of a unique German policy experiment: a compulsory insurance for freelance authors and artists that was introduced with the 1981 Künstlersozialversicherungsgesetz ('social insurance law regarding artists'). ${ }^{77}$

Similarly to the structure for employees, selfemployed artists in the four sectors 'Word authors', 'Visual arts/design', 'Music' and 'Performing arts' (actors, directors) become members of a subsidized national health and pension insurance scheme. The insured artist pays $50 \%$ of the contribution, while 'exploiters of art' (e.g. publishers, record companies, galleries) contribute $30 \%$, and $20 \%$ comes from the Federal Government (general taxation).

76 An analysis of ONS Labour Force Survey data by the GMB union identifies 11,000 authors/writer jobs, and calculates a mean gross annual pay for 2005 as $£ 32,296$ (Independent, 21/08/2006). circumstances of authors and artists: Fohrbeck, Karla; Wiesand, Andreas Johannes (1972), Der Autorenreport. Reinbek b. Hamburg; Fohrbeck, Karla; Wiesand, Andreas Johannes (1975): Der Künstler-Report: Musikschaffende, Darsteller/ Realisatoren, Bildende Künstler/Designer. München-Wien. 
In order to set their individual contribution rate, artists have to declare their yearly income. These insurance data have been published in aggregate form in a report by the Federal Ministry of Employment. ${ }^{78}$ In 1999, 107,167 authors and artists were insured in the insurance scheme Künstlersozialkasse. Of those that could be allocated unambiguously to one professional group, there were 29,245 ('Word') authors, with an average annual income (mean) of DM 25,686 $(€ 13,133) ; 45,486$ visual artists, with an average annual income of DM 19,889 (€10,169); 29,720 musicians, with an average annual income of DM $17,392$ ( $€ 8,892)$; and 12,433 performing artists, with an average annual income of DM 18,920 $(€ 9,674)$. Overall, mean earnings per annum for all insured artists were DM 21,868 (€11,181); median earnings were DM 15,753 (€8,054). This compares to an average (mean) German net income in 2004 of $€ 31,157$, and a median of $€ 28,730.79$ The typical (median) German selfemployed artist earns about one third of the income of a typical (median) worker.

For each sector, the data can be narrowed down to the copyright professions, i.e. the groups that depend most clearly on a statutory right. For example, for the music sector the table below shows that the average annual earnings for a German composer in 1999 (total in Künstlersozialkasse: 3,670 ) were in the region of DM 22,000 (€11,225).

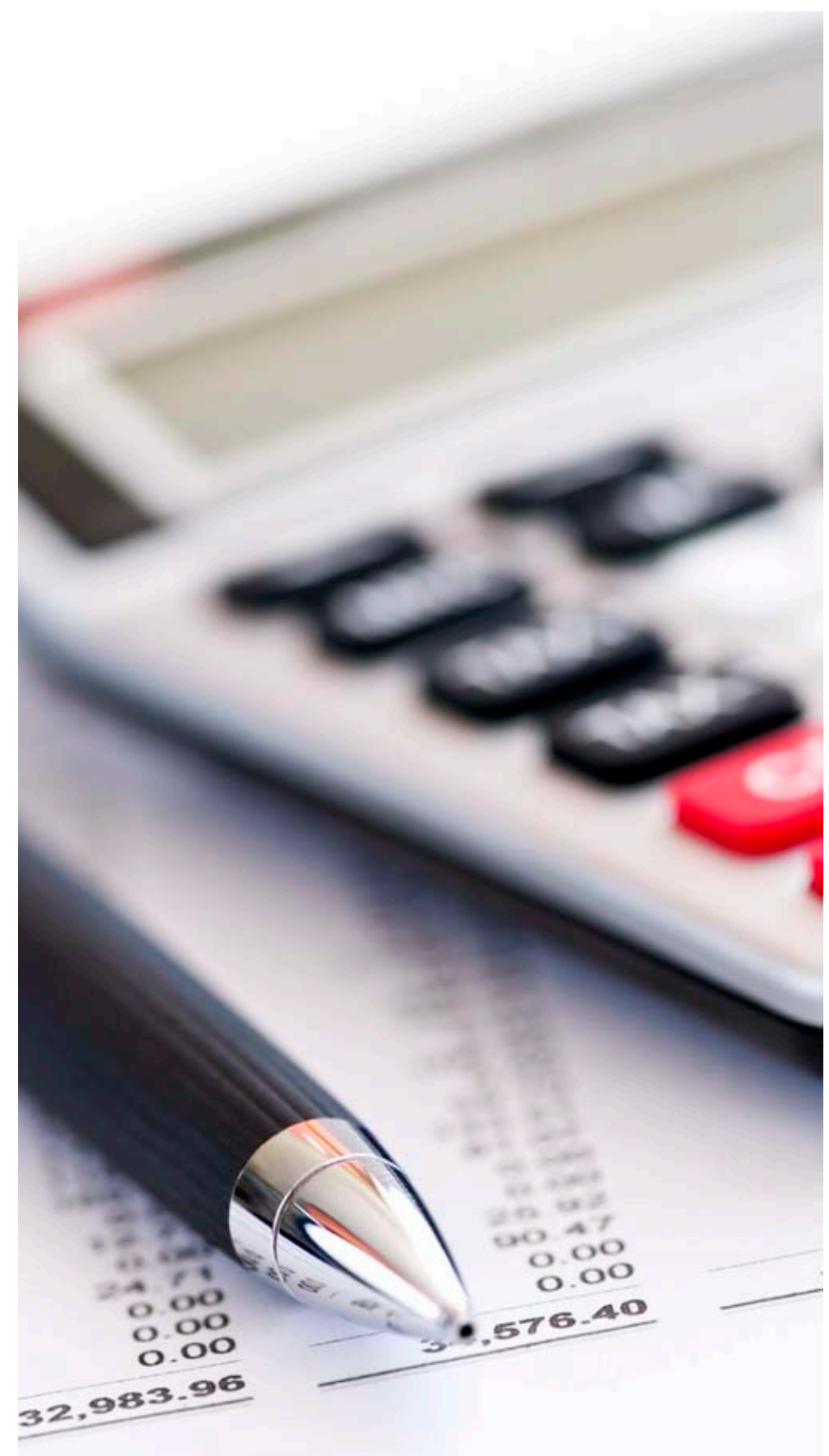
Arbeit und Sozialordnung, 31. März 2000; cited in the following as Künstlersozialkasse (2000).

\begin{abstract}
Ergebnisse des Mikrozensus 2004, Wiesbaden: Statistisches Bundesamt (cited as Mikrozensus 2004). Mikrozensus is an annual representative survey of $1 \%$ of the population. Three possible distortions of the Künstlersozialkasse insurance data should be noted. (i) Artists have an incentive to under-declare their income, as that reduces their annual contribution. For example, according to the 2000 Mikrozensus data, workers in the occupational group Publizistik (including writers, translators and editors) earned an average (mean) of DM 37,199 (€19,020) per annum, and a median of DM 35,160 (€17,977). This is about $€ 5,000$ per annum more than members of the insurance scheme in comparable self-employed professions declared. (ii) As a subsidised scheme the insurance is attractive to many self-employed workers who are not primarily artists (such as music teachers, graphic designers or part-time journalists). (iii) Top-earners can opt out of the scheme in favour of private insurance.
\end{abstract}

Providing Government with strategic, independent and evidence-based advice on intellectual property policy. 
Table: Künstlersozialkasse occupational group music (1999)

\begin{tabular}{|c|c|c|c|}
\hline Activity & Number of artists & $\begin{array}{c}\text { Total income in DM } \\
1,000\end{array}$ & $\begin{array}{c}\text { Average annual } \\
\text { income (DM) }\end{array}$ \\
\hline Composer & 3,670 & 80,570 & 21,954 \\
\hline Lyricist & 215 & 5,770 & 26,837 \\
\hline Arranger & 428 & 7,702 & 17,995 \\
\hline Conductor & 265 & 6,916 & 26,098 \\
\hline Choirmaster & 400 & 8,026 & 20,065 \\
\hline Instrumentalist Solo & 1,618 & 24,971 & 15,433 \\
\hline Orchestra Player (E) & 553 & 7,928 & 14,336 \\
\hline Singer (opera, musical) & 492 & 8,400 & 17,073 \\
\hline Singer (concert) & 398 & 5,963 & 14,982 \\
\hline Singer (choir) & 50 & 746 & 14,920 \\
\hline Singer (popular) & 1,632 & 32,412 & 19,860 \\
\hline Pop musician & 2,661 & 42,508 & 15,974 \\
\hline Kurorchester & 483 & 8,241 & 17,062 \\
\hline Jazz and Rock & 2,899 & 42,084 & 14,517 \\
\hline Technical staff & 506 & 10,260 & 20,277 \\
\hline Teacher & 11,838 & 197,490 & 16,683 \\
\hline DJ & 691 & 12,186 & 17,635 \\
\hline Others & 921 & 14,708 & 15,970 \\
\hline Total & 29,720 & 516,881 & 17,392 \\
\hline
\end{tabular}

Source: German Federal Ministry of Employment, Künstlersozialkasse (2000), p. 14

Figures for the distribution of earnings were only available for an aggregate of all musicians. About $90 \%$ of musicians earned below DM 30,000 (€15,339). 2,650 musicians earned above DM 30,000 , with 125 musicians earning above DM 102,000 (approximately $€ 52,152$ ).
The large number of teachers in the sample (who tend to earn similar amounts), as well as the absence of privately insured top-earners may account for a relatively flat Lorenz curve, and a Gini Coefficient (0.31) that is similar to the total population. 


\section{PAPER 2 - CREATOR CONTRACTS}

\section{Germany: Annual earnings from self-employed} writing (2001)

The German federal office for statistics has calculated the declared taxable income from selfemployed writing for 2001 (the most recent year for which these data were available). ${ }^{1}$ In 2001 ,
24,436 German taxpayers had such income. The following two figures represent the distribution of earnings for all tax-paying self-employed writers, and for a sub-sample (10,220): all tax-paying self-employed writers who earn more than $50 \%$ of their income from writing.

Figure 2.2

Germany: Annual earnings from self-employed writing (2001)

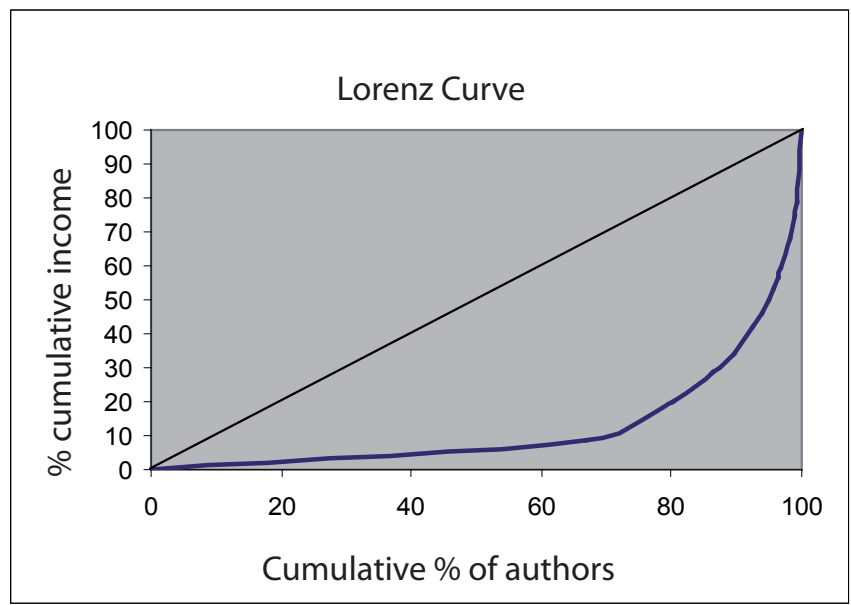

Source:

Commissioned analysis of 24,436 tax payers (2001)

Statistisches Bundesamt (federal office for statistics)

Mean ('average') earnings

$€ 17,306(£ 10,557)$

Median ('typical') earnings

$€ 7,163(£ 4,369)$

Gini Coefficient ('measure of inequality')

0.83

(2001 exchange rate: $€ 1=£ 0.61$ ) 
UK Society of Authors earnings survey 2000

For the UK there exist a number of smaller questionnaire surveys of specific regional subgroups conducted during the 1990s at the instigation of the Arts Councils in England, Wales and Scotland. These studies, reviewed in Towse (2001), are based on small samples but paint a similar picture to the German experience. ${ }^{80}$ Average earnings are low, and are typically supplemented by income from other, often non-artistic, sources (see section 2.2). For example, Ruth Towse's study of 2000 artists in Devon (1989/90) gives mean annual earnings of $£ 8,344$, and median annual earnings of $£ 6,900$. Interestingly, the distribution of income from artistic activity alone (a sub-set of total earnings) is more skewed. According to Towse, mean arts earnings (net of expenses) is $£ 5,881$ per annum, while the median is only $£ 2,100$. In other words, the typical (median) artist living in Devon in 1989/90 earned £2,100/year from his/her artistic activity. The large gap between mean and median suggests the presence of many low and some very high earners in the sample.

A larger scale study bearing this out clearly is the questionnaire survey of authors' earnings reported by the Society of Authors in 2000 . The Society of Authors is the largest professional body of writers in the UK, with a membership in 1999 of 6,600. According to the Authors' Licensing and Collecting Society (ALCS), which can reasonably claim to have almost all commercially published UK authors on its database $(41,701$ payees in 2005), the profile of the Society of Authors membership (e.g. age, gender, genre) corresponds to the total population of UK writers. ${ }^{81} 1,711$ authors responded to the questionnaire (this is a very high response rate of more than $25 \%$ ) and, according to the analysis published by Kate Pool ${ }^{82}$, the profile of respondents again mirrored the Society's membership as a whole.
The questionnaire only asks about the author's earnings as a self-employed writer, excluding salaried writing, second job earnings, investment income, family or social security support. Thus it can be assumed that all reported figures derive from a copyright-related sub-set of the author's principal artistic activity.

The survey revealed average (mean) earnings of $£ 16,600$ per annum, with median earnings of $£ 6,333$, again indicating the presence of many low earners and some very high earners in the sample. $75 \%$ earned under $£ 20,000$ per annum, $61 \%$ under $£ 10,000$ and $46 \%$ under $£ 5,000$. Writing was the sole source of income for only 230 people $(13,5 \%$ of respondents). In the Society of Authors sample, the typical (median) writer earns about a third of the national median wage.

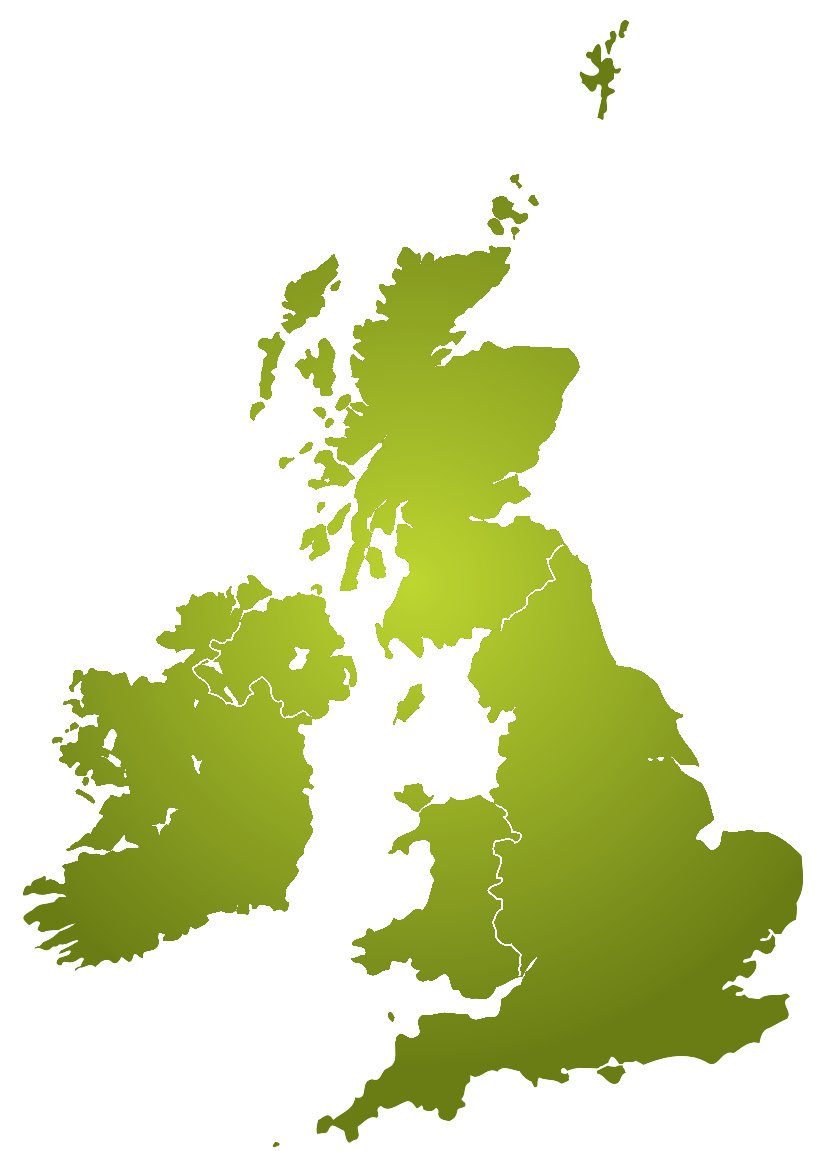
Towse, R. (2001). Creativity, Incentive and Reward: An Economic Analysis of Copyright and Culture in the Information Age. Cheltenham: Edward Elgar; esp. Chapter 3 ('Economics of Artists' Labour Markets').

Personal communication, Owen Atkinson, CEO ALCS. 


\section{Figure 2.3}

\section{UK: Annual earnings from self-employed writing (1998-9)}

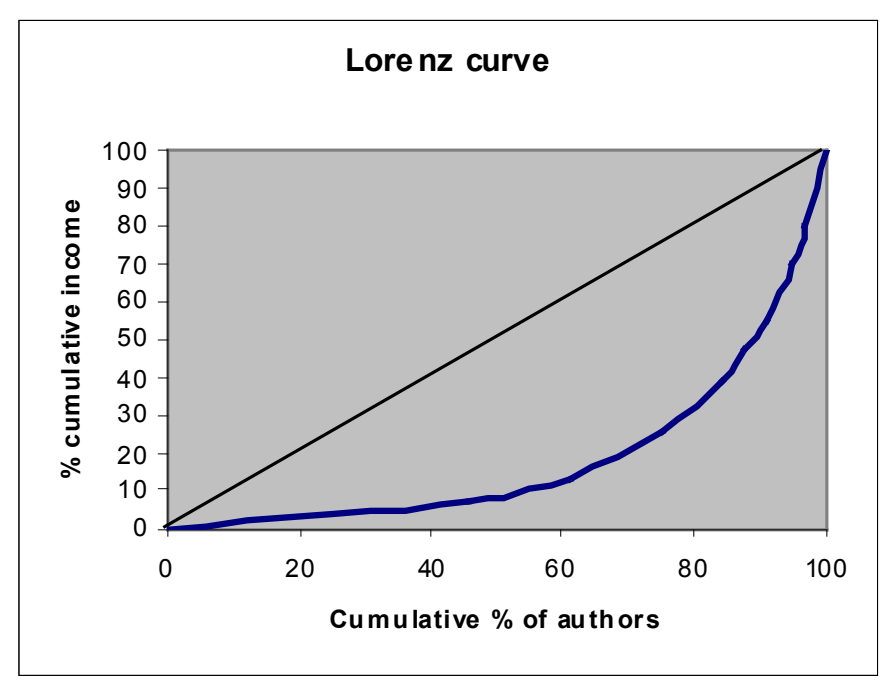

Source:

Society of Authors survey, published 2000 (professional body sample, 1711 respondents)

$\begin{array}{ll}\text { Mean ('average') earnings } & £ 16,600 \\ \text { Median ('typical') earnings } & £ 6,333 \\ \text { Gini Coefficient ('measure of inequality') } & \mathbf{0 . 6}\end{array}$

\section{ALCS survey 2007}

In the largest comparative study to date, Kretschmer and Hardwick's (2007) survey the earnings of 25,000 literary authors in Germany and the UK. For comparison and policy relevance, we define a sub-sample of 'professional authors' as those who allocate more than half their time to being an author. ${ }^{83}$ We find that the median gross earnings of professional writers $(£ 12,330)$ are about $64 \%$ of the median wage of all UK employees $(£ 19,190)$. In Germany the median earnings of professional writers $(€ 12,000)$ are only about $42 \%$ of the national net median wage $(€ 28,730 / £ 19,536)$.
The top $10 \%$ of professional writers in the UK earn about $60 \%$ of total income (they earn $£ 68,200$ or more); the bottom $50 \%$ earn about $8 \%$ of total income (Gini: 0.63 ). In Germany, the top $10 \%$ of professional writers earn about $41 \%$ of total income (they earn $€ 40,000 / £ 27,600$ or more); the bottom $50 \%$ earn about $12 \%$ of total income (Gini: 0.52). sampled all members of the UK collecting society ALCS and the members of two German writers' organisations (VS and VDD). The questionnaire started with a self-definition question: 'How would you introduce your profession when meeting someone for the first time... If you feel you have more than one profession, please indicate how much of your time you spend on each'. 
Figure 2.4

UK: Annual earnings from self-employed writing (2004-5) "professional authors" (= more than $50 \%$ of time allocated to writing)

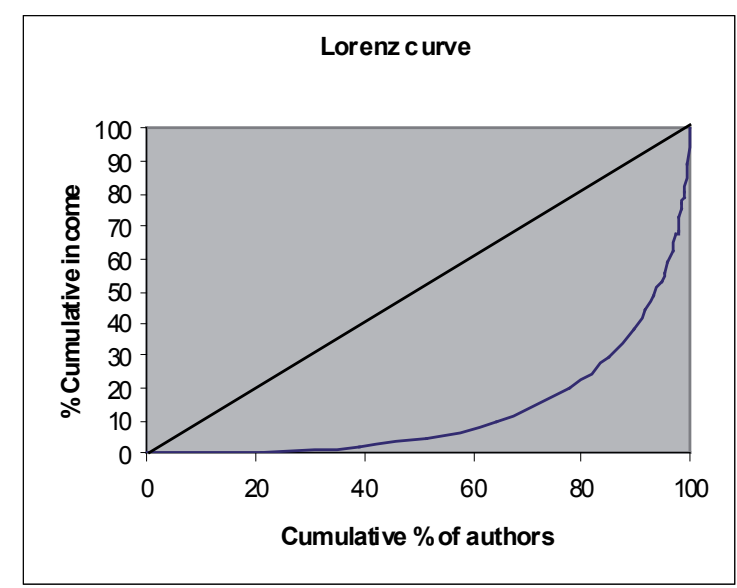

Source:

ALCS Survey

UK writing income

(sub-sample

"professional authors")

Mean ('average') earnings

$£ 28,340$

Median ('typical') earnings

$£ 12,330$

Gini Coefficient ('measure of inequality')

0.63

\section{Figure 2.5}

Germany: Annual earnings from self-employed writing (2005) "professional authors" (= more than $50 \%$ of time allocated to writing)

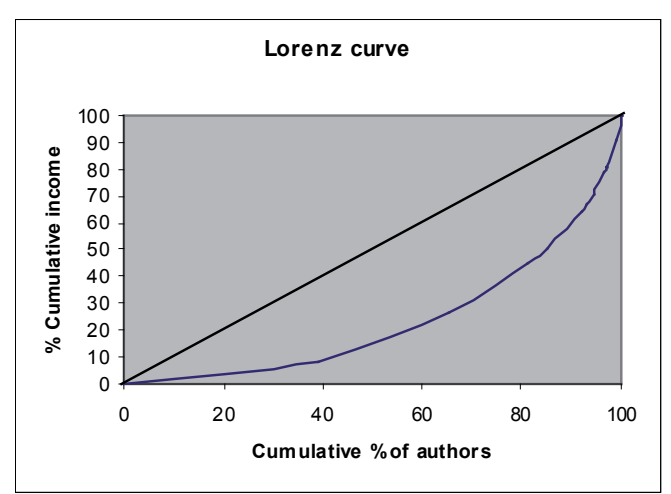

Mean ('average') earnings Median ('typical') earnings

Gini Coefficient ('measure of inequality')
Source:

ALCS Survey

German writing income

(sub-sample

"professional authors") 


\section{Performing Right Society (PRS) payments 1994}

The emerging trend in the distribution of income is confirmed by the payments of copyright collecting societies. These data are privately held, and thus not easily accessible. A 1996 report by the UK Monopolies and Mergers Commission (now Competition Commission) on the UK Performing Rights Society (PRS) is the most reliable source. ${ }^{84}$

The figures show that in 1994, the PRS paid a total of $£ 20,350,000$ to 15,500 entitled composers and songwriters for the public performance and broadcasting of their works.

Table: PRS distribution (1994)

\begin{tabular}{|l|l|l|l|l|l|l|}
\hline $\begin{array}{c}\text { Bands of net } \\
\text { domestic } \\
\text { distributed } \\
\text { revenue* }\end{array}$ & $\begin{array}{c}\text { Number of } \\
\text { writers }\end{array}$ & \% & $\begin{array}{c}\text { Cumulated } \\
\text { \% from top }\end{array}$ & £m & \% & $\begin{array}{c}\text { Cumulated } \\
\% \text { from top }\end{array}$ \\
\hline Up to 24 & 4,812 & 31.0 & 100.0 & 0.04 & 0.19 & 100.0 \\
\hline $25-49$ & 1,624 & 10.5 & 69.0 & 0.06 & 0.29 & 99.8 \\
\hline $50-74$ & 1,001 & 6.5 & 58.5 & 0.06 & 0.30 & 99.5 \\
\hline $75-99$ & 800 & 5.2 & 52.0 & 0.07 & 0.34 & 99.2 \\
\hline $100-149$ & 920 & 5.9 & 46.9 & 0.11 & 0.56 & 98.9 \\
\hline $150-199$ & 632 & 4.1 & 40.9 & 0.11 & 0.54 & 98.3 \\
\hline $200-249$ & 460 & 3.0 & 36.8 & 0.10 & 0.50 & 97.8 \\
\hline $250-499$ & 1,481 & 9.6 & 33.9 & 0.53 & 2.6 & 97.3 \\
\hline $500-749$ & 750 & 4.8 & 24.3 & 0.46 & 2.2 & 94.7 \\
\hline $750-999$ & 452 & 2.9 & 19.5 & 0.39 & 1.9 & 92.4 \\
\hline $1,000-2,499$ & 1,130 & 7.3 & 16.6 & 1.79 & 8.8 & 90.5 \\
\hline $2,500-4,999$ & 590 & 3.8 & 9.3 & 2.11 & 10.4 & 81.7 \\
\hline $5,000-9,999$ & 389 & 2.5 & 5.5 & 2.75 & 13.5 & 71.4 \\
\hline $10,000-19,999$ & 255 & 1.6 & 3.0 & 3.50 & 17.2 & 57.9 \\
\hline $20,000-49,999$ & 164 & 1.1 & 1.3 & 4.98 & 24.5 & 40.7 \\
\hline $50,000-99,999$ & 30 & 0.19 & 0.26 & 2.04 & 10.0 & 16.2 \\
\hline 100,000 and & 10 & 0.06 & 0.06 & 1.26 & 6.2 & 6.2 \\
\hline $0 v e r$ & & & & & & \\
\hline
\end{tabular}

\begin{tabular}{|l|l|l|l|l|l|l|}
\hline Total & 15,500 & 100 & & 20.35 & 100 & \\
\hline
\end{tabular}

*Note: Excluding earnings equalisation allowances, unlogged performance allocations, and revenue from performance of films.

Source: Monopolies and Mergers Commission: Performing Rights (1996) 
We see that, in 1994, 10 composers earned more than $£ 100,000 ; 204$ more than $£ 20,000$; 459 more than $£ 10,000$; 848 more than $£ 5,000 ; 1,438$ more than $£ 2,500$; and 8,237 under $£ 100$. The typical (median) composer earned £84 in performing rights income. Despite dramatically increased turnover and a doubling of the membership to 30,000 by 2000 , the distribution of earnings from PRS payments appears to have remained similar. In 2000, 200 composers and songwriters received more than $£ 100,000 ; 700$ more than $£ 25,000$;

1,500 more than $£ 10,000 ; 2,300$ more than $£ 5,000 ; 16,000$ under $£ 100.85$

The distribution of earnings again can be plotted as a Lorenz curve:

Figure 2.6

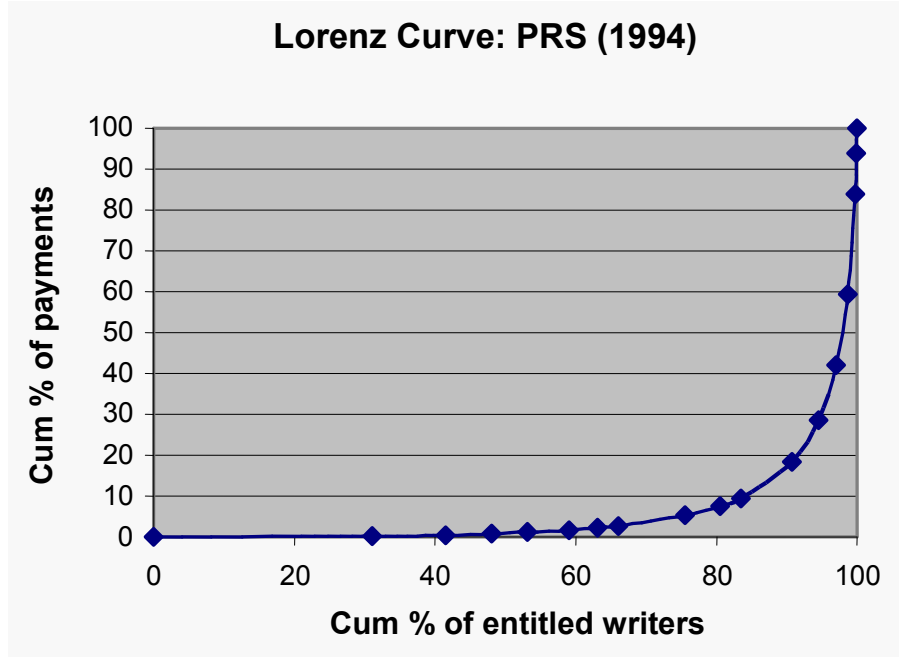

\author{
Average earnings/year (Mean): $£ 1,420$ \\ Median earnings/year: $£ 84$ \\ Gini Coefficent: $\mathbf{0 . 8 8}$
}

In addition to performing royalties, composers/ songwriters can expect to earn a similar amount from mechanical royalties for the sale of sound recordings. The figures for 2000 suggest that in the UK about 1500 (5\%) composers/songwriters reach the average (mean) national wage from copyright earnings alone. According to the German collecting society GEMA (administering both performing and mechanical rights for musical works), about 1,200 German composers/ songwriters $(2.4 \%)$ can live from their creative output. ${ }^{86}$

Summary: In this sub-section we have narrowed the analysis of the distribution of earnings in the cultural professions from the total self-declared income of authors and artists (Künstlersozialkasse insurance data), to income from self-employed artistic activity (Society of Authors), to collectively negotiated copyright income (PRS). It appears that the more copyright related the income stream, the more extreme the distribution of income (reflected in very high Gini Coefficients). ${ }^{87}$ A small number of very high earners earn a disproportionate share of total income.

Source: From data in Monopolies and Mergers Commission: Performing Rights (1996)

85 PRS Annual Report 2000, cited in Bently, Lionel (2002), Between a Rock and a Hard Place: The problems facing freelance creators in the UK media market-place, London: Institute of Employment Rights.

A. Dümling, Musik hat ihren Wert: 100 Jahre musikalische Verwertungsgesellschaft in Deutschland (Regensburg: ConBrio, 2003), 313; citing Wahren, 1995. 'Creative output' in this quote may include income from commissions or grants that would not qualify as copyright income. 


\subsubsection{Earnings from principal artistic activity}

How do the majority of authors and artists who cannot claim to make a living from copyright income balance their books? In order to make progress on this question, it needs to be defined more precisely who counts as a member of the population for which copyright earnings should matter.

In 1989, Bruno Frey and Werner Pommerehne suggested eight criteria for identifying an artist ${ }^{88}$ :

(i) the amount of time spent on artistic work,

(ii) the amount of income derived from artistic activities, (iii) the reputation as an artist among the general public, (iv) recognition among other artists, (v) the quality of artistic work produced, (vi) membership of a professional body, (vii) a professional qualification in the arts, and (viii) a subjective self-evaluation as an artist. In practice, the definition of the relevant population of artists often has been constrained by the available samples.

(a) Government statistics usually use an occupational group approach. For example, under the Annual Survey of Hours and Earnings (ASHE), an employee falls under class 3411 (artists) or class 3412 (authors, writers) if the employer says so.

(b) Questionnaire surveys often rely on the membership of particular professional bodies, such as the Society of Authors.

(c) On-line surveys typically are circulated within professional networks, and depend on the participation of respondents who aspire to be artists.

(d) Being a recipient of payments from a copyright collecting society is yet another criterion.
If, as it already has become clear, most creative workers cannot live from their artistic earnings, perhaps the relevant population should be reduced to those creators in each discipline who can live, or at least aim to live from their principal artistic activity. This may be expressed by a threshold amount of creative earnings, or by a threshold amount of time allocated to creative activity. Perhaps copyright law is only designed for best-sellers.

At the other end of the conceptual spectrum, the literature on the creative industries tends to overstate the size of the cultural sector (including administrative, technical, managerial and retail workers). For example, the EU assumes from consolidated national data that about 4,164,300 workers (or $2.5 \%$ of the total workforce) are occupied in the cultural sector. In the UK alone, the relevant figures are 877,100 workers (or $3.2 \%$ of the total workforce). ${ }^{89}$

From a third perspective, the relevant population where copyright law should matter is constituted by all potential cultural workers from whose increased activity society would benefit.

There are only a small number of pioneering studies that have attempted to capture the professional earnings profile of specific groups of creators. The populations of all the studies discussed rely on an element of sustained practice, typically expressed by membership of a professional organisation.

\section{Austrian composers report (1993)}

A questionnaire survey of 630 Austrian composers by a group of sociologists from the Vienna Hochschule für Musik und Darstellende Kunst (now Musikuniversität), arrived at the following income profiles. ${ }^{90}$ (p. 47). Bundesregierung für Kultur und Medien). 
Table: Income from compositions as percentage of total income

\begin{tabular}{|l|l|}
\hline Below 10\%: & $36.8 \%$ \\
\hline $10-20 \%:$ & $31.2 \%$ \\
\hline $21-49 \%:$ & $14.1 \%$ \\
\hline $50 \%$ and more: & $17.8 \%$ \\
\hline
\end{tabular}

Table: Composers also received income from

\begin{tabular}{|l|l|}
\hline $\begin{array}{l}\text { Other musical activity } \\
\text { (performance \& } \\
\text { teaching): }\end{array}$ & $82.0 \%$ \\
\hline $\begin{array}{l}\text { Non-music } \\
\text { professional activity: }\end{array}$ & $25.6 \%$ \\
\hline Family members: & $18.2 \%$ \\
\hline $\begin{array}{l}\text { Social security } \\
\text { benefits: }\end{array}$ & $3.9 \%$ \\
\hline Investment income: & $1.1 \%$ \\
\hline Other sources: & $3.5 \%$ \\
\hline
\end{tabular}

Finnish music business study (2003) A survey of 688 members of the Finnish Society of Composers and Lyric Writers conducted in 2001/02 by members of the Media Group at the Turku School of Economics and Business Administration ${ }^{91}$ found a large gap between total annual individual income and income from composing.
Table: Income from composing compared to total income

\begin{tabular}{|l|l|l|l|}
\hline $\begin{array}{l}\text { Music } \\
\text { creators } \\
(\mathbf{n = 2 5 3 )}\end{array}$ & $\begin{array}{l}\text { Lower } \\
\text { Quartile }\end{array}$ & Median & $\begin{array}{l}\text { Upper } \\
\text { Quartile }\end{array}$ \\
\hline $\begin{array}{l}\text { Copyright } \\
\text { remunerations }\end{array}$ & $\begin{array}{l}3,500 \\
\text { FIM } \\
(€ 589)\end{array}$ & $\begin{array}{l}11,649 \\
\text { FIM } \\
(€ 1,959)\end{array}$ & $\begin{array}{l}43,572 \\
\text { FIM } \\
(€ 7,328)\end{array}$ \\
\hline $\begin{array}{l}\text { Other } \\
\text { income from } \\
\text { composing }\end{array}$ & $\begin{array}{l}3,000 \\
\text { FIM } \\
(€ 505)\end{array}$ & $\begin{array}{l}(€ 1,959) \\
\text { FIM } \\
(€ 1,682)\end{array}$ & $\begin{array}{l}30,000 \\
\text { FIM } \\
(€ 5,046)\end{array}$ \\
\hline $\begin{array}{l}\text { Total Annual } \\
\text { Income }\end{array}$ & $\begin{array}{l}96,000 \\
\text { FIM } \\
(€ 16,146)\end{array}$ & $\begin{array}{l}153,00 \\
\text { FIM } \\
(€ 25,732)\end{array}$ & $\begin{array}{l}231,000 \\
\text { FIM } \\
(€ 38,851)\end{array}$ \\
\hline
\end{tabular}

\section{Australia Council study of practising professional artists (2003)}

Over a period of 20 years, David Throsby has conducted a number of studies on the economic circumstances of Australian artists. The 2003 report used as its basis a 2002 interview survey of 1063 writers, visual artists, craft practitioners, actors, directors, dancers, choreographers, and 'community cultural development workers' (of a total estimated population of 45,000 Australian professional artists, defined as those 'who operate at a level and standard of work and with a degree of commitment appropriate to the norms of professional practice within their artform'). ${ }^{92}$

91 A.-M. Hansen, V. Pönni, R. G. Picard (2003) Economic Situation of Composers, Lyric Writers and Arrangers in Finland, Turku School of Economics and Business Administration. Thanks to Ruth Towse for the reference.

92 D. Throsby and V. Hollister (2003), Don't Give Up Your Day Job: An economic study of professional artists in Australia, Sydney: Australia Council (available at http://www.australiacouncil.gov.au/research/artists/reports_and_publications/ dontgiveupyourdayjob). 
Throsby and Hollister find that on average, Australian artists tend to be older than the general workforce or the total population. They attribute this to the time it takes for an artist to become established and careers beyond the normal retiring age. The average (mean) age of artists is about 46 years.
Writers and composers are the oldest groups on average, with a mean age of 49 ; dancers make up the youngest group with a mean age of $31.63 \%$ of those surveyed had more than one job, $56 \%$ had two jobs, and $7 \%$ had three.

Table: Australian artists' sources of creative income (per cent)

\begin{tabular}{|c|c|c|c|c|c|c|c|c|c|}
\hline & Writers & $\begin{array}{l}\text { Visual } \\
\text { artists }\end{array}$ & $\begin{array}{l}\text { Craft } \\
\text { practitioners }\end{array}$ & Actors & Dancers & Musicians & Composers & $\begin{array}{l}\text { Community } \\
\text { cultural } \\
\text { development } \\
\text { workers }\end{array}$ & All artists \\
\hline Salaries, wages, fees & 55 & 34 & 21 & 94 & 90 & 95 & 38 & 78 & 63 \\
\hline $\begin{array}{l}\text { Gross sales of work, incl. } \\
\text { commissions }\end{array}$ & 13 & 54 & 68 & 3 & 1 & 2 & 25 & 12 & 22 \\
\hline Royalties, advances & 18 & 2 & 2 & 2 & 1 & 1 & 22 & - & 6 \\
\hline Other copyright earnings & * & * & - & * & 1 & 1 & 1 & - & * \\
\hline $\begin{array}{l}\text { Grants, prizes, } \\
\text { fellowships }\end{array}$ & 5 & 10 & 7 & 1 & 7 & 1 & 11 & 6 & 6 \\
\hline Public lending right & 4 & * & - & - & - & * & - & - & 1 \\
\hline Educational lending right & 5 & * & - & - & - & * & - & - & 1 \\
\hline Other creative source & * & * & 2 & - & - & * & 3 & 4 & 1 \\
\hline TOTAL & 100 & 100 & 100 & 100 & 100 & 100 & 100 & 100 & 100 \\
\hline
\end{tabular}

Source: Throsby and Hollister (2003), p. 103 ( $^{*}$ indicates less than 1\%; - indicates nil)

Half of the artists in the survey had a (median) creative income of less than $\$ 7,300$ (Australian dollars; financial year 2001-02). The familiar distribution of artists' creative incomes with many low incomes and few high incomes resulted in a (mean) creative income of just over $\$ 17,000$.
The median income from all income sources was less than $\$ 30,000$, compared to $\$ 43,700$ for full and part-time ('main job') employees classified as 'professional', and $\$ 54,500$ for occupations classified as 'managerial/administrative'. 
Pew study: American artists, musicians and the Internet (2004)

A study conducted in 2004 by the Pew Internet \& American Life Project tried to capture 'how artists and musicians use the internet, what they think about copyright issues, and how they feel about online file-sharing'. ${ }^{93}$ The study focuses on artists' attitudes and does not provide systematic data on the relative weight of copyright and non-copyright earnings. However, among three instruments, the study includes a web survey of 2,755 selfdeclared musicians that divides the sample into four useful profile groups:

(1) Success Stories (musicians who spend 30 or more hours per week in music-related activities, drawing 80 per cent or more of their income from music);

(2) Starving Musicians (also spending 30 or more hours per week but earning less than 20 per cent of their total income from music);

(3) Part-timers (spending less than 30 hours per week but earning some income from music); and

(4) Non-working Musicians (currently inactive, including aspiring and formerly active musicians not earning money from music).

The numbers of PEW respondents falling into these respective groups were: Success Stories: 296 (10.7\%); Starving Musicians: 1,021 (37\%); Part-timers: 578 (21\%); Non-working Musicians: 851 (30.9\%). $78 \%$ of respondents had a second job, while $41 \%$ earned less than $20 \%$ of their income from music-related activities.

\section{Study of self-employed German authors and artists (2006)}

A more recent study of self-employed artists in Germany uses a conceptual approach developed in the entrepreneurship literature. Artists are treated as micro-entrepreneurs who, typically, do not separate business and household finances. Three categories of self-employment are distinguished: (i) main self-employed occupation defined as the activity with the highest income; (ii) additional self-employed occupation - defined as the only activity of artists who are not otherwise part of the workforce (e.g. students, pensioners, housewives/husbands); (iii) part-time additional self-employment (i.e. as a second job).

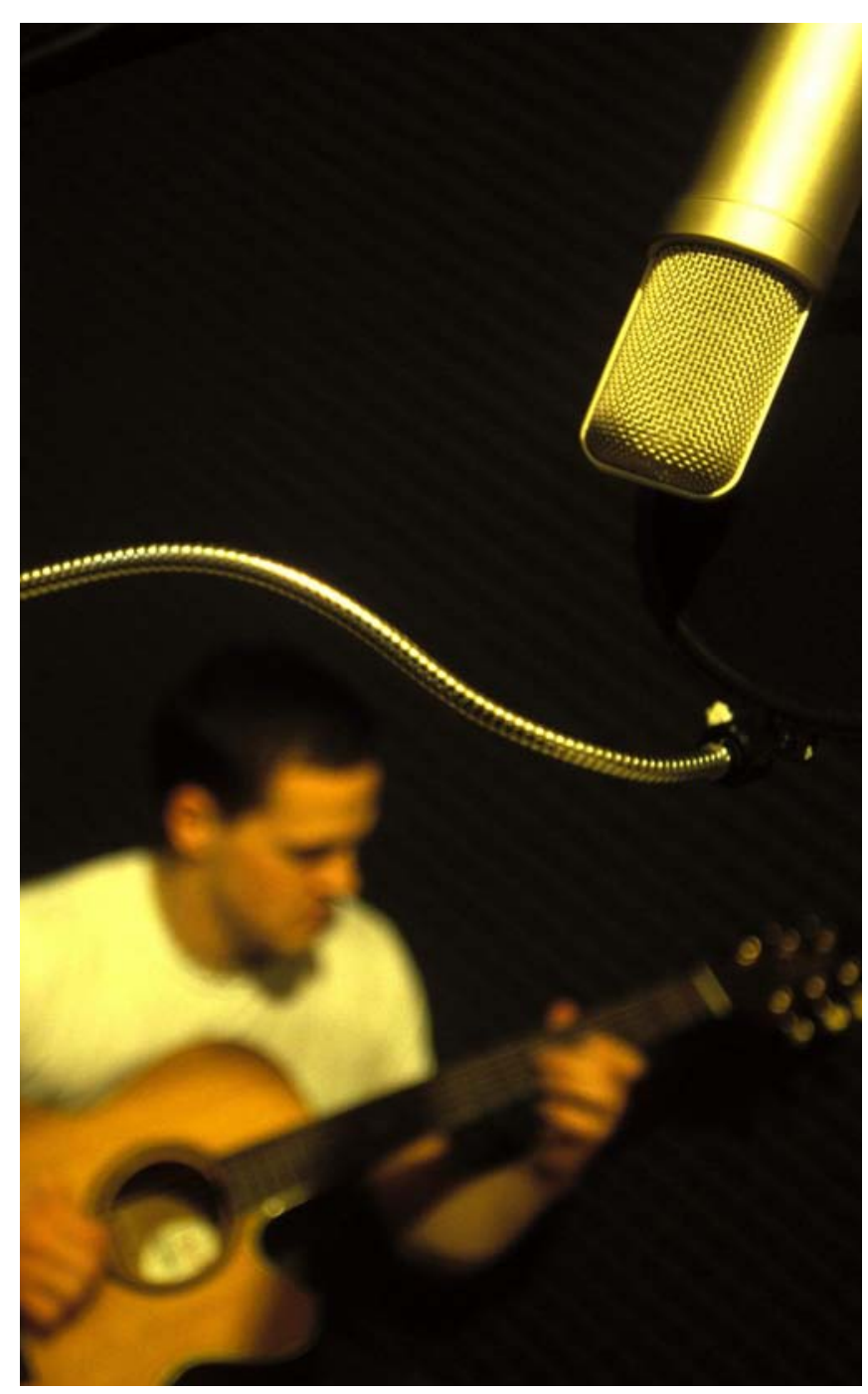

Pew Internet \& American Life Project (2004), Artists, Musicians and the Internet (researcher Mary Madden), Washington, DC, p. ii.

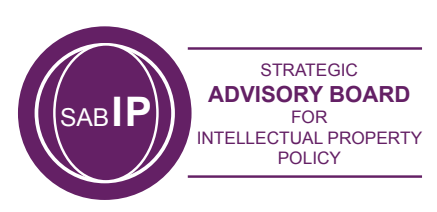


Table: Artistic self-employment as main, additional or part-time occupation

\begin{tabular}{|l|c|c|c|c|c|c|}
\hline \multirow{2}{*}{$\begin{array}{c}\text { Occupational } \\
\text { group }\end{array}$} & \multicolumn{3}{|c|}{ main occupation } & \multicolumn{2}{c|}{ additional occupation } & \multicolumn{2}{c|}{$\begin{array}{c}\text { part-time } \\
\text { (2nd job) }\end{array}$} \\
\cline { 2 - 7 } & number & $\%$ & number & $\%$ & number & $\%$ \\
\hline Music & 70 & 70.7 & 14 & 14.1 & 15 & 15.2 \\
\hline Literature & 92 & 65.2 & 20 & 14.2 & 29 & 10.6 \\
\hline Visual arts & 79 & 65.3 & 18 & 14.9 & 24 & 19.8 \\
\hline Performing arts & 36 & 64.3 & 11 & 19.6 & 9 & 16.1 \\
\hline Total & 277 & 66.4 & 63 & 15.1 & 77 & 18.5 \\
\hline
\end{tabular}

A questionnaire survey of 5,745 self-employed artists on the database of the media union (Vereinte Dienstleistungsgewerkschaft - sector art and culture) finds that for $66 \%$, artistic selfemployment is the main occupation. The figures for respondents in four occupational groups are presented in the table above. ${ }^{94}$

The contribution of self-employed artistic earnings to total household earnings from all sources (including partner's income) is given as $42 \%$ (literature), 42\% (visual arts), 53\% (music) and $67 \%$ (performing arts). ${ }^{95}$ Between $70 \%$ and $80 \%$ of respondents had previously been in employed occupations, and more than $50 \%$ of respondents had continued their employed and/or pre-artistic occupation at least for a time. For $40-60 \%$ of artists there had been prolonged periods when self-employed creative activity had been interrupted (sometimes for years). Both figures can be explained to a large extent by a need to balance the household income.

\section{ALCS survey 2007}

In our comparative survey of 25,000 British and German literary authors, Kretschmer and Hardwick (2007) find that most writers supplement their income from other sources, such as a second job, or household earnings contributed by a partner. We captured this data by asking separate questions for income from writing, total individual income and total household income. The data show that only $20.3 \%$ of UK writers earn all their income from writing. For cross-country comparison, we used the category of professional authors. $60 \%$ of professional writers hold down a second job, both in Germany and the UK.

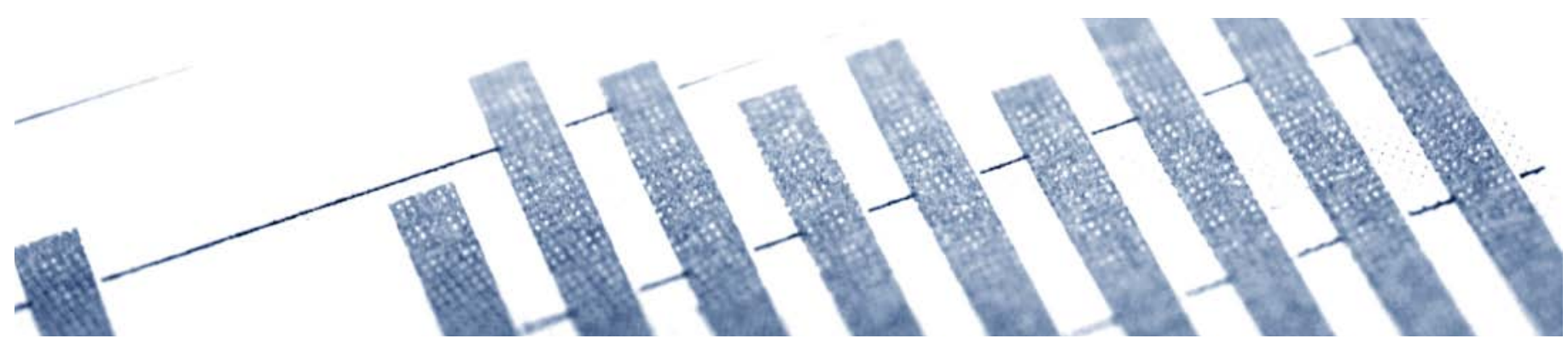
brotloser Kunst and freiem Unternehmertum?, Bonn: Deutscher Kulturrat, p. 17. 
Table: How many professional authors can live from writing alone?

\begin{tabular}{|c|c|c|c|}
\hline $\begin{array}{c}\text { Percentage of UK professional authors } \\
\text { for whom writing income contributes: }\end{array}$ & $\%$ of authors & $\begin{array}{c}\text { Mean writing } \\
\text { income }\end{array}$ & $\begin{array}{c}\text { Median writing } \\
\text { income }\end{array}$ \\
\hline More than $50 \%$ of total individual income & 59.6 & $£ 41,186$ & $£ 23,000$ \\
\hline More than $75 \%$ of total individual income & 48.4 & $£ 48,101$ & $£ 26,500$ \\
\hline More than $90 \%$ of total individual income & 42.8 & $£ 50,090$ & $£ 27,696$ \\
\hline $100 \%$ of total individual income & 40.0 & $£ 49,542$ & $£ 27,500$ \\
\hline
\end{tabular}

\begin{tabular}{|c|c|c|c|}
\hline $\begin{array}{c}\text { Percentage of German authors for whom } \\
\text { writing income contributes: }\end{array}$ & \% of authors & $\begin{array}{c}\text { Mean writing } \\
\text { income }\end{array}$ & $\begin{array}{c}\text { Median writing } \\
\text { income }\end{array}$ \\
\hline More than $50 \%$ of total individual income & 63.1 & $\begin{array}{c}€ 27,544 \\
(£ 19,005)\end{array}$ & $\begin{array}{c}€ 20,000 \\
(£ 13,800)\end{array}$ \\
\hline More than $75 \%$ of total individual income & 52.9 & $\begin{array}{c}€ 29,225 \\
(£ 20,165)\end{array}$ & $\begin{array}{c}€ 20,000 \\
(£ 13,800)\end{array}$ \\
\hline More than $90 \%$ of total individual income & 45.5 & $\begin{array}{c}€ 30,287 \\
(£ 20,898)\end{array}$ & $\begin{array}{c}€ 20,000 \\
(£ 13,800)\end{array}$ \\
\hline $100 \%$ of total individual income & 40.1 & $\begin{array}{c}€ 29,475 \\
(£ 20,337)\end{array}$ & $\begin{array}{c}€ 20,000 \\
(£ 13,800)\end{array}$ \\
\hline
\end{tabular}

It is striking that the typical (median) earnings do not increase in line with the percentage of income derived from writing. This suggests that many authors are not only motivated by money, as their income does not increase with their effort (an effect common to the population of writers both in Germany and the UK). However, German authors are prepared to devote more than $50 \%$ of their time to writing at a much lower mean and median income than UK authors. In other words, the hurdle to being a professional author appears to be lower in Germany.

As the income of authors is uncertain and highly skewed (reflecting the winner-take-all characteristics of cultural markets), non-copyright income sources are important to writers. It appears that risk mitigation is an important effect of these other sources of earnings. For UK professional authors the Gini Coefficient for writing income is $\mathbf{0 . 6 3}$, for total individual income it is 0.51 , and for total household income it is 0.47 . For German professional authors, the Gini Coefficient is 0.52 , for total individual income it is 0.43 , and for total household income it is 0.42 .

The distribution of income for collecting society payments (which follows actual use) is even more skewed than writing income. This suggests that writers' contracts (which often include advances) may already contribute to risk mitigation. 
Table: Contribution to household earnings by UK professional writers (2004-5)

\begin{tabular}{|l|l|l|l|}
\hline \multicolumn{1}{|c|}{ UK professional writers } & Writing income & Individual income & Household income \\
\hline Valid responses & 525 & 514 & 501 \\
\hline Mean (£) & 28,340 & 41,017 & 55,620 \\
\hline Median (£) & 12,330 & 25,337 & 37,000 \\
\hline Coefficient of Variation (\%) & 204.9 & 146.4 & 115.1 \\
\hline GINI COEFFICIENT & 0.63 & 0.51 & 0.47 \\
\hline
\end{tabular}

Table: Contribution to household earnings by German professional writers (2005)

\begin{tabular}{|l|l|l|l|}
\hline \multicolumn{1}{|c|}{ German professional writers } & \multicolumn{1}{c|}{ Writing income } & Individual income & Household income \\
\hline Valid responses & 169 & 168 & 164 \\
\hline Mean $(£)$ & $\begin{array}{l}20,113 \\
(£ 13,878)\end{array}$ & $\begin{array}{l}27,913 \\
(£ 19,260)\end{array}$ & $\begin{array}{l}41,644 \\
(£ 28,734)\end{array}$ \\
\hline Median $(£)$ & $\begin{array}{l}12,000 \\
(£ 8,280)\end{array}$ & $\begin{array}{l}21,000 \\
(£ 14,490)\end{array}$ & $\begin{array}{l}30,000 \\
(£ 20,700)\end{array}$ \\
\hline Coefficient of Variation $(\%)$ & 132.7 & 96.4 & 87.7 \\
\hline GINI COEFFICIENT & 0.52 & 0.43 & 0.42 \\
\hline
\end{tabular}

The typical UK professional writer contributes $33 \%$ to the income of his/her household. The typical German professional writer contributes $40 \%$ to the income of his/her household. Taking account of these other sources of individual and household income, writers and their families earn well above the national average. UK writers' households earn almost double the amount of their German counterparts.
Summary: The picture that emerges in this subsection from the previous empirical studies of artists' occupational profiles reveals risky, often stuttering careers. Earnings from non-copyright, and even non-artistic activities are an important source of income for most creators. Many more creators attempt to embark on artistic careers than are able to sustain them. 


\subsection{THE 'HARMONY OF INTERESTS' ASSUMPTION}

In the light of the review of empirical data on artists' earnings, what can be said about the role of copyright contracts in rewarding artists and authors? Paul Goldstein argues: ${ }^{96}$

Mostly ... copyright is about money. It can cost a lot to conceive, execute, produce, and market a creative work. The right to stop the copying of a work implies the power to allow it - at a price - and prospective copyright owners usually rely on the hope of eventual copyright revenues to repay their initial investment. A songwriter assigns the copyright in a song to a music publisher, for example, in return for the promise of royalties paid on each copy sold or performed. The publisher sells a film company the right to use the song in a movie sound track, again in return for a share of anticipated profits. Only the market place will determine whether a work has commercial value. But if the work has commercial value, copyright's aim is to put that value into the owner's pocket.

The argument needs to be made more precise. Is the proposition that authors earn a living by allowing copying 'at a price' simply a version of the incentive justification of copyright (see Paper 1)? As the costs of conceiving, executing, producing and marketing creative works will be above the costs of copying, creative production would not take place without the incentive of artificial scarcity that copyright law provides.
'The resulting difference between price and marginal cost, summed over the number of copies sold, will generate revenues to offset the cost of expression. ${ }^{97}$

Although, under copyright law, the first owner of a work is usually the author, in practice most works are owned by a third party specialising in commercial exploitation, such as a publisher or producer. Under the orthodox economic analysis, this distinction does not matter. According to Landes and Posner, any legal or institutional devices that limit the assignability of copyright 'reduce the incentive to create by preventing the author or artist from shifting risk to the publisher or dealer'; if 'future speculative gains' must be shared, the author will be paid less. ${ }^{98}$

In 1841, Macaulay had put the same point rather differently: 'I say, therefore, that, from the very nature of literary property, it will almost always pass away from an author's family; and I say, that the price given for it to the family will bear a small proportion to the tax which the purchaser, if his speculation turns out well, will in the course a long series of years levy on the public.' ${ }^{\prime 9}$

P. Goldstein (2003 [1994]), Copyright's Highway: From Gutenberg to the Celestial Jukebox, Stanford: Stanford UP, at 4.

W. Landes and R. Posner (1989), 'An Economic Analysis of Copyright Law', Journal of Legal Studies 18: 325-366, at 327. The article contains the best-known formal expression of the incentive argument.

Ibid. at 327. In their 2003 chapter 'The Optimal Duration of Copyrights and Trademarks' (in The Economic Structure of Intellectual Property Law, Harvard UP), Landes and Posner go even further, arguing for a transferable perpetual copyright term from Congestion Externalities (without copyright, works may become over-used) and Maintenance Incentives (for example, to invest in works that may be brought back in use after the current term has expired). The theory does not sit easily with empirical data: Paul Heald (2008), 'Testing the Over- and Under-Exploitation Hypotheses: Bestselling musical compositions (1913-32) and their use in cinema (1968-2007)', paper presented at Annual Congress of the Society for Economic Research on Copyright Issues (SERCI), Geneva, July 10-11, 2008 (available at http://papers.ssrn.com). 
The 'harmony of interests' assumption can be assessed through the empirical data reviewed in this paper. The poor median earnings of authors and artists, combined with frequent interruptions to income from the principal artistic activity and multiple job-holdings indicate an oversupply in the labour market. ${ }^{100}$

On the demand side, the extremely skewed distribution of earnings suggests that cultural markets are subject to so-called 'winner-takeall' effects. These have been first analysed in the economics of superstars. According to these models, in certain markets small differences in perceived 'relative performance' become magnified. ${ }^{101}$

The information process determining consumption may even lead to a totally random selection of talent. ${ }^{102}$

The combined forces of an oversupply of creative ambitions and 'winner-take-all' demand patterns appear to have two main effects on copyright contracting -
1. Since many more products want to enter the market than can be consumed, there is an important role for the commercial intermediary, acting as selector or gatekeeper. ${ }^{103}$ Publishers, record companies, promoters, broadcasters, galleries or clubs will play this role for different markets. The bargaining power of artists early in their career is therefore weak.

2. Despite ever more sophisticated marketing efforts, commercial intermediaries have been unable to predict demand patterns in winner-take-all markets. Nobody knows the next hit. Only a small percentage of releases will repay their initial investment. ${ }^{104}$ Market intermediaries tend to favour known artists with a track record. The bargaining power of consistently successful artists is therefore high.

Thus Landes and Posner's 'harmony of interests' argument appears plausible for bestselling artists. They may rationally decide if they want to shift the risk for their next release to a commercial intermediary. Similarly, publishers or producers may rationally wish to share the risk through royalty contracts, or acquire the risk through a buy-out.

100 This point is frequently made by cultural economists: D. Throsby (2001), Economics and Culture, Cambridge: CUP, p. 121.

101 R.H. Frank and P.J. Cook, The Winner-Take-All Society (New York: Free Press, 1995). Sherwin Rosen characterises artistic labour markets as lotteries ('The Theory of Equalizing Differences', pp. 641-92 in O. Ashenfelter and R. Layard (eds.), Handbook of Labour Economics (vol. 2), Amsterdam: North-Holland, 1985).

102 According to Adler, information costs lead consumers to choose, in a mimetic process, what other people have already selected: Adler, M. (1985), 'Stardom and Talent', American Economic Review 75: 208-12. For a sociological analysis of the value consumers derive from other people's consumption, see Kretschmer, M., G.M. Klimis, C.J. Choi (1999), 'Increasing Returns and Social Contagion in Cultural Industries', British Journal of Management 10, S61-S72.

103 The gatekeeper concept is developed in Hirsch, P. (1972), 'Processing Fads and Fashions: An Organisation Set Analysis of Cultural Industry Systems', American Journal of Sociology 77/4: 639-670.

104 For the music industry, the ratio is about 1:10 - Kretschmer, M., G.M. Klimis and R. Wallis (2001), 'Music in electronic markets: An empirical study', New Media and Society 3/4: 417-441. The 'nobody knows' doctrine is expounded in Caves, R.E. (2000), Creative Industries: Contracts between Arts and Commerce, Cambridge, MA: Harvard UP.

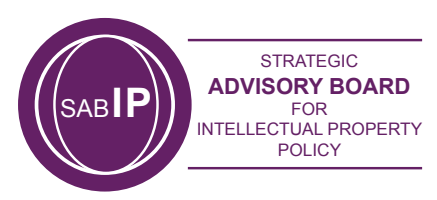


How about the wider community of nonbestselling creators? In which way do copyright contracts incentivise and remunerate these authors and artists?

\subsubsection{What follows from winner-takes- all?}

The evidence reviewed in this paper reveals that the distribution of earnings linked to copyright is highly skewed. For the payments of collecting societies (which reflect actual use of copyright works), the top $10 \%$ of authors receive 60 $90 \%$ of total income. For self-employed income from writing (which may include non-copyright payments, such as time-sensitive commissions, grants, or live events), the top $10 \%$ of authors receive about $40-70 \%$ of total income. Only in supplementing their earnings from non-copyright and non-artistic sources (e.g. second job, partner's income), does the measure of inequality for artists begin to approximate that of many other occupations - albeit at a lower median and mean.

Two arguments can be found for why a winnertake-all distribution of copyright earnings does not conflict with the aims of copyright law to provide an efficient incentive for the creation and distribution of culture.

Argument (1):

\section{The market picks the winner. Copyright law must not presume cultural judgment.}

Under this argument, 'best' means 'bestselling', and bestselling titles are indeed the only ones copyright law is meant to incentivise and reward. Interestingly, exponents of the author rhetoric rarely make this point. This may be because bestsellers include a large share of industrial products (such as singles tied in to populist TV shows, or ghosted autobiographies). It is evident that much that is culturally worthwhile is not reaching, and will never reach, the charts. To admit that much, however, would concede that diversity of cultural production, and support for niche communities is not an aim of copyright law. In turn, this would open the door to arguments treating copyright law as a patent law for industrial cultural production (with a much shorter term of protection).

A second argument insists that copyright law does not only foster bestsellers. Wider cultural aims are served by offering prospects of high earnings to all potential creators:

Argument (2):

Creators are risk takers. Without the prospects of potential superstar earnings, nobody would become an author or artist.

In the literature, attention has been drawn to the puzzle of an intrinsic motivation that seems to drive many authors and artists (at variance with economic premises). ${ }^{105}$ It is unlikely that artistic production by lower earning creators would cease without the incentive of copyright royalties from a possible bestseller. In addition, many developed countries provide non-copyright support for culture as a matter of public policy, be it through broadcasting licence fees, grants, tax incentives or social security benefits. Still, the prospect of financial success appears to be a significant motivation for many emerging artists. The oversupply of creators, and the resulting failure of many authors and artists to make a sustainable living, may be simply due to an overestimation of their chances of success.

Cf. B.S. Frey (1997), Not Just For the Money: An Economic Theory of Personal Motivation, Cheltenham: Edward Elgar; R. Towse (2001), 'Partly for the Money: Rewards and Incentives to Artists', KYKLOS, 54(2/3): 473 - 490. For literary production, see W. St Clair (2004), The Reading Nation in the Romantic Period, Cambridge: Cambridge University Press. Kretschmer suggests, drawing on eight in-depth interviews with mid-level artists in the music sector, that creators have four main interests: to see their work widely reproduced and distributed; to receive credit for it; to earn a financial reward relative to the commercial value of the work; and to be able to engage creatively with other works (in adaptation, comment, sampling etc): M. Kretschmer (2005), 'Artists' Earnings and Copyright: A review of British and German music industry data in the context of digital technologies', First Monday 10/1 (January): pp. 1-20.

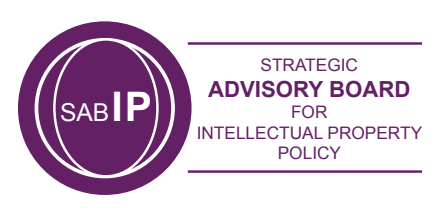


The implications of this position could be summarised thus: although, empirically, copyright contracts do not secure the remuneration of the population of artists and authors, as an incentive they ensure that creative production does take place.

It appears that in many countries the legislator has not been satisfied that an incentive that appears to be based on a systematic cognitive mistake (namely an overestimation of likely success) can be the end of the matter. ${ }^{106}$ In the jurisdictions reviewed, there are specific formalities associated with copyright contracts, and a number of other provisions that intervene in the contractual freedom of parties with the aim to improve the financial position of authors.

\subsection{THE REGULATION OF COPYRIGHT CONTRACTS}

The characteristics of contracts over the exploitation of copyright works will be analysed under the following headings.

\section{- Ownership}

- Specific contract formalities

- Scope of the rights transferred

- Rights to remuneration

- Effects on third parties

- Provisions relating to the revision and termination of contracts

- $\quad$ General doctrine relating to unfair contracts
The comparative international survey of legal provisions draws on the work of Guibault and Hugenholtz (2002), Bently (2002) and LucasSchloetter (2004). Rather than analysing doctrine in detail, for the purposes of this review we aim (i) to summarise a range of regulatory options, (ii) to survey the empirical evidence on their effects.

\subsubsection{Ownership}

Under the so-called 'creator doctrine' (underlying the concept of literary and artistic works in the Berne Convention), the initial owner of the copyright in a work is the natural person who created it. However, in all countries there are certain ownership rules and assumptions for specific, more entrepreneurial kinds of work, and for works created under employment. ${ }^{107}$

From an economic perspective, it is not initial ownership but transferability that matters. It may be useful to illustrate briefly the UK position for works created under employment, commissioned works and moral rights.

\section{Creation under employment}

Under section 11(2) of the Copyright, Designs and Patents Act (CDPA) 1988, for work made "by an employee in the course of his employment, his employer is the first owner'. The language preserves earlier case law.

\section{In Stevenson Jordan v. MacDonald \& Evans} [1953] 69 RPC 10, an employed accountant who gave public lectures on budgetary controls could not be ordered to prepare lectures. The employee owned the copyright.

106 There can be more fundamental doubts about the efficiency of the copyright system. New empirical data appear to show (E. Höffner, Das Urheberrecht: Eine historische und ökonomische Analyse, Munich: VEW Verlag, forthcoming 2010) that in Germany, authors' salaries increased quite dramatically during the rapid growth of the reprinting industry (from around 1770). The introduction of a federal copyright in 1837 appears to have caused a drop in remuneration (cf. Directive for reciprocal copyright protection within the German Confederation (1837), in Primary Sources on Copyright (1450-1900), eds L. Bently \& M. Kretschmer, www.copyrighthistory.org). A possible explanation is that an increase in demand due to stronger competition and lower consumer prices in a non-copyright environment may increase the bargaining power of authors. It also has been suggested that the concentration of back catalogues of rights in an oligopolistic industry structure is an unintended effect of copyright law, creating a barrier to entry for new firms and artists: P. Tschmuck (2009), 'Copyright, Contracts and Music Production', Information, Communication and Society 12(2): 251-266.

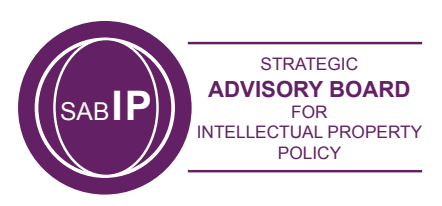


In Missing Link Software v. Magee [1989] FSR 361 , a programmer was employed to write programs of the disputed kind: even though a program was produced outside working hours on the employee's own equipment, the employer owned copyright.

In Noah v. Shuba [1991] FSR 14, a consultant created copyright material in the course of employment (in this case by the NHS). Still, the court implied a term that the employee owned because it was customary for the employee by assigns copyright to publisher and/or collects royalties.

Indicators that inform assessment of employer ownership include the contractual scope of employment, level of responsibility, creation in work time, using work resources (equipment) and the financial risks taken by the employee.

\section{Commissioned works}

For commissioned work, the default ownership remains with the creator. In Robin Ray v. Classic FM [1998] FSR 622, a consultant produced a database of recordings under commission. An implied licence to Classic FM was inferred but not for subsequent exploitation abroad.

\section{Moral rights}

Article 6bis of the Berne Convention (1928 Rome revision) states:

'Independently of the author's economic rights and even after the transfer of the said rights, the author shall have the right to claim authorship of the work and to object to any distortion, mutilation or other modification of, or other derogatory action in relation to, the said work, which would be prejudicial to his honour or reputation.' 108
These so-called 'paternity' and 'integrity' rights are also known as droit moral from their roots in 19th century French case law.

The UK gave formal recognition with the Copyright, Designs and Patents Act (CDPA) 1988. The main provisions are the right to be identified as author or director (ss 77-79), and the right to object to derogatory treatment (ss 80-83).

However, there are extensive exceptions (ss 79 and 81) for computer programs, newspapers, reference works and works produced under employment. Moral rights can be waived (s 87: 'any of those rights may be waived by instrument in writing'). Moral rights can fail for lack of assertion (s 77(1): right to be identified 'is not infringed unless it has been asserted in accordance with section 78').

If moral rights could not be waived (and it is the intention of the Berne provisions that they persist 'after the transfer' of the economic rights) they would have the effect of an automatic term written into any exploitation contract. In most civil law countries (e.g. Belgium, France, Germany) moral rights are inalienable. ${ }^{109}$

\subsubsection{Specific contract formalities}

Many countries regulate the formalities of copyright contracts. In the UK, copyright is transmissible by assignment, by testamentary disposition or by operation of law, as personal or moveable property (CDPA s. 90(1)). However, an 'assignment of copyright is not effective unless it is in writing...' (s. 90(3)). ${ }^{110}$

\footnotetext{
108 Under Berne Convention Article 5, '[t]he enjoyment and the exercise of these rights shall not be subject to any formality'. The UK legislation arguably does not comply: Ginsburg, J.C. (1990), 'Moral Rights in a Common Law System', Entertainment Law Review 121.
}

109 Some countries have also non-Berne disclosure and retraction rights that derive from personality interests: le droit de divulgation (France): right to decide whether at all, when and how to release a work to the public; le droit de repentir (France, Germany: Rückrufungsrecht, Italy, Spain): right to withdraw work from circulation. 
Griggs v. Evans [2003] EWHC 2914 (Ch) (Doc Martens case): a commissioner may achieve equitable ownership (commissioned logo = artistic work) despite failure to obtain assignment (legal title) 'if the Client needs in addition to the right to use the copyright works the right to exclude the Contractor from using the work and the ability to enforce the copyright against third parties' (at 35, citing Lightman $\mathrm{J}$ in Robin Ray v. Classic FM [1998] FSR 622).

Requirements of form may offer an encouragement to negotiate. However, the issues are similar to those for shrink-wrap, click-wrap and browse-wrap licences where non-negotiable terms are standard practice (see discussion in Paper 3). According to Guibault and Hugenholtz (2002, p. 32), the copyright legislations of Austria, Denmark, Finland and Sweden contain no requirement of form, and thus appear to allow oral transfer of rights (as does the United States).

\subsubsection{Scope of the rights transferred}

Many civil law jurisdictions have either by statute or through case law developed doctrine on the interpretation of copyright contracts. An example of the statutory approach is Germany's Zweckübertragungstheorie ('theory of the purpose of transfer') under which author contracts have to specify uses to which a work is put (§31(5) UrhG). Uses not envisaged by the parties at the time of the contract traditionally remained outside the scope of contract (i.e. the rights were retained by the author). Under the new Urhebervertragsrecht of 2002, authors can now transfer rights to yet unknown exploitations but subject to fair or equitable compensation (angemessene Beteiligung). ${ }^{111}$
Under the legislation of several European states (e.g. Belgium, France), copyright contracts must specify the duration, place of exercise, and the amount of remuneration for each of the rights transferred.

UK law does not have any special principles applying to the interpretation of copyright contracts, and recognises 'global' assignments of rights (i.e. for all jurisdictions, all uses etc). In line with general principles on the interpretation of contract, copyright licences do not extend to uses not contemplated at the time of the contract. Non-expressed licences can only be implied if necessary to regulate the rights of the parties at the time of the contract. For example, in Robin Ray v Classic FM [1998] FSR 622, Ray's consultancy agreement for creating a database for use in the UK did not imply a licence for foreign radio stations to exploit the database. Similarly, in Grisbrook v. MGN ${ }^{112}$ Mirror Group Newspapers was held to infringe copyright in photographs supplied under a licence for print publishing by marketing back editions containing these photographs through a website.

$\S 31(5)$ UrhG also specifies: 'If the types of use to which the exploitation right extends have not been specifically designated when the right was granted, the scope of the exploitation right shall be determined in accordance with the purpose envisaged in making the grant. Appropriate factors to consider for the question of whether a right to use is granted are whether it concerns a simple or exclusive right to use, the extent of the right to use and the right to prohibit, and what restrictions affect the right to use.' the copyright owner's statutory rights. It must therefore be for the defendant to justify (absent any express agreement) the basis for extending the licence to cover what would be otherwise separate acts of infringement.' 
In the United States and Canada, there has been high profile litigation regarding the interpretation of contracts of freelance journalists. Did assignments from the analogue era envisage the transfer of rights for digital exploitation? In the case of Robertson $v$. Thomson ${ }^{113}$, the Canadian Supreme Court implied a permission for CD-ROM re-publication of articles by the commissioning newspaper (but not database exploitation), and affirmed the primacy of contract (thus allowing global assignments in the future). In Tasini v New York Times ${ }^{114}$ again the newspaper had engaged free-lance journalists under oral contracts that did not contemplate electronic publication. The US Supreme Court held that the New York Times could not license on back issues of the newspaper for inclusion in electronic databases such as LexisNexis.

\subsubsection{Rights to remuneration}

A right to remuneration can either be introduced as a direct regulation of contract terms, or through rights that will be exercised by collecting societies (either voluntary or by statute).

\section{Collecting societies}

As discussed in paper 1, copyright collecting societies are often seen as operating for the benefits of right holders only: Where the transaction costs of individual licensing are too high, it appears advantageous for copyright owners to inject exclusive rights into a collective organisation that monitors use, issues licenses and distributes royalties to its members. As a collectively negotiated income stream, royalty terms can also be more advantageous to authors than might be achieved in individually negotiated markets. Almost inadvertently, collective licensing may also turn out to deliver important user benefits. A radio station, for example, gets easy access to the world repertoire of music; libraries may offer generous dissemination arrangements.
In European countries, this regulatory strategy of creating statutory rights that can only be exercised by collecting societies has taken hold since the 1965 German Urheberrecht law that introduced a claim to remuneration for unauthorised private copying, compensated via a levy on copying media and equipment. Rights that can only be exercised via collecting societies under European Directives include the rental right (1992/100/EEC), the cable retransmission right (1993/83/EEC) and the resale right or droit de suite (2001/84/EC).

The behaviour of collecting societies has been challenged under European Competition Law (Arts. 81 and 82, EC = Arts. 101 and 102, TFEU), since they are joint ventures creating a superdominant market position in at least two respects: towards users and right holders. The Article 82 case law on collecting societies falls into two groups: abusive conduct towards members, and abusive conduct towards users. These will be briefly summarised.

113 Robertson v. Thomson Corp (2001) 15 CPR (4th) 147 (SCJ); (2004), 34 CPR (4th) 161 (Ont CA); 2006 SCC 43: 'Parties are, have been, and will continue to be free, to alter by contract the rights established by the Copyright Act.' 25 Robertson SCC (at 58). For commentary, see G. D’Agostino (2007), 'Canada's Robertson Ruling: Any Practical Significance for Copyright Treatment of Freelance Authors?', 2 EIPR 66.

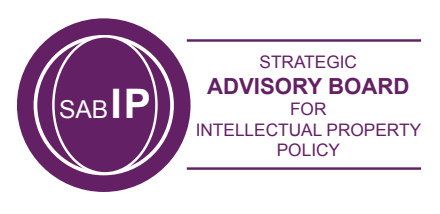




\section{Members}

- Collecting societies cannot discriminate on grounds of nationality. ${ }^{115}$

- $\quad$ There can be no preferential treatment for groups of members, but threshold conditions to full membership, and distribution variations according to genre and cultural value have been tolerated. ${ }^{116}$

- $\quad$ There must be maximum freedom for members to decide which repertoire to inject into collective administration. However, collecting societies can insist on transfer of whole groups of rights, and rights in future works if that is indispensable to the operation of the society. ${ }^{117}$

- $\quad$ Right holders must be able to withdraw from membership, and assign their repertoire elsewhere. Collecting societies can insist on lengthy notice periods. ${ }^{118}$
- Collecting societies can limit the influence of members who are economically dependent on users (i.e. if a publisher is part of the same parent company as a record label). However the least restrictive measure has to be adopted. ${ }^{119}$

- There is no specific ECJ case law on the freedom (or otherwise) of collecting societies to refuse the administration of individual rights and right-holders. ${ }^{120}$

- There is no ECJ case law on the legitimacy of socio-cultural deductions.

115 Membership and collection cannot be restricted to domestic citizens or residents (GEMA I, OJ L134/15, decision of 20 June 1971; Phil Collins v. IMTRAT Handels $\mathrm{GmbH}$ ). Foreign members (authors and publishers) cannot be excluded from participating in the governance of a society, nor from socio-cultural benefits (GVL).

GEMA II (decision of 6 July 1972, OJ L166/22). However, there is a recent policy trend requiring that royalty distribution must match actual use as closely as possible (MMC report on PRS, 1996; COM 261). There is no case law to that effect.

117 A required blanket assignment of all present and future rights was ruled to be abusive in BRT V. SABAM. In GEMA I, the Commission identified seven categories of rights members may assign separately: (1) public performance, (2) broadcasting, (3) film performance, (4) mechanical reproduction, (5) film synchronisation, (6) video reproduction and performance, (7) new categories of right. The MMC report on the PRS (1996) added for the UK the rights to live performances. A mandatory requirement to assign on-line exploitation was held to be an unfair trading condition under Art. 82(a) (Daftpunk decision, Case C2/37.219, Banghalter et Homem Christo v. SACEM, 6 August 2002). Authors also must be able to assign different groups of rights to different societies in different countries (Case 22/79, Greenwich Film Production, Paris v. SACEM, [1979] ECR 3275, [1980] 1 CMLR 629). However, collecting societies can resist cherry-picking (for example, only having those rights assigned that are expensive to administrate).

118 In GEMA II, the commission allowed a minimum membership term of three years. Retaining right for five years after a member's withdrawal is likely to be unfair (BRT V. SABAM). In the CISAC Decision (Case COM/C2/38.698 of 16 July 2008), the Commission prohibited membership clauses applied by 23 collecting societies that prevent an author from choosing or moving to another collecting society.

119 For example, conditions on the exercising of votes are acceptable, exclusions from membership are not (GEMA I). Restrictions can be imposed that strengthen a society's negotiation power toward users (SABAM, para. 9). In GEMA III (OJ L94 /12, decision of 4 December 1981), the Commission authorised the societies statutes imposing uniform effective rates of remuneration (thus preventing members from making payments to users).

120 The general Article 82 case law on refusal to supply applies (e.g. Cases 6 and 7/73, ICl and Commercial Solvents $\mathrm{V}$. Commission, [1974] ECR 223, [1974] 1CMLR 309; Magill: Cases C-241\&2/91, RTE \& ITP v. Commission [1995] ECR 1-743; [1995] 4 CMLR 586). Some national laws provide for a duty to administer rights for all nationals or residents of EU and EEA states (e.g. the German law regulating copyright societies - §6 WahrnG, so-called Wahrnehmungszwang). 
Users

- As a dominant undertaking, a collecting society cannot refuse to license a user in its own territory without a legitimate reason. ${ }^{121}$

- $\quad$ Refusal to license only part of the repertoire is acceptable if necessary for functioning of a society. ${ }^{122}$

- Excessive pricing of licences is abusive but hard to prove. ${ }^{123}$

- $\quad$ Price discrimination between large and small users has been raised as an abusive trading condition, but the Court did not rule on the point. ${ }^{124}$

- There is no ECJ case law on the nature, or lack of an appeals procedure making tariffs contestable. ${ }^{125}$

- Case law is awaited on the introduction of competition between societies. ${ }^{126}$
It appears that the European Courts accept trading conditions with respect to collecting societies that would be considered abusive in many other contexts. The main line of reasoning is a familiar principle of proportionality: restrictive conditions are justified if they are required for the society to carry out its activities on the necessary scale. Yet, there is no clarification of the function of collective administration beyond managing private interests. What are the activities that are necessary? The ECJ has tolerated, not always consistently, a number of practices relating to collective bargaining, licensing conditions and redistribution of royalties that can only be justified on social and cultural policy grounds.

Economists argue that the pie does not automatically get bigger by creating new rights. ${ }^{127}$

121 There are no specific rulings on refusal to license with respect to collecting societies. Again, the general Article 82 case law on refusal to supply applies (supra note Solvents v. Commission).

122 In the French Discothèques cases (Lucazeau, Tournier), the impracticability of setting up a monitoring system in the foreign territory was deemed an acceptable reason.

123 If tariffs in other member states are appreciably different, the collecting society needs 'to justify such a difference by reference to objective and relevant dissimilarities between copyright management' (Lucazeau, para 33). Including a mechanical fee for public performances in a discotheque is acceptable in the context of differences in national licensing systems (Case 402/85, Basset v. SACEM, [1987] ECR 1747, [1987] 3 CMLR 173).

124 In the French Discothèques cases (Lucazeau, Tournier), the appellants complained that large scale users, such as radio and TV broadcasters, obtained lower tariffs. I. A. Stamatoudi, 'The European Court's Love-Hate Relationship with Collecting Societies' (1997), European Intellectual Property Review 19(6): 289-297.

125 According to AG Jacobs in Tournier, the fact that there is no regulatory control of the price charged by a society is relevant. For discussion, see Temple Lang 1998, p. 57. Germany and the UK are the only EU countries with a formalised appeals procedure. For analyses of the jurisprudence of the UK Copyright Tribunal, see W. Cornish and D. Llewelyn, Intellectual Property (6th ed.) (London: Sweet \& Maxwell 2007), sections 13-54 to 13-58; L. Bently and B. Sherman, Intellectual Property Law (3nd ed.) (Oxford: OUP, 2009), pp. 299-301.

126 In the CISAC decision (Case COM/C2/38.698 of 16 July 2008), the Commission declared territorial restrictions unlawful that prevent a collecting society from offering licences to commercial users outside their domestic territory. It was found to be a concerted practice in violation of Art. $81 \mathrm{EC}$ and Art. $53 \mathrm{EEA}$, resulting in a strict segmentation of the market on a national basis. Reciprocal representation contracts between collecting societies in effect make it impossible for commercial users to obtain pan-European licences. The Commission decision is under appeal to the General Court (formerly CFI): CISAC v. Commission, Case T-442/08. The French Discothèques cases (Lucazeau, Tournier) hinted at problems with SACEM's administrative overheads due to lack of competition, but had left the issue to national regulation.

R. Towse and M. Taylor (1998), 'The Value of Performers' Rights: An Economic Analysis', Media, Culture and Society 20(4): 631-652

Providing Government with strategic, independent and evidence-based advice on intellectual property policy.

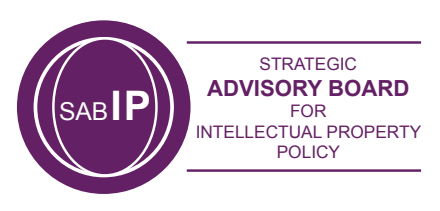


A gallery (droit de suite) or record company (rental right) may simply pay the artist or performer a lower fee to allow for further earnings arising from secondary usage. There are also considerable costs associated with the system needed to administer these rights.

Further analytic and empirical work is needed in this area. ${ }^{128}$

\section{General entitlement to equitable remuneration} The German copyright contract law of 2002 (Urhebervertragsrecht) introduced a new general entitlement to equitable remuneration (§32 - angemessene Vergütung) from any copyright contract into the Copyright Act (Urheberrechtsgesetz - UrhG). §32 was said to codify a long established principle in German copyright jurisdiction. ${ }^{129}$ Before 2002, a so-called bestseller clause (Bestseller-Paragraph) existed. It was applied in only very few cases where the courts held that the contractually agreed remuneration was 'strikingly disproportional' (in einem groben Mißverhältnis, §36 UrhG pre-2002) to the publishers' profits. The 2002 amendment extended the scope of application considerably. According to the parliamentary records, the new copyright contract law attempted to 'achieve contract parity'. ${ }^{130}$ Authors who have received a non-equitable remuneration (or no remuneration at all) are entitled to a retrospective variation of their contracts up to a level that the courts regard as common and honest practice in the trade ( $\$ 32$ (2) - üblicher- und redlicherweise) at the time the contract was concluded.
$\S 36$ of the 2002 copyright contract law provides that collectively negotiated tariffs are deemed to be equitable. However, up to 2009 it was only the writers' professional body VS (Verband der Schriftsteller, a subsection of the services union Vereinigte Dienstleistungsgewerkschaft VERDI), that succeeded in reaching an agreement on recommended tariffs (Gemeinsame Vergütungsregeln) with a number of publishers in 2005..$^{131}$

Greece imposes a minimum royalty for books sales (10\% per 1000 copies), and repeat broadcasts (50\% of original fee for first repeat). ${ }^{132}$ Other countries have so-called bestseller clauses similar to the German model that are supposed to ensure the participation of authors in disproportionate profits.

From an economic perspective, regulating the terms and conditions of copyright contracts may not lead to higher payments for authors and artists. Remuneration clauses within individual contracts are difficult to implement and monitor, and residual ties generally increase the uncertainty of investment decisions. There has been little systematic research comparing individually and collectively negotiated contracts.

The earnings data reviewed earlier in this paper indicate that the distribution of collecting societies' payments is more skewed than income from rights that are individually managed. Kretschmer and Hardwick (2007) show that, for collecting society income, the top 10 percent of writers receive right. It covers all online communications directed to the public. However, in practice no effective mandated collecting society appears to exist that may administer the right: M. Bogataj (2009), 'Mandatory collective management for making available in Slovenian Copyright Act. A mistake or an opportunity?' paper presented at the Communia Project, available at http:// communia-project.eu/downloads.

129 For decisions of BGH and Reichsgericht, see Wandtke and Bullinger (2009, p. 520). Many thanks to Dr Friedemann Kawohl for locating references on German copyright contract jurisprudence.

130 'Ausgleich der gestörten Vertragsparität'. Bundestagsdrucksache 14/6433, 2. Available at dip21.bundestag.de/dip21/ btd/14/064/1406433.pdf.

131 http://www.bmj.bund.de/enid/Urheberrecht/Gemeinsame_Verguetungsregeln_uf.html.

132 Greek Copyright Act of 1993. Articles 33-37 contain detailed remuneration rules summarised in Guibault and Hugenholtz (2002, p. 91). 


\section{PAPER 2 - CREATOR CONTRACTS}

about $60 \%$ (Germany) - 70\% (UK) of collecting society payments, while for total individual income from writing, the top 10 percent of writers account for $50 \%$ (Germany) - $60 \%$ (UK) of total wealth.

Under another economic perspective, membership in a collecting society may be conceived as analogous to joining an insurance scheme (cf. Snow and Watt, 2005). However, for risk mitigation, creators would need to agree a 'progressive' re-distribution of wealth from higher to lower earners.

\subsubsection{Effects on third parties}

In Barker v. Stickney [1919] 1 K.B. 121, the company to which copyright in Barker's book 'The Theory and Practice of Heating and Ventilation' had been transferred went into liquidation. The copyright was sold on to a third party (Stickney) who was found not to be bound to pay royalties to Barker that had been agreed in the original contract of assignment. The ruling in Barker $\mathrm{v}$. Stickney is one instantiation of the doctrine of privity of contract in English law, under which a third party cannot be burdened by a contract to which it is not a party. The rule has potentially severe consequences in an environment in which copyright assignments, and subsequent transfers to third parties, have become common. ${ }^{133}$

Across the countries reviewed there is some variation about the possibility of transferees to sell on, pledge or secure acquired rights. Generally consent of the author is required, but often that will be given in the initial contract assigning or licensing a work. The ruling in Barker v. Stickney appears to be an anomaly.

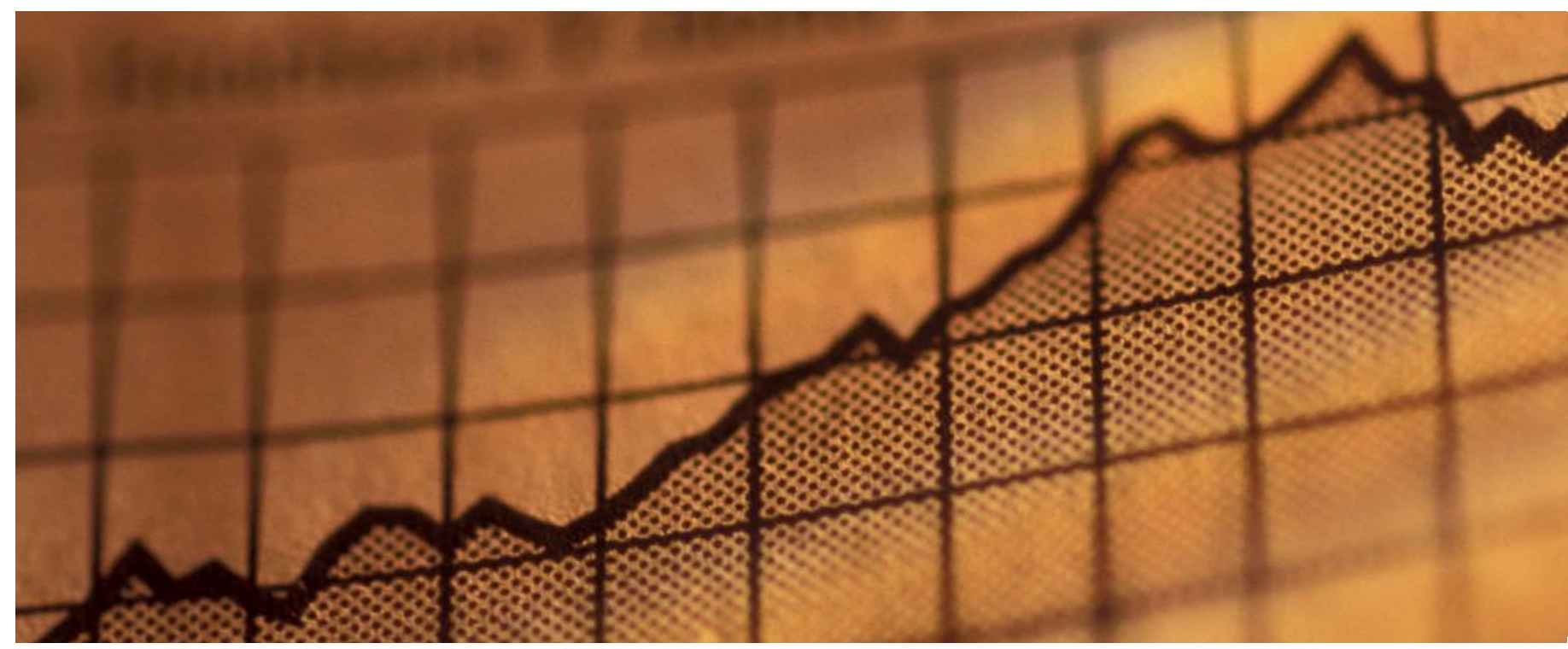

make contractual obligations in intellectual property assignments binding on subsequent owners (2009) 'Assignment and royalties don't mix', Journal of Intellectual Property Law \& Practice 4(4): 283-288.

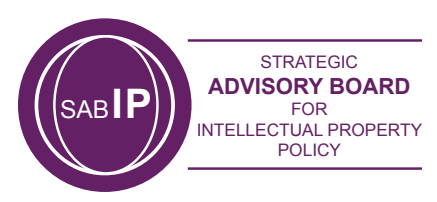




\subsubsection{Provisions relating to the revision and termination of contracts}

Common interventions by the courts include imposing duties on the assignee to promote and exploit, and presumptions in the construction of contracts (for example, regarding uses unforeseen at the time of the contract, as discussed under 2.5.3).

In the UK, the contract doctrine surfacing frequently in copyright disputes is the principle that an agreement which unreasonably restricts a person's ability to carry on his trade cannot be enforced (so-called 'restraint of trade'). ${ }^{134}$

Renewable terms that fall back to the author, or reversionary terms, dramatically increase the bargaining power for works that are still in demand after the first term has expired (or term reversion). This could be an effective way of improving the earnings of authors. Under the Statute of Anne of 1710 copyright fell back to the author after a term of 14 years, and the author could then assign it again for one further term. ${ }^{135}$ Until the 1976 Copyright Act, the United States still followed this structure, with an initial copyright term of 28 years that could be renewed once.
Under Section 304(c) of the 1976 Copyright Act, a copyright owner (or his or her heirs) can terminate all grants, licences or transfers of rights (made prior to 1978) beginning on the 56th year after that assignment was made.

Under the Italian Copyright Act (Art. 122), publishing contracts are restricted to 10 years, after which the remainder of the term reverts to the author. However, this is without prejudice to the rules governing employment contracts and contracts for services. It is unclear what effect Article 122 has in practice.

Under the Proposed Directive extending the term of protection for sound recordings, the performer may terminate the contract in the extended term if copies of the recording are no longer available online. ${ }^{136}$

134 In Schroeder Music Publishing Co. v. Macaulay [1974], 3 All ER 616, an extended term without an obligation on the publisher to exploit was held to be 'in restraint of trade'. See also Zang Tumb Tuum (ZTT) v. Johnson (Frankie Goes to Hollywood) [1993], EMLR 61; Panayiotou (George Michael) v. Sony Music Entertainment [1994], EMLR 2. In addition, contracts concluded under 'undue influence' are void: O’Sullivan v. Management Agency [1985] 3 All ER 351; Elton John v. James [1991], FSR 397. 'Restraint of trade' and 'undue influence' are both general doctrines applying to all contracts.

135 The 1814 Act extended the term to 28 years, renewable once, or life. The 1911 Copyright Act provided that under certain circumstances, copyrighted works granted to a third party revert to the author's heirs, successors, or legal representatives 25 years after the death of the author.

136 Amending Directive 2006/116/EC of the European Parliament and of the Council on the term of protection of copyright and certain related rights (proposal presented by the Commission, $\operatorname{COM}(2008) 464 / 3$ ), Article 10a (Transitional measures relating to the transposition of directive), subsection (6): If, after the moment at which, by virtue of Article 3 (1) and (2) in their version before amendment by Directive [insert: Nr. of this amending directive] EC, the performer and the phonogram producer would be no longer protected in regard of, respectively, the fixation of the performance and the phonogram, the phonogram producer ceases to offer copies of the phonogram for sale in sufficient quantity or to make it available to the public, by wire or wireless means, in such a way that members of the public may access them from a place and at a time individually chosen by them, the performer may terminate the contract on transfer or assignment. Where a phonogram contains the fixation of the performances of a plurality of performers, they may terminate their contracts on transfer or assignment only jointly. If the contract on transfer or assignment is terminated pursuant to sentences 1 or 2 , the rights of the phonogram producer in the phonogram shall expire.

Providing Government with strategic, independent and evidence-based advice on intellectual property policy.

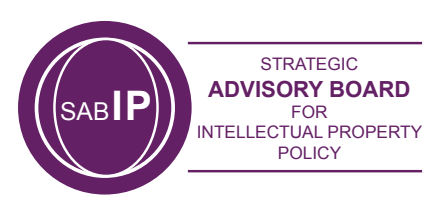


The renewed interest in bringing non-exploited works to market is also reflected in a failed amendment to the Digital Economy bill tabled by Conservative Peer Lord Lucas that proposed an 'artists' right to re-market' if a work is not available in all common current electronic formats in all geographical regions within two years after first publication, or five years after its creation, it had not been published. ${ }^{137}$

\subsubsection{General contract doctrine / Unfair contracts}

In the UK discussion, arguments have been raised that the Unfair Contract Terms Act 1977 (as amended at 1st October 2003) should be made applicable to copyright contracts.

Schedule 1 of the Section 1(2)(c) does not extend its provisions to- (c) any contract so far as it relates to the creation or transfer of a right or interest in any patent, trade mark, copyright [or design right], registered design, technical or commercial information or other intellectual property, or relates to the termination of any such right or interest;

The reason for this exclusion is unclear but in any case the language of the Unfair Contracts Terms Act is intended to protect consumers, and applies to clauses in agreements that attempt to limit liability, not to terms that create, transfer or terminate an interest in intellectual property.

Thus, parties to a copyright contract have to rely on general contract doctrine which will not normally review agreements that are otherwise lawful because they are lop-sided or 'unfair'. For further details, see Paper 3, section 3.4 'Doctrinal analysis of contract limits'. 


\subsection{CROSS-COUNTRY EMPIRICAL RESEARCH}

The only empirical attempt to investigate the effects of different legal frameworks on the earnings of creators appears to be our own survey of British and German literary and audiovisual writers (Kretschmer and Hardwick, 2007).

In Germany, moral rights (Persönlichkeitsrechte) are inalienable - in the UK, these rights can be waived. This difference in implementation is reflected in German commercial practice, which is more responsive to the author's non-economic rights. Moral rights disputes (mainly relating to being credited as the author) are more than twice as likely in Germany (24.6\% of German writers have had such a dispute, compared to $11.4 \%$ of professional UK authors).

Other findings include that about $43 \%$ of professional UK authors have succeeded in changing the terms of a contract offered in 2005 , compared to $44 \%$ in Germany. In both countries, only about $65 \%$ of professional authors take professional advice before signing a publishing or production contract.

In both countries, authors who have engaged in disputes with their publishers or producers tend to earn significantly more than their more compliant colleagues. This is likely to be a two way relationship: publishers or producers may only listen to authors with bargaining power - but equally, engaging in bargaining may increase the author's bargaining power.
Table: Writing income of professional literary authors in Germany and the UK with and without contractual changes

(a) UK (2004-5)

\begin{tabular}{|c|c|c|}
\hline $\begin{array}{c}\text { Have you } \\
\text { succeeded } \\
\text { in changing } \\
\text { the terms of } \\
\text { a contract in } \\
2005 ?\end{array}$ & $\begin{array}{c}\text { Valid } \\
\text { Responses }\end{array}$ & $\begin{array}{c}\text { Mean writing } \\
\text { income }(£)\end{array}$ \\
\hline NO & $245(57 \%)$ & 22,950 \\
\hline YES & $180(43 \%)$ & 40,507 \\
\hline t statistic & & $2.87^{* * *}$ \\
\hline
\end{tabular}

(b) Germany (2005)

\begin{tabular}{|c|c|c|}
\hline $\begin{array}{c}\text { Have you } \\
\text { succeeded } \\
\text { in changing } \\
\text { the terms of } \\
\text { a contract in } \\
\text { 2005? }\end{array}$ & $\begin{array}{c}\text { Valid } \\
\text { Responses }\end{array}$ & $\begin{array}{c}\text { Mean writing } \\
\text { income }(£)\end{array}$ \\
\hline NO & $95(56 \%)$ & 13,080 \\
\hline YES & $76(44 \%)$ & 28,964 \\
\hline t statistic & & $3.73^{* *}$ \\
\hline
\end{tabular}

Source: Kretschmer and Hardwick (2007, p. 31) 


\subsection{CONCLUSIONS}

The relationship between copyright and contract law lies at the heart of the regulatory system governing the creation and dissemination of cultural products. This is so because the exclusive statutory rights provided by copyright law only turn into financial reward, and thus incentives to creators, through a contract with someone who wants to exploit or use a protected work. Copyright law is what allows contracts to be written (i.e. defines the characteristics of the work and the property rights in the work - the contract space). Yet, it turns out that this general statement, plausible as it seems, is neither theoretically well understood, nor empirically supported.

We have robust knowledge about creators' labour markets and earnings, derived from government statistics and several independent empirical studies: artists' occupational profiles over time reveal self-employed, risky often stuttering careers. Many more creators attempt to embark on artistic careers than are able to sustain them ('oversupply'). Earnings from non-copyright, and even non-artistic activities are an important source of income for most creators. A small number of very high earners earn a disproportionate share of total income ('winner-take-all').

Copyright law will only have effects upon the contracts that are written when those contracts lie on the boundaries of the contractable space that copyright offers (see Paper 1). We don't know where these boundaries lie, and therefore the empirical role of copyright law in remuneration remains uncertain. The introduction of new rights (such as the rental right, or the droit de suite) does not automatically lead to higher earnings. A gallery (droit de suite) or record company (rental right) may simply pay the artist or performer a lower fee to allow for further earnings arising from secondary usage.
Overall, it remains an open question whether there is a negative or positive relationship between the strength of copyright protection and the total earnings of creators. We also do not know if there is a negative or positive relationship between the strength of copyright protection and the distribution of earnings of creators. Although the orthodox economic theory of copyright law assumes that there is a harmony of interests between creators and intermediaries (such as publishers and producers), much of the attempted legal regulation of copyright contracts assumes that the incentives of creators and intermediaries are not aligned.

The contractual bargaining outcomes are tilted towards bestsellers. Creators with a track record of success are able to negotiate contracts preserving their interests. For most others, in particular new entrants to the entertainment industries, assignments of rights are common.

Lord Macaulay, in his 1841 speech, had recognised only two means to remunerate authors: patronage and copyright. ${ }^{136}$ Even if we accept, with Macaulay, that neither intrinsic motivation nor accidental private wealth are sufficient to ensure the supply of a desirable mix of cultural products, (i) copyright and (ii) patronage are not the only alternatives.

The financial position of creators may also be improved (iii) as the result of collective negotiations with publishers or producers (facilitated by the professional bodies of cultural workers), (iv) as the result of regulatory public policy measures, such as a favourable tax, insurance or benefit system, ( $v$ ) by directly funding desirable products through grants, or indirectly via bodies with a public service mission (e.g. broadcasting quotas for certain contents). Options (ii), (iv) and (v) have been beyond the scope of this review. valuable books. Such men must be remunerated for their literary labour. And there are only two ways in which they can be remunerated. One of those is patronage; the other is copyright' (op. cit., p. 734).
} 


\section{APPENDIX: THE HOREN CONTRACT (1794)}

Contract signed on 28th May 1794 by J.F. Cotta, for the J.G. Cotta publishing-house, and Friedrich Schiller regarding the publication of the journal 'Die Horen' ('The Horæ').

Manuscript in the German Literature Archive (DLA)/ Schiller National Museum in Marbach, Cotta archive.

Translation by Luis Sundkvist for the digital archive project Primary Sources on Copyright (1450-1900), eds.

L. Bently \& M. Kretschmer (www.copyrighthistory.org).

\section{Contract}

Concerning the monthly literary journal, entitled 'Die Horen', which will appear under the supervision of 'Hofrat' 139 Schiller.

1. An issue of the journal will appear every month, consisting of 8 sheets, printed in German type, each page having 30 lines.

2. All essays included in it must deal with either historical or philosophical or aesthetic matters, and should also be comprehensible to the general reader.

3. It is the Editor's responsibility to ensure that each issue includes something from each of these 3 areas.

4. A small Committee of 5 members will judge the articles that are received, and in each case a majority verdict will decide whether an article is accepted for publication.

5. Neither the Committee nor the Editor have the right to make changes to the contributions received: they must instead always send them back to the author if something therein requires amendment.

6. The minimum fee is 3 louis-d'or, the maximum, 8 louis-d'or. The average fee is 5 louis-d'or. The fee for each article will be decided on by a majority vote in the Committee, except where it is already specified in the contributor's particular contract.
7. The contributors are either permanent or temporary. There must always be at least 12 permanent contributors. Each of the former will receive 3 issues of the monthly journal for free, whilst each of the latter will receive 1 free issue.

8. An article which has been published in 'Die Horen' may only be printed elsewhere after 4 years have elapsed.

9. The Publisher of 'Die Horen' has the right of first refusal of any other works written by the permanent contributors, except where they had already bound themselves by other contracts drawn up before 'Die Horen' was founded.

10. [In addition to the fees for his articles], the Editor will also receive 100 ducats extra.

11. The 4 other members of the Committee responsible for selecting articles, will each receive 10 louis-d'or extra every year for their efforts as critics.

12. Payment of the fee is due as soon as the articles are published, except where the author has arranged otherwise.

13. Postage expenses for the journal will be borne by the Publisher. 
14. Anonymous articles will not be accepted.

15. If more than 2000 copies of any month's issue of the journal are sold, the Publisher will hand over to the Editor and the Committee a third of the profits for each copy sold above this number. The Editor will receive half of this dividend, and the rest will be shared out between the Committee.

16. In the case that this enterprise should thrive and that the Publisher should wish to use part of his surplus profit to further encourage the journal's contributors, each year a Prize of, say, 30 or 50 louis-d'or may be awarded for the article which the Committee deems to be the most important of that year.

17. The names of the members who form part of the Committee are not to be disclosed, although their names will, of course, appear in the list of permanent contributors.

18. All contributors agree to use the orthographic conventions adopted by the journal.

19. Articles which contain either personal attacks or derogatory remarks on Institutions which stand in public esteem, will not be accepted by the journal.

20. If the Editor should die, the contract is to be renewed with the surviving Committee members. The articles, however, which have already been received and selected are to be paid according to the previously agreed fee.

21. If the journal should outlive the present Editor, his widow will receive 10 percent of the fees paid out to its contributors.

22. If the Publisher should die or withdraw from the journal, that which is stipulated in clause 20 regarding articles which have already been received, still holds.

23. Provided the obligation mentioned in clause 22 is fulfilled, the Publisher can cancel his participation in the journal without any notice, whereas the permanent contributors must give half a year's notice.
24. The price of the journal is 5 thaler 8 groschen (Leipzig rate) for a whole year's set of issues. Sold separately, the price of each issue is 12 groschen.

25. At the beginning of each year a list of the subscribers, including their names, will be published, unless they have arranged otherwise.

26. Payments are to be made in 'Convention'money, whereby the 'Convention' thaler is calculated at 1 Imperial thaler 8 groschen (Leipzig rate).

27. The publishing-house has to decide at the latest by the beginning of July 1795 whether it is prepared to undertake publication of the journal. Should it fail to do so by that date, the contributors who have committed themselves to the journal have the right to cancel their obligations towards the publishing-house.

28. As soon as the Cotta publishing-house agrees to bring out 'Die Horen', all articles already received by then will be judged in due order by the Committee, and those that are selected will be treated as stipulated in clauses 20 and 22.

29. As regards [our] true commitment to publish the journal, this contract comes into force only as from the day it has been signed.

Jena, 28th May 1794

J.G. Cotta publishing-house of Tübingen

J.F. Cotta Friedrich Schiller 
PAPER 3: USER CONTRACTS ('DEMAND SIDE’) ${ }^{140}$, Estelle Derclaye and Marcella Favale

\section{ABSTRACT}

A number of doctrinal concerns have been expressed regarding user contracts. To what extent do the terms of these licences depart from copyright law? Are the rights they grant to the owner broader or more restrictive? Are the entitlements of users, beneficiaries of copyright limits, hindered in some form? Whilst no comprehensive empirical study has hitherto been conducted to analyse the different types of licensing agreements deployed on the market and their impact on copyright limits, a body of theoretical legal literature exists on this issue.

This paper provides an overview of the doctrinal debate on this topic, with a particular focus on the United States, the United Kingdom, Belgium, Ireland and Portugal. The latter three countries are interesting for our discourse because they have enacted legislation protecting copyright limits from contracts, by declaring contractual clauses that override some copyright limits null and void. This literature review is not only concerned with copyright exceptions to the exclusive rights of the author, but all of copyright's limits, namely the ideaexpression dichotomy, the originality requirement, the first-sale (or exhaustion) doctrine, the extent of the economic rights and the copyright term.

The review of user contracts is organised as follows:

Section 1 examines the nature of copyright limits and their potential impact on the possibility of being contracted out in current licensing practices. It subsequently describes the legislation of the countries examined in this literature review ${ }^{141}$ that define copyright limits and exceptions, especially the provisions restricting freedom of contract. It also reviews any relevant case law.
Section 2 discusses the terms of the debate. The copyright literature is divided among a) those who believe that contracts override users' 'rights', and therefore legislators should render imperative some or all copyright limits; b) those who believe that contracts are more efficient than copyright law, and therefore we should entrust digital copyright matters to 'private ordering', c) and those who believe the entire question as being falsely posed, because contracts and copyright belong to different but complementary worlds, that act in useful synergy. This section examines all these arguments.

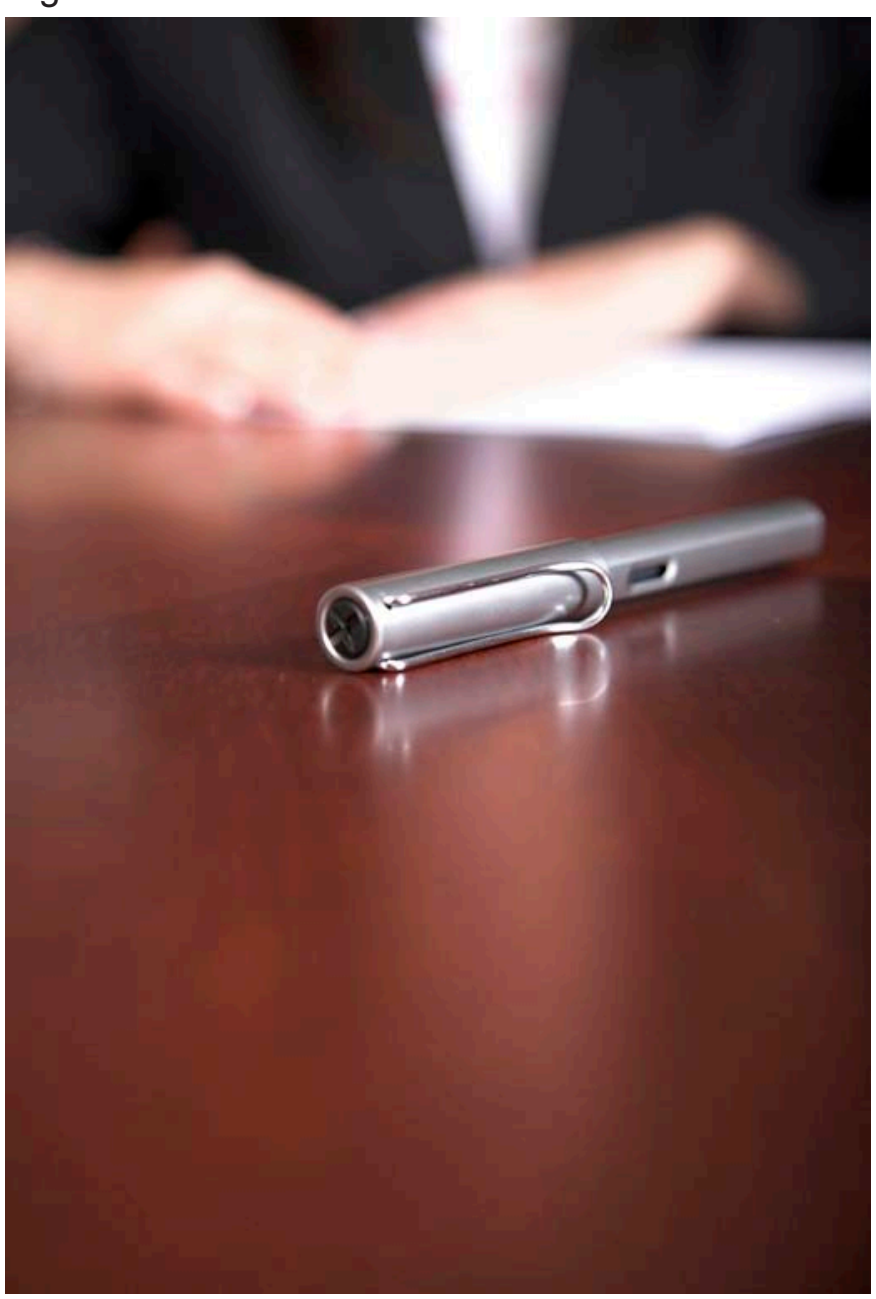

140 The authors would like to thank Professor Severine Dusollier (Belgium), Dr Patricia Akester (Portugal) and Dr John Cahir (Ireland) for the information they provided on the legal situation in their respective countries. Unless otherwise stated, the paper exclusively summarises the statutory law, the case law and the literature and does not reflect the views of the authors. The UK, the US, Belgium, Portugal, Germany and Ireland; EU legislation is considered as well. 
Section 3 reviews the types of contract currently utilised by right holders to license copyright material to users. The analysis is divided by sector of users: a) consumers (natural persons); b) libraries and universities; c) commercial users (broadcasting institutions, leisure-related businesses, audio/ video producers, etc.). This section focuses on the enforceability of electronic standard form contracts (shrink-wrap, click-wrap, browse-wrap), as opposed to arm-length agreements, and on their current and potential impact on users' privileges.

Section 4 examines the limits to freedom of contract residing within copyright law (preemption, misuse), contract law, consumer protection legislation, competition law, and constitutional principles. Current and prospective limits to contracts embedded within copyright law are also discussed in this section. The focus of the analysis is on the law of the countries examined in this literature review and on the international legislation impacting on them, from the point of view of the legal copyright literature.

Section 5 deals with Digital Rights Management (DRM) and its interplay with contracts. It considers the interaction between technological protection measures (TPMs) and end-user licence agreements. It examines the doctrine for or against a right of access of the owner, or of the user. It also briefly reviews the remedies provided to users against DRM which override copyright limits. It concludes with a comparison between contracts and TPMs. ${ }^{142}$

Section 6 identifies gaps in copyright research, either doctrinal or empirical, that may have policy implications in the regulation of the relationship of copyright (including related rights) and contract law.

\subsection{THE LIMITS OF COPYRIGHT LAW}

\subsubsection{The effects of copyright limits on contracting out}

Copyright is limited in many ways: at its outset, by the exclusion of certain works from protection (ideaexpression dichotomy and originality requirement); during its exploitation, by economic limits (limited duration and exhaustion of the distribution right) and by exceptions to the economic rights.

The requirements for protection are based on the idea-expression dichotomy and on the principle of originality. That is, copyright protects the expression of the ideas, not the ideas themselves and only a sufficiently original creation is protected. Copyright is also protected for a limited term. The copyright duration is at the basis of the general 'contract' between the author and the public, according to which authors accept a limited control on their work in exchange for exclusive rights that would grant them a fair reward for their 'sweat of the brow'. ${ }^{143}$

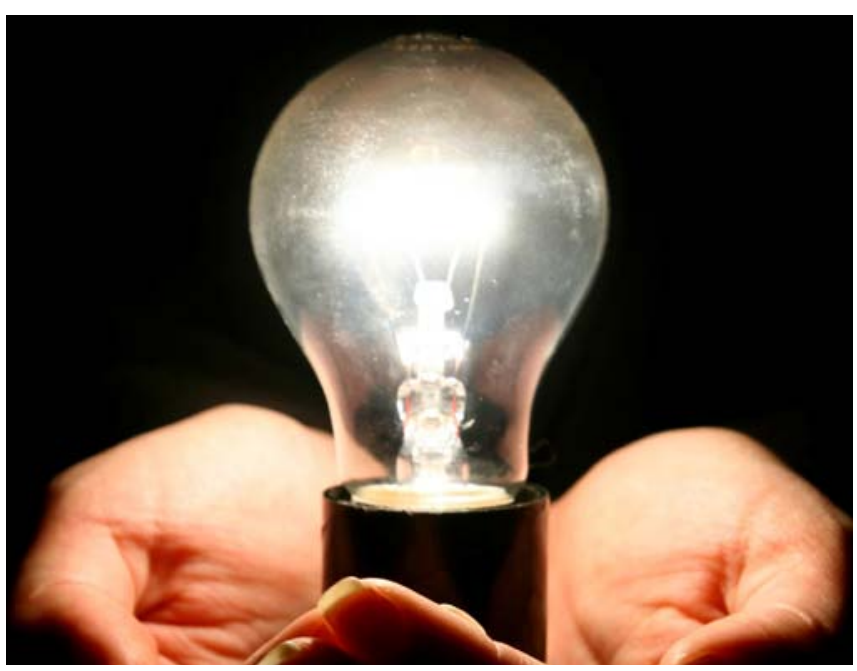

\footnotetext{
142 TPMs and DRM will be defined in section 4.5.

143 Patterson and Lindberg 1991, at 236.

144 Guibault 2002, at 15.
}

Providing Government with strategic, independent and evidence-based advice on intellectual property policy.

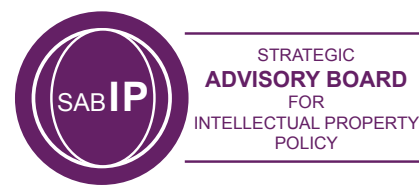


Further, once copyright products embodied in a physical object are introduced in the market in a given territory, the right holder loses control of them: they can be freely resold, lent, or given away by the purchaser. ${ }^{144}$ This is the principle of exhaustion or first sale. The rationale behind the principle of exhaustion is the preservation of the free movement of goods ${ }^{145}$ and also market failure. ${ }^{146}$ Finally, copyright exceptions are special allowances made to benefit particular categories of users such as libraries, teachers, students, researchers, and people with disabilities. All the above exclusions from copyright protection, taken as the general boundaries of copyright, are traditionally underpinned by freedom of expression and access to information or culture. ${ }^{147}$

The debate on the nature of copyright limits is extensive. Whilst some copyright exceptions like those for the purposes of parody, criticism, and news reporting, and copyright exclusions like the idea-expression dichotomy are obviously based on fundamental rights like freedom of expression, other economic limits (e.g. the first-sale principle) and some exceptions (e.g. private copying) are based on market failures.
The distinction among the underpinnings of copyright limits is however not always easy. Even copyright limits that are based on some market failures can have implications on fundamental public interests. For example, the first-sale doctrine is based on the impossibility to control the following uses of a purchased copyright work, but it also allows greater access to the work by the public, thus enhancing the circulation of culture. Moreover, some copyright literature considers the exception for private copy as supported by the fundamental right to privacy. ${ }^{148}$

The answer on the nature of copyright exceptions cannot therefore be uniform. Some European commentators have defined copyright limits not as rights but either as interests or liberties or as a 'claim to the application of a rule of objective right'. ${ }^{149}$

145 Derclaye 2008, at 185.

146 See Professor Peter Jaszi's testimony before the US Government on the Digital Millennium Copyright Act, available at http:// www.copyright.gov/reports/studies/dmca/testimony/jaszi.pdf. The first sale doctrine is based on market failure in the United States but in the EU it is also based on the principle of the free movement of goods and services.

147 This is classic copyright doctrine, underscored by some case law (Associated Newspapers v. News Group Newspapers [1986] RPC 515, and Hyde Park v. Yelland [2001] Ch. 183. See Burrell and Coleman 2005 at 20-21, although the authors state that this construct is currently discredited, at 21.

148 See Cohen 1998, at 1103-1108. See also Hugenholtz 1997.

149 Dusollier 2005a, at 486.

Providing Government with strategic, independent and evidence-based advice on intellectual property policy. 
Others claim they are 'rights' of the user, and there should be a clear definition and protection for them in copyright law. ${ }^{150}$ Similarly, in American doctrine the entitlements of the user have been sometimes qualified as 'rights', ${ }^{151}$ and sometimes as a mere remedy against market failures. ${ }^{152}$

How does the rationale behind exceptions impact on their status? For many authors, the first group of exceptions (i.e. parody, citation, private copying, criticism, news reporting), which safeguard fundamental freedoms, has a public policy character. ${ }^{153}$ In other words, such exceptions cannot be limited unless we question the principles from which they derive, and this is not possible in a democratic society. Consequently, a user cannot be forced by contract to relinquish their freedom of speech or their privacy, as contracts cannot override public policy norms. ${ }^{154}$

Similarly, commentators believe that private agreements cannot supplant the exceptions that are based on the general interest. ${ }^{155}$ However, since copyright is also an instrument at the service of the general interest, a balance should be struck between the interests of the users and those of the authors, for instance by way of an equitable remuneration to the authors. Furthermore, as these exceptions affect less fundamental principles of society, they should be imperative rules rather than public policy norms. ${ }^{156}$

The rationale underlying the exceptions based on the regulation of industry practices or on the facilitation of trade, conversely, is less strong. Exceptions based on regulatory practices could therefore be overridable. On the other hand, the decompilation exception which regulates competition has already been made mandatory in Europe, on the basis that a loyal and free competition is in the public interest. ${ }^{157}$

The exceptions exclusively founded on market failure, which therefore do not reflect a fundamental value of society or the general interest, are bound to disappear in the digital environment, as authors can now prevent the digital copying of works and enforce their copyright. Examples are the exception for ephemeral recordings made by broadcasting organisations, ${ }^{158}$ for the incidental inclusion of a work or other subject-matter in other material, ${ }^{159}$ and the exception for the use in connection with the demonstration or repair of equipments. ${ }^{160}$ In the opinion of some commentators, each Member State should be allowed to attribute a default character to these exceptions. ${ }^{161}$

\footnotetext{
150 Grosheide 2001.

151 Litman 1994.

152 Hugenholtz 1997. Merges 1993 and 2004, Bell 1998, Gordon 1982, but see Gordon 2003 for an adjustment of this argument.

153 Buydens and Dusollier 2001, at 13-14. Dusollier 2005a at 508-509.

154 Netanel 2005, p. 143.

155 Buydens and Dusollier 2001 at 14; Vinje 1999 at 193; Dusollier 2005a at 508-509, arguing that exceptions for public lending, handicapped people, teaching, libraries and archives should be imperative as well as the exception for normal use.
}

156 Buydens and Dusollier 2001, at 14.

157 Derclaye 2008 at 181.

158 Art. $5(2)(d)$ of the InfoSoc Directive. Note that this exception is classified differently by L. Guibault, as an exception intended to regulate industry practices.

159 Art. 5(3)(i) of the InfoSoc Directive.

160 Art. 5(3)(I) of the InfoSoc Directive. Buydens and Dusollier 2001 at 14.

161 This means that they would be overridable by contract. See Buydens and Dusollier 2001, at 14; Dusollier 2005a, at 508-509. 
In conclusion, the nature of each copyright limit is crucial to determine its overridability by contract law. Following the views of the above literature we can assume that, while a clause impeding, for example, any criticism of a work would be clearly unenforceable, market failure-driven exceptions can be safely contracted out. In practice, this is currently decided on a case-by-case basis.
For example, case law in a few EU Member States clearly determined the nature of 'defence', and not 'right', of the entitlement of the user to perform a copy for personal use; ${ }^{162}$ whereas in US courts, fair use seems to be generally prevailing on contract clauses. ${ }^{163}$

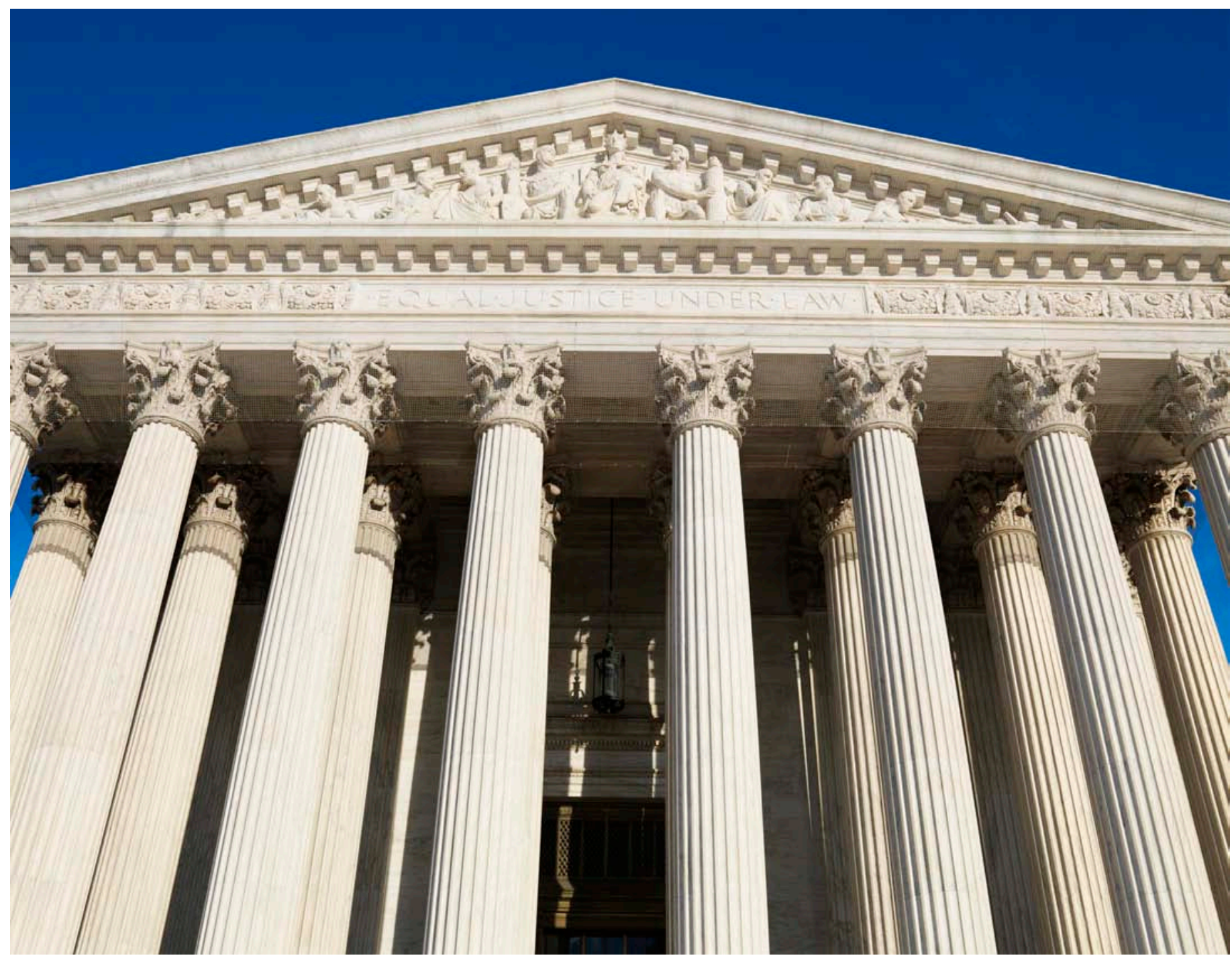

Stéphane P, UFC Que Choisir v. Universal Pictures Video France et Autres - Tribunale de Grande Instance de Paris, 3ème chambre, 2ème section, Jugement du 30 avril 2004; Cour d'Appel de Paris, 4ème chambre, section B, Arrêt du 22 avril 2005; Cour de Cassation - Première chambre civile Arrêt du 28 février 2006. Tribunal de première instance de Bruxelles, L'ASBL Association Belge des Consommateurs TestAchats v. SE EMI Recorded Music Belgium, Sony Music Entertainment (Belgium), SA Universal Music, SA Bertelsmann Music Group Belgium, SA IFPI Belgium, Jugement du 25 mai 2004 , No 2004/46/A du rôle des référes.

DSC Communications Corp. v. DGI Techs., Inc., 81 F.3d 597 (5th Cir. 1996); Lasercomb Am., Inc. v. Reynolds, 911 F.2d 970 (4th Cir. 1990). However, this must be taken with a pinch of salt as other decisions such as ProCD (see below) have enforced contracts which overturn copyright limits.

Providing Government with strategic, independent and evidence-based advice on intellectual property policy.

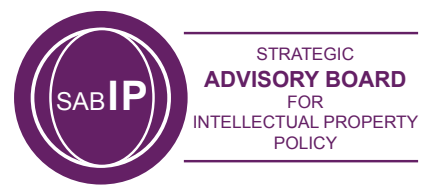




\subsubsection{Comparative review of copyright limits in various countries}

All copyright regimes analysed in this study share the same limits to copyright protection: the ideaexpression dichotomy; the originality requirement; a limited term of protection; the exhaustion or firstsale doctrine and a limited number of economic rights.

However, each of the countries studied in this literature review adopts a different approach on copyright exceptions, and the way they can be varied by contract. This section examines the statutes of these countries on the specific matter of copyright limits, and investigates whether the law provides some protection against private agreements containing clauses that override or modify them.

\section{The United States}

The idea-expression dichotomy in the US in stipulated by $\S 102$ (b) of the Title 17 of the United States Code (USC), which states that 'in no case does copyright protection for an original work of authorship extend to any idea, procedure, process, system, method of operation, concept, principle, or discovery..... Further, some originality of the work is required for copyright protection also in the US, but the requirement is not very strict, as set by Feist v. Rural Telephone in 1991. ${ }^{164}$ Moreover, the term of copyright has been extended by the Sonny Bono Act (from 50 to 70 years). ${ }^{165}$
Finally, the first-sale doctrine applies to digital works stored on physical media, ${ }^{166}$ but it does not apply to works downloadable from the Internet, which are considered services rather than goods. ${ }^{167}$

Copyright exceptions, on the other hand, are protected under the fair-use doctrine codified at $\S 107$, which reads: 168

Notwithstanding the provisions of sections 106 and 106A, the fair use of a copyrighted work, including such use by reproduction in copies or phonorecords or by any other means specified by that section, for purposes such as criticism, comment, news reporting, teaching (including multiple copies for classroom use), scholarship, or research, is not an infringement of copyright. In determining whether the use made of a work in any particular case is a fair use the factors to be considered shall include-

(1) the purpose and character of the use, including whether such use is of a commercial nature or is for nonprofit educational purposes;

(2) the nature of the copyrighted work;

(3) the amount and substantiality of the portion used in relation to the copyrighted work as a whole; and

(4) the effect of the use upon the potential market for or value of the copyrighted work.

164 Feist Publications, Inc. v. Rural Telephone Service, 499 U.S. 340, 345 (1991). Here it was stated: 'only that the work was independently created by the author (as opposed to copied from other works), and that it possesses at least some minimal degree of creativity... even a slight amount will suffice.'

165 The Sonny Bono act of 1998 is available at http://www.copyright.gov/legislation/s505.pdf.

166 Title 17 of the United States Code (hereinafter USC) Section 109(a).

167 The exclusion of Internet goods from the first-sale doctrine is discussed within the copyright doctrine. Some believe that technology could help in rendering digital Internet works similar to those stored on physical carriers, and therefore subject to the first-sale rule (Calaba 2002). Others believe that digital works that can be permanently stored in a computer hard drive have features more similar to products than to services (Mazziotti 2008, at 67).

Title 17, §107 of USC.

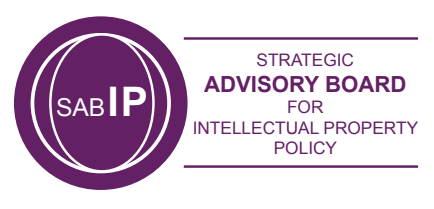


Fair use therefore is an open-ended exception that allows a court to excuse acts that would normally amount to infringement, both in the cases defined in $\$ 107$ and in other similar cases. The United States Code contains also a specific list of exceptions in §§108-122. They can be divided into the following categories: Limitations to support freedom of information; ${ }^{169}$ Limitations for a specific social action or purpose; ${ }^{170}$ Limitations for private use; ${ }^{171}$ Limitations concerning activities that are necessary accessories to other permitted actions and economically reasonable; ${ }^{172}$ compulsory licenses, which may be justified by transaction costs of negotiating licenses, by the importance of certain industry sectors, or by other factors. ${ }^{173}$

Fair use is a mobile concept, always in evolution. For example, during the fair-use history, case law adapted this exemption to the peculiar characteristics of the technology. In Sony Corp. of America v. Universal City Studios, Inc., ${ }^{174}$ the Supreme Court held that private videotaping of free TV broadcast did not amount to copyright infringement. Likewise, in Kelly v. Arriba Soft Corp. ${ }^{175}$ the court held that making thumbnails out of photographs for use on a search page was fair use.
Also the exceptions for libraries in the US have been 'updated' to meet the needs of the digital environment. The Digital Millennium Copyright Act (DMCA) of $1998^{176}$ modified the limitations for libraries, permitting the latter to perform up to three copies for preservation and replacement purposes. The Sonny Bono Copyright Term Extension Act of 1998 (Sonny Bono Act) also expanded library exceptions by giving libraries a limited right to use the works in the last 20 years of their copyright term for purposes of preservation, scholarship or research, if the works are not subject to normal commercial exploitation or are not available at a reasonable price. ${ }^{177}$

With regard to the relationship between copyright limits and contracts, we need to state at the outset that freedom of contract in the US is paramount. Article 1(10) of the US constitution forbids the States to pass legislation impairing the Obligation of Contract without the consent of the Congress. ${ }^{178}$ Moreover, case law has interpreted the 14th Amendment as protecting the freedom of contract. ${ }^{179}$ Therefore, a legally enforceable contract is likely to be able to override copyright limits.

$169 \S 108$ allows qualified libraries and archives to make and distribute noncommercial copies for preservation or research purposes, under specific conditions. $\S \S 110(1)$ and (2) allow performance and display of copyrighted works, through transmissions or otherwise, in connection with nonprofit teaching activities, under specific conditions.

170 §110(3); §110(4); §§110(8), (9) and §121; §118; §120(a).

$171 \quad \S \S 109(\mathrm{a})$ and $(\mathrm{c}) \S 1008$.

172 §110(7); §112; §§113(c); §113(d) and §120(b); §117; §512.

$173 \quad$ §111; §114(d)(2); §115; §116; §§ 119 and 122.

174464 U.S. 417 (1984).

175336 F.3d 811 (9th Cir. 2003).

176 Available at http://www.copyright.gov/legislation/dmca.pdf.

177 Sonny Bono Act, Section 104.

178 Guibault 2002, at 116.

179 Allgeyer v. Louisiana 165 U.S. 578 (1879) at 589, but see following case law limiting the freedom of contract within the terms of reasonable clauses, in Glynn v. Margetson \& Co. [1893] A.C. 351 ; London and North Western Railway Co. v. Neilson [1922] 2 A.C. 263; Cunard Steamship Co. Ltd. v. Buerger [1927] A.C. 1; and by Canada Steamship Lines Ltd. v. The King [1952] A.C. 192 and Sze Hai Tong Bank Ltd. v. Rambler Cycle Co. Ltd. [1959] A.C. 576 in the Privy Council. 
The US copyright act does not contain a provision making copyright limits imperative, i.e. not overridable by contract.

\section{The European Union}

In the European Union, most of the limits to copyright are set by the Directive on Copyright and related rights in the Information Society (InfoSoc Directive), ${ }^{180}$ the Directive for the legal protection of computer programs (Software Directive) ${ }^{181}$ and the Directive for the legal protection of databases (Database Directive). ${ }^{182}$ In the latter two is also set the originality requirement, which states that a work has to be the author's own intellectual creation. ${ }^{183}$ The copyright duration has also been harmonised by the Copyright Term Directive of 1993, modified by the Term Directive of 2006. ${ }^{184}$ The latter is now in the process of being modified: the proposal mainly purports to extend the protection of sound recordings from 50 to 95 years. ${ }^{185}$
The principle of exhaustion (corresponding to the American first sale doctrine) has been made uniform in EU law by Article 4.2 of the InfoSoc Directive, which limits the distribution right. ${ }^{186}$ This limit, as observed in relation to the US, does not apply to copyright works distributed on demand. ${ }^{187}$ The Software and Database Directives stipulate imperative exceptions to copyright, not overridable by contracts. Article 9(1) of the Software Directive of 1992 expressly provides that 'any contractual provision contrary to Article 6 or to the exceptions provided for in Article 5(2) and (3) shall be null and void'. These articles protect, respectively, decompilation, ${ }^{188}$ lawful use, ${ }^{189}$ observation, study and testing of computer programs. ${ }^{190}$

180 Council Directive 2001/29/EC of 22 May 2001 on the harmonisation of certain aspects of copyright and related rights in the information society, Official Journal L 167, 22/06/2001 P. $0010-0019$.

181 Council Directive 91/250/EEC of 14 May 1991 on the legal protection of computer programs, Official Journal $L$ 122, 17/05/1991 P. 0042 - 0046.

182 Council Directive 96/9/EC of 11 March 1996 on the legal protection of databases, Official Journal L 077, 27/03/1996 P. 0020 $-0028$.

183 Software Directive Article 1.3 and Database Directive Recital 16.

184 Council Directive 93/98/EEC of 29 October 1993 harmonising the term of protection of copyright and certain related rights, Official Journal L 290, 24/11/1993 P. 0009 - 0013. According to Article 1(1) of the Term Directive 1993 copyright is protected for 70 years from the death of the author. Directive 2006/116/EC of the European Parliament and of the Council of 12 December 2006 on the term of protection of copyright and certain related rights Official Journal L 372, 27/12/2006 P. 0012 $-0018$.

185 Proposal for a European Parliament and Council Directive, amending Directive 2006/116/EC of the European Parliament and of the Council on the Term of Protection of Copyright and Related Rights Brussels, 16.7.2008 COM(2008) 464 final.

186 InfoSoc Directive Article 4(2): 'The distribution right shall not be exhausted within the Community in respect of the original or copies of the work, except where the first sale or other transfer of ownership in the Community of that object is made by the rightholder or with his consent.'

187 For the debate on this issue, see Calaba 2002 and Mazziotti 2008 at 67.

188 Software Directive, Article 6.

189 Software Directive, Article 5(1).

190 Software Directive, Article 5(3).

Providing Government with strategic, independent and evidence-based advice on intellectual property policy.

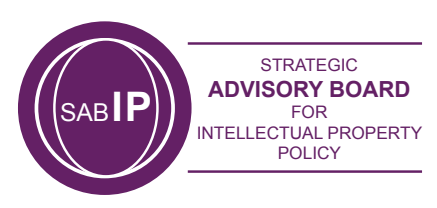


Article 15 of the Database Directive states that 'any contractual provision contrary to Articles 6(1) and 8 shall be null and void'. Article 6(1) stipulates that 'the performance by the lawful user of a database or of a copy thereof of any of the acts listed in Article 5 which is necessary for the purposes of access to the contents of the databases and normal use of the contents by the lawful user shall not require the authorisation of the author of the database'. Finally, Article 8 allows a lawful user of a database to extract and/or to re-utilise for any purposes whatsoever insubstantial parts of the contents of a database protected under the sui generis right.

The above suggests that, in the domain of software and databases, copyright exceptions are protected against contracts. However, copyright literature has raised some concerns. Problems, for example, have been identified as to the practical applications of the provisions of the Database Directive. ${ }^{191}$ Moreover, uncertainty has been voiced on the ability of the Software Directive to establish the statutory nature of its exceptions, whose modes of exercise can be defined by contract. ${ }^{192}$ Further, dissatisfaction has been expressed because the above provisions leave uncovered optional copyright exceptions, copyright exclusions (e.g. works not protected by copyright, idea-expression dichotomy) and copyright economic limits (duration and first sale). ${ }^{193}$ Finally, the EU Member States implemented the above provisions in different ways, creating different levels of protection within the EU. ${ }^{194}$
However, the most discussed piece of legislation of EU copyright law was the InfoSoc Directive, which is mandated to settle owners' and users' entitlements relating to copyright in the digital environment. In its Article 5 the InfoSoc Directive lists a number of copyright exceptions to the reproduction right and to the communication right of the owner. Of these exceptions, only the first (caching copying for technical reasons) ${ }^{195}$ is mandatory for Member States. They can choose whether or not to implement any of the other exceptions. ${ }^{196}$ Article 5 has been extensively criticised by the literature. The main criticisms regard both the optional nature of the list and its misguided ambition of being exhaustive. ${ }^{197}$

Therefore most of the copyright exceptions, according to the InfoSoc Directive, are optional. However, in Article 6(4) the InfoSoc Directive lists seven mandatory exceptions that have to be respected by technological protection measures. According to some, this suggests that at least these exceptions should be considered mandatory against licensing agreements, a fortiori. ${ }^{198}$ But according to the letter of the Directive, this is anything but certain. Rather, the opposite appears to be true, and this is indicated by a number of factors.

\footnotetext{
$191 \quad$ Derclaye 2006 at 184.

192 Dusollier 2007, at 498.

193 See Derclaye 2008, at 176 and Guibault 2006, at 94-97.

194 Guibault 2002, at 219 and 2006, at 97.

195 InfoSoc Directive, Article 5(1).

196 This led a commentator to define the exceptions in the InfoSoc as a 'shopping list': Hugenholtz 2000a.

197 Heide 2000; Hart 1998, at 171; CPB Netherlands Bureau for Economic Policy Analysis; Hugenholtz 1997; Dusollier 2003, at 473; and Guibault 2003, at 39-40. 
First, the InfoSoc directive is posterior to the Software and Database Directives; and the latter two directives contain express provisions on the mandatory nature of the exceptions to the rights they grant. Therefore, if the EU legislators also wanted to stipulate imperative copyright exceptions in the InfoSoc Directive, they would probably have done so. ${ }^{199}$

Second, the above is confirmed by the second reading of the Proposal for the Directive, in which amendment 156 proposed the introduction of a new Article 5(6) stating that '[n]o contractual measures may conflict with the exceptions or limitations incorporated into national law pursuant to Article 5'. This amendment was not accepted by the Commission, and this clearly indicates its position on the matter. ${ }^{200}$

Third, not only is there no express protection of copyright limits from private contracting, but there are also specific allowances for rights or privileges that can be contracted out. Recital 45 states that ' $[\mathrm{t}]$ he exceptions and limitations referred to in Article $5(2),(3)$ and (4) should not, however, prevent the definition of contractual relations designed to ensure fair compensation for the rightholders insofar as permitted by national law.' Further, Article $6(4)$ excludes from the application of copyright exceptions on-demand services 'available to the public on agreed contractual terms in such a way that members of the public may access them from a place and at a time individually chosen by them'[emphasis added].
Recital 45 has been differently interpreted by the doctrine. Some believe the Recital clearly states that the exceptions in Article 5(2) to 5(4) can be overridden by contracts. ${ }^{201}$ Others argue that the meaning of this Recital is that 'the ability to perform legitimate uses that do not require the authorisation of rights holders is a factor that can be considered in the context of contractual agreements about the price'. ${ }^{202}$ This interpretation suggests that the leeway of right holders does not concern contracts, but the determination of the price, with reference to those exceptions that are compensated for compulsory licensing.

However, no doubt exists on the interpretation of the relevant part of Article 6(4), which clearly excludes works made available online from the application of the exceptions listed in Article 6, and leaves the matter to private ordering. This provision has been criticised by legal scholars for setting a two-tier protection for copyright exceptions, and a reform of Article 6(4) has been advised. ${ }^{203}$

Finally, not all legal commentators are convinced that the above provisions stipulate the contractual overridability of copyright exceptions. Some reckon that the question is left to national legislators. ${ }^{204}$ Moreover, others argue that the interpretation of the existing national and European copyright law may provide a sufficient shelter especially for copyright limits based on fundamental rights or liberties and on the public interest. ${ }^{205}$ 199 See Heide 2003, arguing that the Software Directive should have served as a model to the InfoSoc Directive, because its
'copyright exceptions interface' is the most efficient.

200 European Parliament, Committee on Legal Affairs and the Internal Market, 17 January 2001, PE 298.368/5-197, cited in IViR 2007 Part I, at 138.

201 Bechtold 2006, at 371; Dusollier 2007, at 502; Heide 2003, at 327.

$202 \quad$ IViR 2007 Part I, at 137.

203 Dusollier 2007, at 502. Akester 2009, at 122. For a more cautious position on this matter see also Burrell and Coleman 2005, at 309 . 
However, the part of the examined literature that calls for a clear formulation of the imperative and non-overridable nature (by contract or TPMs) of a number of copyright exceptions seems to prevail (see Section B).

No EU case law helps to clarify the prevalence of copyright exceptions on contract, or vice versa. A few rulings in some EU Member States have examined only the question of the exception for private copying, by declaring that it is not a 'right'. ${ }^{206}$ Moreover, these judgements focussed on the duty of the right holder to disclose the existence and functioning of a technological protection measure, considered an essential feature of the product. They were addressed therefore with the instruments of consumer protection. The terms of the licence (probably forbidding the reproduction) were not examined. In conclusion, the EU case law so far leaves open the question of the contractual overridability of copyright limits (except those clearly made imperative in the Software and Database Directives ${ }^{207}$ ).

\section{The United Kingdom}

The Copyright and Related Rights Regulations 2003 (SI 2003/2498) came into force on October 31, 2003 and modified the Copyright, Designs and Patents Act 1988 (CDPA) to bring it into line with the InfoSoc Directive. Other legislation impacting on the protection of copyright includes:

- $\quad$ The Copyright (Computer Programs) Regulations 1992;

- $\quad$ The Duration of Copyright and Rights in Performance Regulations 1995;

- $\quad$ The Copyright and Related Rights Regulations 1996;

- $\quad$ The Copyright and Rights in Databases Regulations 1997;

- $\quad$ The Copyright and Related Rights Regulations 2003;

- $\quad$ The Copyright (EC measures relating to pirated goods and abolition of restrictions on the import of goods) Regulations 1995.

206 Tribunal de première instance de Bruxelles, L'ASBL Association Belge des Consommateurs TestAchats v. SE EMI Recorded Music Belgium, Sony Music Entertainment (Belgium), SA Universal Music, SA Bertelsmann Music Group Belgium, SA IFPI Belgium, Jugement du 25 mai 2004, No 2004/46/A du rôle des référes. For France, see François M. v. EMI France, Auchan France - Tribunal de Grande Instance de Nanterre, 6ème chambre, Jugement du 2 septembre 2003; Cour d'Appel De Versailles, 1re Chambre, 1re section, 30 septembre 2004; Stéphane P, UFC Que Choisir v. Universal Pictures Video France et Autres - Tribunale de Grande Instance de Paris, 3ème chambre, 2ème section, Jugement du 30 avril 2004; Cour d'Appel de Paris, 4ème chambre, section B, Arrêt du 22 avril 2005; Cour de Cassation - Première chambre civile Arrêt du 28 février 2006; and Christophe R., UFC Que Choisir v. Warner Music France, Fnac - Tribunal de Grande Instance de Paris 5 ème chambre, 1ère section Jugement du 10 janvier 2006. For Germany, see BVerfG: 'Verfassungsbeschwerde gegen urheberrechtliche Kopierschutz-Regelungen'(Beschl. v. 25.07.2005 - Az: 1 BvR 2182/04). See also Lucas 2006. imperativity. 


\section{PAPER 3: USER CONTRACTS}

The idea-expression dichotomy in the UK is not defined by statutory law. However, as Lord Hoffmann stated in Designers Guild Itd v. Russell Williams, ${ }^{208}$ it is defined in TRIPS, ${ }^{209}$ to which the UK is a signatory. Article 9.2 TRIPS states that 'copyright protection shall extend to expressions and not to ideas, procedures, methods of operation or mathematical concepts as such'.

The requirement of originality, on the other hand, was recently redefined in Hyperion Records Ltd $v$ Sawkins, ${ }^{210}$ where it was stated:

'In the end the question is one of degree - how much skill, labour and judgement in the making of the copy is that of the creator of that copy? Both individual creative input and sweat of brow may be involved and will be factors in the overall evaluation.'

The level of originality in the UK and Ireland is arguably now governed by the Infopaq case ${ }^{211}$, which requires intellectual creation and is thus higher than skill, judgement and labour. No decision from the UK or Irish courts has been handed down to confirm this as the Infopaq case is still very recent. The above case law shows that the criteria of idea/expression dichotomy and of originality are intertwined, and it is a very delicate matter to identify a subject of protection on the basis of these requirements. ${ }^{212}$
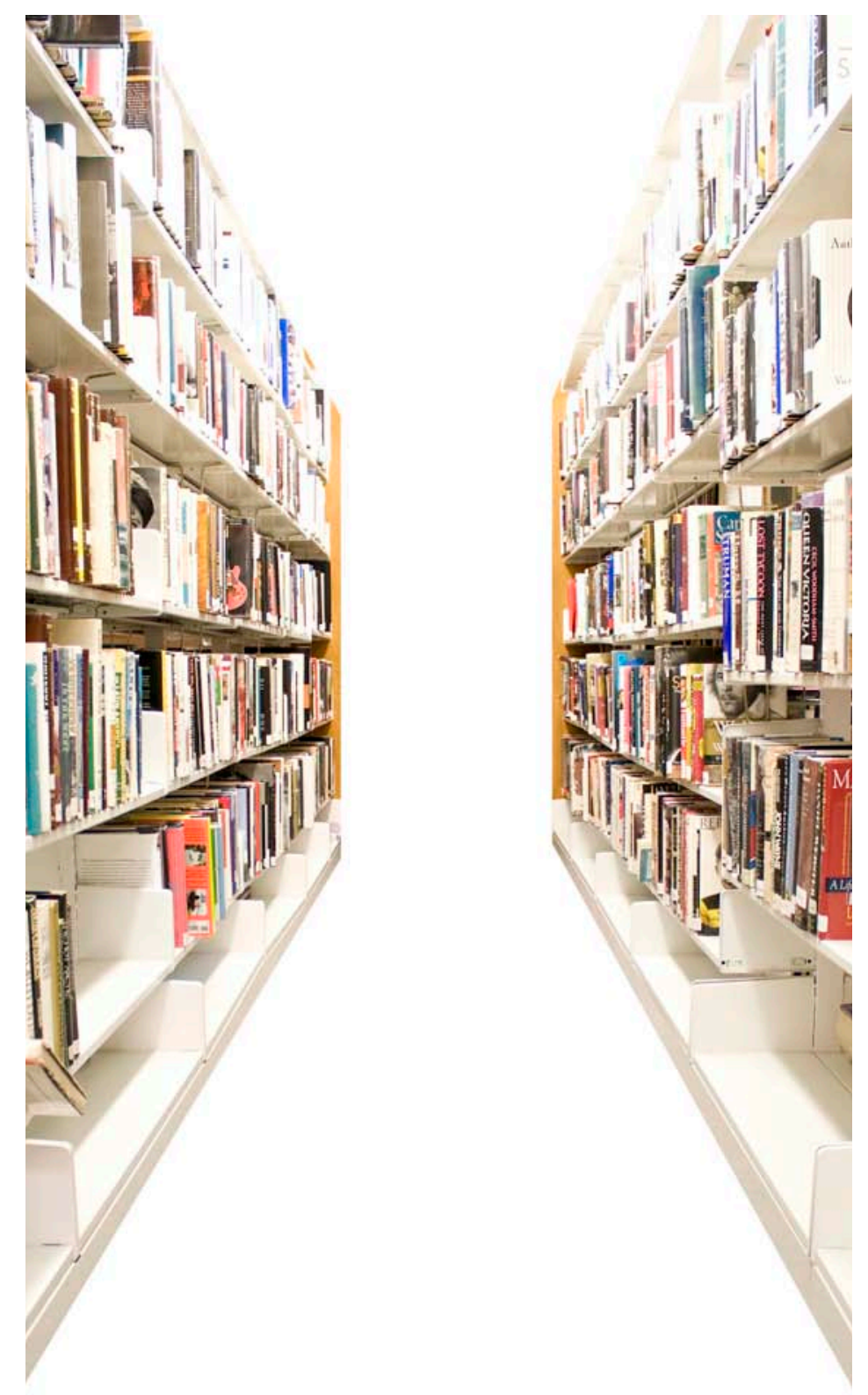

208 [2001] E.C.D.R. 10

209 Agreement on the Trade-related Aspects of Intellectual Property 1994, OJ L 336/213, Article 9.2.

210 Hyperion Records Ltd v Sawkins [2005] EWCA Civ 565 (19 May 2005).

211 Infopaq International A/S v Danske Dagblades Forening, case C-5/08, (ECJ).

See also Burrell and Coleman 2005, at 22.

Providing Government with strategic, independent and evidence-based advice on intellectual property policy.

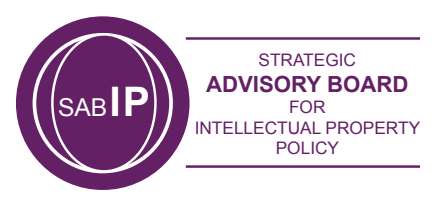


With regard to other copyright limits, the UK has a list of statutory exceptions defined in SS 28a-76, CDPA. These exceptions are for:

- making of temporary copies

- fair dealing for research and private study

- $\quad$ fair dealing for criticism, review and news reporting

- incidental inclusion of copyright material

- visual impairment defences

- $\quad$ education defences

- libraries and archives defences

- $\quad$ public administration, parliamentary and judicial proceedings, (...)

- $\quad$ computer programs: lawful users (including back up copies and decompilation)

- databases

- designs and typefaces

- $\quad$ works in electronic form

- $\quad$ anonymous or pseudonymous works: acts permitted on

- $\quad$ assumptions as to expiry of copyright or death of author

- use of notes or recordings of spoken words in certain cases

- $\quad$ public reading or recitation

- abstracts of scientific or technical articles

- recordings of folksongs

- representation of certain artistic works on public display

- advertisement of sale of artistic work
- making of subsequent works by same artist

- reconstruction of buildings

- lending to public of copies of certain works

- films: acts permitted on assumptions as to expiry of copyright

- $\quad$ recording for purposes of time-shifting

- $\quad$ photographs of broadcasts

- free public showing or playing of broadcast for certain purposes

- $\quad$ recording for archival purposes

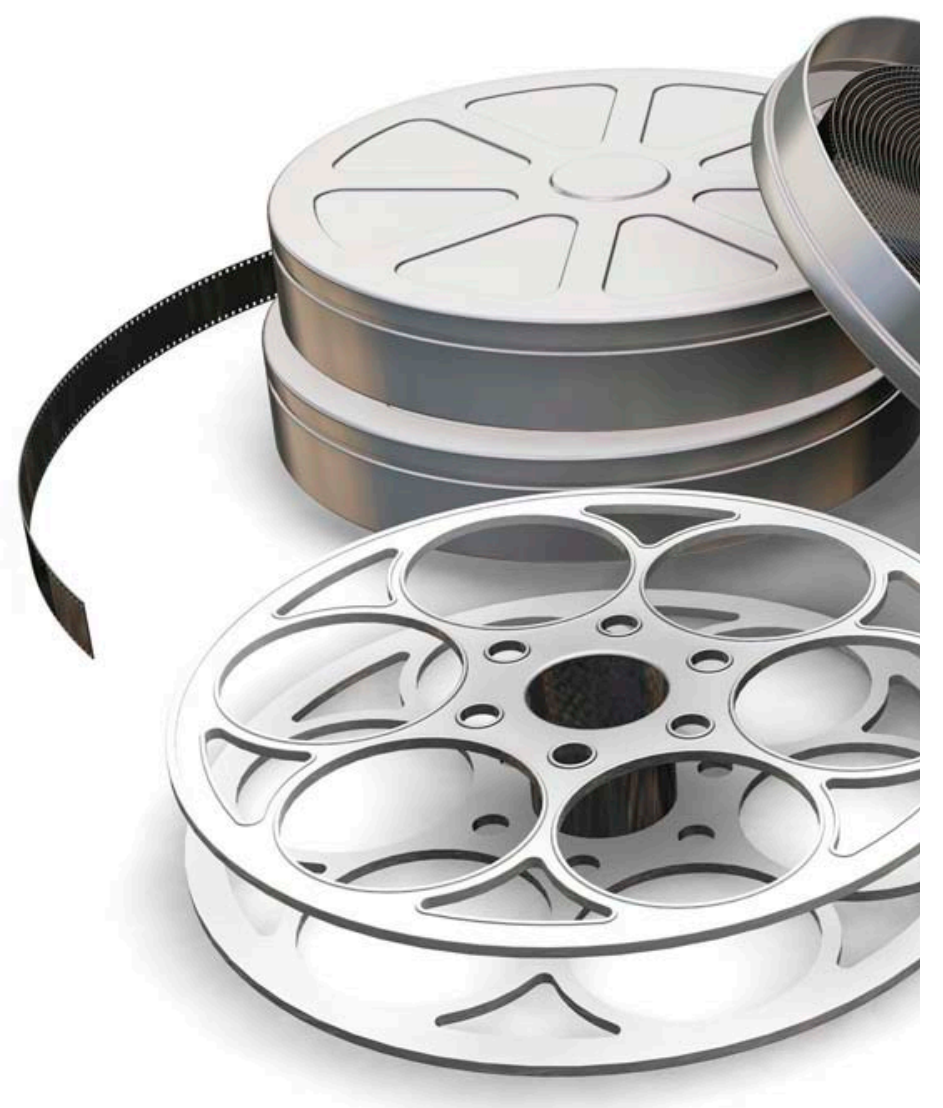

Providing Government with strategic, independent and evidence-based advice on intellectual property policy. 
CDPA's Schedule 5A sets out the permitted acts to which section 296ZE applies ${ }^{213}$ :

- $\quad$ section 29 (research and private study)

- section $31 \mathrm{~A}$ (making a single accessible copy for personal use)

- $\quad$ section 31B (multiple copies for visually impaired persons)

- $\quad$ section $31 \mathrm{C}$ (intermediate copies and records)

- $\quad$ section 32(1), (2) and (3) (things done for purposes of instruction or examination)

- $\quad$ section 35 (recording by educational establishments of broadcasts)

- $\quad$ section 36 (reprographic copying by educational establishments of passages from published works)

- $\quad$ section 38 (copying by librarians: articles in periodicals)

- $\quad$ section 39 (copying by librarians: parts of published works)

- $\quad$ section 41 (copying by librarians: supply of copies to other libraries)

- $\quad$ section 42 (copying by librarians or archivists: replacement copies of works)

- $\quad$ section 43 (copying by librarians or archivists: certain unpublished works)

- $\quad$ section 44 (copy of work required to be made as condition of export)

- $\quad$ section 45 (Parliamentary and judicial proceedings)

- $\quad$ section 46 (Royal Commissions and statutory inquiries)
- $\quad$ section 47 (material open to public inspection or on official register)

- section 48 (material communicated to the Crown in the course of public business)

- $\quad$ section 49 (public records)

- $\quad$ section 50 (acts done under statutory authority)

- $\quad$ section 61 (recordings of folksongs)

- $\quad$ section 68 (incidental recording for purposes of broadcast)

- $\quad$ section 69 (recording for purposes of supervision and control of broadcasts)

- $\quad$ section 70 (recording for purposes of timeshifting)

- $\quad$ section 71 (photographs of broadcasts)

- $\quad$ section 74 (provision of sub-titled copies of broadcast)

- $\quad$ section 75 (recording for archival purposes) 
The implementation of the InfoSoc Directive 2001 has slightly modified the above list of exceptions. For example, the exception to make temporary copies has been introduced, according to Article $5(1)$ of the Directive. Other existing exceptions have been curtailed, as for example the exception for research and private study, that now needs to be carried out only for non-commercial purposes and with acknowledgement of the source, in order to be exempted from infringement.

Moreover, Section 29 of the CDPA stipulates the exceptions for fair dealing for the purposes of research and private study, while Section 30 defines fair dealing for the purposes of criticism, review and news reporting. The definition of fair dealing, operated by the above statute and by some case law ${ }^{214}$ makes it rather more restrictive than the American fair use, to the extent that some commentators raise concerns about its consistency with free speech issues. ${ }^{215}$
Nothing in the Copyright Act forbids contracting out the above exceptions. A notable exception is section 36(4) CDPA which makes section 36 imperative. Section 36(4) states: 'the terms of a licence granted to an educational establishment authorising the reprographic copying for the purposes of instruction of passages from published works are of no effect so far as they purport to restrict the proportion of a work which may be copied (whether on payment or free of charge) to less than that which would be permitted under this section'. As to the other exceptions, existing legal doctrines outside copyright statutes may impact on contracts varying them. For example, commentators argue that fundamental principles as freedom of expression, and the common law defence of 'public interest', now codified under s. 171(3), have to be taken into account. ${ }^{216}$

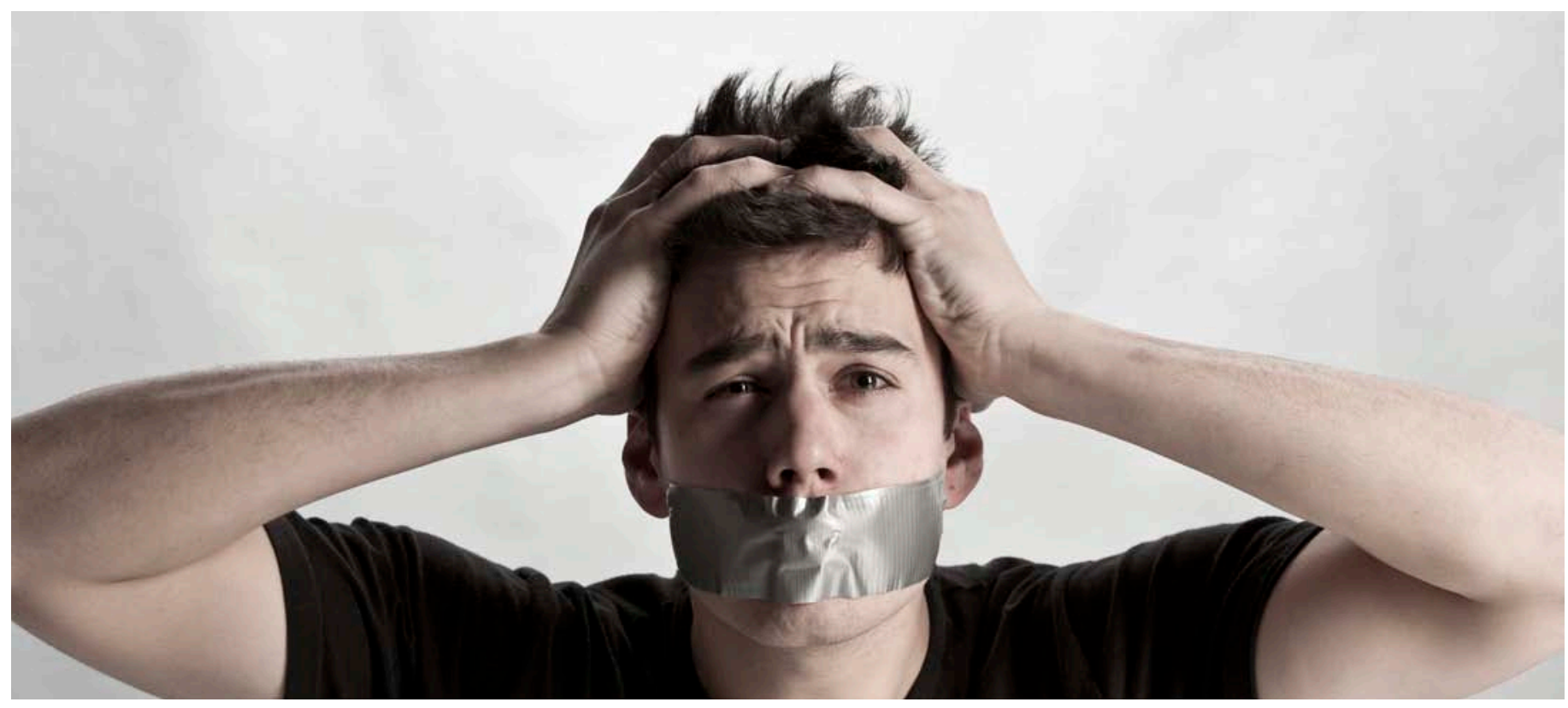

See Beloff v. Pressdram [1973] 1 All ER 262; and ProSieben v. Carlton [1998] FSR 43, 49. For the exclusion of unpublished works from fair dealing see Hubbard $v$. Vosper [1972] 2 QB 84. On the use for an approved purpose, necessary for the fair dealing exemption, see Pro Sieben v. Carlton [1999] FSR 610, 621. For the issue of criticism and review see Time Warner v. Channel 4 [1994] EMLR 1 and Ashdown v. Telegraph Group [2001] Ch 685; [2002] Ch 149; and Hyde Park v. Yelland [1999] RPC 665, 661, for news reporting.

215 Burrell and Coleman 2005, at 45 et seq.

216 Burrell and Coleman 2005, at 80-112. 
Finally, in UK law the Software Directive and the Database Directive have been implemented, and therefore it is not possible to override by contract the lawful access to and use of a database, including everything that is necessary for it, ${ }^{217}$ the carrying out of a back-up copy, ${ }^{218}$ the right to decompile a computer program, ${ }^{219}$ or the observation, study and testing of it. ${ }^{220}$ Moreover, fair dealing to report current events cannot be contracted out with reference to the inclusion of a broadcast in another broadcast. ${ }^{221}$

\section{Belgium $^{222}$}

Copyright in Belgium is regulated by the Law of the 30th of June 1994 on Copyright and Neighbouring Rights (the Copyright Act), ${ }^{223}$ which has been modified by the Law of the 31st of August 1998, implementing the Database Directive, ${ }^{224}$ and by the Law of the 22nd of May 2005 implementing the InfoSoc Directive. ${ }^{225}$
Software is protected in a separate law, of the 30th of June 1994,226 and the sui generis right protecting databases is enshrined in the Law of the 31st of August 1998, implementing the Database Directive. ${ }^{227}$

Some consumer rights related with copyright might be protected by a consumer law of the 14th of July $1991^{228}$ or a competition law of the 1 st of July 1999. ${ }^{229}$

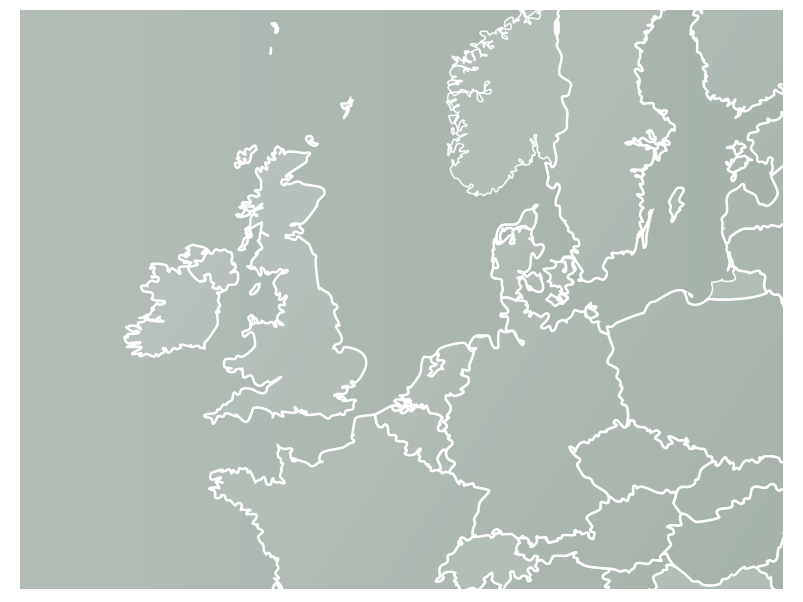

\begin{abstract}
218 CDPA 1988, s 50A.
219 CDPA 1988, s. 50B.

220 CDPA 1988, s 50BA.

$221 \quad$ Broadcasting Act 1996, s. 137.

222 General notions on the Belgian legislation have been drawn by the National Report presented at the ALAl conference in Barcelona 2006 (published by ALAI, ALADDA 2008 - hereinafter ALAI 2008). The report was drafted by Carine Doutrelepont, François Dubuisson, Joris Deene, and Katrien Van der Perre. Regarding the lists of copyright exceptions, free translations and summaries are provided by the author of the present work.
\end{abstract}

223 M.B., 27 juillet 1994, 19297; err. M.B., 5 novembre 1994, 27467 et M.B., 22 novembre 1994, 28832.

224 M.B., 14 novembre 1998

225 Loi du 22 mai 2005 transposant en droit belge la directive européenne du 22 mai 2001 sur l'harmonisation de certains aspects du droit d'auteur et des droits voisins dans la société de l'information, M.B., 27 mai 2005, 24997.

226 Loi transposant en droit belge la directive européenne du 14 mai 1991 concernant la protection juridique des programmes d'ordinateur, M.B., 27 juillet 1994, 19315

227 Loi transposant en droit belge la directive européenne du 11 mars 1996 concernant la protection juridique des bases de données, M. B. 14.11.1998, p. 36914

228 Loi du 14 juillet 1991 sur les pratiques du commerce et sur l'information et la protection du consommateur, M.B., 29 août 1991.

229 Loi du 1er juillet 1999 sur la protection de la concurrence économique (coordonnant la loi du 5 août 1991), M.B., 1er septembre 1999. See also Strowel and Tulkens 2006, at 9, arguing that author's rights are always subject to competition law.

Providing Government with strategic, independent and evidence-based advice on intellectual property policy.

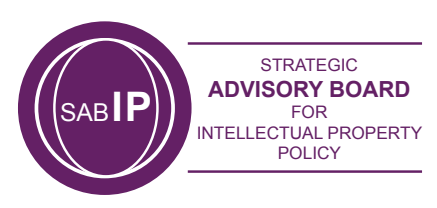


Copyright in Belgium is excluded if the work is not original; and the requirement of originality has been defined by the case law. ${ }^{230}$ The Belgian copyright act makes no mention of the idea/ expression dichotomy but it is clearly applicable in Belgium owing to TRIPs, and the case law takes it into account.

The Copyright Act stipulates a list of exceptions to the exclusive rights of the author, which is intended to be exhaustive, in Articles 21-23. Further exceptions are enshrined in Article 22bis (for databases) and in Articles 46-47 (for neighbouring rights). They are defined by some literature as a 'partial derogation' to the exclusive rights. ${ }^{231}$ According to the current legal doctrine the above exceptions can be divided into: a) legal exceptions; and b) compulsory licences ('exceptions légales' and 'licences légales'). ${ }^{232}$

Amongst others, compulsory licences include: Private reprography; Reprography for teaching and research; Copying for teaching and research; Communication for teaching and research; Private copying.

The legal exceptions are for: Citation; Anthology purposes; Temporary reproduction; News reporting; Reproduction/communication;

Reproduction in family circles; Parody; Public examinations; Archiving; Access from a terminal; Radio broadcasting; Disabled people; Exhibitions in art galleries; Social Institutions; Public Lending.
A similar list of exceptions is stipulated for neighbouring rights, with the addition, in some instances, of the provision for compulsory licences for the fair compensation of the right holder.

In the legal framework envisaged for the protection of databases, the Belgian legislator added two new exceptions from the Database Directive: a) the exceptions for acts necessary to a lawful user for the normal utilisation of the work; and b) the utilisation for reasons of public security or within administrative or judicial proceedings.

Moreover, the Belgian copyright legislation provides with reference to databases protected by copyright many of the exceptions reserved for copyright (Private photocopying; Photocopying for teaching and research; Copyright for teaching and research; Communication for teaching and research; News reporting; Incidental reproduction/communication; Reproduction in family circles; Parody; Public examination; Public lending).

Finally, in the field of computer software, the Law of the 30th of June 1994 authorises the back-up copy, the normal utilisation of the program, the software testing, studying, and reverse engineering exceptions. In this case however the exceptions provided for copyright in general were not extended to computer software. ${ }^{233}$

230 For the originality requirement see Cass., 25 October 1989, Bidelot c/ Egret et Stas, Pas., 1990, I, 238. and Cass., 11 March 2005, Balta Industries S.A. c/ R. Vanden Berghe S.A., http://www.juridat.be. See also Strowel 1991, at 515; for the fixation requirement see Civ. Bruxelles (réf.), 17 July 2001, Cortina c/ État belge, A. \& M., 2002, p. 69 , Palouzie c/ S.A. Épithète Films et Faraldo, J.L.M.B., 2001, p. 1444; all cited in the Belgian response to the questionnaire in ALAI 2008. On the originality requirement, see also Strowel and Derclaye 2001, at 23.

231 Voorhoof and Van der Perre (2003) at 268, cited in ALAI 2008, Belgian Report.

232 Strowel and Triaille (1996), cited in ALAI 2008 lbid.

233 However some literature suggests the application of the traditional copyright exceptions also to software. See Strowel and Derclaye 2001, at $242 \mathrm{nn}$. 280-281; apart from the exceptions for study and private copy, which are already regulated by the directive, these authors think that all the other exceptions stipulated by the Copyright Act are applicable to software. 
In Belgium, all the exceptions to the sui generis right (i.e. the equivalent of Art. 8, 9(a), 9(b) and 9(c) of the Database Directive) have been implemented and are mandatory. ${ }^{234}$ Accordingly, users cannot be presented with either standard form or fully negotiated contracts which would restrain the scope of the exceptions or which would allow some remuneration for acts that are in principle excepted.

The preparatory texts to the Belgian Database Act explain that the mandatory nature has been provided to avoid exceptions being overturned by the application of other laws less favourable to users. Article 11 forbids contractual clauses providing the application of a foreign law. ${ }^{235}$

Furthermore, the exceptions to copyright exclusive rights in Belgium are expressly declared imperative and not overridable by contract. The law of 31 st August 1998 implementing the Database Directive provides, in Article 23bis, that the provisions of articles 21, 22, 22bis et 23(1) and (3), are imperative'. In other words, no derogation is permitted. Every contrary clause is considered null and void.
The choice of the Belgian legislator, to declare all exceptions imperative without distinguishing between fundamental rights and market failures appears puzzling to some commentators. ${ }^{236}$

It has been argued that, in consequence of this choice, these provisions introduced a recognition of the 'rights' of the user; 237 although admittedly they did not establish a 'right of access' of the user. ${ }^{238}$

However, the law of the 22nd of May 2005, which implemented the InfoSoc Directive, added another sub-paragraph to Article 23bis (and to Article 47bis for neighbouring rights), which aligned the Belgian Copyright Act with Article 6(4) of the Directive. Article 6(4), we recall, excludes online services from the list of copyright exceptions that have to comply with technological protection measures. Copyright products accessible on line, therefore, can also in Belgium be subjected to usage restrictions that are regulated by contract law.

While in Europe advocates of the mandatory nature of copyright exceptions cite Belgium as an example to follow for its regulation of copyright and related rights, ${ }^{239}$ Séverine Dusollier, a Belgian commentator, expresses perplexity and dissatisfaction with the above norms.

234 Art. 11 of Law of 31 August 1998, implementing in Belgium the European Directive of 11 March 1996 relating to the legal protection of databases, M.B. 14 November 1998, in force 14 November 1998 ('Database Act'). Note however that the law implementing the Copyright Directive in Belgium (act of 22 May 2005, implementing in Belgian law the European Directive 2001/29/EC relating to the harmonisation of certain aspects of copyright and related rights in the information society, M.B. 27 May 2005, p. 24997) adds a second paragraph to article 11 of the Database Act, which makes an exception to this mandatory nature for databases made available to the public on agreed contractual terms in such a way that members of the public may access them from a place and at a time individually chosen by them.

Art. 11 of Law of 31 August 1998, implementing in Belgian law the European Directive of 11 March 1996 relating to the legal protection of databases, M.B. 14 November 1998, in force 14 November 1998 ('Database Act'). Note however that the law implementing the Copyright Directive in Belgium (act of 22 May 2005, implementing in Belgian law the European Directive 2001/29/EC relating to the harmonisation of certain aspects of copyright and related rights in the information society, M.B. 27 May 2005, p. 24997) adds a second paragraph to article 11 of the Database Act, which makes an exception to this imperativity for databases made available to the public on agreed contractual terms in such a way that members of the public may access them from a place and at a time individually chosen by them.

236 Dubuisson 2001, at 213.

237 Ibid, at 214.

238 Ibid.

239 See comments on the Green Paper of 2008 on Copyright in the Knowledge Economy at http://ec.europa.eu/internal_market/ copyright/copyright-infso/copyright-infso_en.htm. 
First, she voices disappointment because the imperative nature of the exceptions is declared only with reference to contracts and not to technological protection measures. She argues that a fortiori that should have been the case. ${ }^{240}$ Second, she maintains that the exclusion of the copyright works accessible on demand from the purview of Article 23bis suggests that copyright exceptions, while mandatory for digital copyright works commercialised on a physical carrier (e.g. a CD or a DVD), are only optional when the same digital products are commercialised online via download. This creates an unjustified two-tier system. ${ }^{241}$

The status of the exceptions in Belgium, Dusollier argues, assumes a hybrid nature (mandatory and optional) depending on the means of diffusion of the work. ${ }^{242}$ The reasoning of the Belgian legislator, while adding the above exclusion for on-demand copyright works, that the online distribution of copyright goods has to be promoted, does not convince her. She considers this argument fallacious, except maybe for the exception for private copying. By declaring mandatory the exceptions for 'offline' digital works and entirely manageable by contract the exceptions for online digital works, the Belgian legislator indirectly encourages the practice of overriding copyright exceptions. It is regrettable, she concludes, that the Belgian legislator stopped somewhat halfway in a process that had commenced under the right auspices. ${ }^{243}$
Existing case law in Belgium does not clarify the matter. In the most notable case on copyright exceptions in the digital environment, Test-Achats v. EMI, the consumer Association Test-Achats demanded the possibility for users to make a private reproduction of a music $C D$ equipped with DRM impeding the reproduction. The judge declared that the exception for private copying is only a 'legal immunity' against infringement and not a right. ${ }^{244}$ This ruling leaves therefore open both the question of the nature of other copyright exceptions (for example, those underpinned by fundamental rights) and the question of the overridability of copyright exceptions by contract and DRM.

\section{Ireland}

After relevant national and international pressure, Ireland adopted the Copyright act n. 38 of $2000,{ }^{245}$ which was intended to adapt copyright legislation to the needs of the digital environment, and to implement the InfoSoc Directive. However, a few provisions of the Copyright Act 2000 departed from the binding provisions of the InfoSoc Directive and therefore, after an EU action brought against Ireland, the SI n. 16 of 2004 (Copyright and Related Rights Regulations 2004) was adopted.

This Statutory Instrument introduced the exception for caching copy (temporary copyright within a system), and sanctioned a non-interference of Rights Protection Measures with Permitted Acts. ${ }^{246}$ With the latter provision, all permitted acts are protected from TPMs unduly expanding copyright protection.

\section{Dusollier 2007b, at 451.}

241 Ibid.

242 Ibid. at 452 .

243 Ibid.

244 Tribunal de première instance de Bruxelles, L'ASBL Association Belge des Consommateurs TestAchats v. SE EMI Recorded Music Belgium, Sony Music Entertainment (Belgium), SA Universal Music, SA Bertelsmann Music Group Belgium, SA IFPI Belgium, Jugement du 25 mai 2004, N. 2004/46/A du rôle des référes.

245 The previous copyright legislation was the Copyright Act n. 10 of 1963, The Copyright Act of 2000 is available at http://www. irishstatutebook.ie/2000/en/act/pub/0028/index.html. 
The boundaries of copyright protection, including the idea-expression dichotomy and the originality requirement, are expressed in S 17(2) and (3) of the Copyright Act 2000.247 The requirement of originality for databases has also been added in the same statute to comply with the Database Directive. ${ }^{248}$

The Irish Copyright Act provides an extremely detailed list of copyright exceptions. They are grouped by category, under the subsections dedicated to: Education; Libraries and Archives; Public Administration; Design; Computer Programs; Original Databases; Typefaces; Works in Electronic Form; and a miscellaneous section. The exception for private copying is reserved to domestic recording for the purpose of time shifting. ${ }^{249}$
On the mandatory nature of the exceptions, Section 2(10) of the Copyright Act 2000 states:
'Where an act which would otherwise infringe any of the rights conferred by this Act is permitted under this Act it is irrelevant whether or not there exists any term or condition in an agreement which purports to prohibit or restrict that act.'

246 Section 5 of the SI 2004:

'(1) Nothing in this Chapter shall be construed as operating to prevent any person from undertaking the acts permitted -

(a) in relation to works protected by copyright under Chapter 6 of Part II,

(b) in relation to performances, by Chapter 4 of Part III, or

(c) in relation to databases, by Chapter 8 of Part V.

(2) Where the beneficiary is legally entitled to access the protected work or subject-matter concerned, the rightsholder shall make available to the beneficiary the means of benefiting from the permitted act, save where such work or other subjectmatter has been made available to the public on agreed contractual terms in such a way that members of the public may access the work or other subject-matter from a place and at a time individually chosen by them.

(3) In the event of a dispute arising, the beneficiary may apply to the High Court for an order requiring a person to do or to refrain from doing anything the doing or refraining from doing of which is necessary to ensure compliance by that person with the provisions of this section.'

247 (2) Copyright subsists, in accordance with this Act, in-

(a) original literary, dramatic, musical or artistic works,

(b) sound recordings, films, broadcasts or cable programmes,

(c) the typographical arrangement of published editions, and

(d) original databases.

(3) Copyright protection shall not extend to the ideas and principles which underlie any element of a work, procedures, methods of operation or mathematical concepts and, in respect of original databases, shall not extend to their contents and is without prejudice to any rights subsisting in those contents. 
At first sight, the Irish provision seems broader than the corresponding legal provisions of Belgium and Portugal. It seems to cover all copyright limits. But in fact, since it uses the term 'rights', it can be said to refer to economic rights, rather than copyright as such, and thus to exceptions only and not all copyright limits, so that the meaning of the section is similar to its Portuguese and Belgian equivalent. Regrettably, no case law or literature, at national or European level, has elucidated in detail the reasons for the Irish legislator making such a choice. It is unclear therefore whether it is based on the nature of the exceptions or on utilitarian principles. Moreover, no empirical studies have been carried out on the impact that such provisions have had on local copyright industry.

\section{Portugal}

Copyright in Portugal is regulated by the Code of Author's Rights and Related Rights (Código do Direito de Autor e dos Direitos Conexos - CDADC) of the 14th of March 1985, which has been modified by the statutes implementing the Software Directive, ${ }^{250}$ the Rental Rights Directive, ${ }^{251}$ the Satellite-Cable Directive, ${ }^{252}$ the Copyright Term Directive, ${ }^{253}$ the Database Directive, ${ }^{254}$ the Term Directive $1993,{ }^{255}$ and the InfoSoc Directive. ${ }^{256}$
The matter is regulated also by the law on remuneration of private copying (Decreto-lei $n$. $62 / 98$, of the 1 st of September) and by the law on collecting societies (Law n. 83/2001 of the 1st of August)..$^{257}$

The conditions for the protection of copyright works (and therefore the exclusion of copyright protection according to the idea-expression dichotomy and - indirectly - to the originality requirement) are enshrined in Article 2 of the CDADC. Further, exhaustion of the distribution right and copyright duration are stipulated by the above legislation in line with the corresponding directives.

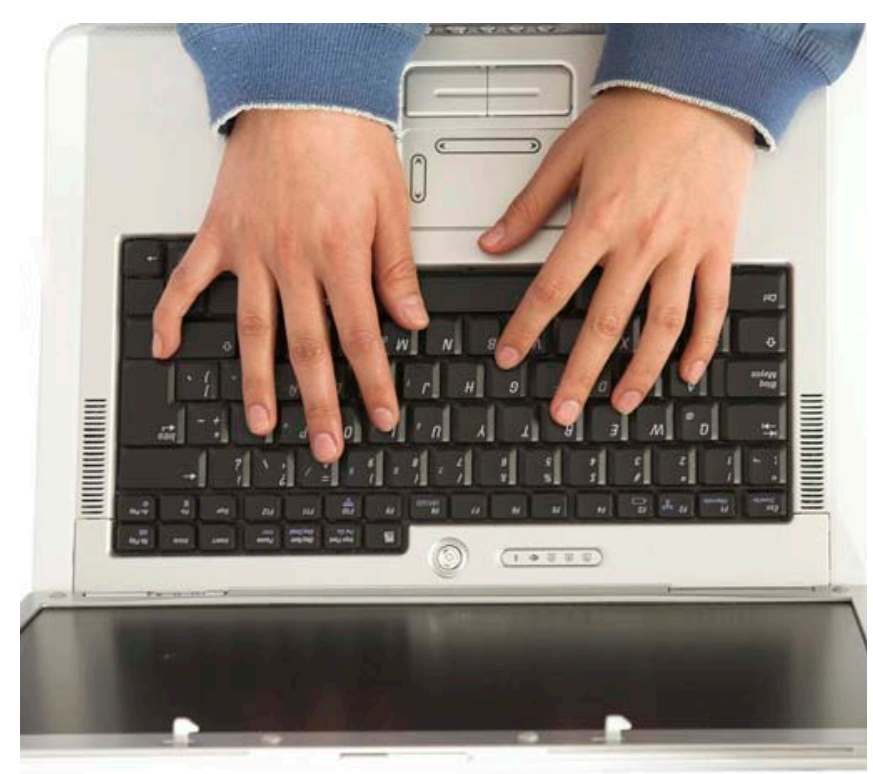

250 Decreto-Lei n. 252/94, of the 20 October 1994.

251 Council Directive 92/100/EEC of 19 November 1992 on rental right and lending right and on certain rights related to copyright in the field of intellectual property, Official Journal L 346, 27/11/1992 P. 0061 - 0066. Decreto-Lei n. 332/97, of the 27th of November 1997.

252 Council Directive 93/83/EEC of 27 September 1993 on the coordination of certain rules concerning copyright and rights related to copyright applicable to satellite broadcasting and cable retransmission, Official Journal L 248, 06/10/1993 P. 0015 - 002. Decreto-Lei n. 333/97, of the 27th of November 1997.

253 Council Directive 93/98/EEC of 29 October 1993 harmonising the term of protection of copyright and certain related rights; Official Journal L 290, 24/11/1993 P. 0009 - 0013. Decreto-lei $n$. 334/97 of the 27th of November.

254 Decreto-lei $n^{\circ} 122 / 2000$, of the 4th of July 2000.

255 Decreto-lei $n^{\circ} 334 / 97$, of the 27th of November 1997.

256 Law n. 24/2006 of the 30th of June 2006.

257 The complete legislation on copyright in Portugal is accessible at http://www.gpeari.pt.

Providing Government with strategic, independent and evidence-based advice on intellectual property policy. 
The system of copyright exceptions provides for an exhaustive list, which is strictly interpreted by courts. ${ }^{258}$ After the implementation of the InfoSoc Directive, the list presents the following exceptions in Article 75:

\section{- Caching copy}

- $\quad$ Private copying (on paper), except for musical scores

- Reproduction and public communication of summaries or excerpts, or speeches

- Press review

- Reproduction and communication of short extracts of literary works in current affairs reporting

- Copying by libraries and museums, for loan and archiving, non-profit

- $\quad$ Teaching (non commercial)

- Quotation for criticism or teaching

- $\quad$ Disabled persons

- Public performance of national anthems, patriotic chants, or religious works and practices

- Inclusion for promotion of expositions or sales/auctions

- $\quad$ News reporting

- Public security and administrative or judiciary proceedings
- Research and private study (with dedicated terminals and within library premises) of works that are not available for sale or licensing

- Reproduction by social institutions

- Architectural works and sculptures placed in public places

- Incidental inclusion

- Demonstrative or maintenance purposes, including buildings, their drawings and plans

- Distribution of works lawfully reproduced, when justified by the act of reproduction. ${ }^{259}$

Citation requirements and fair compensation are also provided for in some instances.

Moreover, private copying is regulated by a dedicated article (Article 81) which exempts the reproduction in one exemplar only, for scientific or humanistic purposes, when the work is not available for sale or is impossible to retrieve elsewhere. The personal copy, subjected to the three-step test (that does not affect the normal exploitation of the work and does not bring unjustified prejudice to the interests of the author $)^{260}$ cannot be communicated to the public and cannot be commercialised. works in certain special cases, provided that such reproduction does not conflict with a normal exploitation of the work and does not unreasonably prejudice the legitimate interests of the author.' 
In consequence of the implementation in the Portuguese legislation of the Software Directive and of the Database Directive, the corresponding imperative exceptions have been incorporated. Therefore, back-up copying, observation, study and testing of a computer program are allowed, and not overridable by contract. ${ }^{260}$ The same is valid for the decompilation of computer software aimed at achieving interoperability. ${ }^{261}$ Likewise the normal utilisation of a database is also guaranteed against contracts. ${ }^{262}$

Also for the exceptions to the exclusive rights of the author, the Portuguese Copyright Act provides for protection against contracts. Article 75(5) of the CDADC states that 'any contractual clause which aims to eliminate or impede the normal exercise by the beneficiaries of the uses listed in paragraphs 1,2 and 3 of this article [which the law calls 'free uses'] is null and void'263 without prejudice to contractual arrangements about the modes of exercise, in particular to establish the amount of fair compensation. ${ }^{264}$

All copyright exceptions in the Portuguese copyright legislation are thus protected against contracting, similarly to the Irish legislation and the Belgian law. ${ }^{266}$

\section{Conclusion}

In conclusion, the above examined countries adopt different approaches in the relationship between copyright exceptions and contracts. Some leave them to private ordering, some select few exceptions and declare them imperative, some protect all exceptions from contracts and technical locks. Apart from Belgium, there is no sufficient analysis of this legislation, in the literature or in the case law of the examined countries, to clarify the reasons for the choice of the respective legislators (e.g. whether the underpinning justifications for copyright limits determine their resistance to contracts). Moreover, there is no empirical research reviewing the impact of these different regulations on the relationship between owners and users of copyright works. In sum, it is difficult to understand whether legislation providing for imperative copyright exceptions helps users to benefit from them or harms the interests of right holders. In addition, apart from Portuguese law which seems clear on the point, it is unclear whether the whole contract or simply the clause overriding the exception will be void (art. 9(1) of the Software Directive, 15 of the Database Directive and s. 36(4) of the CDPA are good examples of such confusion).

\footnotetext{
261 Article 6 of the Decreto-Lei n. 252/94, of the 20 October.

262 Article 7, ibid.

263 Article 9 of the Decreto-lei n. 122/2000, of the 4th of July.

264 Translation by Patricia Akester, University of Cambridge.

265 Translation by the author.

266 See Dubuisson 2001, at 213
} 


\subsection{ACADEMIC COMMENTARY}

\subsubsection{Contracts override users' freedoms}

Contracts have always been part of the copyright law scenario. ${ }^{267}$ They are essential to the correct implementation of the copyright system. ${ }^{268}$ Authors and publishers use contracts to define the profit sharing deriving from copyright protection. Commercial copyright users arrange with authors or their representatives (often collecting societies) the terms of use of creative works. Private users purchase copyright works on analogue media (e.g. a book) under the standard terms of a sale contract. These contracts in the digital environment take the form of licences, setting the usage rules of a given copyright product. ${ }^{269}$ This is how we see the emergence, in relation with digital copyright works, of standard form electronic contracts, such as shrink-wrap, click-wrap and browse-wrap licenses.

Electronic licences, whose terms are determined by the rightholder, leave no room for negotiation to the user, who is confronted with a 'take it or leave it' choice. They are therefore different from armlength contracts, in which consent of both parties is fully informed and freely expressed. ${ }^{270}$
Some literature suggests that these licences are not at all contracts. They therefore do not require consent from the user. They are unilateral actions by which the owner exercises their property right, and indicates to the user what uses of their property they wishes to exclude. It is in sum a permission to use a property which is subject to conditions. ${ }^{271}$

From the point of view of the end users these licences are often too long. Some have suggested that in practice users do not read them, in the ever rapid Internet environment, but they regret to have agreed to them when they learn what their terms are. $^{272}$

Moreover, end-user licences are often worded in legal jargon, unintelligible to common users. ${ }^{273}$ But even when they are comprehensible, they 'are not as clear as the indication of the price of a product'. This means that the user is unable fully to determine the real impact of the terms and conditions on their interest. For example, they cannot know in advance whether they will be inspired by the content of that particular creative work to produce further creations. ${ }^{274}$ Despite the above, some case law in the United States has held shrink-wrap licences to be enforceable, even when the user expressed only minimal assent. ${ }^{275}$

\footnotetext{
267 Goldstein 1997, at 866.

268 Nimmer 1998, at 63.

269 Ibid.

270 Cohen 1998, at 30.

271 Elkin Koren 2009, at 8.

272 Good et al. 2005, cited by Lemley 2006 at 462. See also Lemley 2006 at 463, footnote 10, referring to an anecdote according to which a company put in its end-user licence agreement (EULA) that it would pay a prize to anyone who read the terms of use.
}

273 Ghestin 1993, at 367, cited in Guibault 2002, at 119.

274 Elkin Koren 2009, at 8.

275 See ProCD Inc., 86 F. 3d 1447.

Providing Government with strategic, independent and evidence-based advice on intellectual property policy.

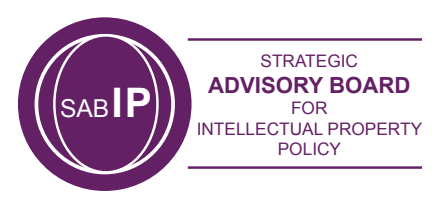


Furthermore, often the contract is bundled with the digital copyright work: either it is written on the product (e.g. on a music CD) or it pops up in the reading device at the first, or every, utilisation of the product (e.g. in computer software). This means that not only the original buyer of the product, but also each and every person subsequently utilising it, is bound by the terms of the agreement. In this way the right in personam of the owner, obtained by contract, bears the characteristics of a right in rem, like a property right. ${ }^{276}$

On this point Elkin Koren argues that the outcome of cases like the ProCD ${ }^{277}$ in the United States, suggests as acceptable a total contractual control on every access to the copyright work, not only by the original contractor (the purchaser) but also by every subsequent user. In this way, the contract creates rights that are similar to property rights, enforceable against everybody. After the ProCD case, in practice, no third party will be allowed to use a CD without being bound by the original contract between the offerer and the purchaser. ${ }^{278}$ She rejects the argument that copyright and contract do not hinder each other because the first creates initial entitlement and the second merely regulates the transfer of the entitlements.
Although the contract cannot operate on the initial entitlement, she argues, it can operate on the final outcome of the rights on this entitlement, and the final result is often contrary to copyright policy. 279

A few other copyright commentators maintain that end-user licences can override the privileges of the users. ${ }^{280}$ For example, most terms and conditions within these licences forbid any use or copy of the work, for any purpose whatsoever, thereby impeding the exercise of fundamental freedoms like citation, criticism, parody, and transformative works. ${ }^{281}$ Yet, abiding by the terms of the contract can become a pre-condition for the user to benefit from copyright exceptions.

Dusollier argues for example that, in order to benefit from the exceptions, the use has to be 'lawful'. The lawful use has been defined in several EU directives always in different terms, as the person that 'has lawfully acquired the work', ${ }^{282}$ the person that has the right to access the work (by law or by contract), ${ }^{283}$ or the person regularly licensed to access (by contract) from the owner. ${ }^{284}$

$276 \quad$ Elkin Koren 2009, at 9.

277 ProCD, Inc. v. Zeidenberg 86 F. 3d 1447 (7th Cir. 1996). The ProCD decision will be discussed below.

278 See the reading of ProCD in Elkin Koren 1997.

279 Ibid

280 See for example Vivant 2008.

281 Guibault 2002, IViR 2007 Part 1, Samuelson 1999, Gasser 2004, Vinje 1999.

282 Consistent with the definition of the Software Directive, and supported by part of the literature. See Dusollier 2007 , at 453.

283 Consistent with the InfoSoc Directive and with the Belgian Copyright Law. This construct is debated within the literature: certain commentators find that a lawful user is by law a beneficiary of a copyright exception. Others state this reasoning is circular. For the full debate see Dusollier 2007 at 451. See also Vanovermeire 2000.

284 Consistent with the Database Directive and supported by another part of the literature. See Dusollier 2007 , at 454.

285 See Dusollier 2007, at 456-459.

286 Kupferschmid 1998. See also Netanel 1996, foreseeing this scenario, at 306.

287 Kretschmer 2003, at 337.

288 Hugenholtz 1997, Vinje 1999. Samuelson 2003, Dusollier 2003a, Guibault 2003, Westkamp 2004 , Favale 2008. 
In all the above definitions the importance of the role of the contract is obvious.

The user cannot benefit from a copyright exception by their own initiative (for example by performing a reproduction that is forbidden by contract but allowed by a copyright exception) without becoming an unlawful user who cannot benefit from copyright exceptions. The only available remedy (far more costly and time-consuming) would be to resort to courts or mediation boards. In this way the construct of a lawful user is used by owners as a supplementary tool to control and restrict copyright exceptions. ${ }^{285}$

It is not only copyright exceptions which are threatened by contract, but all copyright limits. The first-sale principle, for example, that allows a lawful purchaser to resell the product on the second-hand market, finds no place in the digital environment. If the licence prevents any copy of the work, for whatsoever purpose, this entails that reselling, lending, and giving away the work is forbidden. ${ }^{286}$ Also the copyright duration could be endangered by the licences 'in perpetuity', granted by the copyright owner. ${ }^{287}$

In the views of the above literature, in sum, the balance between the exclusive rights of the owner and the access privileges of the user created by copyright is hindered by the implementation of contract and technology; 288 and so is the ultimate goal of copyright: the circulation of culture.
Rigid control on access to copyright content, enabled by contracts and technology, produces negative externalities like stifling new creative processes. ${ }^{289}$ The only way to avoid this dysfunction of the digital copyright is to subject these contracts to the principles that inform copyright law. ${ }^{290}$

In more detailed terms, copyright law should require that each contract including a clause incompatible with copyright legislation is null and void. To this end, the implementation of imperative copyright exceptions, which would not be overridable by contract, has been deemed necessary. Some reckon the imperative exceptions should be those underpinned by fundamental rights; ${ }^{291}$ others point to those enabling productive uses, able to foster innovation; ${ }^{292}$ some add also the exceptions likely to have an impact on the internal market. ${ }^{293}$ Another part of the literature believes that the whole copyright law, with all its exclusions, limited economic rights, and exceptions should preempt contracts infringing its provisions. ${ }^{294}$ Finally, others suggest that there should be a clause in supranational copyright law to declare null and void clauses in standard form contracts incompatible with copyright law. ${ }^{295}$ It has been argued that in an ever borderless market national copyright laws would not suffice to provide an effective safeguard for users' entitlements, and therefore we need to resort to legal frameworks also outside copyright law and at a supranational level. ${ }^{296}$

\footnotetext{
$289 \quad$ Elkin-Koren 2007.

$290 \quad$ Nimmer 1998 at 871.

291 Dusollier et al. 2000, at 18; Geiger 2006; Derclaye 2008; Favale 2008.

292 Heide 2000 and 2003.

293 IViR 2007, Part I, at 64.

294 Netanel 1996, at 382. Guibault 2008, at 10.

295 IViR 2007, Part I, at 163.

296 De Werra 2003; Hugenholtz and Okediji 2008.
} 
Alternatively, instead of the modification of current copyright legislation, a correct interpretation of its principles could be sufficient. To this end, the fundamental function of copyright needs to be taken as a guideline. 297 The interpretation of copyright and of its limits should be underpinned by its democratic function, rather than by utilitarian justifications. Thus contracts overriding copyright limits would be preempted by copyright law. ${ }^{298}$ In short, even in the absence of an express indication in copyright laws, court should hold enduser agreements incompatible with copyright law unenforceable. ${ }^{299}$

In conclusion, in the view of the above literature, while contracts have always been part of copyright, they have often created an imbalance between the interested parties. Initially, the authors were victims of the overreaching bargaining power of the publisher; and legislators enacted norms intended to protect them. Now, end-users are the weakest party in the relationship among copyright players. To assist them, either legislators should take normative action, or courts should inform their interpretation of copyright law in a different way.

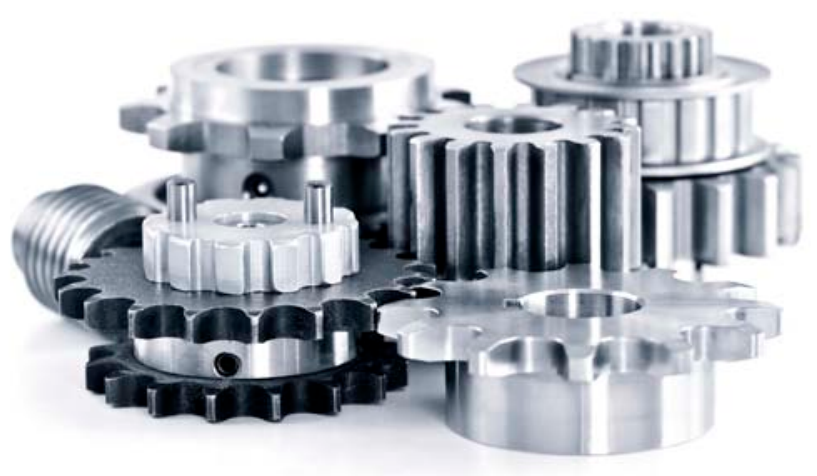

\subsubsection{Contracts are more efficient than Copyright}

Another stream of the literature is significantly more positive on the effects of private ordering on copyright law. They reckon that contracts and technological protection measures are more efficient than public ordering. This is because the law is not capable to quickly adapt to the needs of copyright users, whereas the market is able to generate the most efficient transaction terms for the benefit of both owners and users. Fair use and other instruments to address traditional copyright market failures would then be safely replaced by 'fared use'. ${ }^{300}$

This stance in the copyright literature is based on the assumption that copyright limits are based on the inefficiencies of the market: mainly, the impossibility to negotiate licences one by one with end-users. Digital technology bypasses this market failure by offering an individual negotiation. Thus, the intrusion of public policy tools to regulate copyright matters is no longer necessary, and the interaction between owners and users is left to the more efficient instrument of private ordering. Thanks to price discrimination, ${ }^{301}$ for example, users will get only the usage privileges they are ready to pay for.

\section{Geiger 2008.}

298 Netanel 1996, at 382. But see Nimmer 1998, at 828, arguing that only a naïve observer can claim that policy in intellectual property can trump contract.

299 Derclaye 2006.

$300 \quad$ Bell 1998; Dam 1999; Easterbrook 1996; Hardy 1996; Merges 1997; O’Rourke 1997.

$301 \quad$ Fisher 2004; Ganley 2004. 
This, in the final analysis, will not restrict users' privileges: it will broaden them. ${ }^{302}$ Against this scenario, it has been argued that information goods cannot be completely commodified, because of their peculiar characteristics. They are inherently different from other commodities, and therefore they cannot be efficiently subjected to the laws of the market. ${ }^{303}$

Private agreements are also recognised as a vehicle for opportunities rather than threats in the field of open-access licences. ${ }^{304}$ These are new ways in which authors and creators make available their work to the general public (normally on the Internet) without charges, but under given terms and conditions ('some rights reserved'). The General Public Licence (GPL), originally issued by the GNU Project, is designed for software developers. ${ }^{305}$ Literary works, instead, can be licensed under the Creative Commons (CC) terms. ${ }^{306}$ These new forms of licensing are conceived to facilitate access to copyright works by the broadest possible share of the public, while at the same time protecting authors from abuse and misuse of their creations. According to some, open-access contracts are perfectly fit for the borderless digital environment, unlike copyright law. By acting worldwide, they offer unprecedented opportunities to improve the general functioning of the copyright system. ${ }^{307}$
However, on this issue some commentators are cautious. According to Elkin Koren, for example, the multiple choices offered by $\mathrm{CC}$ licences augment the costs of information searching for users of CC works. This, in turn, ends up screening access to information rather than facilitating it. 308 Moreover, Dusollier ${ }^{1}$ argues that the culture and philosophy at the basis of CC and GNU projects can lead to unintentional negative consequences. In particular, the relevant focus on the user and their need to access copyright works shadows the interests of the author. CC authors selflessly make available their creations to the public, for the benefit of the circulation of culture. But the diffusion of this type of licensing somewhat generates the expectation that all works of art should be made available for free. Moreover, the tool utilised by open-access projects to provide an alternative to the existing copyright system, is ironically the same tool that the copyright industry is using to tip the balance of copyright towards the owner: the 'viral' contract. This type of contract stipulates terms and conditions that bind not only the first user, but also every following user of the work. Thanks to 'viral' contracts, the rights enforceable with respect to the copyright work are more similar to property rights than to contractual rights. ${ }^{309}$ The open-source licensing system is therefore criticised with the same arguments opposing commercial electronic licences.

\section{$302 \quad$ Easterbrook 1996, at 211.}

303 Benkler 2000.

304 Dizon 2009.

305 The project took off in 1984 and was supported by the Free Software Foundation. To avoid free software being copied by commercial software producers (and then patented), GNU elaborated the General Public Licence (GNU GPL). The functioning of the GNU GPL is simple: whoever wants to cooperate to produce and distribute free software has to patent it, in order to control the exploitation of the work. Afterwards, they can give away for free the software licence, thus ensuring that the creation will circulate for free and remain free. See http://www.gnu.org/copyleft.

306 Creative Commons found inspiration in the GNU GPL model, and it applied its concept to copyright. Some authors want their works to be freely accessible by the public, in order to maximise their distribution. This purpose cannot be achieved by simply putting a work in the public domain, because others could copy the work and claim its paternity. That is where the Creative Commons licence comes into play. On the CC website a licence is automatically generated according to the rights that the creator wishes to retain. For example, they can choose to claim the reproduction right only partially, by allowing free reproduction but only for non-profit activities. See http://creativecommons.org.

307 Dizon 2009.

$308 \quad$ Elkin Koren 2005 and 2009.

309 Dusollier 2006b. 


\subsubsection{Copyright and contracts are independent}

Between contract supporters and contract detractors, however, there is a third stream of copyright commentators. While not necessarily supporting an expansion of the use of contracts to regulate copyright matters, some are not at all concerned by the effects of private contracting on the copyright balance. Contracts and copyright are somewhat symbiotic systems that coexist, serve and help each other. They do not risk hindering each other, because they impact on different legal areas. Copyright is generally regulated by international law (implemented in national law), it creates rights in rem (enforceable erga omnes), and it creates initial entitlements only. Contracts instead are generally regulated by national law, they create rights in personam (enforceable only against the contractors) and regulate the subsequent transfer of entitlements. Moreover, fair use and the first-sale principle are not endangered by contracts because these are default norms that apply only in the absence of an arrangement between the parties. ${ }^{311}$

For other commentators, the current legislation, correctly interpreted, is sufficient to rein in copyright's excesses. ${ }^{312}$ They reckon that a strict solution like rendering imperative copyright exceptions would be 'too inflexible'. ${ }^{313}$ A similar solution cannot but be an extrema ratio: only a strong positive policy implication can justify overriding the freedom of parties to negotiate their agreements. ${ }^{314}$ Moreover, on a practical note, the financial implications of the interference of contract on copyright are held to be minimal. Even when the contract modifies copyright entitlements, remedies offered by contract law are far from being as onerous as those offered by copyright law. This is because in the case of breach of contract, all the owner can do is demand monetary damages in proportion with the real injury suffered, and the amount of those is likely to be minimal. ${ }^{315}$

\section{Conclusion}

In conclusion, the examined literature is divided among supporters of a legal action (normative or interpretative) to be taken in favour of copyright users, those who would phase out copyright law in favour of contracts, and those that deem the status quo to be sufficiently balanced. In the absence of empirical data on the impact on users of electronic licences it is impossible to evaluate these arguments correctly. Moreover, different types of contract may be used depending on the type of user of copyright works and on the sector (e.g. database, software, music, film sectors...). The following section reviews the different licensing agreements and preliminarily explores their potential impact on users.

\footnotetext{
$311 \quad$ Nimmer 1998.

312 Burrell and Coleman 2005, at 70.

313 Ibid.

314 Ibid, citing Lemley 1995.

315 See Gasser 2004 at 18 and Nimmer 1998

316 ProCD, Inc. v. Zeidelberg ERG 86 F. 3d 1447 (7th Cir. 1996).

317 Arizona Retail Systems v Software Links 831 F.Supp. 759, 763-766 (D. Arizona, 1993).
} 


\subsection{COPYRIGHT WORKS AND THEIR COMMERCIALISATION}

A wilful consent from a party to an agreement is important to determine the enforceability of that agreement against that party. Even in some recent case law, where minimal forms of assent were deemed to be sufficient to hold a purchaser bound to the terms of the contract, ${ }^{316}$ the possibility of accepting or rejecting the terms of the agreement was held to be crucial. ${ }^{317}$ While fully negotiated arm-length contracts presume wilful consent from all parties, and therefore do not raise this type of issue, standard form contracts, especially when entrusted to the jacket of a CD or to a URL on a web page, may create some problems. In order to explore the potential extent of these problems, it is useful to determine what share of copyright products is commercialised with the former or the latter form of contract. The analysis is organised by sector of copyright users: consumers; libraries and universities; commercial users.

\subsubsection{Consumers}

Although official data on this issue are missing, a growing share of the digital copyright commerce (B2C) seems to take place through electronic standard form contracts. This can be inferred from the figures on the diffusion of electronic commerce (e-commerce), which normally deploys this type of agreements, which in the field of copyright take the form of licences. ${ }^{318}$ For the purpose of this study, we will divide electronic licences into three types: a) shrink-wrap, b) click-wrap, and c) browse-wrap. The terms and conditions of shrink-wrap licences, when they are enforceable, are binding for the purchaser from the moment the packaging of the product is open. Click-wrap licences require the user to read the terms and conditions before proceeding with the purchase, and to accept them by clicking a button carrying 'I agree', or 'I accept' or other similar formulas. For browse-wrap licences, the terms and conditions are accessible via a link on the front-page of the website. It is irrelevant whether the user has effectively read them or understood them. It is sufficient for the acceptance of the agreement that the user 'utilizes' the website. ${ }^{319}$

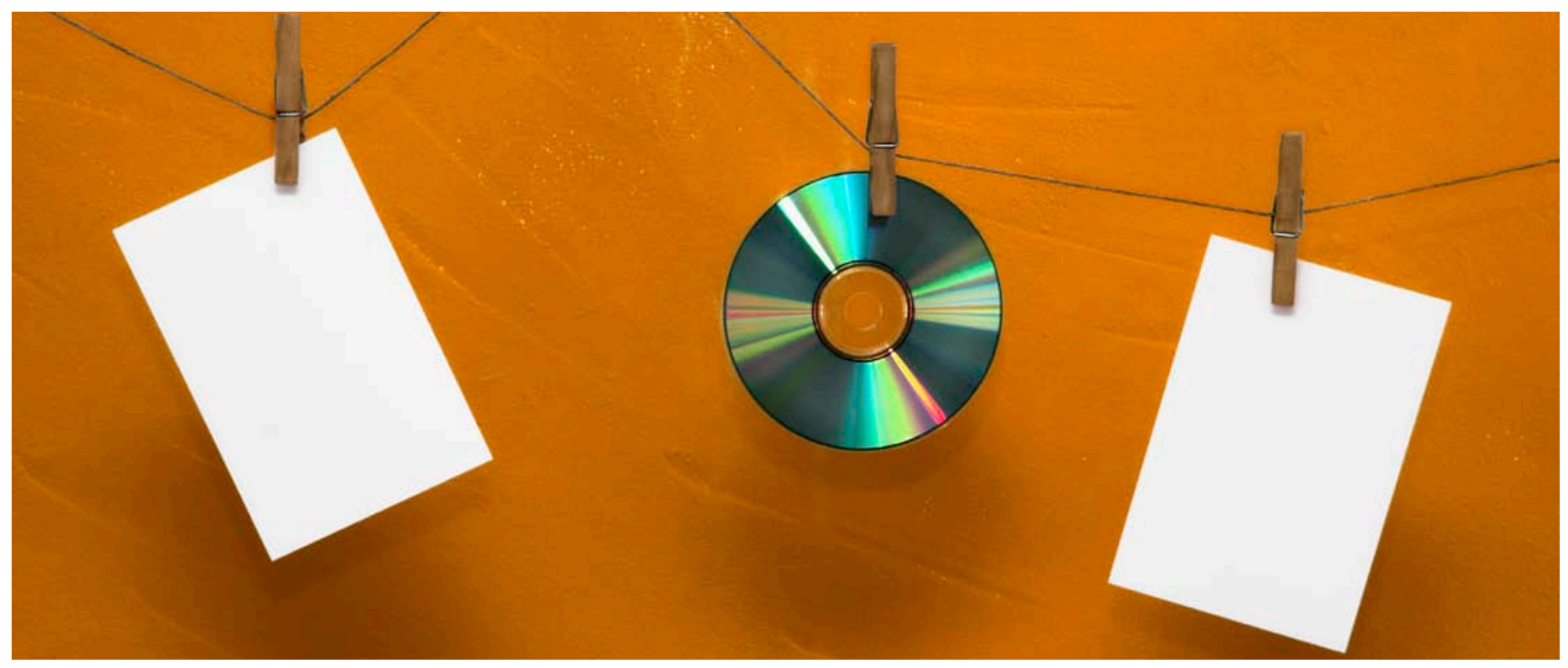

318

See IFPI Report 2009 at 4. See also the EU Commission Report on E-commerce 2009, on the diffusion of e-commerce in the EU. It reports that on average (among EU 27 Member States) 30/40\% of copyright goods are sold online. More 'mature' markets like the UK, France and Germany reach 70\% of the share. See also Guibault 2002 at 297. 
Some digital copyright works can be accessed on a physical medium (e.g. CDs or DVDs) which can be purchased or rented on the Internet or in a shop. These products sometimes have terms and conditions external to the packaging, sometimes internal. Some others have a notice exterior to the package referring to terms and conditions inside. ${ }^{320}$ For example, when the transaction involves the purchase of computer software on a material carrier, like a compact disk (CD), the terms of the licence are often printed in the instruction manual, or on a separate booklet that can be found in the package.$^{321}$ On the other hand, when a music CD is purchased, the terms and conditions are succinctly printed on the disk (and sometimes, but not always, on the jacket too). ${ }^{322}$ Video DVDs, in addition, show a longer copyright notice before displaying the content. ${ }^{323}$ Between the purchaser and the retailer, normal conditions of sale apply. However, between the right holder and the final purchaser the licence regulates the agreement. To digital products commercialised on a physical carrier the doctrine of shrink-wrap licences applies. ${ }^{324}$
The above products can also be purchased directly in digital form. They can be downloaded from a website onto the computer of the purchaser, and they do not require either packaging or delivery fees. For these products, click-wrap (or clickthrough, or click-on) contracts are more common. ${ }^{325}$

Music compilations or music files, audio books, and multimedia material (games and films) are nowadays increasingly commercialised online, via download. This trend is particularly recent for video material because of technological progress and the diffusion of powerful broadband connections. The most popular online service specialised in downloadable music files (and now also films) is Apple iTunes, which accounts for the biggest market share of copyright digital products. ${ }^{326}$ This service involves the use of proprietary software to sell the products, and it implements click-wrap licenses to set users' restrictions relating to the software and the products, and browse-wrap licences for the use of the website. ${ }^{327}$

320 Derclaye 2006 at 169-170.

321 See Belgrove 2008 (for the National Consumer Council - UK). The study relates to EULAs implemented on computer software.

322 An example of terms and conditions is: "unauthorised copying, lending, hiring, public performance and broadcast of the recording' is prohibited. See Gowers Review 2006 at 40.

$323 \quad$ IViR 2007 Part I, at 143.

$324 \quad$ lbid

325 See IViR 2007, Part I at 140 et seq.

$326 \quad$ lbid

327 See Gasser 2004.

Providing Government with strategic, independent and evidence-based advice on intellectual property policy. 
Also photo, image and footage stocks or collections are nowadays mostly licensed on line (although $C D$ versions still exist), and they implement clickwrap contracts. ${ }^{328}$

Finally, online newspapers and magazines, whose diffusion on the market is increasing every year, ${ }^{329}$ are often commercialised via browse-wrap licences. This is a common practice in the copyright management of websites. However, some of them only report on the front page the indication: 'ㄷ All Rights Reserved', or similar. No data are available on the share of websites/services implementing the former or the latter practice.

To conclude the examination of digital products destined to private consumers, some business models that propose standard form contracts in more traditional forms need to be mentioned. These are providers that often propose 'bundles' of digital copyright products and hardware. Examples are mobile phones able to play music and videos, or TV services via cable or Internet. ${ }^{330}$ These products are commercialised either in shops or online, and they involve the purchase or rental of a material product (e.g. phone, set-top box, router) and subscription to a service, through standard form contracts.
Most of the informational products considered above are commercialised through standard form contracts. As mentioned above, the terms of those types of contract are integrally set by the owner of the copyright work. This suggested to some literature that the position of the user is weak, and it needs special protection. ${ }^{331}$ This argument is refuted by others maintaining that standard form contracts are perfectly acceptable in contract law because the user has the choice to buy or not to buy the product; and the impact of this choice on industry's policies should not be underestimated. When many users refuse to buy a product with over-restrictive terms of use, the owner is likely to change them. ${ }^{332}$ The main debate of copyright literature and of case law, however, is on the enforceability of shrink-wrap, click-wrap and browse-wrap licences.

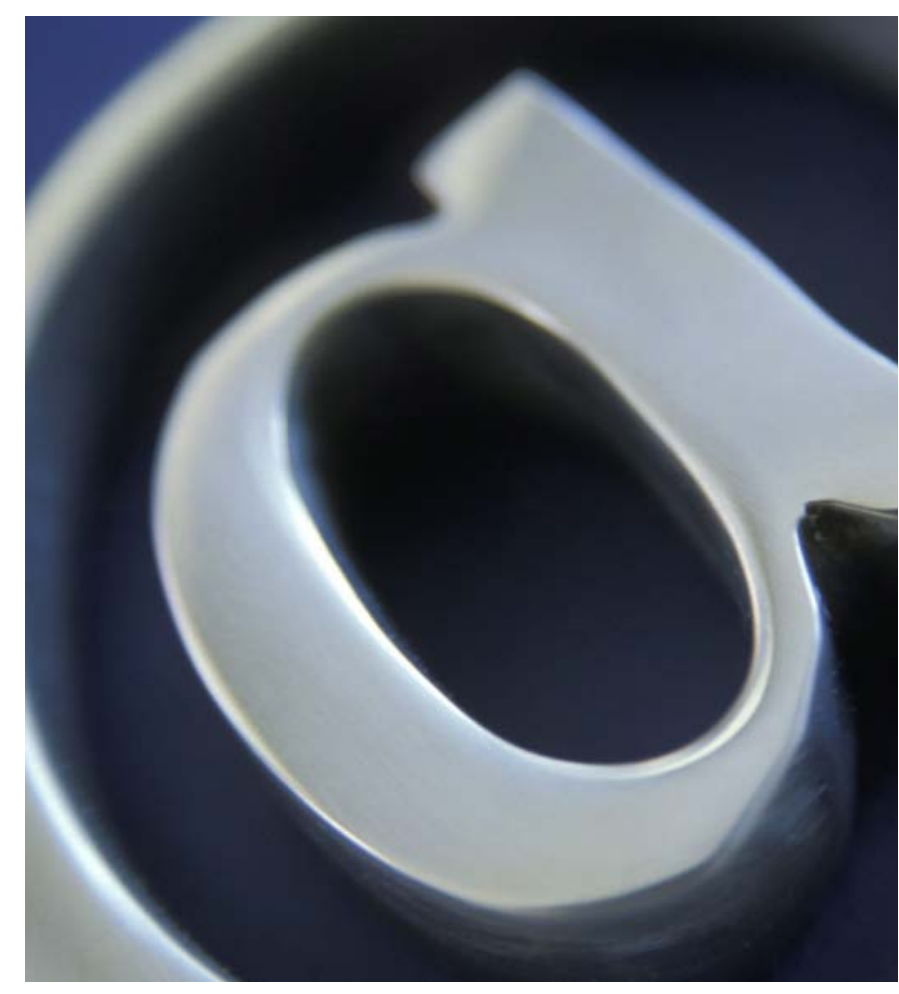

328 Grosheide 2001.

329 IFPI Report 2009. at 4.

$330 \quad$ IViR 2007, Part I at 8.

331 Elkin-Koren 1997, Dusollier 2005 and 2007, Lemley 2006.

332 Nimmer 1998. Note that this is the case only if there is competition on the specific product market (Derclaye 2008).

ProCD, Inc. v. Zeidenberg 86 F. 3d 1447 (7th Cir. 1996)

Providing Government with strategic, independent and evidence-based advice on intellectual property policy. 


\subsubsection{The enforceability of electronic contracts}

The status of shrink-wrap, click-wrap and browsewrap licences is all but certain at international level. Shrink-wrap contracts in the US are held enforceable in some States (see ProCD) ${ }^{333}$ and not enforceable in other states (see Vault). ${ }^{334}$ Many variables have to be considered: the juridical nature of the purchaser (natural or legal person: that is, private or professional user); ${ }^{335}$ the opportunity for the acceptant to have knowledge of the contract terms; ${ }^{336}$ and the possibility to accept or reject the agreement and to return the product free of charges. ${ }^{337}$ Common law instruments (e.g. the doctrine of unconscionability, misuse of rights, etc.) can be called upon to protect copyright users on a case-by-case basis, along with consumer protection instruments and antitrust law (see below, Section D). ${ }^{338}$
In the US, the legal doctrine is divided. While some express concerns about the minimal level of assent $^{339}$ sufficient to enforce shrink-wrap licences, others are in favour of upholding them. They argue that a contract also exists without formalities based on the fact that both parties have voluntarily started to deliver their performance. ${ }^{340}$ Therefore, in the US the validity of shrink-wrap licences is unclear. ${ }^{341}$

In Europe, some courts would not hold them enforceable, because the terms of the contract are known by the purchaser only after they have entered the transaction. ${ }^{342}$ Moreover, the indication on the jacket of the CD or on the disk itself that no copy is allowed is not considered a term of a contract, but rather a notice that copyright law applies, and therefore it is valid only to the extent to which it recalls the provisions of the respective national copyright law. ${ }^{343}$ In France, some legal commentators suggested that shrinkwrap contracts could be enforceable provided that the user is aware of assenting to the terms of the contract by opening the package. ${ }^{344}$ But no case law confirms such a construct.

334 Vault Corp. v. Quaid Software Ltd., 655 F.Supp. 750 (E.D.La.1987).

335 See Lemley 2006, at 261-262, arguing that most courts that have enforced a shrink-wrap licence have done so against a company, while most courts that have refused to enforce them have done so to protect consumers.

336 Arizona Retail Systems v. Software Links 831 F.Supp. 759, 763-766 (D. Arizona, 1993).

337 Derclaye 2006 at 173

338 Guibault 2002 at 207- 213.

339 Lemley 2006 at 464-465, discussing the 'death of assent', and citing Radin 2002.

340 In the US this is sanctioned by the Restatement (Second) of Contracts 19(1981). In civil law countries this is what is called to conclude a contract per facta concludentia.

341 Derclaye 2006 at 173.

342 See the Playstation case, Tribunal of Bolzano, Italy, 31 December 2003 [2006] E.C.D.R. 18. Also Coss Holland BV. v. TM Data Netherlands BV Dirstrict Court of Amsterdam, decision of 24th May 1995, Computerrecht 1997 at 63-65.

343 See Vermande v. Bojokovsky; District Court of The Hague, decision of 20th March 1998, in Informatierrecht/AMI 1998, at 65-67. 
Also in the UK, no case law exists on the specific matter of shrink-wrap licences, although some commentators expressed scepticism on their enforceability. ${ }^{345}$ We can only infer that case law on standard form contracts in general (the 'ticket cases') ${ }^{346}$ would be recalled in similar matters. In Scotland, a shrink-wrap licence has been held valid, but according to its commentators this case is of little help to clarify the possible fate of this type of agreement in the rest of Europe. ${ }^{347}$ Some other principles may be used to set aside such contracts. As they are applicable generally to all contracts, they will be reviewed in section 3.4.1. Click-wrap contracts, in contrast, are generally held valid both in the US and the EU. ${ }^{348}$ In Europe, the enforceability of such contracts is confirmed by Article 9(1) of the E-commerce Directive, ${ }^{349}$ and some European case law has upheld them. ${ }^{350}$
Finally, browse-wrap licenses, which are able to bind the user purely by the fact of being available for consultation in the first page of the website/ service, are held enforceable by some US courts, ${ }^{351}$ although some literature is highly sceptical about their validity. ${ }^{352}$ In a seminal case on this matter, Specht $v$ Netscape, ${ }^{353}$ a 'terms of use' link at the bottom of a page was not considered binding for the user, with the argument that for a contract to be binding, both parties need to know the terms of the contract and to agree to them.

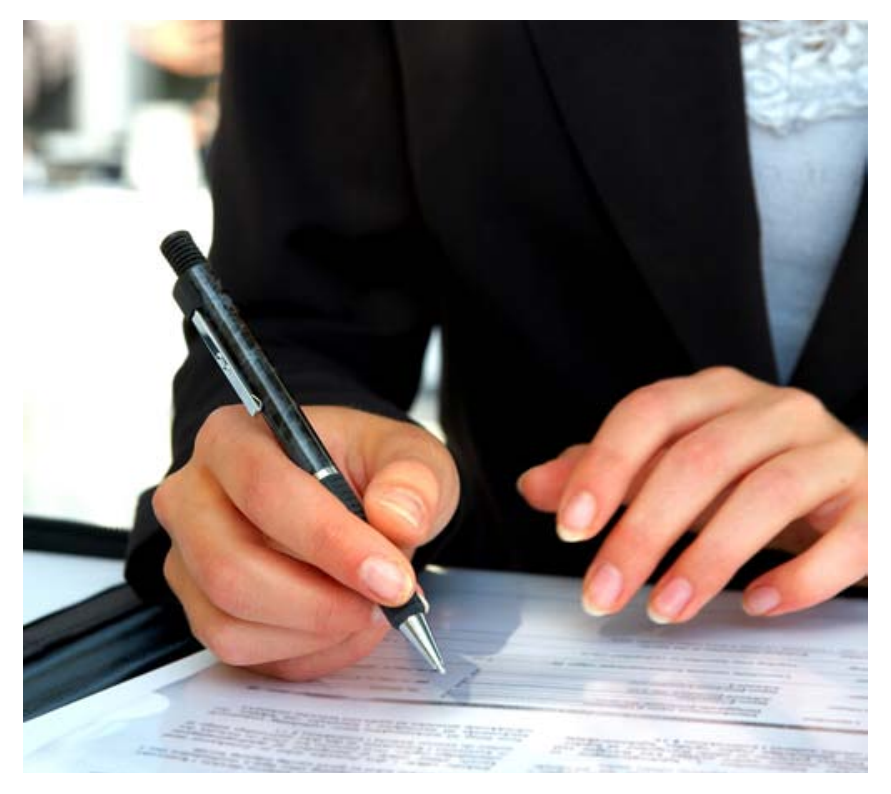

345 Derclaye 2006 at 174.

346 Parker v. South Eastern Railway [1877] 2 C.P.D 416. L'Estrange v. Graucob [1934] 2 K.B. 394. Grogan v. Robert Meredith Plant Hire [1996] 15 Tr. L.R. 371. In essence, these cases state that standard form contracts are enforceable whether or not the purchaser has effectively read the terms and conditions. It is sufficient ('reasonable notice') that the purchaser had the opportunity to read them (for example, in case of the train ticket, on timetables), and that they had the possibility to return the ticket.

347 Derclaye 2006, at 174.

348 Derclaye 2006, at 180.

349 Directive 2000/31/EC of the European Parliament and of the Council of June 8, 2000, on Certain Legal Aspects of Information Society Services, in Particular Electronic Commerce, in the Internal Market, Official Journal of the European Communities $L$ 178 (Jul. 17, 2000), 1.

350 See Association Famille de France v. SA Père-Noel.fr, SA Voyage Père-Noel.fr, Tribunale de Grande Instance de Paris, decision of 4 February 2003; Netwise v. NTS Computers, Rechtbank Rotterdam, 5 December 2002, in Computerrecht 2003/ 02 , at 149 .

351 Register.com, Inc., 356 F.3d 393; but see Specht below.

352 Lemley 2006.

353 Specht v. Netscape Communications Corp., 150 F. Supp. 2d 585 (S.D.N.Y.2001).

Providing Government with strategic, independent and evidence-based advice on intellectual property policy.

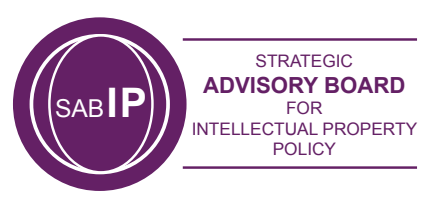


However, following case law (Register.com, ${ }^{354}$ eBay ${ }^{356}$ ) refuted this argument. In Register.com $v$. Verio the fact that Verio did not indicate assent by clicking the 'I agree' button was rejected. Moreover, in eBay, even a robot mining data from the eBay website was held capable of infringement; the judges argued that a person engaging an electronic agent 'selected for making an authentication, performance, or agreement, including manifestation of assent, is bound by the operation of the electronic agent, even if no individual was aware of or reviewed the agent's operations or the result of the operations' ${ }^{356}$ The fact that the infringer in these two cases was a commercial entity, however, might have heavily weighed on the decision. This may suggest that browse-wrap licences are normally enforceable against professional users and not enforceable against private consumers. ${ }^{357}$

Rulings by European courts on similar circumstances are still to come. ${ }^{358}$

\subsubsection{The terms of the electronic licences}

No empirical study has been undertaken on the real impact of shrink-wrap, click-wrap or browsewrap licences on copyright limits. They commonly implement different terms and conditions, based on the commercialised product and the type of contract, and therefore they would need an analytic and systematic study in order to be correctly assessed.

However, a few commentators have analysed one, or a few of, these standard form contracts as a case study or as 'samples' of a growing phenomenon. iTunes for example has often been chosen as a case study. ${ }^{359}$ The choice is not without justification: iTunes leads the world market of music services unchallenged, and the terms and conditions of its competitors cannot but be more permissive if they want to gain a place in the market. However, iTunes as a case study presents some drawbacks. This service has peculiar characteristics that do not allow qualifying it as an 'average' service. It subjects the purchase of its products to the use of proprietary software, and hitherto it has obliged its customers to buy specific hardware (Apple iPods) in order to use its products. ${ }^{360}$

\footnotetext{
354 Register.com v. Verio Inc.356 F. 3d 393 (2d Cir. 2004).

355 Ebay v. Bidders Edge 100 F. Supp. 2d 1058 (N.D. Cal. 2000).

356 Uniform Computer Transactions Act (UCITA) §107(d), cited in Deveci 2007, at 229.

357 Lemley 2006.

358 A threatened action from the National Portrait Gallery (NPG) against Derrick Coetzee (an administrator of Wikipedia), for copying more than 3000 high resolution images from its database could, if brought to court, shed some light on the matter. The NPG argued the application of UK law, and breach of a browse-wrap contract. For more information, see http://www. francisdavey.co.uk/2009/07/national-portrait-gallery-photographs.html and http://www.technollama.co.uk/national-portrait-gallery-copyright-row.
}

Gasser 2004 and Grondal 2006. 
Other services instead offer single music tracks or albums to download, without the use of any specific software, relying on terms and conditions accessible from the front page of the service. ${ }^{361}$ Their products are normally compatible with most music players.

iTunes and the other services analysed by the literature commonly include in their clauses statements like: 'you shall not copy, distribute, publish, perform, modify, download, transmit, transfer, sell, license, reproduce, create derivative works from or based upon, distribute, post, publicly display, frame, link, or in any other way exploit any of the Site Content'. The commentators that analysed this text found it might pose problems (amongst others) with some copyright limits and exceptions (namely fair use). ${ }^{362}$

Photographic stock services such as Corbis $^{363}$ and Getty ${ }^{364}$ which license on line photographic material and footage have not been studied like iTunes. However, a few passages of Corbis's terms and conditions, for example, seem to indicate the same potential for concern. Passages in Corbis's EULA terms include the following:

3(c) (...) 'The rights granted under this Paragraph include the right to make the Royalty-Free Content available to ten (10) separate individuals (cumulatively over the Term) for the sole purpose of manipulating or otherwise using the Royalty-Free Content to create the End Use according to the terms provided herein ('Users'), in any and all media now known or hereafter devised.' (...)

\author{
4 (...) 'Any right, title or interest arising in any \\ compilation or derivative work created using \\ any Content shall not entitle You to use any \\ Content except as permitted hereunder' (...)
}

According to the above, royalty-free pictures allow a limited private copy allowance (embedded into the fair use doctrine). On the other hand, transformative works are made difficult. However, royalty-free pictures are often not protected by copyright, and therefore any usage restriction on them could be interpreted as an abuse. Services like Corbis, in fact, have been questioned by copyright commentators because they license images which have passed into the public domain. ${ }^{365}$ As with the other similar services mentioned in this study, analytical research is needed to clarify how and to what extent these terms of use depart from copyright legislation.

In conclusion, while the above case studies clearly suggest the potential problems caused to the entitlements of copyright works users by overreaching terms and conditions, the real extent of such problems needs to be carefully measured by systematic empirical studies before identifying its policy implications.

\footnotetext{
361 This is true for music services, like Amazon (http://www.amazon.com/MP3-Music-Download) and Tesco (http://direct.tesco. com/), but not for video services which normally, like iTunes, use proprietary software. See http://www.netflix.com and http:// www.cinemanow.com.
}

362 Gasser 2004; Grondall 2006; Bechtold 2004.

363 http://www.corbis.org.

364 http://www.gettyimages.com/.

365 Grosheide 2001, at 324.

$366 \quad$ Akester 2009.

Providing Government with strategic, independent and evidence-based advice on intellectual property policy.

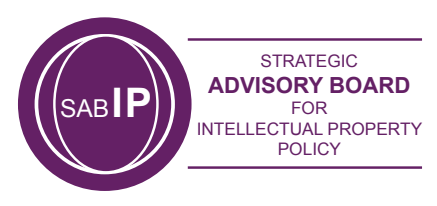




\subsubsection{Libraries and educational institutions}

Among publicly-funded institutions libraries are certainly the most affected by usage restrictions in copyright contracting. A recent empirical study carried out on the impact of DRM on the beneficiaries of copyright exceptions revealed that technological protection measures are not the main obstacle for libraries to access copyright works. ${ }^{366}$ In the course of this study, Benjamin White, the Publishing Licensing and Copyright Compliance Manager of the British Library, interviewed by Patricia Akester, declared that the biggest challenge faced by the British Library is not the technology but the licensing practices. He stated: 'Most of the licences imposed on the British Library are more restrictive than copyright law, including restrictions around copying such as only copy one per cent, copy once, only copy in the same medium or no wholesale copying, which prevent archiving and inter-library loans. ${ }^{367}$

The British Library carried out an empirical study on contracts they have been proposed by the copyright industry. ${ }^{368}$ They examined 100 contracts and they found that $90 \%$ of them did not allow for at least one of the following: 1) Archiving; 2) Downloading and electronic copying; 3) Fair dealing; 4) Use by the visually impaired; 5) Interlibrary loan. Moreover, they found that the contracts did not make any reference to any exceptions from the UK copyright law or from another jurisdiction. In the conclusion of this study the British Library required the UK Government to take action against this practice of the copyright industry, in order to preserve the national literary heritage. ${ }^{369}$ They also submitted their position on copyright exceptions to the European Commission. ${ }^{370}$

No other empirical study on contracts with public libraries and university libraries has been carried out in the countries that this literature review examines. But interesting information can be drawn from a survey performed by the Australian Vice-Chancellors' Committee (AVCC). ${ }^{371}$ This survey was drafted as a submission to the public consultation undertaken by the Australian Copyright Law Review Committee (CLRC), which has carried out the most comprehensive study to date on copyright and contracts. ${ }^{372}$

The AVCC provided a number of examples of online licences. Many of them came from overseas (mostly the US), and imposed several restrictions on users. The Committee reports that 'most contracts give universities and their staff and students rights which are in many respects broader than those allowed for by the exceptions - as you would expect given the subscription or licence fees that are paid by universities. However, in most cases there will also be provisions which exclude or restrict uses and activities that would be allowed by copyright exceptions (...)'

\section{$367 \quad$ Ibid at 36}

368 See http://www.bl.uk/ip/pdf/ipmatrix.pdf.

369 See the conclusion of this study on http://www.bl.uk.

370 See comments of the British Library on the Green Paper on the Infosoc Directive of 2008 at http://circa.europa.eu/Public/irc/ markt/markt_consultations/library?.

371 The AVCC is an association of Australian universities. See http://www.universitiesaustralia.edu.au/10.

372 Available at http://www.ag.gov.au/www/agd/agd.nsf/Page/Copyright CopyrightLawReviewCommittee_CLRCReports CopyrightandContract_CopyrightandContract. 
They also provided examples of some worrisome restrictions:

- $\quad$ restrictions on the ability of a university to copy, download or otherwise incorporate excerpts from the relevant copyright work into hard copy or electronic coursepacks, (...)

- $\quad$ restrictions on the creation of an electronic reserve within a university by the copying or downloading of extracts from licensed copyright material. Such reserves may carry significant advantages in terms of convenience of search and access for students, and management of resources by universities. (...)

- $\quad$ not allowing users who have access to licensed copyright material to print or download that material to the full extent that they would otherwise be allowed to in the exercise of their fair dealing rights (...)

- $\quad$ restricting the extent to which non-authorised users can be granted access to material or allowed to make copies from that material. Often the definition of authorised users will be limited to enrolled students and staff of the relevant university or even faculty. (...) Even where members of the public are entitled to access material, there will often be requirements that this is done on the premises of the licensed subscriber (...)

- $\quad$ (..) restrictions on copying or communication for the purpose of inter-library loans (...) and on copying done on behalf of other universities $(\ldots)^{373}$
Also the Australian National Library, in the context of the same public consultation of the CLRC, carried out a similar study on electronic licences. On 218 titles of publications accessed from their reading room they found:

- 8 titles (3\%) where downloading was not permitted (...); one (...) where readers were not permitted to remove downloaded data from the library; and $82(37 \%$, mostly the Informit range of databases) where downloading was limited to 'one copy of search output';

- $\quad 11$ titles (5\%) that did not enable emailing of extracts; for some of these (the Pioneer Indexes) this is probably for technological reasons, but it is interesting to note here products such as the New Grove dictionary of music and musicians and Yearbook Australia;

- 6 titles where printing is not permitted, two which allow a 'single copy only,' and three others where printing is permitted 'for personal or internal use of the organisation' or 'only $1 \%$ of database material' (...), total 11 (5\%);

- $\quad 26$ titles (11\%) (principally newspapers received as part of the Electric Library subscription) where inter-library loan was not permitted; and

- $\quad 7$ titles (3\%) where reference staff were not permitted to use short extracts in answering email enquiries $^{374}$

\footnotetext{
373 See the complete study at http://www.ag.gov.au/agd/www/CIrhome.nsf/Page/F5EDCD258D62B255CA256B3B007D8616? OpenDocument.

374 At http://www.nla.gov.au/policy/clrcccip.html.
} 
The Max Planck Institute for Intellectual Property, Competition and Tax Law also participated in the debate on access to scientific information by the academic community. They submitted their conclusion to the EU Commission as a comment on the Green Paper on 'Copyright in the Knowledge Economy'. ${ }^{375}$ They propose to re-draft Article 5 of the Infosoc Directive ${ }^{376}$ so as to favour users and right holders on the one hand, and on the other hand the community of researchers, by distinguishing copyright exceptions on the basis of the category of user. In short, to address the scarce possibility of dissemination of scientific works, they propose a two-tier approach within copyright law, with exceptions and rules specifically designed for scientific research.

In conclusion the Max Planck Institute makes a number of recommendations: a) Copyright exceptions should be based on the purpose of the use of the protected material; b) There should be no restrictions for non-commercial uses; c) The compensation system for right holders should be streamlined; d) The exceptions should be mandatory; e) Circumvention of copyright limits by contract or by technical locks should be sanctioned. ${ }^{377}$

Although the theoretical research and the examples of empiric evidence provided above do not have the value of a comprehensive study on the sector of the institutions benefitting from copyright limits, useful indications can be drawn concerning the problems that might be encountered by libraries dealing with electronic licensing. The research examined, moreover, suggests interesting questions. Although libraries and research institutions are professional users in the sense that they have the means to be correctly informed of their statutory rights and they have the bargaining power to negotiate their contracts at arm length, they seem to be confronted by the copyright industry with standard form contracts whose terms and conditions they have to accept. The reason why this happens is not clear from the above submissions. The licensing practices of the copyright industry vis-à-vis institutions benefitting from copyright exceptions, therefore, would deserve a separate study in order to clarify this matter.

\subsubsection{Commercial users}

Not all commercial users benefit from copyright exceptions. However, all of them benefit from copyright limits and exclusions (e.g. first sale, duration, idea-expression dichotomy). Examples of commercial users of protected copyright works are: broadcasting/ webcasting institutions (TV and radio), businesses related to leisure activities (e.g. sports clubs, dance classes, hotels or motels, eating and drinking establishments, night clubs, etc.), sound and audiovisual producers, and music services.

While the latter two categories interact directly with the right holder for the licence of one (e.g. a song, some footage, or a picture) or more (up to millions of music tracks) copyright works, and therefore they are able to negotiate at arm's length their terms and conditions, broadcasting organisations and leisure businesses pay blanket licenses to collecting societies. The licences vary according to the use the business makes of the copyright material, the size of the business and other factors. ${ }^{378}$ Their general terms and conditions, and the amount of the remuneration, are negotiated by the association of each category. There is no margin for individual negotiation, especially in countries in which the system of collecting societies is centralised. ${ }^{379}$

\footnotetext{
375 Green Paper, Copyright in the Knowledge Economy, Brussels, COM(2008) 466/3.

376 Council Directive 2001/29/EC of 22 May 2001 on the harmonisation of certain aspects of copyright and related rights in the information society, Official Journal L 167, 22/06/2001 P. 0010 - 0019.

377 Max Planck Institute 2009 at 2.4.1.

378 See e.g. for the US Stim 2007, at 123.

379 See Ricolfi 2005.
}

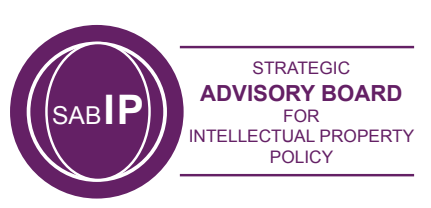


However, in general, commercial users seem to have the chance, directly or indirectly, to negotiate the usage restrictions of the copyright works for which they purchase a licence.

\section{Conclusion}

The above review of the commercialisation of copyright works suggests that standard form contracts prevail in the commercialisation of information goods, although no empirical research assessed the exact share of the adoption of such contracts by the different industries (software, music, literary works, etc). Individual users, not surprisingly, seem to be more affected than corporate bodies from overly restrictive terms and conditions. But the real impact of the latter on users' entitlements stemming from copyright law and principles has not yet been systematically assessed. The position of public libraries and educational institutions is also interesting: the studies reported above highlight licensing terms inconsistent with copyright law, however none of them report attempts to directly negotiate different terms with the copyright industry.

\subsection{DOCTRINAL ANALYSIS OF CONTRACT LIMITS}

Freedom of contract is an established principle both in the EU and the US. In Europe, some argue it is indirectly protected by fundamental human rights. ${ }^{378}$ In the US, contracts enjoy rather extensive protection from constitutional principles. For example, Art. 1(10) of the Constitution forbids the States to pass legislation able to impair the Obligation of Contracts without the consent of the Congress. ${ }^{379}$ Moreover, the 14th Amendment has been interpreted by case law as protecting the freedom of contract. ${ }^{380}$

Both in the EU and the US most contract norms are default rules, which can be overridden by a different agreement between the parties. ${ }^{381}$ In general, the interpretation of contract terms by courts is not literal, but it is based on the presumed will of the parties, in view of the principle of good faith and of business practices. ${ }^{382}$ The fairness of the contract, in short, is not investigated by courts of law. But they do enquire into freedom of will. In fact, common reasons to rescind a contract, in both the US and the EU, are a) mistake, b) fraud, c) duress. ${ }^{383}$

We need to recall, however, that the above standard contract rules were conceived in the 19th century, when most transactions were carried out at arm's length by parties with equal bargaining power. This scenario is radically changed with the industrial revolution and mass production.

379 Ibid, at 116.

$380 \quad$ Allgeyer v. Louisiana, 165 U.S. 578 (1879), at 589.

381 Guibault 2002, at 116.

382 See e.g. the French Civil Code, Artt 1154-64, and the German BGB Art. 157.

383 Guibault 2002, at 117.
} 
Nowadays it is common practice to offer products to the public accompanied by standard form contracts. In these contracts the seller sets the conditions of the agreement and proposes them to the purchaser for acceptance on a take-it-or-leaveit basis.

In order to protect consumers, as the weaker party of this bargain, legislators have issued a number of statutory limits to contracts. ${ }^{384}$ For example, unlike in the case of arm-length contracts, in relation to standard form contracts courts can enquire into the fairness of the terms and conditions. ${ }^{385}$ Moreover, contract law doctrines such as unconscionability and good faith are also used for consumer protection.

\subsubsection{Unconscionability and good faith}

In the US, contracts can be limited by the doctrine of unconscionability, stipulated by Section 2-302 of the Uniform Commercial Code (UCC) and by Section 111 of the Uniform Computer Information Transactions Act (UCITA). Under this doctrine, a clause is not enforceable if there is a flaw in the bargaining process or if the term is unfair. ${ }^{2}$ In general, this doctrine is more likely to be applied in defence of private consumers, rather than corporate bodies or cultural institutions.
The latter in fact can hardly demonstrate that a term is 'beyond reasonable expectations of an ordinary person or it causes an unfair surprise'. ${ }^{386}$ However, according to some this doctrine can fail to assist copyright works users. A term contradicting copyright law would not be automatically declared unconscionable. In practice, it is argued, every case would be judged assessing what were the reasonable expectations of the purchaser in view of all the facts and circumstances. ${ }^{387}$ Others add that this doctrine is of limited use for consumers of copyright works, because in order to pass the unconscionability test a contract has to be clearly one-sided in favour of the owner; and contract overriding copyright limits would not necessarily appear one-sided to courts. ${ }^{389}$

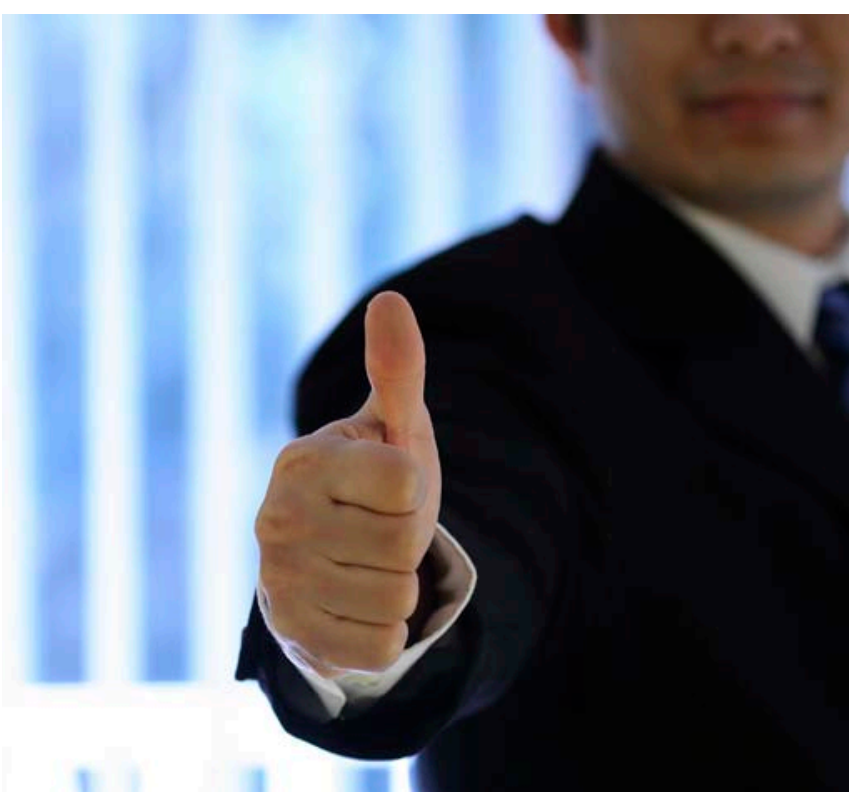

384 Guibault 2002, at 118-119.

385 See the EU Directive 93/13/EEC OJ L 95/29; and for the US the UCC section 2-302, the Restatement of Contracts Section 208 and the UCITA Section 111. Guibault 2002, at 151.

386 Guibault 2002, at 261.

387 Wilson Pharmacy Inc. v. General Computer Corp., Tennessee Ct. App. N. E2000-00733-COA-R3-CV, 2000, cited in Guibault 2002 at 261.

O'Rourke 1998, at 69. 
In Europe, the principle of good faith corresponds to the doctrine of unconscionability. In general, the good faith principle sets a number of rules of correctness to follow before and during the transaction. Civil Law countries all implement a principle of good faith in contract law, although the details of each national provision are different. ${ }^{390}$ Also some common law countries reserve specific legal coverage to the principle of good faith. In the UK the Unfair Terms Regulation 1999 stipulates that a contract term is unenforceable if "contrary to the requirement of good faith, it causes a significant imbalance in the parties'. ${ }^{391}$ 'Whilst another related act, the Unfair Contract Terms Act, does not apply to intellectual property matters and is therefore of no help ${ }^{392}$, some other principles could be helpful. First of all, if a clause of a contract contains a particularly onerous or unusual condition, the party seeking to enforce that condition has to show that it had been brought fairly and reasonably to the attention of the other party, otherwise the term does not apply. ${ }^{393}$ Secondly, the doctrine of undue influence could also be helpful. This doctrine applies when a person in a position of domination uses that position to obtain an unfair advantage for him or herself, and so influences the person relying on their authority or aid. It must be shown that there was a relationship where one party had a dominating influence over the other and the influence was used to bring a manifestly disadvantageous transaction. So far there is no decision applying this doctrine in relation to users' contracts but as we have seen some case law exists in respect of creators' contracts ${ }^{394}$ (see paper 2).
Thirdly, the doctrine of restraint of trade could also be used in a few cases. As is mentioned in paper 2, contracts should not restrict the right of a person to practice their trade. In Schroeder Music Publishing $v$ Macaulay ${ }^{395}$, the court held that a contract with an extended term with no obligation on the publisher to exploit the works of the creator was in restraint of trade. The effect of these two doctrines is to render the contract or else the clause unenforceable. However, these doctrines have been applied in most egregious cases and only in relation to creators' contracts so that it is not immediately obvious that those doctrines would be as applicable in the field of users' contracts. Indeed, few contracts will be entered into under undue influence (unless one could say that a party having a dominant position is akin to exercising undue influence). However, some user contracts may more often restrain the ability of the person to practise their trade. One can think of the case of a journalist or reviewer who relies on the criticism or review and/or news reporting exceptions for their trade.

Their trade would be restricted if a contract overrode these exceptions. However, there is no literature on this case law which relates to its application in users' contracts.

Finally, common law equity plays a remedial role in contract law, which can also usefully be applied to user contracts. As far as we know, there is no case law relating specifically to users' contracts.

\footnotetext{
390 The doctrine of good faith is different from country to country. See Musy 2000.

391 Unfair Terms in Consumer Contract Regulation (SI 1999 N. 2083), S 5(1).

392 See Schedule 1 paragraph 1(c) of the UCTA. The UCTA can be applied to terms in IP contracts but it does not apply to the terms that create or transfer a right or interest in intellectual property, or relate to the termination of any such right or interest, which are the relevant terms in most users' contracts.
}

393 Interfoto Picture Library v. Stiletto Visual Programmes [1988] 2 W.L.R. 615; [1989] Q.B. 433.

394 O’Sullivan v. Management Agency [1985] QB 428); Elton John v. James [1991] FSR 397. 
Another European doctrine impacting on contracts is the contra proferentem rule. ${ }^{396}$ According to this norm, in case of doubt, a clause of a contract is interpreted by courts in the sense less advantageous for the party that sets the clause. The rationale of this provision is in addition underpinned by the aim to protect the weakest party of a contract. ${ }^{397}$

No case law hitherto applied the principle of good faith or the contra proferentem rule to the interplay between contract and copyright limits. But the literature on the point highlights that the potential outcome of practical case law is difficult to foresee. Even in countries all applying the above principles to contracts, courts could take different stances on the matter. Guibault suggests that, for example, a contract would probably prevail on copyright exceptions in France, but it could have some of its clauses rejected as unfair in the Netherlands and Germany. ${ }^{398}$

In conclusion contract law principles are of uncertain help in the case of users of copyright works restrained in their access and use of creative works from overreaching terms and conditions. However, as far as the UK is concerned, the lack of case law and doctrinal analysis on the issue probably shows another gap in the literature. It may be useful to consider a doctrinal study on the application of general English contract law to copyright

\subsubsection{Limits to contracts set by Copyright law: The doctrine of pre-emption}

As observed in Section A, in the US copyright limits can in principle be overridden by contract. However, the interplay between contract law and copyright law is complicated in the US by the federal structure of the country. Contract law is a matter for state legislation and copyright law falls under the jurisdiction of federal law. The latter, under certain circumstances, can preempt the former. This is the essence of the preemption doctrine.

Section 301(a) of the US Copyright Act ${ }^{399}$ prevents states from granting protection equivalent to copyright. Two questions need to be answered positively for a state law to be preempted by federal law. The first question is whether the subject-matter protected by the state law in question is eligible for copyright protection under sections 102 and 103 of the Copyright Act (i.e. the state law must deal with a fixed work of authorship that comes within copyright subject-matter). The second question is whether the rights granted by state law are equivalent to the exclusive rights provided under section 106 of the Copyright Act ${ }^{400}$.

396 This principle has been codified in Art 4(6) of the UNIDROIT Principles of International Commercial Contracts 2004, available at http://www.unidroit.org/english/principles/contracts/principles2004/blackletter2004.pdf.

397 Guibault 2002, at 144

398 Guibault 2002, at 298-299.

39917 U.S.C. $\S 301$ et seq.

400 See Abrams 1983, at 548-549; and McGee 1998, at 1038. 
This second part of the test is called the 'extra element test'. ${ }^{401}$ According to the 'extra element test' a right provided by state law is equivalent to copyright, and therefore pre-empted by federal law, if it is infringed by the mere act of reproduction, adaptation, performance, distribution or display of the work. ${ }^{402}$ The legislative history of section 301 is muddled to the point that it is impossible to know with certainty whether misappropriation and contract laws are or are not pre-empted. ${ }^{403}$ This has caused some difficulties to courts when having to apply Section 301 .

In this respect preemption is similar to the French unfair competition law. The latter provides that a fact or act distinct from infringement is necessary for the action against parasitism to succeed. Similarly, in the US, if the act in question is identical to copyright infringement no misappropriation claim is possible; as in France there must be an additional or different element. In other words it is not possible to protect an uncopyrightable work with the misappropriation doctrine unless the allegedly unlawful behaviour involves an extra element other than mere copying.

A seminal case involving the tension between copyright limits and contract is ProCD. ${ }^{404}$ ProCD commercialised a telephone directory on CD$\mathrm{ROM}$, incorporated in a database managed by proprietary software. The use of the software and of the telephone directory was limited by usage restrictions included in a licence agreement, which was prompted on the computer screen at every access to the product. Zeidenberg bought the $C D$, copied the directory, and published it on his website.
ProCD claimed both copyright infringement and breach of contract. The first claim was not upheld (in relation to the directory listing) for lack of originality. The second claim, on the contrary, was upheld, although Zeidenberg claimed that he did not have the possibility of reading the terms of the licence. ${ }^{405}$

In the ProCD case, Judge Easterbrook rejected the preemption of the licence under Section 301. He reasoned that a simple two-party contract is not 'equivalent to any of the exclusive rights within the general scope of copyright' and therefore may be enforced. ${ }^{406}$

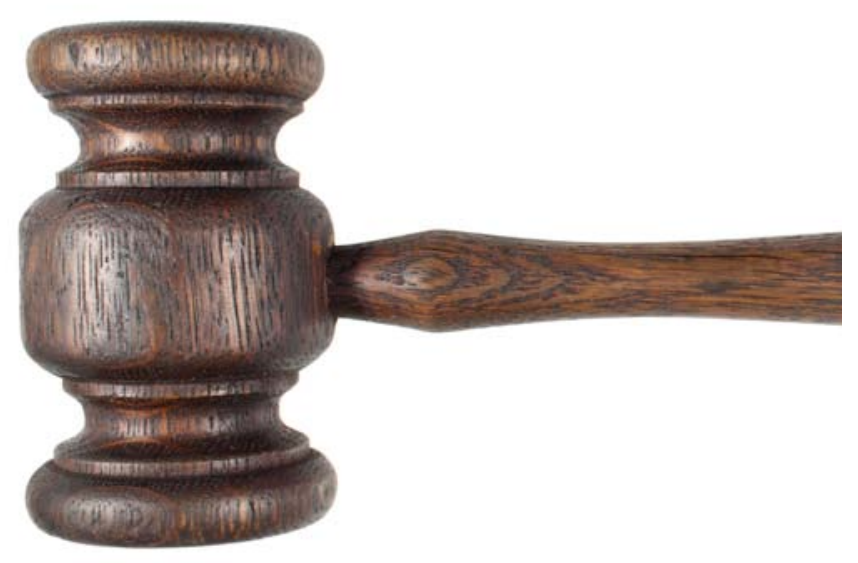

401 For an in-depth analysis of the test see De Werra 2003, at 264.

40217 U.S.C. §106; Computer Associates Int'l, Inc. v. Altai, Inc., 982 F.2d 693, at 716 (2d Cir. 1992); Guibault 2002, p. 231.

403 For an explanation regarding misappropriation see Ginsburg 1992, p. 356-357. For an explanation regarding contracts, see Guibault 2002, p. 232.

404 ProCD, Inc. v. Zeidenberg 86 F. 3d 1447 (7th Cir. 1996). See also Madison 1998.

405 For a detailed analysis of the ProCD case and its impact on the interplay between copyright and contract see De Werra 2003, at $255-263$.

406 ProCD v. Zeidenberg, 86 F.3d at 1455.

407 See e.g; Guibault 2002, Elkin Koren 1997, De Werra 2003.

Providing Government with strategic, independent and evidence-based advice on intellectual property policy.

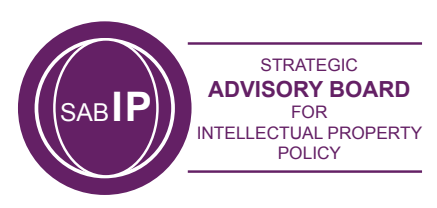


The case had wide coverage from copyright scholars arguing either in favour of or against Easterbrook's construct. ${ }^{407}$ Moreover, US e-commerce legislation (the UCITA) following the ProCD case was underpinned by the same reasoning that inspired Judge Easterbrook. ${ }^{408}$ The drafters of the UCITA specified that the preemption doctrine would 'seldom apply to contracts'. In sum, the reasoning in both case law and legislation was essentially the following: federal copyright law cannot normally preempt state contract law because contracts are simply not equivalent to copyright. ${ }^{409}$ And this reasoning was resumed also in subsequent case law. ${ }^{410}$

A previous ruling to Pro $C D$, however, had expressed the opposite view. In the Vault case, ${ }^{411}$ Vault manufactured a diskette with a copy protection device. Quaid circumvented the copy protection device, to be able to copy the content of the diskette. $\mathrm{He}$ also studied the protection system, so when Vault upgraded his product, Quaid was ready with a new work-around. The court in Vault upheld the prevalence of federal copyright law over state law. Under the law of the state in question (the Licence Act of Louisiana) the unauthorised reproduction of protected material is not permitted. The federal Copyright Act, on the other hand, allows archival copies and copies which are an essential step in the utilisation of a computer program. Moreover, in Vault it was argued that the Louisiana Licence Act grants unlimited protection to copyright material, while the federal Copyright Act grants a protection which has limits in terms of duration and originality. In conclusion, although the court did not expressly mention the preemption doctrine, Vault's claims were rejected.

In Bowers which followed the ProCD ruling, Justice Ryk dissented, recalling the reasoning in Vault. He argued that only when a contract is negotiated at arm's length is the extra element fulfilled and the preemption is barred. ${ }^{412}$ According to him, Bowers is different from ProCD because Baystate needed to reproduce part of the program to benefit from the fair use exemption. State law prohibiting reverse engineering contrasts with federal law allowing it, and therefore the latter should preempt the former. ${ }^{413}$

408 The same aim that inspired the outcome of ProCD, that is not stifling online commerce, also inspired the US Government, which added an Article 2B to the Uniform Commercial Code, upholding electronic licenses once and for all. This Article was the object of extensive debate among copyright commentators, and eventually entered the Uniform Computer Information Transactions Act (UCITA), which was also greatly criticised. See Cohen1998, Ginsburg 1998, Samuelson 1999, Litman 1998, Nimmer 1998, Dam 1999. For a summary of many of these positions see Samuelson 1999. The UCITA however was adopted in only two states of the US (Virginia and Maryland), and other states enacted specific legislation (BOMBSHIELD) to avoid the possibility that the UCITA could be applied on their territory via contractual clauses of 'choice of forum.' See http:// www.ucita.com/.

409 Guibault 2002, at 233.

410 Bowers v. Baystate Technologies, Inc., 29 Jan 2003, 320 F.3d 1317 (the federal Copyright Act did not preempt the prohibition of reverse engineering embodied in Bower's shrink-wrap license).

411 Vault Corp. v. Quaid Software, Ltd., 847 F.2d 255 (5th Cir. 1988).

412 Bowers, at 1337.

413 Ibid, at 1338.

Providing Government with strategic, independent and evidence-based advice on intellectual property policy. 
In conclusion, while cases like Vault may suggest that contracts cannot override copyright limits, cases like ProCD, which is still cited in subsequent case law, indicates the opposite.

It is unclear whether adhesion contracts, which provide right holders with even more protection than negotiated contracts, are pre-empted under section 301 of the Copyright Act. ${ }^{414}$ In line with the reasoning of Justice Ryk who dissented in Bowers ${ }^{415}$, some argue that the preemption doctrine applies specifically to standard form contracts, and does not apply to arm-length contracts, because only the former offers a protection to right holders that is equivalent to statute. In short, they think that the private ordering provided by standard form contracts equates with copyright law, and therefore is preempted by federal law according to the second step of the preemption test. ${ }^{416}$ In sum, courts seem to be divided on this issue, which makes contract law rather unreliable as a tool to override copyright limits. ${ }^{417}$
However, the preemption doctrine is not limited to the interface between state law and federal copyright law. Even if a State cause of action based on misappropriation or contract survives section 301 preemption, it can still be preempted on the basis of the Supremacy Clause of the Constitution (art. VI §2 ${ }^{418}$ ). Under this clause, a cause of action may be preempted if its enforcement would 'stand as an obstacle to the accomplishment of the full purposes and objectives of Congress'. ${ }^{419}$ In the Feist case, the last precedent on the point, the Supreme Court seemed adamant that certain unfair competition claims survive to protect sweat of the brow efforts. ${ }^{420}$ However, it is unclear under which conditions such claims would survive preemption. ${ }^{421}$ In sum, in the absence of a ruling of the Supreme Court on this issue, the law on this matter is uncertain. The constitutional preemption will be discussed below, in the subsection dedicated to constitutional limits to contract.

\footnotetext{
$414 \quad$ Derclaye 2006, at 183.

415 Ibid, at 1337.

416 Karjala 1997.

417 De Werra 2003 at 272.

418 Derclaye 2008, citing Djavaherian 1998, at 88-90. The Clause states: 'This Constitution, and the Laws of the United States which shall be made in Pursuance thereof; and all Treaties made, or which shall be made, under the Authority of the United States, shall be the supreme Law of the Land; and the Judges in every State shall be bound thereby, any Thing in the Constitution or Laws of any State to the Contrary notwithstanding.' In ProCD the court did not analyse the issue. If the analysis in Vault had been applied to ProCD's facts, the licence may well have been pre-empted under the Supremacy Clause. Guibault 2002, at 235 citing Nimmer, Brown and Frishling 1999, at 63; Karjala 1997, at 540. This is because ProCD was restricting the use of facts that both the Supreme Court (in the Feist case) and Congress (in the Copyright Act) decided to leave unprotected.
}

419 Kewanee Oil Co. v. Bicron Corp., 416 U.S. 470, 479 (1974).

420 Feist Publications, Inc. v. Rural Tel. Serv. Co., Inc., 499 U.S. 340, 354 (1991), citing Nimmer, § 3.04, at 3-23: 'Protection for the fruits of such research ['sweat of the brow'-type research] ... may in certain circumstances be available under a theory of unfair competition'.

421 Hovarth 1998, at 479 and Fujichaku 1998, at 467 nevertheless believe this reference in Feist implied that misappropriation is not pre-empted by the Copyright Act. 
In Europe, the relationship between Community law and national law is clearer. EU law prevails over national law.422 Thus, national legislation overriding imperative copyright exceptions set by $\mathrm{EU} \mathrm{law}^{423}$ is not applicable, and clauses protected by such national law should be declared null and void. Cases such as ProCD therefore would be resolved by competition law legislation, or the legislation protecting the sui generis right of database producers. ${ }^{424}$ Regrettably, no such cases have yet been decided by European courts.

A threatened litigation between the National Portrait Gallery of London (NPG) and Derrik Coetzee (a Wikipedia administrator) has the potential to shed some light on the matter. The NPG threatened to sue Coetzee for database right violation, copyright violation, circumvention of TPMs, and breach of contract (a browse-wrap licence), because he copied more than 3000 images from the NPG website and published them in Wikipedia. ${ }^{425}$ The images are photographs of paintings that are no longer covered by copyright protection.

If the UK law applies (Wikipedia is based in the US), and if the photographs are found unprotected by copyright, a ruling could finally clarify a) whether browse-wrap licences are enforceable, and b) whether a contractual clause that forbids the reproduction of a public domain work is unlawful because it overrides copyright limits. ${ }^{426}$

\subsubsection{The doctrines of misuse and abuse of rights}

Stemming from US intellectual property principles, the doctrine of misuse of copyright is another instrument to be possibly employed which can be used to limit contractual clauses attempting to expand copyright protection. Under copyright misuse doctrine, practices which preclude others from developing and creating new works under pretext of copyright protection are abusive. Copyright misuse does not give the victim of misuse a right (and therefore it does not give them standing in a legal action) but only a defence against copyright infringement. During the period copyright is misused, the exclusive rights of the owner are suspended, thus excusing the acts of infringement. ${ }^{427}$ This doctrine is mostly used in connection with antitrust claims, or it is considered together with claims of an economic nature. ${ }^{428}$ It is therefore more likely to be employed between commercial entities rather than in favour of a private consumer.

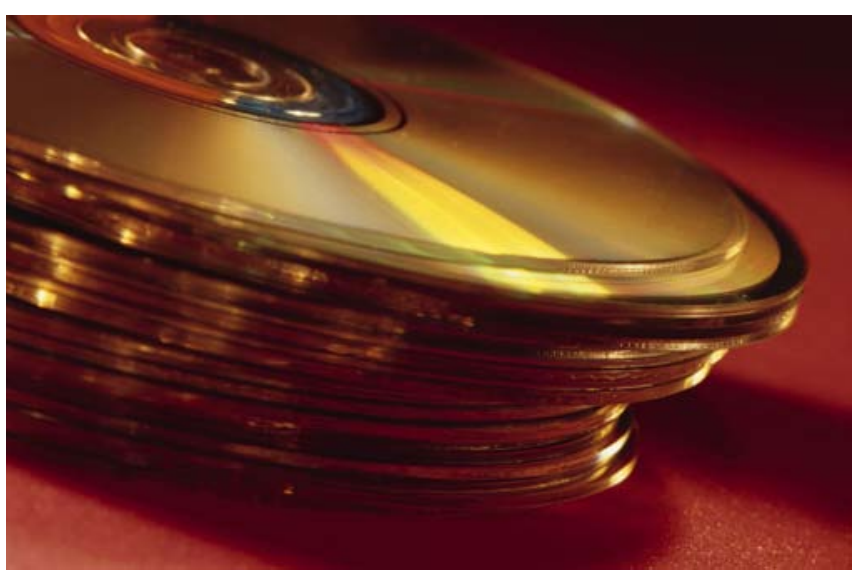

422 See Costa v. ENEL Case 6/64 [1964] ECR 585, 593.

423 For example the exceptions stipulated by the Software directive and the Database Directive.

424 As the EU Database Directive. This point is argued by De Werra 2003, at 263.

425 A global online encyclopedia built up with voluntary contributions by users. http://www.wikipedia.org.

426 However, this second point has not yet been addressed by the letters of the respective counsels. See the terms of the debate and the letters of NPG and Coezee counsels at http://commons.wikimedia.org/wiki/User:Dcoetzee/NPG_legal_threat.

427 Bell 2007, at 578 .

428 Guibault 2002, at 286. De Werra 2003, at 278.

Providing Government with strategic, independent and evidence-based advice on intellectual property policy. 
The doctrine of misuse of Intellectual Property Rights is not stipulated by statutes. It was first articulated in Morton Salt Co, ${ }^{429}$ and then in Lasercomb. ${ }^{430}$ In the latter it was declared '[t] he question is not whether the copyright is being used in a manner violative of antitrust law . . . but whether the copyright is being used in a manner violative of the public policy embodied in the grant of a copyright.' 431 In other words, when copyright is used in a way to run afoul of the public policy rationale under which copyright is protected, there is a copyright misuse.

In most countries in continental Europe, the doctrine of abuse of right corresponds to the American doctrine of misuse. Abuse of right can be caused by: a) fault, when a person does not adopt a reasonable and prudent behaviour; ${ }^{432} \mathrm{~b}$ ) intention to harm; ${ }^{433}$ and c) exercise of the right for a different purpose from that for which it was conferred. ${ }^{434}$ According to Guibault this last occurrence shares with its American counterpart the underpinning on which it is based: the protection of public policy. It is in the interest of the community, in essence, that the rights granted by law are used coherently with the purpose for which they were conceded. ${ }^{435}$
Guibault argues that, given the public interest function of copyright, clauses violating statutory copyright law or fundamental copyright exceptions, like the exception for parody, for example, would be abusive under the misuse doctrine. ${ }^{436}$ But clauses that do not impede innovation and creation, as for example the exception for copying from libraries and similar institutions, would not be considered a misuse. A fortiori the same would apply for copyright exceptions justified by the elimination of transaction costs. ${ }^{437}$ Guibault concludes that in practice in the US the copyright misuse doctrine is rarely applied to protect copyright users. Moreover, in Europe it would not be possible to resort to the doctrine of abuse of right in circumstances that in the US would allow protection under the misuse doctrine. This makes these doctrines of limited utility overall. ${ }^{438}$

A few commentators reflecting on the copyright misuse doctrine have argued in favour of its application to cases of contracts overriding copyright limits (arguments based on fair use). ${ }^{439}$

\footnotetext{
429 Morton Salt Co. v. Suppinger Co. 314 U.S. 488(1942). Guibault 2002, at 191.

430 Lasercomb America. Inc. v. Reynolds. 9ll F.2d 970, 979 (4th Cir. 1990). Guibault 2002, at 192.

$431 \quad$ Lasercomb, at 978.

432 Guibault 2002, at 186.

433 Ibid

434 Ibid, at 187.

435 Guibault 2002, at 192.

436 Lasercomb America, Inc. v Reynolds, 911 F.2d. 970 (4th Cir. 1990), at p 978, cited in Guibault Ibid.

437 Guibault 2002, at 285-286.

438 Guibault 2002, at 194.
}

439 Bell 2007 in footnote n.10, citing Judge 2004 (arguing that any attempt to use copyright to gain control over an idea or to deter fair use should constitute misuse and that courts should discourage copyright misuse by denying equitable relief), Knight 2006 (proposing that courts follow a multi-factor balancing test to invalidate copyright licenses that facilitate misuse), Pallas Loren 2004 (proposing that 'if a shrink-wrap or click-wrap clause purports to limit activity that a majority of courts have found to be fair use, that clause should also trigger a presumption of misuse'). 
Some have also called for a modification of copyright statutes to introduce a formal copyright misuse doctrine that can be used against overreaching contracts. ${ }^{440}$ Thomas Bell went a step further by wording a new prospective article in the US UCC that codifies the doctrine of copyright misuse in the sense of outlawing contracts that limit noninfringing uses. ${ }^{441}$ Importantly, in his case law review on the copyright misuse doctrine he admits that current case law (wrongly, in his opinion) applies the misuse doctrine only in cases of copyright infringement, and not against contracts. ${ }^{42}$

In conclusion, on the one hand the preemption doctrine, which is characteristic of the US system, is unreliable as a tool to defend users of copyright works against overreaching contracts. On the other hand, while commentators on the misuse doctrine call for its modification in order to use it against terms and conditions overriding copyright limits (or at least the most fundamental among them), they also admit that current statutes and case law do not suggest the possibility to use such doctrine in this sense.

\subsubsection{Other limits to contracts: Public policy}

Public policy considerations can also limit freedom of contract both in the US and in the EU. In Europe, private agreements are required to respect the ordre public and the good morals, ${ }^{443}$ while in the US contracts cannot run afoul of public policy. ${ }^{444}$
According to a classification operated by Guibault, public policy considerations can be divided into two categories: a) economic public order and b) protective public order. The first produces norms of competition law (rules of antitrust in the US, and rules of fair competition in the EU); the second creates norms of consumer protection.

In relation to competition law, Lucie Guibault analysed Article 81 (ex Art. 85 and 86) of the EC Treaty and title 15 §1-7 of the US Sherman Act, which address respectively the abuse of dominant position in the market and the acquisition or maintenance of monopolistic positions. In both cases the condition for any of the two violations to exist is to have acted 'with improper means'.

The survey of case law she carried out demonstrates that in practice it is very difficult to prove the unlawful behaviour. ${ }^{445}$ Competition law therefore can be of limited utility if a contract overrides one or more copyright limits. Moreover, it is more likely to be used in relation to functional works (like patents) rather than copyright because of the support to innovation that underscores competition law and antitrust policies. ${ }^{446}$ However, the music and film industry probably represent an exception, where the concentration of market power in the hands of few companies can often raise competition issues. ${ }^{447}$

\footnotetext{
440 Bell 2007, at 575. citing Judge 2004 at 937.

$441 \quad$ Ibid, at 573.

$442 \quad$ Bell 2007, at 579.

443 See French Civil Code art. 6, and German Civil Code Art. 138.

444 See Restatement of Contracts, Art. 178(1).

445 Guibault 2002, at 294.

446 De Werra 2003, at 287.

447 De Werra 2003, at 288.
} 
In the US, the essential facilities doctrine has been examined as a potential instrument to limit overreaching contracts. The doctrine of essential facilities requires: a) the possession of an essential facility by a monopolist, b) the impossibility for the competitor to access such facility, c) the denial of a licence by the owner, d) and the viability of practical access to the facility.

In the famous antitrust case against Microsoft, ${ }^{448}$ which was considered by copyright literature as a perfect opportunity for the application of the essential facilities doctrine, ${ }^{449}$ this doctrine was not applied. It is true that Microsoft was obliged to disclose features of its products to its competitors, but only under section 2 of the Sherman Act (abuse of dominant position). This clearly shows the difficulty of applying such doctrine to the interplay between copyright and contracts.

De Werra argues that, albeit useful to regulate abusive behaviours based on copyright protection, antitrust law alone cannot be relied upon to protect the interests of copyright users. Public policy as a limit to contracts overriding copyright limits can be difficult to apply. He warns that the legislation embodying public policy, which cannot be overridden by private agreement, has to be 'crystal clear'; and this is not necessarily easy in the copyright field, where fundamental concepts like fair use and the idea-expression dichotomy are defined by courts and not by law. ${ }^{450}$ Copyright law and antitrust law, he concludes, should both be used to stem overreaching behaviours of those implementing technical protection measures and contracts. ${ }^{451}$

\subsubsection{Consumer protection}

In the EU a limit to national contract law resides in national and supranational consumer protection legislation. The EU Directives providing for consumer contractual rights are:

- $\quad$ Directive 85/577/EEC on Contracts Negotiated Away from Business Premises;

- $\quad$ Directive 93/13/EEC on Unfair Terms in Consumer Contracts (Unfair Terms Directive);

- $\quad$ Directive 97/7/EC on the protection of consumers in respect of Distance Contracts (Distance Contracts Directive);

- Directive 1999/44/EC on Certain Aspects of the Sale of Consumer Goods and Associated Guarantees;

- Directive 2000/31/EC Directive on Electronic Commerce (E-commerce Directive).

They generally set duties of correct behaviour for the seller of products, either commercialised online or through traditional means. A few of their provisions may also apply to consumers of copyright works.

According to Article 4 of the Distance Contracts Directive, for example, right holders should disclose to the purchaser 'the main characteristics of goods and services'. When implementing TPMs on copyright works, therefore, the owner has the duty to inform the end-user preliminarily. ${ }^{452}$

\footnotetext{
$448 \quad$ United States v. Microsoft Corp., 84 F. Supp. $2 d 9$ (D.D.C. 1999).

449 See O'Rourke 1995, at 546-548 and De Werra 2003, at 290-291.

450 De Werra 2003, at 280.

451 De Werra 2003, at 293.

452 See Helberger and Guibault 2005, at 12. See also the OECD 2006 report on disclosure of this information on DRM regarding digital copyright works.
} 
Moreover, to those digital copyright works that are considered goods (the statutes seem to suggest that on-demand downloadable works are services) the same directive stipulates, in Article 6(1), a right of withdrawal from the purchase, without penalty or justification. However, Article 6(3) excludes from its scope audio/video recordings and computer software.

The Unfair Terms Directive of 1993 outlaws contracts contrary to good faith, and lists a number of unfair clauses as an example. However, the overridability of copyright exceptions is not mentioned in the list, and it is therefore unclear whether a similar clause would be considered contrary to good faith by courts. ${ }^{453}$

It is worth noting that the above-mentioned directives on e-commerce and unfair terms are in the process of being modified by the Consumer Rights Directive, whose proposal was launched in 2008. ${ }^{454}$ The proposal, among other things, replaces the indicative list of unfair terms with a black list of mandatory unfair terms and a grey list of presumed unfair terms. Neither of them, however, states that terms contrary to statutory law are unfair. ${ }^{455}$

In the UK, consumer protection is covered by specific legislation, also implementing the above EU directives:

- $\quad$ Unfair Contract Terms Act 1977

- Sale of Goods Act 1979

- $\quad$ Consumer Protection Act 1987
- $\quad$ Unfair Terms in Consumer Contracts Regulations 1999

- $\quad$ Consumer Protection (Distance Selling) Regulations 2000

- $\quad$ Electronic Commerce Regulations 2002

The Unfair Terms Regulation 1999 stipulates that a contract term is unenforceable if "contrary to the requirement of good faith, it causes a significant imbalance in the parties'. ${ }^{456}$ This provision of consumer law has been identified by copyright doctrine as the only one applicable to copyright users. ${ }^{457}$

In the US, Section 2-302 of the UCC (later Section 111 of the UCITA) serves a comparable function by applying the unconscionability doctrine to consumer protection. As noted in the previous section, the US unconscionability doctrine seems to be more restrictive than the European good faith doctrine, and both appear to have a limited utility for the protection of consumers of copyright material. ${ }^{458}$ Consumer protection therefore does not seem to add a particular protection to users of copyright works beyond the already examined contract law doctrines. Specific legislation on consumers is rarely applicable to consumers of copyright works. In fact, copyright literature from both the EU and the US criticises consumer legislation in that it does not take into account the peculiarity of the consumers of copyright information. ${ }^{459}$

$453 \quad$ Helberger and Guibault 2005, at 14.

454 Proposal for a Directive of the European Parliament and of the Council on consumer rights, Brussels, 8.10.2008 COM(2008) 614 final.

455 Ibid.

456 Unfair Terms in Consumer Contract Regulation (SI 1999 N. 2083), S 5(1).

457 Helberger and Guibault 2005, at 14.

458 Guibault 2002, at 261

459 For the US see for example Elkin Koren 2007, arguing that the DMCA and consumer legislation should take into account the peculiar nature of the consumer of information goods. The point is similarly stated by Benkler 2000b. For Europe see Guibault 2002, who seems sceptical on the ability of consumer legislation to protect copyright users. However, according to other commentators, consumer law, if correctly interpreted, has the potential to offer some protection. Mazziotti 2008 , at 132. 


\subsubsection{Constitutional limits to contracts}

Constitutional principles and human rights have been examined by Lucie Guibault as applicable to private relationships, and therefore liable to have an impact on copyright user protection against abusive contract terms. ${ }^{460}$ Preliminarily she addressed the issue of the vertical or horizontal application of constitutional principles.

Constitutional principles are traditionally invoked to protect citizens against the State (vertical action), but more recently they have been used to protect citizens against other citizens (horizontal action). The horizontal action can be direct (when a citizen brings to court another citizen for the breach of a constitutional principle) or indirect (when a citizen acts against the State to obtain the application of a constitutional principle within a private litigation). In Europe the direct horizontal action of the constitutional principles is not obvious. The indirect action is mostly recognised, however. ${ }^{461}$ According to Guibault this is confirmed by European literature and by the case law of the European Court of Human Rights. ${ }^{462}$

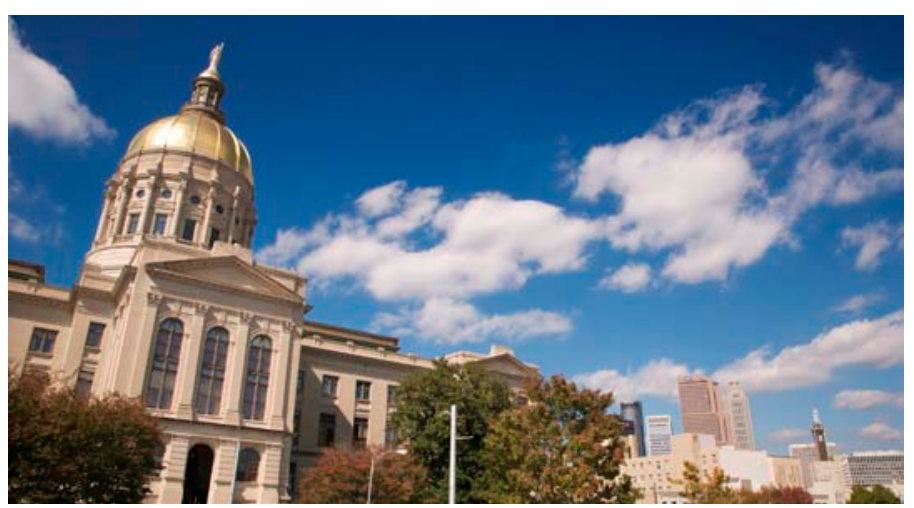

In the US, the Bill of Rights protects citizens only against the State. As a general principle, in fact, the US Government tends not to intrude into private relationships. Therefore the real responsibility of the State in a case of violation of constitutional principles by a private citizen needs to be ascertained case by case. ${ }^{463}$ However, the issue of the direct application of the Constitution among citizens needs to take into account the possibility that a person can waive their constitutional rights. In Europe this is not possible. Only contractual arrangements that do not affect the essential content of constitutional rights are allowed. In the US, on the contrary, the waiver of constitutional principles is allowed, to enable self-governance. But in the case of waiver of fundamental rights the courts subject the validity of the assent to a strict scrutiny. ${ }^{464}$

In the US, constitutional principles on copyright, including the fundamental justification for copyright protection and freedom of expression (underpinning some instances of fair use) can be used to limit contracts on the basis of the Supremacy Clause preemption.

Patterson and Lindberg, for example, maintain that copyright has been invented firstly and mainly to enhance the learning process of the community at large. ${ }^{465}$ Copyright does so by promoting the circulation of culture and the transmission of knowledge.

\section{$460 \quad$ Guibault 2002, at 152-175.}

461 Guibault reports that in France there are two opposed doctrines on the direct horizontal working of constitutional rights, while in Germany the horizontal working is confirmed by Article 1 of the Constitution. Moreover the case law mostly recognises the indirect horizontal working. See lbid.

462 According to Guibault the case law of the ECHR points to an indirect application of constitutional rights to private relationships. See lbid.

463 Guibault 2002, at 295.

464 Guibault 173-184.

465 Patterson and Lindberg 1991. 
Neil Netanel ${ }^{466}$ claims that copyright is a direct vehicle of democracy, by boosting exchange of ideas and communication of thoughts. All these authors maintain that if copyright law were applied by courts in such a way as to uphold and guarantee these fundamental copyright underpinnings, the balance between owners and users would be achieved. ${ }^{467}$

Guibault argues on this basis that she would expect a contract clause overturning copyright fundamental principles, founded on freedom of expression and the diffusion of culture, to be held null and void. 468 But the real potential and scope of the constitutional preemption is unclear, and the outcome of case law addressing the above issues would be uncertain both in Europe and in the US. ${ }^{469}$ In practice, examining case law on freedom of expression, Guibault concludes that the courts decide on the basis of whether the restriction imposed by the owner is content-based or content-neutral. ${ }^{470}$ Content-based restrictions are very difficult to enforce because more obviously in breach of freedom of expression. In contrast content-neutral clauses are upheld if they satisfy a 'substantial governmental interest.' 471
Finally some commentators argue that, just like federal preemption, constitutional preemption also applies only to standard form contracts. ${ }^{472}$ But there is no case law confirming such a construct. In the case Goldstein v. California the Supreme Court held that states cannot use their legislation 'to protect that which Congress intended to be free and free that which Congress had protected.' But the case at hand refers to state legislation directly, and not to a contract. ${ }^{473}$

\section{Conclusion}

The above suggests that limiting contracts to protect the interests of copyright users can hardly be done effectively outside copyright legislation. ${ }^{474}$

$466 \quad$ Netanel 1996.

467 For an analysis of the solution to overreaching contracts through an interpretation of contract law in the light of copyright law itself see Derclaye 2006, at 188-211. The author argues, in essence, that a correct interpretation of existing copyright law and case law would provide an answer to the question of the overridability by contract of copyright exceptions

468 Guibault 2002 at 270.

469 Ibid.

470 See Netanel 2005. In the case of content-based restrictions, copyright legislation (including both exclusive rights and exceptions) impacts on works whose content is the reason why the rights are claimed. This normally occurs in cases where parody or criticism is called into play. In this case, Netanel argues, the scrutiny in the light of freedom of expression has to be strict. This means that freedom of expression can be identified also beyond the boundaries of copyright limits. In the case of content-neutral restrictions, copyright entitlements are claimed irrespective of the content of the work. One example could be the exception for private copying. In the case of content-neutral claims, Netanel claims it is not necessarily 'a strict scrutiny' on compliance with freedom of expression. This means that in this second case copyright exceptions have to be interpreted narrowly; i.e. their construct should not go beyond their boundaries. Strowel and Tulkens add that all issues regarding access are content-neutral, therefore they only require an intermediate scrutiny. This means that the in-built safety valves of copyright provide enough scrutiny for freedom of expression. See Strowel and Tulkens 2005.

471 Guibault 2002, at 296.

472 Karjala 1997, at 540 and De Werra 2003, at 271.

473 De Werra 2003, at 272.

474 Derclaye 2006.

Providing Government with strategic, independent and evidence-based advice on intellectual property policy.

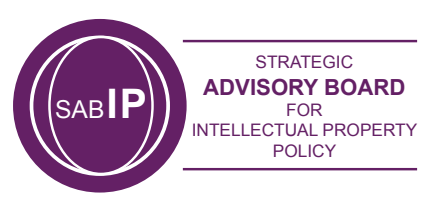


The InfoSoc Directive may be modified as a result of consultations following the Green Paper on 'Copyright in the Knowledge Economy'475 and the moment is timely to introduce some provisions that would guarantee such results. Some of the questions in the Green Paper include: Should there be encouragement or guidelines for contractual arrangements between right holders and users for the implementation of copyright exceptions? Should some limits be made imperative?

Many academics and institutions have responded by suggesting the introduction of new provisions which would at least protect fundamental copyright limits from contracts and TPMs. ${ }^{476}$ It remains to be seen to what extent the EU legislature will listen to the calls from the above commentators.

Hitherto we have analysed the interplay between contracts and copyright exceptions. However, it is worth noting that electronic licences are typically directed towards millions of end-users who are very difficult to track down and to bring to justice in case of infringement. The difficulty in enforcing electronic licences would limit in practice the threat posed by contracts to copyright limits. However, the implementation of technological protection measures has provided unprecedented possibilities for effective self-enforcement.

\subsection{DIGITAL RIGHTS MANAGEMENT (DRM), AND THE ENFORCEMENT OF CONTRACTS}

\subsubsection{The dangers of digital lock-up}

DRM consists of licensing agreements and technological protection measures (TPMs) which set access and usage restrictions on information works. DRM reduces dramatically the costs of negotiation between owners and users of copyright works, and the costs of enforcement of copyright law (transaction costs). Often the acronyms DRM and TPM are used interchangeably, to indicate the latter. This is because the technological part of DRM (i.e. the TPM), by self-enforcing - in other words unilaterally as opposed to bilaterally as with contracts - the rules of the contract, raises the most significant issues in terms of copyright users' protection.

With the advent of the digital era, where the reproduction of copyright works is easy and perfect, many legal commentators envisaged scenarios of substantial change in copyright legislation. Most of them foresaw an increase in copyright protection, in line with the trend of the last decades. ${ }^{477}$ Opposite positions, forecasting a reduction in copyright protection, are rather isolated. ${ }^{478}$

\footnotetext{
475 Green Paper: Copyright in the Knowledge Economy, Brussels, COM(2008) 466/3.

476 See the Comments to the Green Paper at http://circa.europa.eu/Public/irc/markt/markt_consultations/library?/=/copyright_ neighbouring/legislation_copyright\&vm=detailed\&sb=Title. In particular, see the comments from the IViR center in Amsterdam, the MaxPlank Institute in Munich, and the British Library.

477 Minassian 1997, at 21. He states that the diffusion of shrink-wrap licensing in the computer software field will lead to the end of copyright regulations, at least for digital goods, which will be more and more contract-based.

478 Martin Kretschmer, for example, hypothesised a radical subversion of copyright law within a generation. He argues that the current legislation (American, European and international) is counterproductive and ineffective because it hinders the diffusion of culture and information, whereas it should enhance it - and indeed repeatedly claims this in its declaration of intents. The author puts forward his vision: 'Within a generation [...] copyright laws will change, so as to be unrecognisable. There will be a short burst of exclusivity, encouraging fast exploitation, followed by a remuneration right for the lifetime of the creator. Criminal law will retreat to the traditional domain of unauthorised or deceptive commercial exploitation. As we reflect, digital copyright at the turn of the millennium will have marked the end of an era'. See Kretschmer 2003, at 341.
}

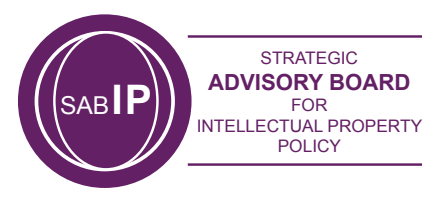


Some commentators salute new technologies such as DRM as the way to fix the imperfections of the market (market failures), which are worsened by the digital environment. Therefore, for some commentators the expansion of copyright through the protection of DRM represents the way ahead. 479 At the opposite end of the spectrum there are other copyright commentators who fear that DRM and the protection of DRM are damaging users' traditional rights. They argue that this trend is dangerous for the public interest, because it dispels traditional allowances for the public to access copyright works. ${ }^{480}$ Some of them advocate radical changes to copyright law in order to resist this trend. ${ }^{481}$ For example, self-enforcing tools should be provided to the user as they have been provided to the owner. ${ }^{482}$ Others argue that a simple transposition of the traditional copyright principles to the digital environment could be sufficient. This in practice would need to ensure that the same balance of rights and exceptions guaranteed by copyright law is re-created in the digital world. ${ }^{483}$
Against the detractors of DRM it has been argued that the technology in itself is neutral, and the use or misuse of it is the only circumstance liable to create problems with copyright law. The study of Patricia Akester mentioned in Section 3 has revealed that DRM developers are able to finetune the technology to meet the needs of the users. ${ }^{484}$ But they do not fine-tune it, because they are not asked to do so by the owner. On the contrary, sometimes users' allowances created by some DRM developers are not utilised. For example, researchers investigating the respect of the exception for disabled people (namely visually impaired people) have found that technical allowances implemented on digital products for the benefit of disabled people are deactivated upon request of right holders. They state:

Microsoft and Adobe, which have implemented the use of TTS [text-to-speech synthesizer] in their eBook reading systems, have heard from publishers that the audio rights to their eBooks may have been sold. Therefore a feature has been added that allows the use of TTS to be turned off. This means that at the time of creation a decision can be made by the publisher to disable the use of TTS for this particular eBook. ${ }^{485}$

\footnotetext{
479 Among these, self-declared copyright optimist Paul Goldstein. See Goldstein 1996, at 236. See also Bell 1998 , at 580.

$480 \quad$ Patterson and Lindberg 1991; Netanel 2001.

481 Hugenholtz 1996, at 99; and Geller 1994, arguing that in the digital environment it would not be enough to adapt old principles. We need a radical revision of copyright.
}

482 Reichman et al. 2007. Heide 2003.

483 Netanel 2001, at 289-290. See also Dreier 2005.

484 See also Turnbull and Marks 2000, reaching the same conclusion.

485 See Kerscher and Fruchterman 2002. On the same topic see Bechtold 3003, at II.3. 
Technology therefore does not seem to be the main problem. ${ }^{486}$ Rather, the use that copyright owners make of the technology on their products can raise concerns. Some have suggested that such overreaching behaviour is allowed by law, and in particular, by the InfoSoc Directive in Europe and by the Digital Millennium Copyright Act (DMCA) in the US. This legislation seems to have created an expanded copyright protection in the digital environment, allowing right holders to control every use and access of copyright works. All in all, they argue, a new right has been created for the owner: a 'right of access'. ${ }^{487}$

Also in Europe the copyright literature has detected in the last decades an expansion of the prerogatives of copyright owners, which in practice gives birth to an enhanced access control on copyright works. They argue that, broadly interpreted, the reproduction right ${ }^{488}$ and the communication right, ${ }^{489}$ as drafted in the InfoSoc Directive, can grant access-control prerogatives to copyright owners. However, a narrow interpretation of these exclusive rights, which in the view of the same literature is the correct one, would outlaw only infringing reproduction and communication to the public, and would not unduly expand the privilege of the owner. ${ }^{490}$
Other commentators argue that access privileges are guaranteed by the anti-circumvention provisions of the InfoSoc Directive, ${ }^{491}$ and are de facto empowered by TPMs. ${ }^{492}$ For some this is a natural effect of the transition from the analogue to the digital world, ${ }^{493}$ while for others this transition unduly creates new privileges. ${ }^{494}$ Also these authors agree that TPMs should not expand the exclusive rights of the owner, and they should respect copyright limits. ${ }^{495}$

However, concerns of legal commentators picturing an evolution of DRM towards technical standards ${ }^{496}$ that do not take into account the entitlements of the user is somewhat contradicted by some recent trends in the music industry. Recently, music service providers are offering their products DRMfree. Initially, these DRM-free business models only interested music supplied by independent labels. ${ }^{497}$

\footnotetext{
486 Bechtold 2003, who states that DRM is an instrument sufficiently flexible to adapt to the new digital environment; contra, see Burk 2005. See also Dam 1999, claiming that this is an ideal instrument to ensure copyright compliance and more efficiency in protecting copyright in the digital environment.
}

487 Vaidhyanathan 2001, at 160. See also generally Lessig 1999.

488 Dusollier 2005b; Westkamp 2004.

489 Dusollier 2000, Heide 2001, Westkamp 2004

490 Dusollier 2005b, at 202; Westkamp 2004, at 1098 and 1103; Dusollier 2000, at 39; Heide 2001, at 368.

491 The provision that forbids the circumvention of TPMs is Article 6 of the InfoSoc Directive. See Koelman 2000 , at 276.

492 Dusollier 2005a, at 109

493 See generally Ginsburg 2000 and 2003.

494 Heide 2001, at 378-379.

495 Ginsburg 2003, at 131; Heide 2001, at 381-382.

496 Burk 2005.

497 See the case of eMusic at http://www.emusic.com.

Providing Government with strategic, independent and evidence-based advice on intellectual property policy.

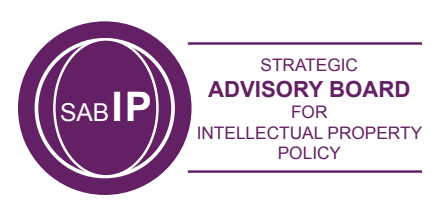


Currently, also the major music labels (the first was $E M{ }^{498}$ ) have agreed to license DRM-free products for mass distribution. Nowadays several music services offer either their whole catalogue in DRMfree version ${ }^{499}$ or they price-differentiate DRM-free products and DRM-protected ones. ${ }^{500}$

This DRM-free feature, however, seems to be limited to interoperability. This means that the above DRM-free products can be played on different rendering devices. But some of them (e.g. the iTunes files) can still be copied only on a limited number of hardware devices. These usage restrictions, set in the licensing agreement, ${ }^{501}$ are likely still to be guaranteed by the implementation of TPMs. Empirical data on this issue are missing, but further research on these new DRM-free business models could be able to shed some light on many issues. First, it could determine to what extent the possibility of enforcing licensing agreements has changed with the introduction of DRM-free products, and what the impact of this new trend on owners and users is. Second, it could clarify whether fine-tuning rather than eliminating DRM systems could meet the needs of users of copyright works, as has been suggested by some theoretical research. ${ }^{502}$

\subsubsection{Remedies for users against 'unfair' DRM}

Remedies available for beneficiaries of copyright exceptions in case of DRM impeding permitted acts are different, both between the US and the EU and within the EU. The reason for this latter difference is that the EU legislation on this matter did not take a clear position, and left ample leeway to Member States.

In fact the InfoSoc Directive in Article 6(4) enjoins right holders to take 'voluntary measures' in order to comply with a selected number of copyright exceptions. Failure to do so, according to the directive, should lead Member States to take 'appropriate measures' to make sure that right holders comply with the listed copyright exceptions. Further clarification of both 'appropriate measures' and 'voluntary measures' is provided by Recital 51 of the InfoSoc Directive. On 'voluntary measures' the Recital offers the example of agreements between right holders and other parties concerned, ${ }^{503}$ clearly showing its preference for self-regulation. If self-regulation fails, Member States have to take 'appropriate measures', which are also specified in Recital 51, and which can involve 'modifying an implemented technological measure' or 'other means. ${ }^{504}$

Such loose wording induced Member States to take different positions on this matter. A synoptic table on the next page provides the solutions adopted by all countries studied in this literature review.

\footnotetext{
498 See http://www.eff.org/deeplinks/2007/04/emi-begins-licensing-drm-free-music-downloads.

499 For example Amazon; see http://www.amazon.com.

500 For example iTunes; see http://www.itunes.com.

501 In fact a survey showed that these DRM-free products are licensed under the usual restrictive terms. See IViR 2007 Part II, at 139 .

502 Favale 2007.

503 Council Directive 2001/29/EC, Recital 51, second paragraph

504 Council Directive 2001/29/EC, Recital 51, third paragraph.
} 


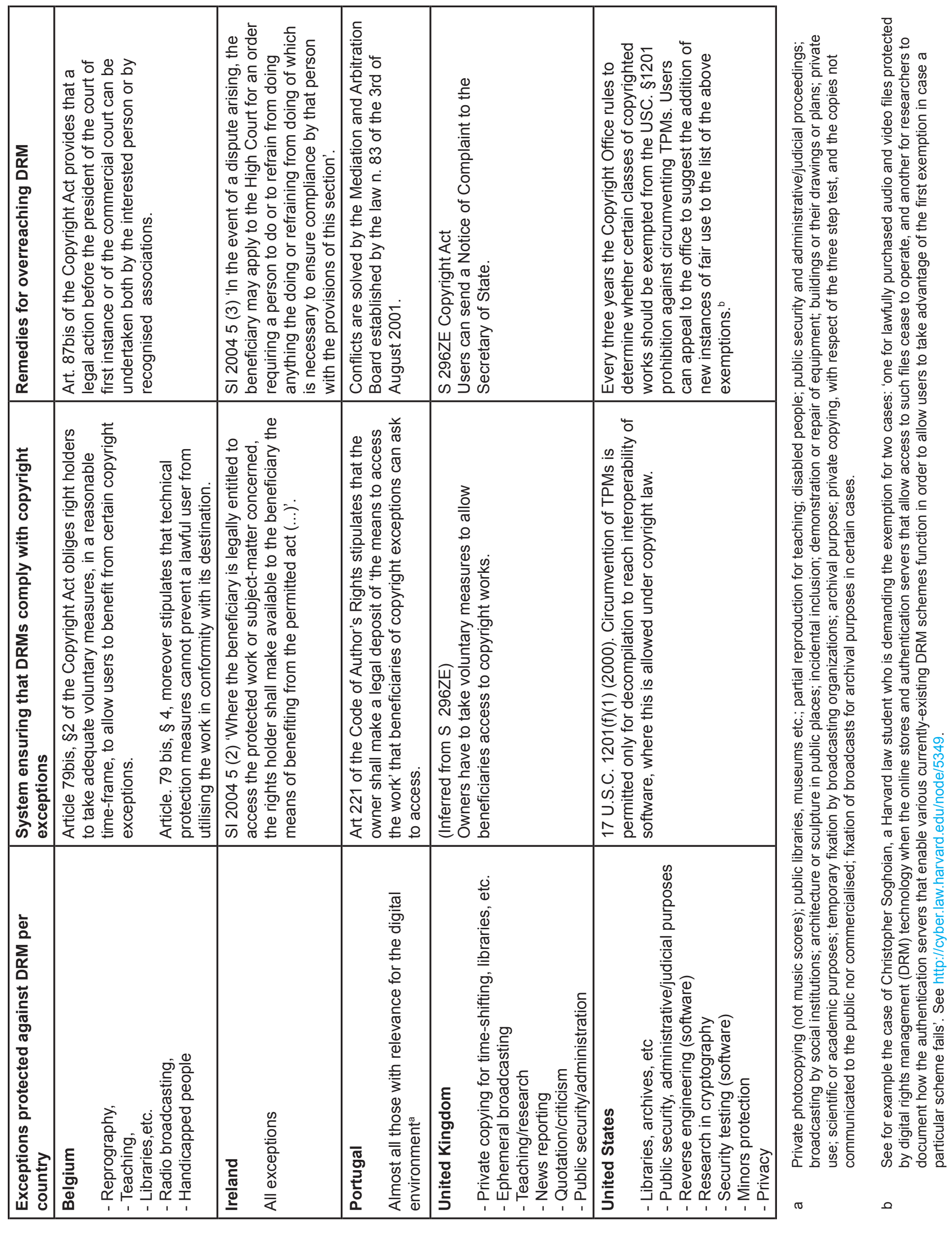


The above shows that the remedies available to beneficiaries of copyright exceptions are very different from country to country. Some of them have also been criticised by the literature for their lack of efficiency or for the excessive burden they set on the user. ${ }^{505}$ The discussion on the effectiveness of the remedies against an 'unfair DRM' is outside of the scope of the present study; however, what is relevant to our discourse is that none of these measures seem to be envisaged to be directed towards contractual abuses from right holders.

\subsubsection{Interplay between DRM and contract}

Copyright mass licensing is a by-product of the Internet revolution. Copyright owners not only license their works to institutions and businesses, but also to end users. However, in case of copyright infringement an end user is extremely difficult to sue. A solution to this problem has been provided by technology: the digital product itself bears some features that enforce the rights of the owner. These are the TPMs, which impede every access and use not authorized by the right holder. Normally, authorized acts are stipulated by the licensing agreement: the contract sets the rules, and the TPMs force users to respect them. ${ }^{506}$

DRM is a composite system formed by licensing agreements and TPMs, which has the objective of setting usage restrictions on digital copyright works. These usage restrictions should normally be limited by the boundaries of copyright protection. In other words, copyright owners should implement TPMs only to the extent that they enforce their exclusive rights provided by copyright law. Contracts (the licences) and technical locks (the TPMs) work in synergy to guarantee the enforcement of exclusive rights in the digital environment, where traditional enforcement tools, like a lawsuit, are not effective. Moreover, among the rules set by the contract, often there is a clause that protects TPMs. The clause might enjoin, for example, that it is forbidden to circumvent, to hinder, or to remove the technological lock. Circumvention of TPMs, therefore, is not only sanctioned by law, both in the US and the $\mathrm{EU}^{507}$, but sometimes also by contract. This creates a circular protection between contracts and TPMs. ${ }^{508}$

\section{Conclusion}

In conclusion, the strict inter-relation between contract and TPMs may suggest that contracts are akin to TPMs. Both are part of the product, ${ }^{509}$ and both set usage rules that in the views of many go beyond the exclusive rights of the owner. Furthermore, some highlight that licensing agreements and DRM licences are often formulated in a similar fashion. ${ }^{510}$ However, the literature overview in the previous subsection suggests that the only relevant similarity between licences and TPMs consists in the ability to set norms of private ordering that might run afoul of copyright doctrine. Surely, TPMs and contracts are indissolubly intertwined. They work together and according to the prevailing literature they should be designed to comply with copyright law, that is, to protect the exclusive rights of the owner only within their boundaries.

\section{See Brown and Bohm 2001.}

506 Without the TPMs users would not respect the terms and conditions set by contracts. See De Werra 2003 at 250.

507 See Title 17 USC $\S 1201$, Article 6 of the InfoSoc Directive, and S 296ZA of the UK Copyright Act.

508 See IViR 2007 Part 1, at 153-149.

509 In ProCD the judge argued that 'Terms of use are no less a part of 'the product' than are the size of the database and the speed with which the software compiles listings'; see ProCD II, 86 F.3d at 1453. 1996 U.S. App. LEXIS 14951. See also Friedman 1998, at 1159 arguing that TPMs are a feature of the product, as part of its design. However, he specifies that TPMs are not the contract. patterns to that of the usage rules of the service. Cited in Derclaye 2008, at 175.

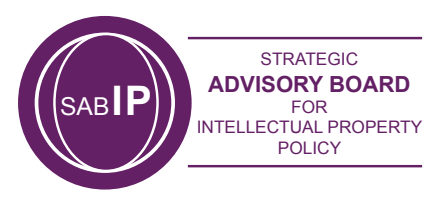




\subsection{EMPIRICAL AND COMPARATIVE STUDIES OF USER CONTRACTS AND DRM}

\subsubsection{Proportion of copyright material diffused electronically}

Of relevant interest to this literature review are first data provided by the International Federation of the Phonographic Industry (IFPI) and by the EU Commission, both in 2009. They are relevant to inferring the diffusion of electronic licences, and the products on which they are implemented. The IFPI reports that the market share of digital products is growing every year. Figures relative to 2008 reported a share of $35 \%$ for games, $20 \%$ for recorded music, $4 \%$ for newspapers, $4 \%$ for films, and $1 \%$ for magazines. ${ }^{511}$ The EU Commission Report on e-commerce 2009 discusses the penetration of e-commerce in the EU Internal Market. The data of interest to our discourse is that on average (in $27 \mathrm{EU}$ Member States) 30\% to $40 \%$ of copyright goods are sold online. More 'mature' markets like the UK, France, and Germany reach $70 \%{ }^{512}$ All material commercialised online potentially implements electronic contracts or end-user licence agreements. However, specific data on the type of contracts (e.g. shrink-wrap; click-wrap or browse-wrap) or the media via which they are diffused (e.g. web pages or booklets) are missing.

\subsubsection{Contracts}

The most comprehensive theoretical study on copyright and contracts in Europe has been performed by Lucie Guibault of the IViR centre in Amsterdam. Her analysis focuses on the US, France, Germany and the Netherlands. In essence, Guibault concludes that the limits on freedom of contract, including consumer protection law, competition law, constitutional principles and copyright law, appear insufficient to ensure that the legitimate interests of users of copyright works are respected by copyright licensing agreements. ${ }^{513}$

From 2002 when Guibault published her comprehensive study new literature, case law and legislation have been produced, impacting on the relationship between contract and copyright law. However none of this seems to bring substantial changes to the general scenario outlined by Guibault. However, her conclusions regarding potential overridability of copyright limits by contract still awaits confirmation by systematic empirical studies. The theoretical debate about the tension between copyright exceptions and contract continues to engross the copyright doctrine. Some authors believe, as Guibault does, that copyright law should offer enhanced shelter to beneficiaries of copyright exceptions against contracts. Some others, conversely, believe that the balance between copyright and contract does not need to be touched. For others, contracts are even more efficient than copyright in protecting the exclusive rights of the owner in the digital environment.

\footnotetext{
511 See IFPI 2009, at 4.

512 EU Commission Staff Working Document, Brussels 5.3.2009 SEC(2009) 283 final.

513 Guibault 2002, at 302-304.
} 
No comprehensive supranational survey seems to have been performed on the interplay between contracts and copyright exceptions. ${ }^{514}$ At national level, outside our area of reference, the most interesting and in-depth theoretical and empirical study has been carried out by the Australian Copyright Law Review Committee..$^{515}$

The theoretical part of the study provides a literature and statute review including Australia, the US and the EU. They also examined potential limits to contract stemming from - or out of - contract law, as Guibault did. Similar conclusions were reached: remedies outside copyright law are of scarce effectiveness. ${ }^{516}$

The data utilised in the empirical part of the study are focused on Australian sources, and were gathered from a public consultation process and an open forum which involved several right holders, users' associations, libraries, and academic institutions. ${ }^{517}$ An Issues Paper was distributed among the stakeholders illustrating the terms of reference and posing a number of questions instrumental to determining the interplay between copyright limits and contracts. ${ }^{518}$ While the representatives of the right holders generally reported that they did not detect any use of licences overriding copyright limits, a few libraries and universities produced examples of contracts hindering copyright exceptions. ${ }^{519}$

The Australian study concludes that 'library and user interests generally identified a problem regarding the use of online licences to modify the exceptions and wanted legislative or other intervention. Owner interests variously asserted that contract law and the market can and should regulate the situation or that although the situation is uncertain, it is too early to take corrective action. ${ }^{, 520}$ The Australian report also highlighted that licensing agreements that are the subject of the analysis are more and more likely to be governed by foreign law. Therefore national solutions could be of limited relevance. ${ }^{521}$

An empirical study on digital media and consumer issues in relation to electronic licences has been performed in Germany by the local branch of the BEUC (the European Consumer Organization). ${ }^{522}$ The study detected legal uncertainties in Germany regarding the application of the exhaustion principle (related to physical copies of digital works, CDs, DVDs, etc.), and cross-border licensing. The legal wording of the licences was also found difficult and detrimental for consumers.

514 The OECD confirmed that empirical studies and measurement of the practices in the distribution of digital content through systematic collection and analysis of data are missing. See OECD $2006 a$ at 34.

515 Available at http://www.ag.gov.au/www/agd/agd.nsf/Page/Copyright_CopyrightLawReviewCommittee_CLRCReports_ CopyrightandContract_CopyrightandContract.

516 Australian CLRC Report 2002, Chapter 1, at 2.09.

517 The full list of the submissions is available at http://www.ag.gov.au/www/agd/agd.nsf/Page/Copyright CopyrightLawReviewCommittee_CLRCReports_CopyrightandContract_CopyrightandContract-Submissions.

518 The Issue Paper can be found at http://www.ag.gov.au/www/agd/rwpattach.nsf/VAP/(756EDFD270AD704EF00C15CF396D 6111) CLRC+Copyright+and+Contract+-+Issues+Paper.pdf/\$file/CLRC+Copyright+and+Contract+-+Issues+Paper.pdf.

519 See the Australian CLRC Study 2002, Chapter 4, Part II.

520 Australian CLRC Discussion Paper, available at http://www.ag.gov.au/agd/www/CIrhome.nsf/Page/F8CF4FE5DCBF1405C A256B3C0076354A?OpenDocument.

521 Ibid. See also DeWerra 2003, arguing for a supranational solution.

522 http://www.verbraucherzentrale.de/.

523 The summary of this study in English is available at http://www.vzbv.de/mediapics/consumer_protection_in_digital_ media_2006.pdf. The study (in German) is available at http://www.vzbv.de/go/dokumente/545/5/24/index.html. 
Another interesting finding for our analysis is that legal entitlements of copyright users (such as the possibility to make a back-up copy of a computer program) were also often impaired. ${ }^{523}$

Case studies have also been performed in the US and Norway on the largest online retail music vendor (iTunes) and some other similar services. They all revealed that the terms and conditions of the service could run afoul of copyright limits (such as the fair use doctrine, for example), negatively affecting consumer statutory rights. ${ }^{524}$

In the UK, the British Library carried out an examination of one-hundred licensing agreements that were offered to them. ${ }^{525}$ They questioned whether the licences at hand allowed the following operations (or accommodated the following needs, or even only mentioned them): Archiving; Printing; Downloading and electronic copying; Fair dealing; Visually impaired; Inter-library loans; Exceptions. The British Library found that $90 \%$ or these licences did not respect these copyright exceptions and limitations. ${ }^{526}$ They elaborate therefore a position on copyright exceptions, which includes a number of principles that, according to the British Library, should inform UK copyright policy. ${ }^{527}$
Also, the National Consumer Council carried out a survey on End User Licence Agreements on computer software, ${ }^{528}$ and found that most of the licences examined infringe consumer protection legislation. Unfortunately, the study did not address copyright issues, but it suggested that the Office of Fair Trading undertake a systematic survey on the practice of electronic licensing to detect potential incongruence with the current legislation.

\subsubsection{DRM}

On the issue of DRM, empirical studies seeking to identify the impact of DRM on beneficiaries of copyright exceptions have been carried out by Intrallect Inc. ${ }^{529}$ and by CIPIL ${ }^{530}$. Intrallect adapted the 'use cases' approach (which is a method originating from the field of software engineering) to the relation between DRM and education and research communities in the UK. ${ }^{531}$ Their study examines a broad number of practical situations affecting researchers, teachers, students, and libraries while interacting with DRM. Their purpose is to suggest to the Joint Information Systems Committee (JISC) $)^{532}$ the best approach and practice to adopt in relation to DRM.

524 Gasser 2004, Grondall 2006, Bechtold 2004.

525 As for the methodological approach relating to this collection, the BL specifies 'The study of 100 contracts comprises a randomly selected collection of agreements offered to the British Library. Given the complexities of licensing and copyright exceptions, being able to map accurately provisions in a licence over to the intent provided for by exceptions law is a complex procedure and one open to debate. The study was carried out in good faith and is intended to be no more than broadly representative.' See http://www.bl.uk/ip/pdf/ipmatrix.pdf.

526 See http://www.bl.uk/ip/pdf/ipmatrix.pdf.

527 See http://www.bl.uk/ip/pdf/digitalexceptions.pdf.

528 The study involved standard questionnaires to users of computer software. See Belgrove 2008.

529 Intrallect. Incc, Digital Rights Management, final report, 22-11-2004 at www.intrallect.com/drm-study/DRMFinalReportv2.pdf.

530 Centre for Intellectual Property and Information Law of Cambridge University, UK. See www.cipil.law.cam.ac.uk.

531 Intrallect's method is illustrated in what follows: 'The methodology is based on identifying the key participants (sometimes called 'actors') and their goals. For each primary actor and goal, one use scenario (or 'use case') is developed in detail and is examined to consider all possible alternatives to that scenario. A set of use cases is complete when use cases have been developed for the goals of all the primary participants. These use cases are described in terms of the user's actions and make no assumptions about underlying technology. The use cases are then used to define the requirements for a system that will support these scenarios'. In short, as the authors of the report state, '[t]he use cases are simply a way of defining what people want to achieve'. See the JISC DRM Study - final report, at 23. 
Their method consisted in organising a number of workshops (six in total) to which they invited a relevant number of representatives of stakeholders (in total 47 participants). ${ }^{533}$ The workshop participants, after an introduction on DRM, were invited to work on their own to produce two case summaries each ('short descriptions of a primary actor and their goals, usually no more than one or two sentences'). The workshop produced 125 case summaries in total. Afterwards, the participants were invited to work in pairs to expand on one of their case summaries to develop a use case. ${ }^{534}$

As a key finding, they identify the needs of the mentioned categories (researchers, teachers, students, and libraries) and suggest an alternative right expression language (REL) ${ }^{535}$ compatible with these needs. They show therefore that TPMs are neither good nor bad. They should be fine-tuned in order to accommodate users' needs.

Patricia Akester from CIPIL carried out another survey on the impact of DRM on selected beneficiaries of copyright exceptions. Nine standardized questionnaires were submitted to representatives of the following copyright players: 1) Libraries, 2) The visually impaired and partially sighted, 3) Private users, 4) Lecturers, 5) Students/ researchers, 6) DRM developers, 7) content owners, 8) The European Commission, and 9) The UK Intellectual Property Office. ${ }^{536}$
The questionnaires were partly open (allowing a free answer from the interviewee) and partly closed (with multiple-choice answers). ${ }^{537}$

She concluded that some beneficiaries of copyright exceptions are being adversely affected by the use of DRM. She therefore suggested a number of legal solutions, involving the modification of article $6(4)$ of the InfoSoc Directive and the involvement of third parties that would guarantee to beneficiaries of copyright exceptions lawful access to copyright works. ${ }^{538}$ Similar solutions have already been proposed by some literature. ${ }^{539}$ However, it has been submitted that, in order to be effective, solutions in a complex field such as DRM , should involve both technological and legal solutions at the same time, coordinated between them. ${ }^{540}$

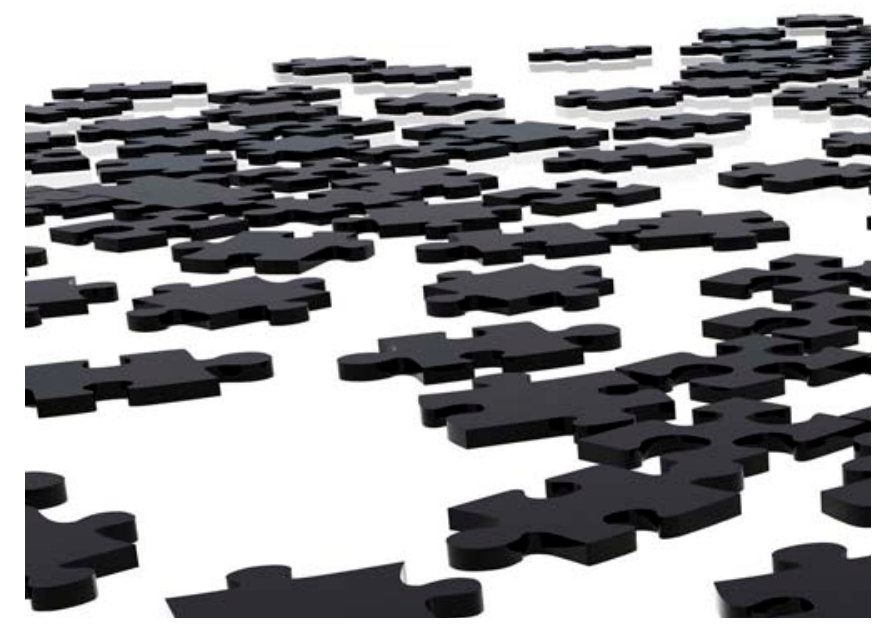

533 For the list of the participants see JISC DRM Study - final report at 23.

534 JISC DRM Study - final report 2004, at 24.

535 Rights Expression Language or REL is a machine-processable language used for Digital Rights Management

$536 \quad$ Akester 2009, at 31.

537 The reason of this choice was 'to combine the need for rigour with the need to understand how respondents themselves describe the issue, in their own language'. Akester 2009, at 31.

538 She proposes to modify Article 6(4) as follows: a) clarifying the expression 'appropriate measures' that Member States have to take in order to have TPMs comply with copyright exceptions, in the sense of creating standardized 'access to works portals'. These would function through a DRM deposit system 'according to which the means to enable beneficiaries of privileged exceptions to benefit from them would be deposited and made available through access to works portals, in specified circumstances.' See Akester 2009, at 2.

$539 \quad$ Erickson 2003; Burk and Cohen 2001.

$540 \quad$ Favale 2007.

Providing Government with strategic, independent and evidence-based advice on intellectual property policy.

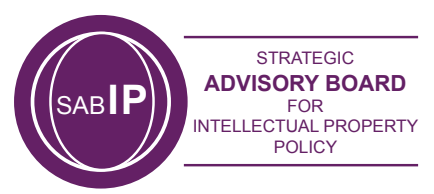


The OECD issued a Background Report on Empowering E-consumers in December 2009 to serve in the conference on the same topic. ${ }^{541}$ The conference and the report, together with other OECD publications, will be instrumental to the second edition of the OECD Guidelines for Consumer Protection in the Context of Electronic Commerce, to be released in 2010 . The protection of consumers of digital products from restrictive Terms of Use or DRM are raised. The duty of disclosure of the right owner, the dangers for consumer privacy, and other consumer-related issues are discussed, but there is no specific focus on the issue of contracts overriding copyright exceptions.

An empirical survey of 514 websites making available digital media products has been carried out as part of the EC Framework 7 COUNTER project. ${ }^{542}$ The survey codes business models and terms of use, including the use of DRM and transferability of content to portable media players and mobile phones. A database containing the survey codes will be available online from March 2010, and could be used to analyse the contractual approach to copyright exceptions.

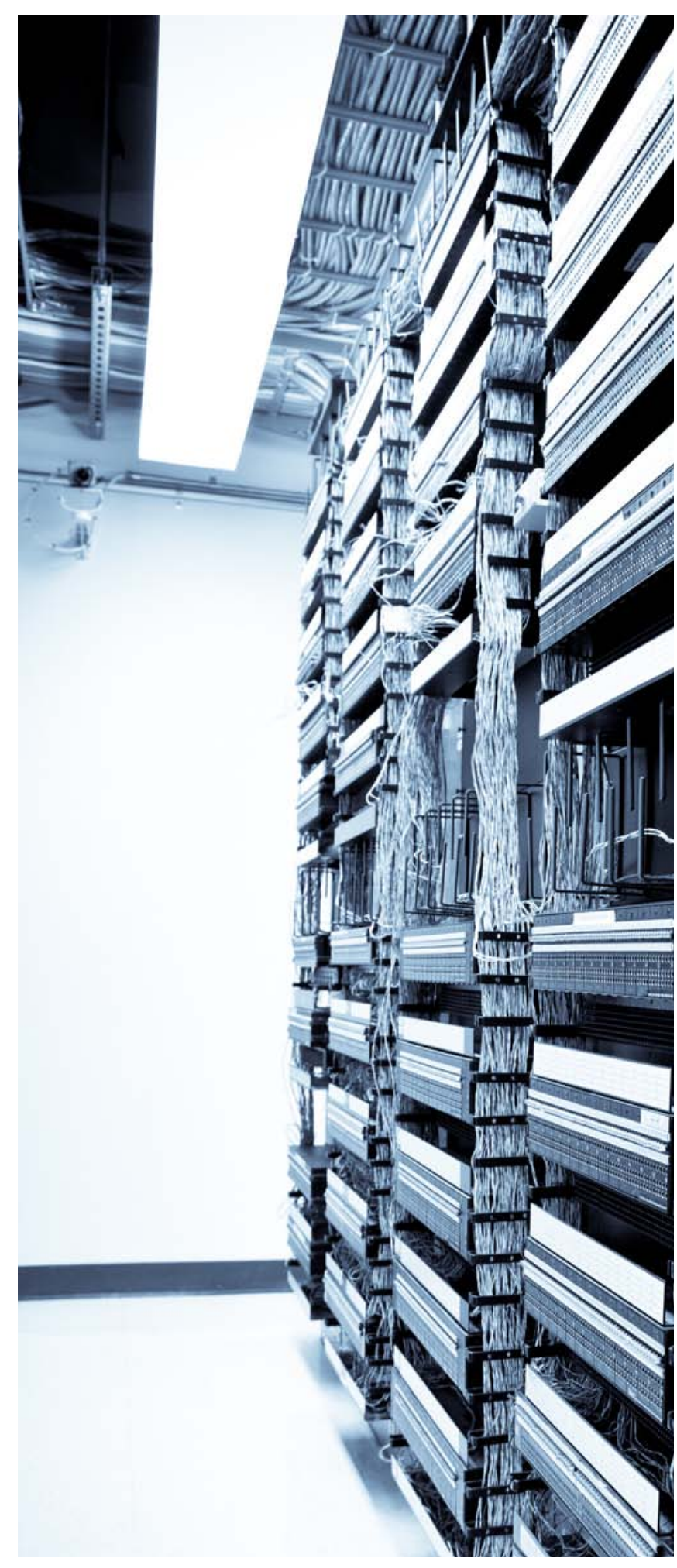

541 DSTI/CP(2009)20/FINAL, available online at http://www.oecd.org/dataoecd/44/13/44047583.pdf. Conference documents are available at http://www.oecd.org/icr/econsumerconference.

542 Montagnani, M.L. and M. Borghi (2009), 'Models for Managing Intellectual Property Rights on the Internet: An Empirical Survey of Online Distribution of Digital Media Content', Report for EC Framework 7 COUNTER Project, available at www. counter2010.org.

Providing Government with strategic, independent and evidence-based advice on intellectual property policy.

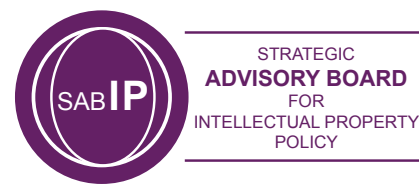




\subsection{CONCLUSIONS}

The analysis of the legislation, the case law, and the literature of the targeted countries so far reveals a substantial body of literature and case law on the interplay between copyright and contract within the United States. The European Union follows, with substantial legislation and literature, but not much relevant case law. Among the individual Member States examined, the United Kingdom and Belgium provided the richest doctrinal contribution to the present study, while hardly any case law or literature was found in relation to Ireland and Portugal.

On the basis of the above data, potential research gaps have been identified. These gaps can be seen as new research questions that may provide the basis for subsequent research in support of copyright policy development. It also details the approaches and methodologies that could be used in answering such questions.

\section{Section 1}

Apart from a few notable exceptions, ${ }^{543}$ hardly any literature and case law discussed the impact that imperative copyright exceptions had on contracting licences in those countries that stipulate mandatory exceptions. Moreover, the difference between countries implementing imperative exceptions and countries where freedom of contract prevails has not been the object of a comparative empirical study.

\section{Section 2}

Against overreaching licence agreements the examined literature proposed self-regulatory solutions, to be enacted through model licences and codes of conduct. ${ }^{544} \mathrm{~A}$ study on the feasibility of such solutions could be interesting for policy makers.

\section{Section 3}

The sector of the commercialization of digital copyright works seems to be most in need of empirical evidence. First of all, no comprehensive research has been done to determine the exact proportion of works commercialised online to further determine the pervasiveness of the problem of the overridability of copyright limits by contracts and/or TPMs/DRMs. ${ }^{545}$ In addition, specific data on the type of contracts (e.g. shrink-wrap; clickwrap or browse-wrap) or the media via which they are diffused (e.g. web pages or booklets) are missing. No systematic cross-border study has been carried out specifically with respect to copyright exceptions by licensing agreements. The lawfulness of end-user licence agreements vis-àvis consumer statutory rights has been taken in consideration in a few countries, as we mentioned above in this conclusion. But they hardly refer to any copyright issue, other than indirectly. In this sector, sweeping techniques ${ }^{546}$ could be usefully implemented to gather data systematically online, while quantitative social research methods would be necessary to examine shrink-wrap licences on material carriers (CDs, etc.).

$543 \quad$ For Belgium, Dusollier 2007 and Dubuisson 2001.

544 See the Green paper on Copyright in the Knowledge Economy 2008, the Australian CLRC Study 2002, Garnett 2006, Hugenholtz 2008.

545 See the studies by IFPI and the EU Commission in 2009 cited above.

546 These involve exploring the Internet in search of relevant material. In addition this method is particularly attractive for its relatively contained costs. 
An interesting research gap has been identified in the licence purchasing practices of public libraries and educational institutions. Their needs in terms of copyright allowances as well as their ability to negotiate clauses allowing them need to be explored.

\section{Section 4}

At present, studies on the limits to contract and copyright, such as those carried out by Guibault, appear sufficiently exhaustive. Subsequent research should address practical solutions to accommodate the needs of copyright owners and users. This may include, for example, concrete proposals for normative action, or alternatively, for the adoption of model licences or codes of conduct. Incidentally, the exclusion of digital copyright works from a number of users' privileges, as in Article $6(4)$ of the InfoSoc Directive, is underpinned by their status as services rather than goods. Both their status and their exclusion from copyright exceptions (despite the fact that they are copyright works in every respect) could usefully be addressed by theoretical research.

\section{Section 5}

Many theoretical and technological solutions have been proposed in the field of DRMs. The CIPIL study revealed that technical solutions for TPMs compliant with copyright exceptions are already available. ${ }^{547}$ Nonetheless, the enjoyment of copyright exceptions is sometimes hindered by DRM. It is therefore a matter for policy makers to implement the correct solutions.

However, recent business models emerging in the copyright industry should be included in the picture. The impact on users of copyright works of emerging DRM-free business models (in terms of acceptability) and their impact on right holders (in terms of benefits) should both be assessed and analysed theoretically (by economists) and verified empirically.

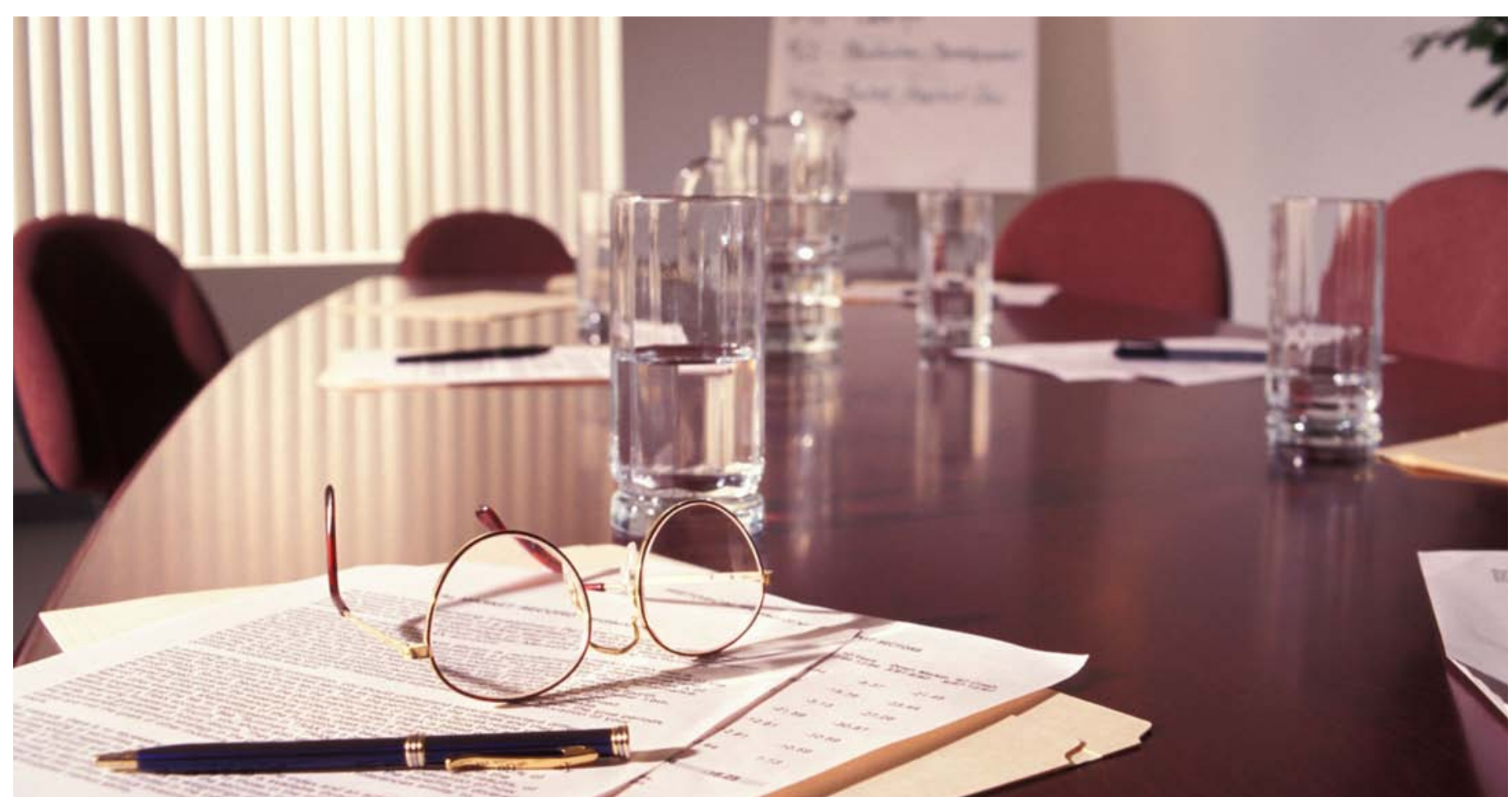

Providing Government with strategic, independent and evidence-based advice on intellectual property policy.

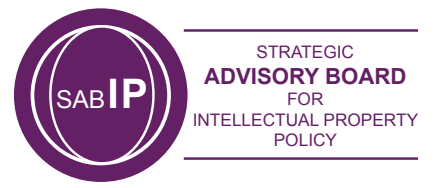




\section{A. ARTICLES, BOOKS AND REPORTS}

Abrams, H. (1983), 'Copyright, misappropriation and pre-emption: constitutional limits of state law protection', Supreme Court Review 509.

Adams, J. N. (1998), 'Barker v Stickney revisited', Intellectual Property Quarterly 1: 113-115.

Adler, M. (1985), 'Stardom and Talent', American Economic Review 75: 208-12.

Akester, P. (2009), Technological accommodation of conflicts between freedom of expression and DRM: The first empirical assessment, Cambridge: CIPIL 5/5/2009 [available at http://www.law.cam. ac.uk/faculty-resources/download/technological-accommodation-of-conflicts-between-freedom-ofexpression-and-drm-the-first-empirical-assessment/6286/pdf]

Alonso, J. and R. Watt (2003), 'Efficient Distribution of Copyright Income', in Gordon, W. and R. Watt (eds.), The Economics of Copyright: Developments in Research and Analysis, Cheltenham, UK and Northampton, MA: Edward Elgar Publishing.

Anderson, M. (2009), 'Assignment and royalties don't mix', Journal of Intellectual Property Law \& Practice 4(4): 283-288.

Australian Vice-Chancellors' Committee (2001), Submission to the Copyright Law Review Committee Reference on Copyright and Contract [available at http://www.universitiesaustralia.edu.au/].

Banerjee, D. (2006), 'Enforcement Sharing and Commercial Piracy', Review of Economic Research on Copyright Issues 3(1): 83-97.

Barczewski, M. (2005), 'International Framework of Digital Rights Management Systems,' European Intellectual Property Review 27(5): 165-169.

Baumol, W. (1987), Superfairness, Cambridge, MA; MIT Press.

Baumol, W. and P. Heim (1967), 'On Contracting With Publishers: Or What Every Author Should Know', American Association of University Professors' Bulletin 53: 30-46. Reprinted as Chapter 22 in Towse, R. (ed.), Baumol's Cost Disease: The Arts and Other Victims, Cheltenham, UK and Northampton, MA: Edward Elgar Publishing.

Bechtold S. (2004), 'Digital Rights Management in the United States and Europe', American Journal of Comparative Law 52: 323-82.

Bechtold, S. (2003), 'The Present and Future of Digital Rights Management - Musings on Emerging Legal Problems', in Eberhard Becker et al. (eds). Digital Rights Management - Technological, Economic, Legal And Political Aspects (Springer), pp. 597-654.

Bell, T. W. (1998), 'Fair Use vs. Fared Use: The Impact of Automated Rights Management on Copyright's Fair Use Doctrine', N. C. L. Rev. 76: 557-620.

Bell, T. W. (2007), 'Codifying Copyright's Misuse Defense', Utah Law Review, p. 573. 
Benhamou, F. (2003), 'Artists' Labour Markets', pp. 69-75 in R. Towse (ed.), A Handbook of Cultural Economics, Cheltenham: Edward Elgar.

Benkler, Y. (2000), 'An Unhurried View of Private Ordering in Information. Transactions', Vand. L. Rev. 53: 2063.

Bently, L. (2002), Between a Rock and a Hard Place: The Problems Facing Freelance Creators in the UK Media Market-Place, London: Institute of Employment Rights.

Bently, L. (2009), 'Authorship of Popular Music in UK Copyright Law', in Copyright and the Production of Music (special issue, ed. M. Kretschmer \& A. Pratt), Information, Communication and Society 12(2): 179-204.

Bently, L. and J.C. Ginsburg (2010), "The sole right . . shall return to the Authors': Anglo-American Authors' Reversion Rights from the Statute of Anne to Contemporary US Copyright', Berkeley Technology Law Journal.

Bernault, C., A. Lebois and A. Lucas (2005), Peer-to-Peer File Sharing and Literary and Artistic Property, University of Nantes: Institute for Research on Private Law.

Besen, S. and S. Kirby (1989), 'Private Copying, Appropriability, and Optimal Copying Royalties', Journal of Law and Economics 32: 255-80.

Besen, S. and S. Kirby (1989), Compensating Creators of Intellectual Property: Collectives that Collect, Santa Monica, CA: RAND.

Besen, S., S. Kirby and S. Salop (1992), 'An Economic Analysis of Copyright Collectives', Virginia Law Review 78: 383-411.

Bird, D. (2004), Methodology for the 2004 Annual Survey of Hours and Earnings, Employment Earnings and Productivity Division, Office for National Statistics.

Bogataj, M. (2009), 'Mandatory collective management for making available in Slovenian CopyrightAct: A mistake or an opportunity?', paper presented at 6th Communia Workshop Memory Institutions and Public Domain (Barcelona, 1-2 October 2009) [available at http://communia-project.eu/downloads].

Boldrin, M. and D. Levine (2002), 'The Case Against Intellectual Property', American Economic Review, Papers and Proceedings 92: 209-12.

Boldrin, M. and D. Levine (2004), 'IER Lawrence Klein Lecture: The Case Against Intellectual Monopoly', International Economic Review 45: 327-50.

Boldrin, M. and D. Levine (2005), 'Intellectual Property and the Efficient Allocation of Social Surplus from Creation', Review of Economic Research on Copyright Issues 2(1): 45-67.

British Library (2009), Study on Contracts and Copyright Exceptions [available at http://www.bl.uk/ip/ pdf/ipmatrix.pdf]. 
Brodie, D. (2007), 'The employment contract and unfair contracts legislation', Legal Studies 27(1): 95-109.

Brown, I. and N. Bohm (2001), Implementing the European Copyright Directive [available at http:// www.fipr.org/copyright/guide/uk.htm].

Burk, D.L. (2005), 'Legal and Technical Standards in Digital Rights Management Technology', Fordham L. Rev. 74: 537.

Burk, D. L. and J.E. Cohen (2001), 'Fair Use Infrastructure for Rights Management Systems', Harv. J.L. \& Tech. 15: 41.

Burrel, R. and A. Coleman (2005), The Copyright Exception: The Digital Impact, Cambridge: Cambridge University Press.

Buydens, M. and S . Dusollier (2001), 'Les exceptions au droit d'auteur: Evolutions dangereuses', CCE 13.

Calaba, V. F. (2002), 'Quibbles 'N Bits: Making A Digital First Sale Doctrine Feasible', Mich. Telecomm. \& Tech. L. Rev 9: 1-34.

Caves, R. (2000), Creative Industries: Contracts Between Art and Commerce, Cambridge, MA, and London UK: Harvard University Press.

Charnes, A., W. W. Cooper, and E. Rhodes (1978), 'Measuring the efficiency of decision making units', European Journal of Operational Research 2: 429-444.

Coase, R. H. (1960), 'The Problem of Social Cost', Journal of Law and Economics 3: 1-44.

Cohen, J. E. (1998), 'Copyright and the Jurisprudence of Self-Help’, Berkeley Tech. L.J. 13: 1089.

Cohen, J. E. and D.L. Burk (2001), 'Fair Use Infrastructure for Copyright Management Systems', Harv. J. L. Tech. 15(1): 41.

Conneely, M.C. (2000), 'Ireland's Copyright Act 2000: Copyright Legislation for the New Millennium' 9.6.4.1.V2 Suffolk Transnational Law Review, Winter.

Connolly, M. and A.B. Krueger (2006), 'Rockonomics: The Economics of Popular Music', in Ginsburgh, V.A. and D. Throsby (eds.), Handbook of the Economics of Art and Culture: Volume 1, Amsterdam; Elsevier.

Cornish, W. R. and D. Llewelyn (2007), Intellectual Property: Patents, Copyright, Trade Marks and Allied Rights (6th ed.), London: Sweet \& Maxwell.

CPB Netherlands Bureau for Economic Policy Analysis (nd), Copyright protection: Not more but different, Centraal Planbureau [available at http://www.cpb.nl/eng/]

D'Agostino, G. (2001), 'The Globalisation of Copyright: A Comparative Analysis of the Anglo-American and Continental European copyright laws in relation to the Author', Hibernian LJ 2: 35. 
D’Agostino, G. (2007), 'Canada's Robertson Ruling: Any Practical Significance for Copyright Treatment of Freelance Authors?', EIPR 2: 66-69.

Dam, K. W. (1999), 'Self-help in the digital jungle', Journal of Legal Studies 28: 393.

Dangel, C., M.-B. Piorkowsky and T. Stamm (2006), Selbstständige Künstlerinnen und Künstler in Deutschland - zwischen brotloser Kunst and freiem Unternehmertum?, Bonn: Deutscher Kulturrat

Davis, G. (2000), 'Technical Devices as a Solution to Private Copying', in I. A. Stamatoudi and P. Torremans (eds.), Copyright in the New Digital Environment, London: Sweet \& Maxwell.

De Werra, J. (2003), 'Moving Beyond the Conflict Between Freedom of Contract and Copyright Policies: In Search of a New Global Policy for On-Line Information Licensing Transactions: A Comparative Analysis Between U.S. Law and European Law', Colum. J.L. \& Arts 25: 239-268.

Derclaye, E. (2006), 'Copyright Contracts, Public Policy and Competition: Can Adhesion Contracts Override Copyright Limits? The Answer Lies within Copyright Law Itself' in Heath C. and K. Liu (eds.), Copyright Law and the Information Society in Asia, IIC STUDIES, Oxford: Hart Publishing, pp. 167211.

Derclaye, E. (2008), The legal protection of databases: A comparative analysis, Cheltenham: Edward Elgar Publishing.

Deveci, H. A. (2007), 'Consent in online contracts: old wine in new bottles', C.T.L.R. 223.

Dizon, M. A. C. (2009), 'The symbiotic relationship between global contracts and the international IP regime?', Journal of Intellectual Property Law \& Practice 4(8).

Djavaherian, D. (1998), 'Hot News and No Cold Facts: NBA v. Motorola and the Protection of Database Contents', Richmond Journal of Law and Technology 5:8.

Domon, K. and K. Nakamura (2007), 'Unauthorized Copying and Copyright Enforcement in Developing Countries: A Vietnam Case Study', Review of Economic Research on Copyright Issues 4(1): 87-96.

Dreier, T. (2005), 'Contracting Out of Copyright in the Information Society: The Impact on Freedom of Expression' in Griffiths J. and Suthersanen U. (eds), The Legal Protection of Databases Copyright and Free Speech, Comparative and International Analyses, (Oxford: University Press), PP 385-400

Dubuisson, F. (2001), 'Le régime des exceptions au droit d'auteur après la loi du 31 aout 1998 concernant la protection juridique des bases de données', A \& M 2: 200-216.

Dümling, A. (2003), Musik hat ihren Wert: 100 Jahre musikalische Verwertungsgesellschaft in Deutschland, Regensburg: ConBrio.

Dusollier, S. (1999), 'Electrifying the Fence: The Legal Protection of Technological Measures for Protecting Copyright', E.I.P.R. 21(6): 285-297.

Dusollier, S. (2000), 'Incidences et Réalité d'un Droit d'Access', Cahier du CRID 18 (Bruylant). 
Dusollier, S. (2003a), 'Tipping the Scale in Favour of the Right Holders: The European AntiCircumvention Provisions', in Becker E., Buhse W., Günnewig D., Rump N. (eds.), Digital Rights Management: Technological, Economic, Legal and Political Aspects, (Berlin: Springer-Verlag) pp.462478.

Dusollier, S. (2003b), 'Fair Use by Design in the European Copyright Directive of 2001: An Empty Promise', Communications of the ACM April 2003/Vol. 46(4). Also available in IIC 2003/1, pp. 62-75.

Dusollier, S. (2005a), Droit d'auteur et protection des œuvres dans l'univers numérique, Larcier.

Dusollier, S. (2005b), 'Technology as an Imperative for Regulating Copyright: from the Public Exploitation to the Private Use of the Work', E.I.P.R. 27(6): 201-204.

Dusollier, S. (2006), 'The Master's Tools v. the Master's House: Creative Commons v. Copyright', Colum. J.L. \& Arts 29: 271.

Dusollier, S. (2007a), Droit d'auteur et protection des oeuvres dans l'univers numérique - Droits et exceptions à la lumière des dispositifs de verrouillage des œuvres, Bruxelles: Larcier, 2ème édition.

Dusollier, S. (2007b), 'La contractualisation de l'utilisation des oeuvres et l'expérience belge des exceptions impératives', Propriétés Intellectuelles 25: 443-452.

Dusollier S., Y. Poullet and M. Buidens (2000), 'Copyright and Access to Information in the Digital Environment', a study prepared for the Third UNESCO Congress on Ethical, Legal and Societal Challenges of Cyberspace Infoethics, Paris, 17 July 2000.

Easterbrook, F. H. (1996), 'Cyberspace and the Law of the Horse', University of Chicago Legal Forum 1996: 207-216.

Economides, N. S. (1988) 'The Economics of Trademarks', Trademark Reporter 78: 523-539.

Einhorn, M. (2002), 'Music Licensing in the Digital Age', in Towse, R. (ed.), Copyright in Cultural Industries, Cheltenham UK and Northamption MA: Edward Elgar, pp. 165-77.

Einhorn, M. (2006), 'Transactions Costs and Administered Markets: Licence Contracts for Musical Performance Rights', Review of Economic Research on Copyright Issues 3(1): 61-74.

Elkin-Koren, N. (1997), 'Copyright policy and the limits of freedom of contract', Berkeley Technology Law Journal 12(1).

Elkin-Koren, N. (2005), 'What Contracts Can't Do: The Limits of Private Ordering in Facilitating a Creative Commons', Fordham Law Review 74.

Elkin-Koren, N. (2007), 'Making Room for Consumers Under the DMCA', Berkeley Technology Law Journal 22(3).

Elkin-Koren, N. (2009), 'Governing Access to Users-Generated-Content: The Changing Nature of Private Ordering in Brousseau', in Marzouki E. M. and C. Meadel (eds.), Digital Networks, Governance, Regulations and Powers on the Internet, Cambridge University Press. 
Erickson, J. S. (2003), 'Fair use, DRM and Trusted Computing', Communications of the ACM 46(4): 34-39.

Favale, M. (2007), Access to Copyright Works: Fine-Tuning DRM to Balance the Rights of Owners and Users, PhD dissertation (University of Nottingham 2007).

Favale, M. (2008), 'Fine-Tuning European Copyright Law to Strike a Balance Between the Rights of Owners and Users', European Law Review 33(5): 687-708.

Fisher, W.W. (2004), Promises to Keep: Technology, Law and the Future of Entertainment, Stanford University Press.

Fohrbeck, K. and A.J. Wiesand (1972), Der Autorenreport, Reinbek b. Hamburg.

Fohrbeck, K. and A.J. Wiesand (1975), Der Künstler-Report: Musikschaffende, Darsteller/Realisatoren, Bildende Künstler/Designer, München-Wien.

Frank, R.H. and P.J. Cook (1995), The Winner-Take-All Society, New York: Free Press.

Fraser, S. (1997), 'The Copyright Battle', J. Marshall J. Computer \& Info. L. 15: 759.

Frey, B.S. (1997), Not Just For the Money: An Economic Theory of Personal Motivation, Cheltenham: Edward Elgar.

Friedman, D. (1998), 'In Defense of Private Orderings: Comments on Julie Cohen's 'Copyright and the Jurisprudence of Self-Help," Berkeley Tech. L.J. 13: 1151.

Frith, S. and L. Marshall (eds.) (2004), Music and Copyright, Edinburgh: Edinburgh UP.

Fujichaku, R. (1998), 'The misappropriation doctrine in cyberspace: Protecting the commercial value of 'hot news' information', University of Hawaii Law Review 20: 421.

Gallagher, T. (2002), 'Copyright Compulsory Licensing and Incentives', in Towse, R. (ed.), Copyright in Cultural Industries, Cheltenham UK and Northamption MA: Edward Elgar, pp. 85-98.

Gallini, N. and S. Scotchmer (2002), 'Intellectual Property: When is it The Best Incentive System?', in Jaffe, A., J. Lerner and S. Stern (eds.), Innovation Policy and the Economy, vol. 2, Cambridge, MA: MIT Press.

Garnett, N. (2006), Automated Rights Management Systems and Copyright Limitations and Exceptions, a report for The WIPO-Standing Committee on Copyright and Related Rights, Fourteenth Session, Geneva, May 1-5.

Gasser, U. (2004), iTunes - How Copyright, Contract, and Technology Shape the Business of Digital Media. A Case Study, Berkman Center for Internet \& Society at Harvard Law School Research Publication, No. 2004-07.

Gasser, U. (2006), 'Legal frameworks and technological protection of digital content: Moving forward towards a best practice model', Fordham Intellectual Property, Media Entertainment Law Journal 17: 39.

Providing Government with strategic, independent and evidence-based advice on intellectual property policy.

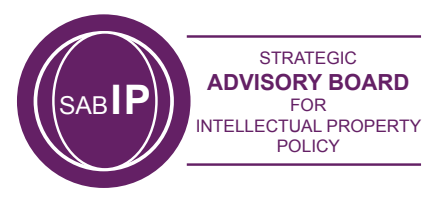


Geiger, C. (2006), "Constitutionalising' intellectual property law? The influence of fundamental rights on intellectual property in the European Union', I/C 371.

Geller, P. E. (1994), 'Toward an Overriding Norm In Copyright: Sign Wealth', RIDA 159(3): 27.

Ghestin, J. (1993), Traité de droit civil - La formation du contrat, 3e éd.(Paris, L.G.D.J.).

Ginsburg, J.C. (1990), 'Moral Rights in a Common Law System', Entertainment Law Review 121.

Ginsburg, J.C. (1992), 'No 'Sweat'? Copyright and other protection of works of information after Feist v Rural Telephone', Columbia Law Review 92: 338.

Ginsburg, J.C. (2000), 'Access to work in the United States', Cahier du CRID 18 (Bruylant).

Ginsburg, J.C. (2003), 'Essay: From Having Copies to Experiencing Works: The Development of an Access Right in U.S. Copyright Law', J. Copyright Soc. USA 50.

Girot, C. (1998), 'La validité des licences de logiciel sous plastique en droit français: Les renseignements du droit comparé', Droit de l'informatique et des télécoms 1998/1: 7-14.

Goldstein, P. (1996), 'The Future of Copyright in a Digital Environment' in Hugenholtz, P.B. (ed.), The Future of Copyright in a Digital Environment, Kluwer Law International.

Goldstein, P. (1997), ‘Copyright and its Substitutes', Wisconsin Law Review 865-871.

Goldstein, P. (2003), Copyright's Highway: From Gutenberg to the Celestial Jukebox, Stanford: Stanford UP.

Good, N., J. Grossklags, A. Peronowski, D. Thaw, D. Mulligan and J. Konstan (2006), 'User Choices and Regret: Understanding Users' Decision Process about Consensually Acquired Spyware', I/S: A Journal of Law and Policy for the Information Society.

Gordon, W. (1982), 'Fair Use as Market Failure: A Structural and Economic Analysis of the Betamax Case and its Predecessors', Col L. R. 82: 1600-1657.

Gordon, W. (2003), 'Excuse and Justification in the Law of Fair Use: Transaction Costs Have Always Been Only Part of the Story', J. Copyright Soc. USA 50: 149.

Graddy, K. and S. Szymanski (2005), A Study into the Likely Impact of the Implementation of the Resale Right for the Benefit of the Author of an Original Work of Art, London: Intellectual Property Institute.

Grøndal, L. (2006), 'DRM and contract terms', INDICARE Monitor 2(12), February.

Grosheide, W. (2001), 'Copyright Law from a User's Perspective: Access Rights for Users', E.I.P.R. 23(7): 321-325.

Guibault, L. (2002), Copyright Limitations and Contracts - An Analysis of the Contractual Overridability of Limitations on Copyright, Kluwer Law International. 
Guibault, L. (2003), 'The Nature And Scope Of Limitations and Exceptions to Copyright and Neighbouring Rights with regard to General Interest Missions for the Transmission of Knowledge: Prospects for their Adaptation to the Digital Environment', E-Copyright Bulletin, October/December.

Guibault, L. (2006), 'Wrapping Information in Contract: How Does it Affect the Public Domain?' in Guibault, L. and P. B. Hugenholtz (eds.), The Future of the Public Domain (Identifying the Commons in Information LAW), Kluwer Law International BV, Netherlands.

Guibault, L. and P.B. Hugenholtz (2002), Study on the Conditions Applicable to Contracts relating to Intellectual Property in the European Union, Amsterdam: Institute for Information Law.

Handke, C. and R. Towse (2007), 'Economics of Copyright Collectives', International Review of Intellectual Property and Competition Law 8(38): 937-57.

Harcourt, A. (1996), 'The Unlawful Deduction Levied upon UK Composers' Performing Rights Income', Copyright World 64:15.

Hart, M. (1998), 'The Proposed Directive for Copyright in the Information Society: Nice Rights, Shame about the Exceptions', E.I.P.R. 20(5): 169.

Heald, P. (2008), 'Testing the Over- and Under-Exploitation Hypotheses: Bestselling musical compositions (1913-32) and their use in cinema (1968-2007)', paper presented at Annual Congress of the Society for Economic Research on Copyright Issues (SERCI), Geneva, July10-11, 2008 (available at http://papers.ssrn.com).

Heide, T. (2000), 'The Approach to Innovation under the Proposed Copyright Directive: Time for Mandatory Exceptions', I.P.Q. 3: 215-23.

Heide, T. (2001), 'Copyright In The EU And U.S.: What 'Access-Right'?, J. Copyright Soc. USA 48.

Heide, T. (2003), 'Copyright, Contract and the Legal Protection of Technological Measures - Not 'the Old Fashioned Way': Providing a Rationale to the 'Copyright Exceptions Interface", Journal of the Copyright Society of the U.S.A. 50.

Helberger, N. and Guibault, L. (2005), Copyright Law and Consumer Protection [available at http:// www.ivir.nl/publications/other/copyrightlawconsumerprotection.pdf]

Hirsch, P. (1972), 'Processing Fads and Fashions: An Organisation Set Analysis of Cultural Industry Systems', American Journal of Sociology 77(4): 639-670.

Hollander, A. (1984), 'Market Structure and Performance in Intellectual Property: The Case of Copyright Collectives', International Journal of Industrial Organization 2: 199-216.

Hovarth, K . (1998), 'NBA v. Motorola: A case for federal preemption of misappropriation?', Notre Dame Law Review 461.

Hugenholtz, P.B. (1996), 'De databankrichtlijn eindelijk aanvaard: een zeer kritisch commentaar', Computerrecht 131. 
Hugenholtz, P.B. (1997), 'Fierce Creatures Copyright Exceptions: Towards Extinction?' at the IFLA/ IMPRIMATUR Conference 30-31 October 1997, Amsterdam, Netherlands.

Hugenholtz, P.B. (2000a), 'Why the Copyright Directive is Unimportant, and Possibly Invalid', E.I.P.R. 11: 501-502.

Hugenholtz, P.B. (2000b), 'The Future of Copyright Limitations' at Infoethic 2000, Third UNESCO Congress on Ethical, Legal and Societal Challenges of Cyberspace, Paris, 13-15 November 2000.

Hugenholtz, P.B. and R.L. Okediji (2008), Conceiving an International Instrument on Limitations and Exceptions to Copyright, study supported by the Open Society Institute (OSI) [available at http://www. ivir.nl/staff/hugenholtz.html].

IFPI (2009), Digital Music Report [available at http://www.ifpi.org/content/library/DMR2009.pdf].

IViR (2007), Study on the Implementation and Effect in Member States' Laws of Directive 2001/29/EC on the Harmonisation of Certain Aspects of Copyright and Related Rights in the Information Society, part I and II [available at http://www.ivir.nl].

JISC (2004) DRM Study - Final Report, study carried out by Intrallect Ltd on behalf of JISC [available at http://www.intrallect.com/index.php/intrallect/content/download/641/2662/file/ FinalReportAppendixv2.pdf and http://www.intrallect.com/drm-study/DRMFinalReportv2.pdf].

Johnson, D. R. and D.G. Post (1996), 'Law and Borders: The Rise of Law in Cyberspace', First Monday 1(1) [available at www.firstmonday.org].

Judge, K. (2004), 'Note, Rethinking Copyright Misuse', Stan. L. Rev. 57: 901.

Karjala, D. (1997), 'Federal preemption of shrinkwrap and on-line licenses', University of Dayton Law Review 22: 511.

Karp, L. and J. Perloff (1993), 'Legal Requirements that Artists Receive Resale Royalties', International Review of Law and Economics 13: 163-77.

Katz, A. (2005), 'The Potential Demise of Another Natural Monopoly: Rethinking the Collective Administration of Performing Rights', Journal of Competition Law and Economics 1(3): 541.

Katz, A. (2006), 'The Potential Demise of Another Natural Monopoly: New Technologies and the Administration of Performing Rights', Journal of Competition Law and Economics 2(2): 245.

Kay, J. (1993), 'The Economics of Intellectual Property Rights', International Review of Law and Economics 13: 337-348.

Kerscher, G. and J. Fruchterman (2002), The Soundproof Book: Exploration of Rights Conflict and Access to Commercial eBooks for People with Disabilities [available at http://firstmonday.org/htbin/ cgiwrap/bin/ojs/index.php/fm/article/view/959/880].

Knight, J. R. (2006), 'Comment, Copyright Misuse v. Freedom of Contract: And the Winner Is', Tenn L. Rev. 73: 262-65. 
Koelman, K. J. (2000), 'A Hard Nut to Crack: The Protection of Technological Measures,' E.I.P.R. 22(6): $272-288$

Komponisten-Report (1993), hg. v. Alfred Smudits, Irmgard Bontinck, Desmond Mark, Elena Osterleitner, Wien: WUV Universitätsverlag.

Koski, H. (2005), 'OSS Production and Licensing Strategies of Software Firms', Review of Economic Research on Copyright Issues 2(2): 111-125.

Kretschmer, M. (2002), 'The Failure of Property Rules in Collective Administration: Rethinking Copyright Societies as Regulatory Instruments', European Intellectual Property Review (EIPR) 24(3): 126-137.

Kretschmer, M. (2003), 'Digital Copyright: The End of an Era', European Intellectual Property Review (EIPR) 25(8): 333-341.

Kretschmer, M. (2005a), 'Artists' Earnings and Copyright: A Review of British and German Music Industry Data in the Context of Digital Technologies', First Monday 10(1) [available at www. firstmonday. org].

Kretschmer, M. (2005b), 'The Aims of European Competition Policy Towards Copyright Collecting Societies', Society for Economic Research on Copyright, Montreal (7-8 July 2005) [revised 2006 as 'Access and Reward in the Information Society: Regulating the Collective Management of Copyright', available at www.cippm.org.uk].

Kretschmer, M. (2006), 'Copyright and Contracts: A Brief Introduction', Review of Economic Research on Copyright Issues 3(1): 75-81.

Kretschmer, M. and P. Hardwick (2007), Authors' Earnings from Copyright and Non-Copyright Sources: A Survey of 25,000 British and German Writers, Bournemouth: CIPPM and ALCS.

Kretschmer, M., G.M. Klimis and C.J. Choi (1999). 'Increasing Returns and Social Contagion in Cultural Industries', British Journal of Management 10: 61-72.

Kretschmer, M., G.M. Klimis and R. Wallis (2001), 'Music in electronic markets: An empirical study', New Media and Society 3/4: 417-441

Kupferschmid, K. (1998), 'Lost In Cyberspace: The Digital Demise Of The First-Sale Doctrine', J. Marshall J. Computer \& Info. L. 16: 825-856.

Landes, W.M. and R.A. Posner (1989), 'An Economic Analysis of Copyright Law', Journal of Legal Studies 18: 325-366.

Landes, W.M. and R.A. Posner (2003a), 'The Economics of Trademark Law', in The Economic Structure of Intellectual Property Law, Cambridge, Mass.: Harvard UP, pp. 166-209

Landes, W.M. and R.A. Posner (2003b), The Economic Structure of Intellectual Property Law, Cambridge, Mass.: Harvard UP. 
Lemley, M.A. (1995), 'Intellectual Property and Shrink Wrap Licences', Southern California Law Review 68: 1239-1274.

Lemley, M.A. (2006), 'Terms of Use', Minnesota Law Review 91.

Lessig, L. (1999), Code and Other Laws of Cyberspace, Basic Books.

Lessig, L. (2001), The Future of Ideas, New York: Vintage.

Lessig, L. (2004), Free Culture, New York: Penguin [available at http://www.free-culture.cc/].

Leveque, F. and Y. Meniere (2007), 'Copyright vs. Patents: The Open Source Software Legal Battle', Review of Economic Research on Copyright Issues 4(1): 27-46.

Lewinsky, S. (2004), 'Mandatory Collective Administration of Exclusive Rights - A Case Study on its Compatibility with International and EC Copyright Law', Unesco Copyright Bulletin, JanuaryMarch: 1-20 [available at: http://portal.unesco.org/culture/en/ev.php-URL_ID=19552\&URL_DO=DO_ TOPIC\&URL_SECTION=201.html].

Liebowitz, S. (1985), 'Copying and Indirect Appropriability: Photocopying of Journals', Journal of Political Economy 93(5): 945-957.

Liebowitz, S. (1987), 'Some Puzzling Behavior by Owners of Intellectual Products: An Analysis', Contemporary Policy Issues 5: 44-53.

Liebowitz, S. (2006), 'MP3 and Copyright Collectives: A Cure Worse than the Disease?', in Takeyama, L., W.J Gordon and R. Towse (eds.), Developments in the Economics of Copyright, Cheltenham: Edward Elgar, pp. 37-59.

Litman, J. (1994), 'The Exclusive Right to Read', Cardozo Arts \& Ent. L.J. 13: 29.

Litman, J. (1998), 'The Tales that Article 2B Tells', Berkeley Technology Law Journal 13: 935.

Lorenz, M.O. (1905), 'Methods of measuring the concentration of wealth', Publications of the American Statistical Association 9: 209-219.

Lucas, A. (2006), 'L'apposition d'une mesure technique de protection sur un DVD est légitime au regard de l'exception de copie privée', La Semaine Juridique 21-22: 1065-1068.

Lucas-Schloetter, A. (2004), Les droit d'auteur des salaries en Europe continentale, Paris: Cahiers IRPI 5 (Institut de Recherche en Propriété Intellectuelle Henri-Desbois).

Macaulay, T.B. (1952), in Young, G.M. (ed.), Macaulay: Prose and Poetry, London: Hart-Davis.

Macdonald, E. (1999), 'The Emperor's Old Clauses: Unincorporated Clauses, Misleading Terms and the Unfair Terms in Consumer Contracts Regulations', Cambridge Law Journal 58: 437.

Madison, M.J. (1998), 'Legal-Ware: Contract and Copyright in the Digital Age', Fordham L. Rev. 67: 1025. 
Max Planck Institute for Intellectual Property, Competition and Tax Law (2009), Comments to the European Commission Green Paper: Copyright in the Knowledge Economy 2008.

Mazziotti, G. (2008), EU Digital Copyright Law and the End-User, Springer.

McGee, S. (1998), 'Cooling off the hot-news exception: National Basketball Ass'n v Motorola, Inc.', 105 F.3D 841 (2d Cir. 1997)', University of Cincinnati Law Review 66: 1019.

Merges, R.P. (1993), 'Are You Making Fun of Me? Notes on Market Failure and the Parody Defense in Copyright', AIPLA Q.J. 21: 305-312.

Merges, R.P. (1996), 'Contracting into Liability Rules: Intellectual Property Rights and Collective Rights Organizations', California Law Review 84: 1293.

Merges, R.P. (2004), 'Compulsory Licensing vs. the Three 'Golden Oldies', Property Rights, Contracts, and Markets', Cato Institute, Cato Policy Analysis No. 508.

Michel, N.J. (2006), 'Digital File Sharing and Royalty Contracts in the Music Industry: A Theoretical Analysis', Review of Economic Research on Copyright Issues 3(1): 29-42.

Minassian, A. (1997), 'The Death of Copyright: Enforceability of Shrinkwrap Licensing Agreements', UCLA L.R. 45: 569-609.

Montagnani, M.L. and M. Borghi (2009), Models for Managing Intellectual Property Rights on the Internet: An Empirical Survey of Online Distribution of Digital Media Content, Report for EC Framework 7 COUNTER Project [available at www.counter2010.org].

Musy, A.M. (2000), Law and the Pre-contractual Duty to Disclose: Comparative Analysis of New Differences in Legal Cultures [available at http://www.icer.it/docs/wp2000/Musy192000.pdf].

Muthoo, A. (2006), 'Bargaining Theory and Royalty Contract Negotiations', Review of Economic Research on Copyright Issues 3(1): 19-27.

National Consumer Council (2008), Whose licence is it anyway? A study of end user licence agreements for computer software.

Netanel, N.W. (1996), 'Copyright and a Democratic Civil Society', Yale L.J. 106: 283-387.

Netanel, N.W. (2005), 'Copyright and the First Amendment: Eldred', in Griffith, J. and U. Suthersanen (eds.), Copyright and Free Speech, Oxford University Press.

Nimmer, D., E. Brown and G. Frischling (1999), 'The Metamorphosis of Contract into Expand', California Law Review 87: 17.

Nimmer, R.T. (1998), 'Breaking Barriers: the Relation Between Contract and Intellectual Property Law', Berkeley Technology Law Journal 13: 3.

O' Rourke, M. (1995), 'Drawing the Boundary Between Copyright and Contract: Copyright Preemption of Software License Terms', Duke L.J. 45: 479-518. 
O'Rourke, M. (1998), 'Copyright Preemption after the PROCD Case: A Market Based Approach', Berkeley Technology Law Journal 12: 1

OECD (2000), Guidelines for Consumer Protection in the Context of Electronic Commerce [available at http://www.oecdbookshop.org/oecd/display.asp?sf1=identifiers\&st1=932000023P1].

OECD (2006a), Study on Digital Broadband Content DSTI/ICCP/IE(2005)3/Final19-May-2006 [available at http://www.oecd.org/document/62/0,3343,en_2649_34223_32160190_1_1_1_1,00. html].

OECD (2006b), Report on Disclosure Issues Related to the Use of Copy Control and Digital Rights Management Technologies DSTI/CP(2005)15/FINAL 18-Apr-2006 [available at http://www.oecd.org/ dataoecd/47/31/36546422.pdf].

Pallas Loren, L. (2004), 'Slaying the Leather-Winged Demons in the Night: Reforming Copyright Owner Contracting with Clickwrap Misuse', Ohio N.U. L. Rev. 30: 495-523.

Patterson, L. R. and W.S. Lindberg (1991), The Nature of Copyright: A Law of Users' Rights, University of Georgia Press.

Peacock, A. and R. Weir (1975), The Composer in the Market Place, London: Faber.

Pew Internet \& American Life Project (2004), Artists, Musicians and the Internet, researcher Mary Madden, Washington, D.C.: December 5, 2004 [available at www.pewinternet.org]

Poddar, S. (2006), 'Music Product as a Durable Good and Online Piracy', Review of Economic Research on Copyright Issues 3(2): 53-66.

Pool, K. (2000), 'Love, Not Money', The Author 58 (summer 2000): 58-66.

Radin, M. J. (2002) 'Online Standardization and the Integration of Text and Machine', Fordham L. Rev. 70: $1125-1138$.

Reichman J. H. and P. Uhlir (2003), 'A Contractually Reconstructed Research Commons for Scientific Data in a Highly Protectionist Intellectual Property Environment,' SPG Law \& Contemp. Probs. 66: 315.

Reichman, J.H., G. Dinwoodie and P. Samuelson (2007), 'A Reverse Notice and Takedown Regime to Enable Public Interest Uses of Technically Protected Works', Berkeley Tech. L.J. 22: 981.

Ricolfi, M. (2005), 'Collective Rights Management in a Digital Environment', paper delivered at the iLaw conference, Turin 25-27 May 2005.

Rochelandet, F. (2003), 'Are Copyright Collecting Societies Efficient Organisations? An Evaluation of Collective Administration of Copyright in Europe', in Gordon, W.G. and R. Watt (eds.), The Economics of Copyright: Developments in Research and Analysis, Cheltenham UK: Edward Elgar.

Rosen, S. (1986), 'The Theory of Equalizing Differences', in Ashenfelter, O. and R. Layard (eds.), Handbook of Labour Economics (vol. 2), Amsterdam: North-Holland, pp. 641-92. 
Samuelson, P. (1999), 'Intellectual Property and Contract Law for the Information Age: Foreword to a Symposium', California Law Review 87: January.

Samuelson, P. (2003), 'DRM \{AND OR VS\} the Law', Communications of the ACM, April, Vol. 46(4).

Scotchmer, S. (2005), Innovation and Incentives, Cambridge MA: MIT Press.

Shavell, S. (2009), Should Copyright of Academic Works be Abolished?, working paper, Harvard Law School.

Smith, N.A. (1996), 'United States of America', in Dellabeke, M. (ed.), Copyright in Cyberspace, ALAI Study Days Amsterdam.

Snow, A. and R. Watt (2005), 'Risk Sharing and the Distribution of Copyright Collective Income', in Takeyama, L.N., W.J. Gordon and R. Towse, (eds.) Developments in the Economics of Copyright, Cheltenham: Edward Elgar, pp. 23-36.

St Clair, W. (2004), The Reading Nation in the Romantic Period, Cambridge: Cambridge University Press.

Stim, R. (2007), Getting Permission (Nolo), 3rd ed.

Strowel, A. (1991), 'L'originalité en droit d'auteur : un critère à géométrie variable ', Journal des Tribunaux: 513-518

Strowel, A. and E. Derclaye (2001), Droit d'auteur et numerique: Logiciels, bases de données, multimedia (Bruxelles, Bruylant 2001).

Strowel, A. and J.P. Triaille (1996), 'Le droit d'auteur. Du logiciel au multimédia', Cahier du CRID 11, nr. 148.

Strowel, A. and F. Tulkens (2005), 'Freedom of Expression and Copyright under Civil Law: Of Balance, Adaptation and Access', in Griffith, J. and U. Suthersanen (eds.), Copyright and Free Speech, Oxford University Press.

Strowel, A. and F. Tulkens (2006), 'Équilibrer la liberté d'expression et le droit d'auteur. À propos des libertés de créer et d'user des oeuvres', in Strowel, A. (ed.), Droit d'auteur et liberté d'expression, Bruxelles: Larcier.

Takeyama, L. (1994), 'The Welfare Implications of Unauthorized Reproduction of Intellectual Property in the Presence of Demand Network Externalities,' The Journal of Industrial Economics 42(2): 155-66.

Takeyama, L., W.J Gordon and R. Towse (eds.) (2006), Developments in the Economics of Copyright, Cheltenham: Edward Elgar.

Thorpe, J. (1998), 'Regulating the Collective Exploitation of Copyright', in special issue: Trade and Intellectual Property (ed. P. Drahos), Prometheus 16(3): 317-329. 
Throsby, D. (2001), Economics and Culture, Cambridge: Cambridge University Press.

Towse, R. (1997), 'Copyright as an Economic Incentive', in 'Innovation, Incentive and Reward: Intellectual Property Law and Policy', David Hume Papers on Public Policy 5(1): 31-45.

Towse, R. (1999), 'Copyright and Economic Incentives: An Application to Performers' Rights in the Music Industry', Kyklos 52(3): 369-90, reprinted in Towse, R. (2001), Creativity, Incentive and Reward: An Economic Analysis of Copyright and Culture in the Information Age, Cheltenham UK and Northampton MA: Edward Elgar.

Towse, R. (2001a), 'Partly for the Money: Rewards and Incentives to Artists', Kyklos 54(2-3): 473-90.

Towse, R. (2001b), Creativity, Incentive and Reward: An Economic Analysis of Copyright and Culture in the Information Age, Cheltenham UK and Northampton MA: Edward Elgar.

Towse, R. and M. Taylor (1998), 'The Value of Performers' Rights: An Economic Analysis', Media, Culture and Society 20(4): 631-652.

Tschmuck, P. (2009), 'Copyright, Contracts and Music Production', in Copyright and the Production of Music (special issue, ed. M. Kretschmer \& A. Pratt), Information, Communication and Society 12(2): 251-266

Turnbull, B. and D. Marks (2000), 'Technical protection measures: The intersection of technology, law and commercial licenses', EIPR 198.

Vaidhyanathan, S. (2001), Copyrights \& Copywrongs: The Rise of Intellectual Property \& How It Threatens Creativity, New York University Press.

Vanovermeire, V. (2000), 'The concept of the lawful user of a database in the European database directive', International Review of Industrial Property and Copyright 62: 63-81.

Varian, H. (2000), 'Buying, Sharing and Renting Information Goods', Journal of Industrial Economics 48(4): 473-88.

Varian, H. (2007), Intermediate Microeconomics (7th revised edition), New York: WW Norton.

Vinje, T.C. (1999), 'Copyright Imperilled', EIPR 21(4): 192-207.

Vivant, M. (2008), 'La limitation ou 'réduction' des exceptions au droit d'auteur par contrats ou mesures techniques de protection: De possibles contrepoids', General Report, Proceedings of the ALAl Congress, Barcelona, 2006, (ALAI, ALADDA 2008).

Voorhoof, D. and K. Van der Perre (2003), 'L'exception au droit d'auteur - droit belge', in De Lamberterie (ed.), La numérisation pour l'enseignement et la recherche: Aspects juridiques, Paris: Editions Maisons des Sciences de l'Homme.

Wandtke, A. and W. Bullinger (2009), Praxiskommentar zum Urheberrecht, München: Beck. 
Watt, R. (2000), Copyright and Economic Theory: Friends or Foes?, Cheltenham UK and Northampton MA: Edward Elgar Publishing Ltd.

Watt, R. (2006), 'Licensing and Royalty Contracts for Copyright', Review of Economic Research on Copyright Issues 3(1): 1-17.

Watt, R. (2007), 'What Can the Economics of Intellectual Property Learn from the Economics of Insurance?', Review of Law and Economics 3(3).

Westkamp, G. (2004), 'Transient Copying and Public Communications: The Creeping Evolution of Use and Access Rights In European Copyright Law', Geo. Wash. Int'I L. Rev 36(5): 1057-1108.

Williamson, O.E. (1975), Markets and Hierarchies: Analysis and Antitrust Implications, New York: Free Press.

Williamson, O.E. (1985), The Economic Institutions of Capitalism: Firms, Markets, Relational Contracts, New York: Free Press.

Woodfield, A.E. (2006), 'Piracy Accomodation and the Optimal Timing of Royalty Payments', Review of Economic Research on Copyright Issues 3(1): 43-60.

\section{B. CASES}

\section{i. Belgium}

L'ASBL Association Belge des Consommateurs TestAchats v. SE EMI Recorded Music Belgium

Balta Industries S.A. c/ R. Vanden Berghe S.A., Cass., 11 March 2005 http://www.juridat.be

Bidelot c/ Egret et Stas, Pas., Cass., 25 October 1989,1990, I, 238.

Cortina c/ État belge, Civ. Bruxelles (réf.), 17 July 2001, A. \& M., 2002, p. 69

Palouzie c/ S.A. Épithète Films et Faraldo, J.L.M.B., 2001, p. 1444

Sony Music Entertainment (Belgium), SA Universal Music, SA Bertelsmann Music Group Belgium, SA IFPI Belgium, Tribunal de première instance de Bruxelles, Jugement du 25 mai 2004, No 2004/46/A du rôle des référes

\section{ii. Canada}

Robertson v Thomson Corp (2001) 15 CPR (4th) 147 (SCJ); (2004), 34 CPR (4th) 161 (Ont CA); 2006 $\operatorname{SCC} 43$ 


\section{iii. European Commission Decisions}

CISAC decision, Case C2/38.698, 16 July 2008

Daftpunk decision, Case C2/37.219, Banghalter et Homem Christo v. SACEM, 6 August 2002

GEMA I, OJ L134/15, decision of 20 June 1971

GEMA II, OJ L166/22, decision of 6 July 1972

GEMA III, OJ L94 /12, decision of 4 December 1981

\section{iv. European Court of Justice}

Basset v. Société des Auteurs, Compositeurs et Editeurs de Musique (SACEM), Case 402/85, [1987] ECR 1747, [1987] 3 CMLR 173

Belgische Radio en Televisie BRT v. SV SABAM and NV Fonior, Case 127-73, [1974] ECR 313, [1974] 2 CMLR 238

Costa v. ENEL, Case 6/64 [1964] ECR 585

Greenwich Film Production, Paris v. Société des Auteurs, Compositeurs et Editeurs de Musique (SACEM), Case 22/79, [1979] ECR 3275, [1980] 1 CMLR 629

ICl and Commercial Solvents v. Commission, Cases 6 and 7/73, [1974] ECR 223, [1974] 1 CMLR 309

Infopaq International A/S v. Danske Dagblades Forening, Case C-5/08, Judgment of 16 July 2009 (not yet published, available at www.curia.europa.eu).

Lucazeau v. Société des Auteurs, Compositeurs et Editeurs de Musique (SACEM), Cases 110/88, 241/88 \& 242/88, [1989] ECR 02811

Phil Collins v. Imtrat Handelsgesellschaft, Cases C-92/92 \& C-326/92, Judgment of 20 October 1993

RTE \& ITP v. Commission (Magill case), Cases C-241 \& 2/91, [1995] ECR 1-743; [1995] 4 CMLR 586

\section{v. France}

Christophe R., UFC Que Choisir v. Warner Music France, Fnac - Tribunal de Grande Instance de Paris 5ème chambre, 1ère section Jugement du 10 janvier 2006

François M. v. EMI France, Auchan France - Tribunal de Grande Instance de Nanterre, Gème chambre, Jugement du 2 septembre 2003; Cour d'Appel De Versailles, 1re Chambre, 1re section, 30 septembre 2004 
Stéphane P, UFC Que Choisir v. Universal Pictures Video France et Autres - Tribunale de Grande Instance de Paris, 3ème chambre, 2ème section, Jugement du 30 avril 2004; Cour d'Appel de Paris, 4ème chambre, section B, Arrêt du 22 avril 2005; Cour de Cassation - Première chambre civile Arrêt du 28 février 2006

UFC Que Choisir v. Amazon.com et a., Tribunale de Grande Instance de Paris, 1re Chambre, Section Cos., Jugement du 28 octobre 2008

\section{vi. Germany}

BVerfG: 'Verfassungsbeschwerde gegen urheberrechtliche Kopierschutz-Regelungen' (Beschl. v. 25.07.2005 - Az: 1 BvR 2182/04)

vii. Italy

Playstation (Salvatore v. Sony Playstation), Tribunal of Bolzano, Italy, 31 December 2003 [2006] E.C.D.R. 18

\section{viii. The Netherlands}

Coss Holland BV. v. TM Data Netherlands BV, District Court of Amsterdam, decision of 24th May 1995, Computerrecht 1997 at 63-65

Vermande v. Bojokovsky; District Court of The Hague, decision of 20th March 1998, in Informatierrecht/ AMI 1998, at 65-67

\section{ix. United Kingdom}

Ashdown v. Telegraph Group [2001] Ch 685; [2002] Ch 149

Associated Newspapers v. News Group Newspapers [1986] RPC 515

Barker v. Stickney [1919] 1 K.B. 121, CA

Beloff v. Pressdram [1973] 1 All ER 262

Canada Steamship Lines Ltd. v. The King [1952] A.C. 192

Cunard Steamship Co. Ltd. v. Buerger [1927] A.C. 1

Designers Guild Itd v. Russell Williams [2001] E.C.D.R. 10

Elton John v. James [1991], FSR 397 
L'Estrange v. Graucob [1934] 2 K.B. 394

Glynn v. Margetson \& Co. [1893] A.C. 351

Grisbrook v. MGN Ltd [2009] EWHC 2520 (Ch)

Grogan v. Robert Meredith Plant Hire [1996] 15 Tr. L.R. 371

Hubbard v. Vosper [1972] 2 QB 84

Hyde Park v. Yelland [2001] Ch. 183

Hyperion Records Ltd v. Sawkins [2005] EWCA Civ 565 (19 May 2005)

London and North Western Railway Co. v. Neilson [1922] 2 A.C. 263

Missing Link Software v. Magee [1989] FSR 361

Noah v. Shuba [1991] FSR 14

O'Sullivan v. Management Agency [1985] 3 All ER 351

Panayiotou (George Michael) v. Sony Music Entertainment [1994], EMLR 229

Parker v. South Eastern Railway [1877] 2 C.P.D 416

ProSieben v. Carlton [1998] FSR 43, 49; [1999] FSR 610, 621

Robin Ray v. Classic FM [1998] FSR 622

Schroeder Music Publishing Co. v. Macaulay [1974] HL, 3 All ER 616

Stevenson Jordan v. MacDonald \& Evans [1953] 69 RPC 10

Sze Hai Tong Bank Ltd. v. Rambler Cycle Co. Ltd. [1959] A.C. 576

Zang Tumb Tuum (ZTT) v. Johnson (Frankie Goes to Hollywood) [1993], EMLR 61

\section{x. United States}

Allgeyer v. Louisiana 165 U.S. 578 (1879)

Arizona Retail Systems v. Software Links 831 F.Supp. 759, 763-766 (D. Arizona, 1993)

Bowers v. Baystate Technologies, Inc., 29 Jan 2003, 320 F.3d 1317

Computer Associates Int'l, Inc. v. Altai, Inc., 982 F.2d 693, at 716 (2d Cir. 1992) 
DSC Communications Corp. v. DGI Techs., Inc., 81 F.3d 597 (5th Cir. 1996)

Ebay v. Bidders Edge 100 F. Supp. 2d 1058 (N.D. Cal. 2000)

Feist Publications, Inc. v. Rural Telephone Service, 499 U.S. 340, 345 (1991)

Kelly v. Arriba Soft Corp.336 F.3d 811 (9th Cir. 2003)

Kewanee Oil Co. v. Bicron Corp., 416 U.S. 470, 479 (1974)

Lasercomb America. Inc. v. Reynolds. 9II F.2d 970, 979 (4th Cir. L990)

Morton Salt Co. v. Suppinger Co. 314 U.S. 488 (1942)

ProCD, Inc. v. Zeidenberg 86 F. 3d 1447 (7th Cir. 1996)

Register.com v. Verio Inc.356 F. 3d 393 (2d Cir. 2004)

Specht v. Netscape Communications Corp., 150 F. Supp. $2 d 585$ (S.D.N.Y.2001)

Sony Corp. of America v. Universal City Studios, Inc. 464 U.S. 417 (1984)

Tasini v. New York Times, 533 US 483, 121 S Ct 2381 (2001)

United States v. Microsoft Corp., 84 F. Supp. $2 d 9$ (D.D.C. 1999)

Vault Corp. v. Quaid Software Ltd., 655 F.Supp. 750 (E.D.La.1987)

Wilson Pharmacy Inc. v. General Computer Corp., Tennessee Ct. App. N. E2000-00733-COA-R3-CV, 2000

\section{LEGISLATION}

\section{i. International Legislation}

Berne Convention of September 9, 1886, last updated at Paris 1979

International Convention for the Protection of Performers, Producers of Phonograms and Broadcasting Organisations (Rome Convention) (1961)

WIPO Copyright Treaty, adopted in Geneva on December 20, 1996, Official Journal L 089, 11/04/2000 p. $0008-0014$

WIPO Performances and Phonograms Treaty, adopted in Geneva on December 20, 1996, Official Journal L 089, 11/04/2000 p. 0006 - 0007 
WTO Agreement on Trade-related Aspects of Intellectual Property Rights (TRIPS), signed 14 April 1994 as part of the Final Act of the Uruguay Round, OJ L 336/213

\section{ii. Belgium}

Law of the 30th June 1994. - Loi relative au droit d'auteur et aux droits voisins, (M. B., 27 juillet 1994, 19297 ; err. M.B., 5 novembre 1994, 27467 et M.B., 22 novembre 1994, 28832)

Law of the 22nd of May 2005. (implementing the InfoSoc Directive), Moniteur Belge, 27/05/2005, p. 24997

Law of the 31st of August 1998, (implementing the Database Directive), M.B., 14 novembre 199 Law of the 30th of June 1994 (implementing the Software Directive), M.B., 27 juillet 1994, 19315

Law of the 14th of July 1991 on commercial practices and on the information and protection of consumers, M.B. 29 août 1991

Law of the 1st of July 1999 on the protection of competition, M.B., 1er septembre 1999

\section{iii. Germany}

1837 Preußisches Gesetz zum Schutze des Eigenthums an Werken der Wissenschaft und Kunst gegen Nachdruck und Nachbildung vom 11. Juni 1837 ('Prussian Act for the Protection of Property in Works of Science and the Arts from Reprint and Reproduction')

1965 Urheberrechtsgesetz (UrhG, BGB1 I 1273) (copyright act), September 9, 1965, as amended on September 10, 2003

1982 Künstlersozialversicherungsgesetz (KSVG, BGBI. I 105) (social insurance law for artists), July 27, 1981, as amended Dezember 21, 2008

2002 Urhebervertragsrecht (BGBI. I 1155) (copyright contract law), March 28, 2002

\section{iv. Republic of Ireland}

Copyright Act 2000 as amended by the S.I. No. 16 of 2004 - European Communities (Copyright and Related Rights) Regulations 2004, consolidated version available at http://www.irishstatutebook. ie/2000/en/act/pub/0028/index.html

SI n. 16 of 2004 (Copyright and Related Rights Regulations 2004) http://www.irishstatutebook.ie/ statutory.html 


\section{v. Portugal}

Decreto-Lei n. 63/85 de 14 de Março (Código de Direito de Autor e dos Direitos Conexos) as modified by Leis $\mathrm{N} .{ }^{\circ} 45 / 85$, de 17 de setembro, N. ${ }^{\circ}$ 62/98, de 1 de setembro, N. ${ }^{\circ}$ 50/2004, de 24 de agosto, N. ${ }^{\circ} 16 / 2008$, de 1 de abril

Decreto-Lei n. 332/97, of the 27th of November 1997

Decreto-Lei $n$. 333/97, of the 27th of November 1997

Decreto-Lei $n .334 / 97$ of the 27th of November 1997

Decreto-Lei $n .122 / 2000$, of the 4 th of July 2000

Decreto-Lei $n .334 / 97$, of the 27th of November 1997

Law n. 24/2006 of the 30th of June 2006

[All available at http://www.gpeari.pt]

\section{vi. United Kingdom}

1710 An Act for the Encouragement of Learning, by Vesting the Copies of Printed Books in the Authors or Purchasers of such Copies, During the Times therein mentioned, 8 Anne, c19 (Statute of Anne)

1842 An Act to amend the Law of Copyright, 5 \& 6 Vict. c.45 (1842 Copyright Act)

1977 Unfair Contract Terms Act (as amended at 1st October 2003)

1979 Public Lending Right Act (PLR)

1988 Copyright, Designs and Patents Act (CDPA 1988) as amended

2003 Communications Act

2003 Copyright and Related Rights Regulations (Statutory Instrument 2003/2498)

2010 Digital Economy Act

\section{vii. United States}

1976 Copyright Act, 17 U.S.C. $\S \S 101-810$

1998 Sonny Bono Copyright Extension Act, Pub. L. No. 105-298

1998 Digital Millennium Copyright Act, Pub. L. No. 105-304, 17 U.S.C. §§1201-04 


\section{EUROPEAN DIRECTIVES (CHRONOLOGICAL)}

Council Directive 85/577/EEC of 20 December 1985 to protect the consumer in respect of contracts negotiated away from business premises Official Journal L 372, 31/12/1985 P. 0031 - 0033

Council Directive 91/250/EEC of 14 May 1991 on the Legal Protection of Computer Programs, Official Journal L 122, 17/05/1991 P. 0042 - 0046.

Council Directive 92/100/EEC of 19 November 1992 on rental right and lending right and on certain rights related to copyright in the field of intellectual property (Rental Directive) codified as Directive 2001/84/EC of 12 December 2006

Council Directive 93/13/EEC of 5 April 1993 on Unfair Terms in Consumer Contracts Official Journal L 095 , 21/04/1993 P. 0029 - 0034

Council Directive 93/83/EEC of 27 September 1993 on the coordination of certain rules concerning copyright and rights related to copyright applicable to satellite broadcasting and cable retransmission (Satellite and Cable Directive), Official Journal L 248, 06/10/1993 P. 0015 - 0021

Council Directive 93/98/EEC of 29 October 1993 harmonising the term of protection of copyright and certain related rights (Term Directive) codified as Directive 2006/116/EC of the European Parliament and of the Council of 12 December 2006 on the term of protection of copyright and certain related rights Official Journal L 372, 27.12.2006, p. 12-18

Directive 96/9/EC of the European Parliament and of the Council of 11 March 1996 on the Legal Protection of Databases, Official Journal L 077, 27/03/1996 P. 0020 - 0028.

Directive 97/7/EC of the European Parliament and of the Council of 20 May 1997 on the Protection of Consumers in respect of distance contracts - Official Journal L 144, 04/06/1997 P. 0019 - 0027

Council Directive 98/84/EC of 20 November 1998 on the legal protection of services based on, or consisting of, conditional access, Official Journal L 320, 28.11.1998, P. 54-57

Directive 99/44/EC of the European Parliament and of the Council of 25 May 1999 on Certain Aspects of the Sale of Consumer Goods and Associated Guarantees OJ L 171/12 7. 7. 1999

Directive 2000/31/EC of the European Parliament and of the Council of 8 June 2000 on certain legal aspects of information society services, in particular electronic commerce, in the Internal Market ('Directive on electronic commerce') Official Journal L 178, 17.7.2000, p. 1-16

Directive 2001/29/EC of the European Parliament and of the Council of 22 May 2001 on the harmonisation of certain aspects of copyright and related rights in the information society (Information Society Directive) Official Journal L 167, 22/06/2001 P. 0010 - 0019.

Directive 2001/84/EC of the European Parliament and of the Council of 27 September 2001 on the resale right for the benefit of the author of an original work of art (droit de suite Directive) Official Journal L $272,13 / 10 / 2001$ P. $0032-0036$ 


\section{E. OFFICIAL DOCUMENTS (CHRONOLOGICAL)}

Performing Rights (1996), UK Monopolies and Mergers Commission, HMSO Cm 3147

Report from the Commission on the implementation of Council Directive 93/13/EEC of 5 April 1993 on Unfair Terms in Consumer Contracts, Brussels, 27.04.2000 COM(2000) 248 final

Report on the outcome of the public consultation on the Green Paper on the review of the Consumer Acquis, COM (2006) 744 final

Report from the Commission to the Council, the European Parliament and the Economic and Social Committee on the implementation and effects of Directive 91/250/EEC on the legal protection of computer programs, Brussels, 10.04.2000 COM(2000) 199 final

Mikrozensus (2000), Ergebnisse des Mikrozensus, Wiesbaden: Statistisches Bundesamt

Künstlersozialkasse (2000), Bericht der Bundesregierung über die soziale Lage der Künstlerinnen und Künstler in Deutschland, Bundesministerium für Arbeit und Sozialordnung, 31. März 2000

'Ausgleich der gestörten Vertragsparität' ('rebalancing contract parity') (2001), draft copyright contract bill Bundestagsdrucksache 14/6433, 2 (26 June 2001) [available at dip21.bundestag.de/ dip21/btd/14/064/1406433.pdf]

Proposal Directive 2001/29/EC: COM (97) 628 final-1997/0359/COD, Official Journal C 108/6, 7/41998

Amended proposal 2001/29/EC and explanatory memorandum: COM/99/0250 final - COD 97/0359, Official Journal C 180, and 25/06/1999 P. 0006

Copyright Law Review Committee (Australian Government, General Attorney) (2002), Copyright and Contract Report (Australian CLRC Report 2002) [available at http://www.ag.gov.au/www/agd/ agd.nsf/Page/Copyright_CopyrightLawReviewCommittee_CLRCReports_CopyrightandContract_ CopyrightandContract]

WIPO (Garnett 2004) Report on DRM standing committee on copyright and related rights, Tenth Session Geneva, November 3 to 5 2003, SCCR/10/2

Communication COM(2004) 261, The Management of Copyright and Related Rights in the Internal Market

Staff Working Document, Study on a Community Initiative on the Cross-Border Collective Management of Copyright, 7 July 2005

Commission Recommendation, On the Collective Cross-border Management of Copyright and Related Rights for Legitimate Online Music Services, adopted 12 October 2005

DG Internal Market and Services Working Paper, First evaluation of Directive 96/9/EC on the legal protection of databases, Brussels, 12 December 2005, [available at http://ec.europa.eu/internal_ market/copyright/docs/databases/evaluation_report_en.pdf] 
Gowers Review of Intellectual Property (2006), London: HM Treasury (HMSO) [available at http://www.hm-treasury.gov.uk/independent_reviews/gowers_review_intellectual_property/ gowersreview_index.cfm]

Green Paper on the Review of the Consumer Acquis, Brussels, 08.02.2007, COM (2006) 744 final

Report to the Council, the European Parliament and the Economic and Social Committee on the application of Directive 2001/29/EC on the harmonisation of certain aspects of copyright and related rights in the information society, Brussels, 30.11.2007

Proposal for a European Parliament and Council Directive, amending Directive 2006/116/EC of the European Parliament and of the Council on the term of protection of copyright and related rights Brussels, 16.7.2008 COM(2008) 464 final

Green Paper: Copyright in the Knowledge Economy, Brussels, COM(2008) 466/3

Proposal for a Directive of the European Parliament and of the Council on consumer rights, Brussels, 8.10.2008 COM(2008) 614 final

Commission staff working document accompanying the proposal for a directive on consumer rights Impact Assessment Report, COM(2008) 614 final

Strategic Priorities for Copyright (2009), Strategic Advisory Board for Intellectual Property Policy (SABIP) [available at http://www.sabip.org.uk/home/research/research-copyright.htm]

Digital Britain Report (2009), London: Dept for Culture, Media and Sport / Dept for Business Innovation and Skills

Study on The Implementation and Application of Directive 96/9/EC on the Legal Protection of Databases, at http://ec.europa.eu/internal_market/copyright/docs/databases/etd2001b53001e72_ en.pdf

Reflection Document, Creative Content in a European Digital Single Market: Challenges for the Future, Brussels, 22.10.2009, DG INFSO and DG MARKT 

Strategic Advisory Board for Intellectual Property Policy (SABIP) 21 Bloomsbury Street London WC1B 3 HF

$\mathrm{T}+44(0) 2070342833$ $F+44(0) 2070342856$

www.sabip.org.uk twitter.com/SABIP

Providing Government with strategic, independent and evidence-based advice on intellectual property policy 